\title{
Remediation of Uranium in the Hanford Vadose Zone Using Ammonia Gas: FY 2010 Laboratory-Scale Experiments
}

in Support of the

Deep Vadose Zone Treatability Test Plan for the Hanford Central Plateau
JE Szecsody
Z Wang
MJ Truex
J Bargar
L Zhong
D Faurie
NP Qafoku
CT Resch
MD Williams
JL Phillips
JP McKinley

November 2010

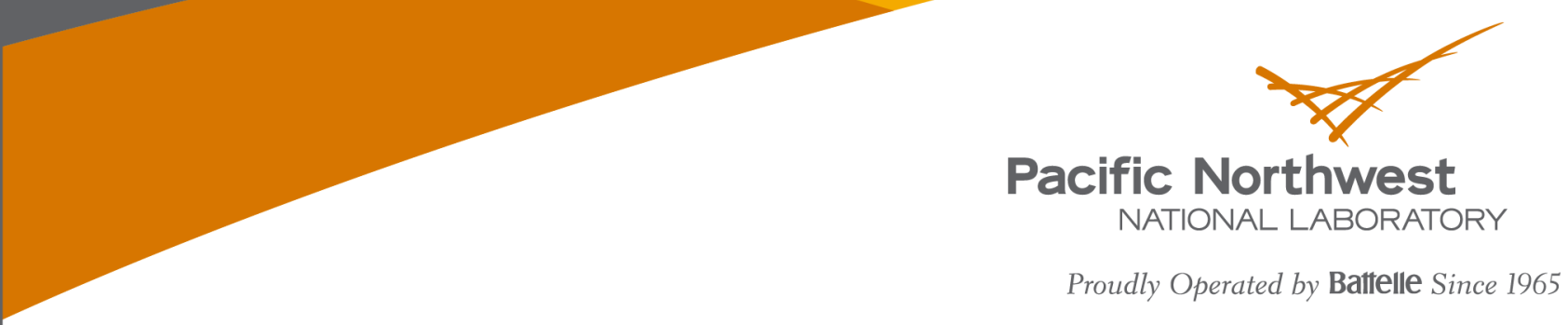




\title{
DISCLAIMER
}

This report was prepared as an account of work sponsored by an agency of the United States Government. Neither the United States Government nor any agency thereof, nor Battelle Memorial Institute, nor any of their employees, makes any warranty, express or implied, or assumes any legal liability or responsibility for the accuracy, completeness, or usefulness of any information, apparatus, product, or process disclosed, or represents that its use would not infringe privately owned rights. Reference herein to any specific commercial product, process, or service by trade name, trademark, manufacturer, or otherwise does not necessarily constitute or imply its endorsement, recommendation, or favoring by the United States Government or any agency thereof, or Battelle Memorial Institute. The views and opinions of authors expressed herein do not necessarily state or reflect those of the United States Government or any agency thereof.

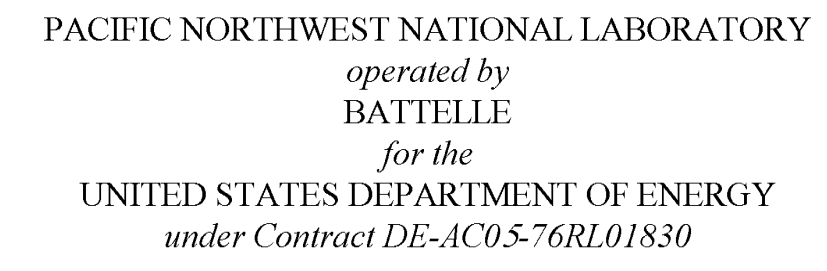

Printed in the United States of America

Available to DOE and DOE contractors from the Office of Scientific and Technical Information,

P.O. Box 62, Oak Ridge, TN 37831-0062; ph: (865) 576-8401 fax: (865) 576-5728

email: reports@adonis.osti.gov

\author{
Available to the public from the National Technical Information Service, \\ U.S. Department of Commerce, 5285 Port Royal Rd., Springfield, VA 22161 \\ ph: (800) 553-6847 \\ fax: $(703) 605-6900$ \\ email: orders@ntis.fedworld.gov \\ online ordering: http://www.ntis.gov/ordering.htm
}

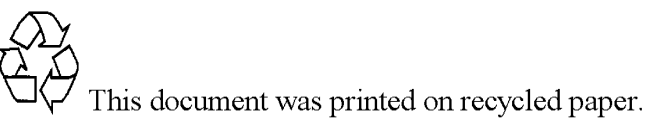

$(9 / 2003)$ 


\section{Remediation of Uranium in the Hanford Vadose Zone Using Ammonia Gas: FY 2010 Laboratory-Scale Experiments}

in Support of the

Deep Vadose Zone Treatability Test Plan for the Hanford Central Plateau

$\begin{array}{ll}\text { JE Szecsody } & \text { Z Wang } \\ \text { MJ Truex } & \text { J Bargar } \\ \text { L Zhong } & \text { D Faurie } \\ \text { NP Qafoku } & \text { CT Resch } \\ \text { MD Williams } & \text { JL Phillips } \\ \text { JP McKinley } & \end{array}$

November 2010

Prepared for

CH2M HILL Plateau Remediation Company under Contract DE-AC05-76RL01830

Pacific Northwest National Laboratory

Richland, Washington 99352 


\section{Executive Summary}

This investigation is focused on refining an in situ technology for vadose zone remediation of uranium by the addition of ammonia $\left(\mathrm{NH}_{3}\right)$ gas with no addition of water. The objectives were to: a) refine the technique of ammonia gas treatment, b) identify the geochemical changes in uranium surface phases, c) identify broader geochemical changes that occur, and d) predict and test injection of ammonia gas for intermediate-scale systems to identify process interactions that could impact field-scale implementation. For ammonia gas injection into vadose zone sediments to be successful as a uranium remediation technology, it needs to show decreased U mobility of the most mobile $U$ phases (aqueous, adsorbed) in a variety of field conditions. Uranium is present in Hanford sediment include in multiple phases including aqueous U(VI)-carbonate complexes, adsorbed, uranium coprecipitated with carbonates, and U-bearing minerals Na-boltwoodite and uranophane. Ammonia treatment of sediments raises the $\mathrm{pH}$ in Hanford sediments from 8.0 to $11-13$, which has resulted in a decrease in uranium mobility, as evidenced by decrease in aqueous and adsorbed uranium in $85 \%$ of the different sediments tested (different $U$ surface phase distributions or $\mathrm{NH}_{3}$ treatments) and an increase in $8 \mathrm{M} \mathrm{HNO}_{3}$ extracted $\mathrm{U}$ (hard to extract U phases, silicates/phosphates/oxides) for $79 \%$ of sediments tested. There were also inconsistent changes in two acetate extractions, likely the result of dissolution of multiple surface $U$ phases (U-carbonates, Na-boltwoodite, uranophane). Surface phase analysis by laser induced fluorescence spectroscopy and extended x-ray absorption structure has showed essentially no $U$ surface mineral change in sediments initially containing Na-boltwoodite, but some U surface phase changes in U-calcite coprecipitates to uranyl oxyhydroxide, Na-boltwoodite, and uranyl tricarbonate. Therefore, the ammonia gas treatment appears most effective for $\mathrm{U}$ present in the most mobile phases: aqueous $\mathrm{U}$, adsorbed $\mathrm{U}$, and carbonate associated $\mathrm{U} . \mathrm{NH}_{3}$-treated sediments containing Na-boltwoodite and uranophane showed decreased leaching even though solid phase analysis showed little changes in the U mineralogy. The decreased leaching may be the result of other mineral precipitates coating these phases. Minerals that leached the most significant mass of ions were montmorillonite, muscovite, and kaolinite. A greater understanding of these dissolution/precipitation/coating processes is needed to predict the long-term impact on uranium mobility.

Ammonia gas injection experiments conducted in 20- to 30-ft long 1-D systems and a layered 2-D radial flow system were used to characterize the physicochemical changes at the $\mathrm{NH}_{3}$ reaction front and treatment coverage in heterogeneous sediments. For $5 \% \mathrm{NH}_{3}\left(95 \% \mathrm{~N}_{2}\right)$ injection, an average of 234 pore volumes were needed to achieve the elevated $\mathrm{pH}$ (10.2 to 11.4) of the reaction front observed, with 465 pore volumes needed to achieve $\mathrm{pH}$ equilibrium $(\mathrm{pH}=11.88)$, at $4 \%$ water content and $35 \%$ porosity. The desiccation front required 8600 pore volumes to dry sediment, so would be confined to a small volume at field scale. Injection into layered systems showed $\mathrm{NH}_{3}$ reaction front advance decreased with lower permeability and higher water content. Injection into a system with discontinuous low-K lenses at differing initial water contents did show $\mathrm{NH}_{3}$ diffusion into the low-K zones. 


\section{Acronyms and Abbreviations}

adsorbed uranium

aqueous uranium

autunite

$\mathrm{CO}_{2}$

DOE-RL

EC

EDS

EXAFS

foam

$\mathrm{H}_{2} \mathrm{~S}$

ICP-MS

$\mathrm{K}_{\mathrm{d}}$

LIFS

mist

Na-boltwoodite

$\mathrm{NH}_{3}$

oxide-U

ppb

SEM

XANES

XRD

uranium surface phases

uranophane

vanadate

ZVI mass of uranium extracted from the sediment with a $1 \mathrm{M} \mathrm{Mg}\left(\mathrm{NO}_{3}\right)_{2}$ solution; second sequential extraction after aqueous uranium

mass of uranium extracted from the sediment with Hanford Site 100-N Area groundwater ( $\mathrm{Ca}, \mathrm{Mg}-\mathrm{CO}_{3}$ saturated) at a sediment/water ratio of 1:1

uranium-phosphate precipitate, $\mathrm{Ca}\left(\mathrm{UO}_{2}\right)_{2}\left(\mathrm{PO}_{4}\right)_{2} \cdot \mathrm{XH}_{2} \mathrm{O}$

carbon dioxide gas

U.S. Department of Energy, Richland Operations Office

electrical conductivity (aqueous) of pore water in low water saturation sediments

energy dispersive $x$-ray spectroscopy

extended x-ray absorption fine structure

$0.5 \%$ solution of sodium laureth sulfate (surfactant) at a water/gas ratio pumped through a porous plate to form bubbles

hydrogen sulfide gas

inductively coupled plasma/mass spectrometry

distribution coefficient for uranium defined as fraction uranium adsorbed

divided by the fraction uranium in aqueous phase

Laser induced fluorescence spectroscopy

$0.1 \%$ to $0.3 \%$ water pumped through a venturi with $99.9 \%$ gas (air or $\mathrm{N}_{2}$ ) to form small droplets of the aqueous solution

hydrous uranium-silicate, $\mathrm{Na}\left(\mathrm{UO}_{2}\right) \mathrm{SiO}_{4} 1.5 \mathrm{H}_{2} \mathrm{O}$

ammonia gas

extracted uranium from sediment with $0.1 \mathrm{M}$ ammonium oxalate, $0.1 \mathrm{M}$ oxalic acid; fifth sequential extraction.

parts per billion

scanning electron microscopy

$\mathrm{X}$-ray near edge structure

x-ray diffraction

includes aqueous and adsorbed uranium, and precipitates that in the Hanford 200 Area subsurface typically include uranium coprecipitated with calcite, uranophane, and Na-boltwoodite.

hydrous uranium silicate, $\mathrm{Ca}\left(\mathrm{UO}_{2}\right)_{2}\left(\mathrm{SiO}_{3} \mathrm{OH}\right)_{2}\left(\mathrm{H}_{2} \mathrm{O}\right)_{5}$

$\mathrm{U}-\mathrm{VO}_{4}$ mineral phases, tyuyamunite, $\left(\mathrm{Ca}\left(\mathrm{UO}_{2}\right)_{2}\left(\mathrm{VO}_{4}\right)_{2} \cdot 5-8 \mathrm{H}_{2} \mathrm{O}\right)$ and carnotite $\left(\mathrm{K}_{2}\left(\mathrm{UO}_{2}\right)_{2}\left(\mathrm{VO}_{4}\right)_{2} \cdot 3 \mathrm{H}_{2} \mathrm{O}\right)$

zero valent iron 


\section{Contents}

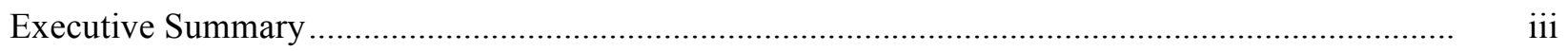

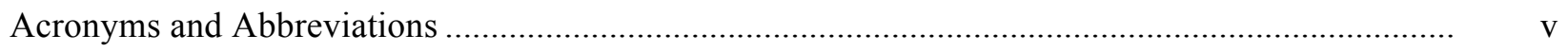

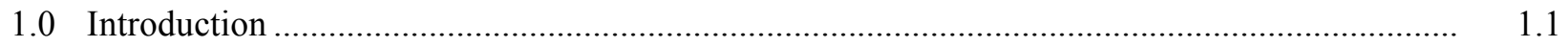

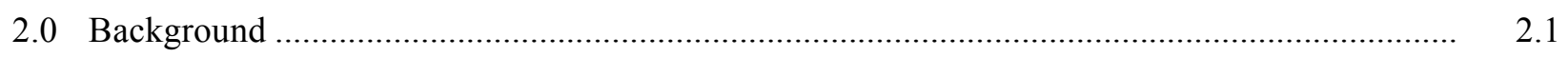

2.1 Uranium Contamination Distribution in the Hanford Vadose Zone ................................ 2.1

2.2 Ammonia Treatment and Aqueous Geochemistry ........................................................ 2.4

2.3 Ammonia Treatment and Sediment Mineralogy ......................................................... 2.6

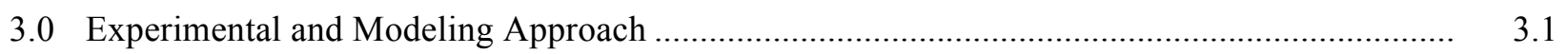

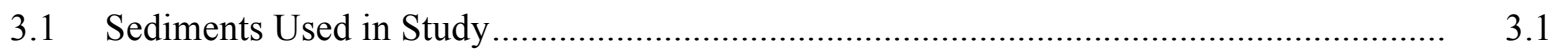

$3.2 \quad \mathrm{NH}_{3} \mathrm{Gas} /$ Water Experiments................................................................................ 3.3

$3.3 \quad \mathrm{NH}_{3}$ Gas/Sediment/Water Batch Experiments ............................................................. 3.3

$3.4 \quad \mathrm{NH}_{3}$ Gas Injection into 1-D Sediment Columns.......................................................... 3.5

$3.5 \quad \mathrm{NH}_{3}$ Gas Injection into 2-D Experiments ........................................................... 3.7

3.6 Ammonia Gas Concentration Measurement and Flow Control ........................................ 3.8

3.7 Aqueous Characterization: pH, EC, Cations, Anions, U Liquid Extractions................... 3.10

3.8 Major Mineralogy Surface Phase Characterization....................................................... 3.11

3.9 Uranium Surface Phase Characterization ................................................................... 3.12

3.10 Geochemical Equilibrium Modeling …..................................................................... 3.13

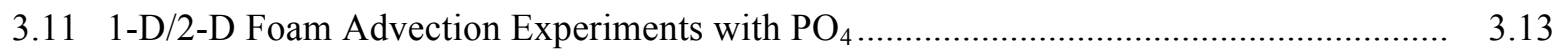

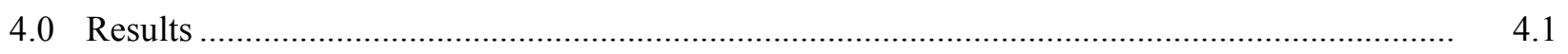

4.1 Short-Term Geochemical Performance: Change in Uranium Mobility for All Tested Technologies ............................................................................................ 4.1

4.2 Ammonia Gas - Water Partitioning: $\mathrm{pH}$ and Electrical Conductivity ............................ 4.3

4.3 Ammonia Gas: Sediment Pore Water Partitioning and pH, EC Change......................... 4.6

4.3.1 Sediment Pore Water pH .............................................................................. 4.6

4.3.1.1 Batch Experiments at Low Water Content........................................... 4.6

4.3.1.2 Batch Experiments at $>8 \%$ Water Content ........................................... 4.7

4.3.1.3 pH Distribution in 1-D and 2-D Systems ............................................ 4.8

4.3.2 Pore Water pH Measurement Methods and Scaleup Issues ................................. 4.9

4.3.3 Sediment Pore Water Electrical Conductivity.................................................. 4.11

4.4 Ammonia Gas Treatment: Mineral Dissolution and Precipitation ................................... 4.12

4.4.1 Predicted Aqueous Ions Based on Geochemical Equilibrium Modeling .............. 4.12

4.4.2 Aqueous Cation Concentrations for Individual Mineral Dissolution.................... 4.16

4.4.3 Sediment Aqueous and Adsorbed Cation Concentration Changes ...................... 4.18

4.4.3.1 Range of Sediments and Water Content .............................................. 4.18

4.4.3.2 ERDF Pit Sediment at Differing $\mathrm{NH}_{3}$ Concentration.............................. 4.21

4.4.3.3 Comparison of Pore Water Cations for Extraction Methods ................... 4.23 
4.4.4 Sediment Aqueous Anion Concentration Changes ........................................... 4.24

4.4.5 Mineral Dissolution/ Precipitation: Solid Phase Analysis .................................. 4.25

4.5 Uranium Surface Phase Changes ............................................................................... 4.29

4.5.1 Predicted Uranium Mineral Phase Changes ....................................................... 4.29

4.5.2 Sequential Liquid Extractions to Estimate U Mobility ...................................... 4.30

4.5.3 Solid Phase Analysis ...................................................................................... 4.37

4.6 Mixed Ammonia/Carbon Dioxide Gas Treatments...................................................... 4.39

4.7 Influence of $\mathrm{NH}_{3}$ Gas Advection on Geochemical Changes: 1-D Columns .................... 4.42

4.8 Scale Up of Reactivity: Batch to 1-D Columns with Co-Contaminants .......................... 4.45

4.8.1 Reactivity in Static (Batch) Sediment/Water/Gas Systems................................ 4.45

4.8.2 Reactivity in a 1-D Column........................................................................... 4.49

4.9 Influence of $\mathrm{NH}_{3}$ Gas Diffusion on Geochemical Changes: 1-D Columns .................... 4.52

4.10 Influence of Heterogeneities: $\mathrm{NH}_{3} \mathrm{Gas}$ Advection in 2-D Systems ............................... 4.53

$4.11 \mathrm{NH}_{3}$ Gas and Co-Contaminants: Influence on Pertechnetate Mobility ........................... 4.56

4.12 Alternate Technology: Foam $/ \mathrm{PO}_{4}$ Advection into Sediment at Low Water

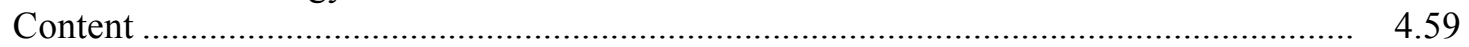

4.12.1 Foam Advection in Sediments at Low Water Saturation .................................... 4.59

4.12.2 Influence of the Presence of Foam and $\mathrm{PO}_{4}$ on $\mathrm{U}$ Advection .............................. 4.61

4.12.3 Influence of Heterogeneities on Foam Transport................................................. 4.64

5.0 Discussion: U Remediation Mechanisms and Scale Up to Field ......................................... 5.1

$5.1 \mathrm{NH}_{3}$ Reactions with Sediment: Uranium Mineral and Mobility Change ........................ 5.1

$5.2 \mathrm{NH}_{3}$ Reactions with Sediment: Major Mineralogical Changes ....................................... 5.6

5.3 Reactive Transport of $\mathrm{NH}_{3}$ : Laboratory Results and Field-Scale Planning ..................... 5.8

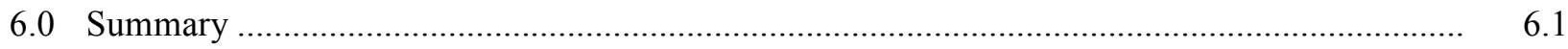

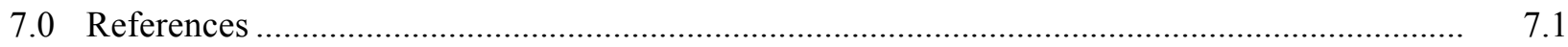

Appendix A - Electron Microprobe Analysis of $\mathrm{NH}_{3}$-Treated Sediments........................................ A.1

Appendix B - Scanning Electron Microscopy Pictures and EDS Elemental Identification of $\mathrm{NH}_{3}$-Treated Sediments 


\section{Figures}

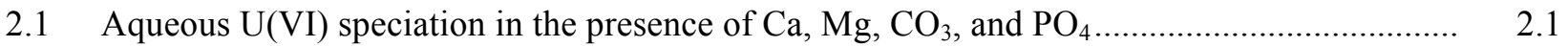

2.2 Conceptual diagram of $U$ contamination in the vadose zone, as controlled by physical and geochemical processes at multiple scales

2.3 Comparison of $\mathrm{U}$ surface phase characterization with depth from U105 borehole C5602 ........

2.4 1-D water-saturated column breakthrough of uranium after 1 week, 1 month, or 1 year of ${ }^{233} \mathrm{U}$-sediment aging showing ${ }^{233} \mathrm{U}$ breakthrough

2.5 Desorption of uranium from Hanford 300 Area smear zone sediments in a 1-D column with stop flow events.

2.6 Dissolution of Na-boltwoodite with increasing $\mathrm{pH}$ and carbonate.

$3.130-\mathrm{ft}$ long 1-D column of $100 \% \mathrm{NH}_{3}$ injection.

3.2 Ammonia gas injection into a 20-ft long 1-D column with data logging of temperature, reaction front visually shown, and $\mathrm{pH}$ indicator paper.

3.3 2-D wedge-shaped flow system used for ammonia gas injection into a radial flow system containing layers and discontinuous low-K lenses.

3.4 2-D wedge-shaped flow system built for approximating field scale ammonia gas injection processes

3.5 Ammonia gas phase concentration calibration by UV absorption at $204 \mathrm{~nm}$

4.1 Sequential U liquid extractions results of differing low water content treatments of sediment TX-104

4.2 Ammonia gas partitioning into water shown by equilibrium calculation, $\mathrm{pH}$ increase in batch system, and electrical conductivity increase

4.3 Calculated aqueous ammonia speciation over $\mathrm{pH}$ and aqueous species concentrations during ammonia addition to water

4.4 Sediment pore water reaction with: different fraction of ammonia/nitrogen gas and different pore volumes of $100 \%$ ammonia gas

4.5 Sediment temperature during $\mathrm{NH}_{3}$ gas injection in a 1-D column .....

4.6 Sediment $\mathrm{pH}$ over time during ammonia gas treatments, as measured by dilution.

4.7 Sediment pore water $\mathrm{pH}$ over time during ammonia gas treatments, as measured by centrifuging: differing $\mathrm{NH}_{3}$ concentration, differing $\mathrm{NH}_{3}$ mass.

4.8 Pore water $\mathrm{pH}$ in: 20 -ft long 1 -D column with $5 \% \mathrm{NH}_{3}$ injection and $1.3 \mathrm{~m}$ long 2-D wedge shaped flow system with sediment layers and $100 \% \mathrm{NH}_{3}$ injection.

4.9 Sediment pore water $\mathrm{pH}$, as pore water was extracted by different methods

4.10 Use of $\mathrm{pH}$ indicator paper for in situ measurement during ammonia gas injection into sediment.

4.11 Differing sediment grain size distributions subjected to ammonia gas treatment with $\mathrm{pH}$ and EC measurement

4.12 Sediment pore water EC over time during ammonia gas treatments in: batch, 1-D column, 2-D system $\mathrm{pH}$, and 2-D system EC

4.13 Predicted aqueous complexation as Hanford groundwater $\mathrm{pH}$ is varied from 8 to 11

4.14 Predicted solid phase composition as Hanford groundwater $\mathrm{pH}$ is varied from 8 to 11 
4.15 Predicted mineral phase dissolution or precipitation as individual mineral phases in contact with Hanford groundwater $\mathrm{pH}$ changes from 8 to 11: quartz aqueous species, precipitates, orthoclase aqueous species, and precipitates, and muscovite aqueous species, and precipitates

4.16 Pore water aqueous cations for untreated minerals and $\mathrm{NH}_{3}$-treated minerals

4.17 Sediment pore water cation concentrations over time during ammonia gas treatments.

4.18 Sediment pore water cation concentration change over time during $\mathrm{NH}_{3}$ treatment.

4.19 Sediment pore water cation concentrations for Hanford sediments after $10 \% \mathrm{NH}_{3}$ gas treatment

4.20 Sediment pore water cation concentrations at $5100 \mathrm{~h}$ after $100 \% \mathrm{NH}_{3}$ gas treatment.

4.21 Changes in pore water cations with $\mathrm{NH}_{3}$ gas treatment.

4.22 Aqueous silica in water saturated and unsaturated systems

4.23 Sediment pore water cation concentration for Hanford formation ERDF pit sediment at $8 \%$ initial water content with: dilution method and centrifuge method.

4.24 Sediment pore water anion concentrations for Hanford formation ERDF pit sediment at $8 \%$ initial water content in a $2-\mathrm{D}$ flow system.

4.25 SEM images of soil particles and surface coatings from sediments with 490 pore volumes of $100 \%$ ammonia treatment

4.26 SEM images from water-saturated samples $\left(1 \mathrm{~mol} \mathrm{~L}^{-1} \mathrm{NH}_{4} \mathrm{OH}\right)$...

4.27 SEM images from water-saturated samples $\left(0.01 \mathrm{~mol} \mathrm{~L}^{-1} \mathrm{NH}_{4} \mathrm{OH}\right)$

4.28 Predicted speciation of reaction of Hanford groundwater with $0.1 \mathrm{~mol} / \mathrm{L} \mathrm{NH}_{4} \mathrm{OH}$.....

4.29 U Mineral dissolution

4.30 Sequential liquid extractions and $\mathrm{U}$ analysis for $\mathrm{NH}_{3}$-treated $\mathrm{TX}-104$ sediment, which contains primarily $\mathrm{U}$ coprecipitated with calcite

4.31 Sequential liquid extractions and $U$ analysis on TX-104 sediments from different depth .........

4.32 Sequential liquid extractions and $U$ analysis on $\mathrm{BX}-102$ sediments that received $\mathrm{NH}_{3}$ treatment for 1 month

4.33 Sequential liquid extractions and $U$ analysis on Hanford sediments that received $\mathrm{NH}_{3}$ treatment for 1 month

4.34 Sequential liquid extractions and U analysis on U105 sediments in borehole C5602 that received $\mathrm{NH}_{3}$ treatment for 1 month.

4.35 Fraction change in $U$ liquid extractions over $U$ concentration as a fraction of the total $U$ or fraction change in each extraction.....

4.36 Fraction change in $U$ for each extraction.

$4.37 \mathrm{U}$ characterization of $\mathrm{BC}$ Crib boreholes with groundwater, Na-acetate, and $8 \mathrm{M} \mathrm{HNO}_{3}$ liquid extractions

4.38 X-ray fluorescence of untreated and $\mathrm{NH}_{3}$-treated $\mathrm{C} 5602,52.3$ - $\mathrm{ft}$ sediment.......

$4.39 \mathrm{X}$-ray fluorescence of $\mathrm{NH}_{3}$-treated $\mathrm{C} 5602,52.3-\mathrm{ft}$ sediment

4.40 X-ray fluorescence of untreated and $\mathrm{NH}_{3}$-treated TX-104, 152-ft depth sediment...................

4.41 XANES/EXAFS analysis on untreated and $\mathrm{NH}_{3}$-treated $\mathrm{C} 5602$, 52.3-ft depth sediment.......... 
4.43 Results of mixed gas treatments with: U extractions, aqueous cations, and adsorbed cations

4.44 Sequential gas treatments showing: $\mathrm{U}$ extractions just after $\mathrm{NH}_{3}$ treatment, and sequential treatments of differing gasses.

4.45 Velocity of gas injection in well

$4.46100 \%$ ammonia gas injection: reaction front, temperature, and $\mathrm{pH}$ distribution in sediment.

$4.475 \% \mathrm{NH}_{3}$ injection into 20-ft 1-D column with resulting: $\mathrm{pH}$ and $\mathrm{EC}$

$4.48 \mathrm{NH}_{3}$ injection at different flow rate with resulting: $\mathrm{pH}$ and $\mathrm{EC}$

4.49 Pore volumes of $\mathrm{NH}_{3}$ injection for 1-D columns at different velocity

4.50 Batch $\mathrm{NH}_{3}$ treatments showing: $\mathrm{pH}, \mathrm{EC}, \mathrm{NH}_{3}$ (aq), and $\mathrm{NH}_{3}$ (ads)

4.51 Batch $\mathrm{NH}_{3}$ treatments showing aqueous cations, adsorbed cations, and aqueous anions

4.52 Batch $\mathrm{NH}_{3}$ treatments showing changes in aqueous $\mathrm{Si}, \mathrm{Al}, \mathrm{Fe}$, and $\mathrm{Mg}$

4.53 Batch $\mathrm{NH}_{3}$ treatments showing changes in $\mathrm{U}$ surface phases

$4.54 \mathrm{NH}_{3}$ injection into a 20-ft column, showing: $\mathrm{pH}, \mathrm{EC}$, and $\mathrm{NH}_{3}$ concentration

$4.55 \mathrm{NH}_{3}$ injection into a 20 -ft column, showing aqueous cations, and aqueous anions

$4.56 \mathrm{NH}_{3}$ injection into a 20-ft column, showing aqueous: $\mathrm{Si}, \mathrm{Al}, \mathrm{Fe}$, and $\mathrm{Mg}$.

$4.57 \mathrm{NH}_{3}$ injection into a $20-\mathrm{ft}$ column, showing $\mathrm{U}$ concentrations in liquid extractions.

$4.58 \mathrm{NH}_{3}$ diffusion into 1-D columns: $\mathrm{pH}$ for $100 \% \mathrm{NH}_{3}, \mathrm{pH}$ for $5 \% \mathrm{NH}_{3}$, $\mathrm{EC}$ for $100 \%$ $\mathrm{NH}_{3}$, and $\mathrm{EC}$ for $5 \% \mathrm{NH}_{3}$

$4.59 \mathrm{NH}_{3}$ injection into a 2-D radial flow system containing continuous layers and lenses

$4.60 \mathrm{NH}_{3}$ reaction front droplets.

$4.61 \mathrm{pH}$ and $\mathrm{EC}$ in 2-D wedge system.

$4.62 \mathrm{NH}_{3}$ reactions with sediment shown by: anions, cations, and $\mathrm{U}$ extraction

4.63 Calculated pertechnetate stability and iron oxide stability over an Eh-pH range. 4.56

4.64 Liquid extractions of BC crib sediments and ${ }^{99} \mathrm{Tc}$ analysis

4.65 1-D column experiments of Tc-99 leaching with groundwater without and with $\mathrm{NH}_{3}$ treatment in field-contaminated sediment, or Tc-99 addition to sediment

4.66 Effluent $\mathrm{pH}$ in Tc-99 1-D column experiments.

4.67 Tc-99 extraction of $\mathrm{NH}_{3}$-treated sediment

4.68 Foam injection showing: surfactant, EC, and water content, water content and $\mathrm{Br}-$

4.69 Influence of foam quality on moisture distribution in sediment

4.70 Groundwater injection into U-contaminated sediment with: no phosphate, and $47 \mathrm{mmol} / \mathrm{L} \mathrm{Na}-\mathrm{PO}_{4}$

4.71 Foam injection into U-contaminated sediment with: no phosphate, no phosphate (repeat) and $47 \mathrm{mmol} / \mathrm{L} \mathrm{Na}-\mathrm{PO}_{4}$

4.72 Uranium cumulative effluent mass in columns, and mass balance from effluent and liquid extractions .....

4.73 Liquid distribution in heterogeneous vadose zone sediment systems: infiltration vs. foam injection

4.74 Liquid distribution comparison between fluid infiltration and foam injection. 
4.75 2-D foam injection experiment moisture distribution and $\mathrm{PO}_{4}$ distribution

4.76 Moisture, phosphate, and surfactant concentration distribution in matrix, high-perm layer, low-perm layer from the foam injection flow cell test

5.1 Representative U surface phase changes as defined by liquid extractions: high $\mathrm{U}$ concentration as Na-boltwoodite in shallow Hanford formation, moderate U concentration as U-carbonate deeper in the Hanford formation, low U concentration as primarily aqueous/adsorbed $U$ deep in the Hanford formation, and $U$ in the Cold Creek Formation primarily as aqueous/adsorbed U

5.2 Fraction change in $U$ liquid extractions over $U$ concentration as a fraction change in each extraction 


\section{Tables}

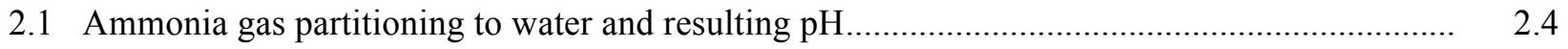

3.1 Uranium-contaminated sediments used in this study ........................................................ 3.2

3.2 Sediment grain size and mineralogy characterization ....................................................... 3.2

4.1 Pore water cations from mineral dissolution ...................................................................... 4.17

4.2 Changes in liquid phase elemental composition after sediment exposure to three

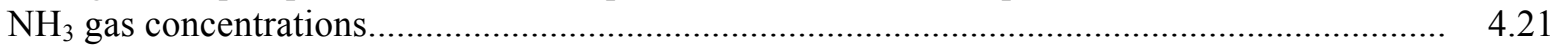

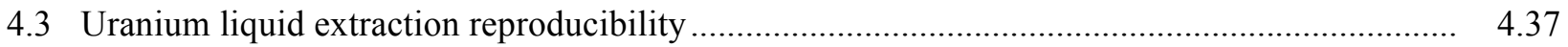

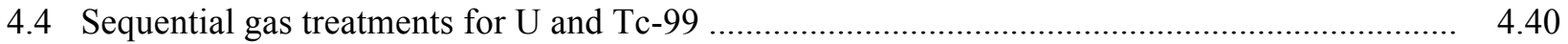

4.5 Mixed gas treatments for $\mathrm{U}$ surface phase change ............................................................. 4.41

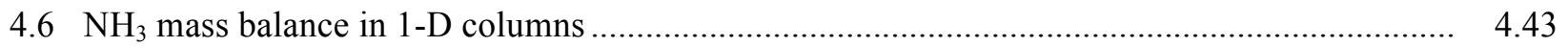

5.1 Uranium surface phase change from ammonia gas treatment ................................................ 5.3

5.2 Ammonia gas treatment needed under varied field conditions ............................................. 5.10 


\subsection{Introduction}

This investigation is focused on refining an in situ technology for vadose zone remediation of uranium by the addition of ammonia $\left(\mathrm{NH}_{3}\right)$ gas. As part of the Deep Vadose Zone Treatability Test Plan for the Hanford Central Plateau (DOE/RL 2008), investigations during the previous year evaluated 10 different technologies for their potential to decrease uranium mobility in the Hanford Site vadose zone using a reactive gas, a gas-advected liquid, or a foam-advected liquid (Szecsody et al. 2010). In terms of the short-term decrease in uranium mobility (in decreasing order), $\mathrm{NH}_{3}, \mathrm{NaOH}$ mist, $\mathrm{CO}_{2}, \mathrm{HCl}$ mist, and $\mathrm{Fe}$ (III) mist showed $20 \%$ to $35 \%$ changes in uranium surface phases. For long-term decreases in uranium reduction, mineral phases that had low solubility (phosphates and silicates) were desired. Additions of $\mathrm{NH}_{3}$, phosphates (mist and foam delivered), and $\mathrm{NaOH}$ mist led to the greatest formation of these minerals. In laboratory-scale tests, advection of reactive gases was the easiest approach to implement in low-water-content sediments (presumably this also would be true in field-scale tests). The mist and foam advection approaches both show potential and need further development, but their current implementation techniques move reactants shorter distances than reactive gases. Overall, the $\mathrm{NH}_{3}$ and $\mathrm{CO}_{2}$ exhibited the best overall geochemical performance and ability to implement at the field scale.

This study has the following primary objectives: a) refine the technique of ammonia gas treatment of low water content sediments to minimize uranium mobility by changing uranium surface phases (or coat surface phases), b) identify the geochemical changes in uranium surface phases during ammonia gas treatment, c) identify broader geochemical changes that occur in sediment during ammonia gas treatment, and d) predict and test injection of ammonia gas for intermediate-scale systems to identify process interactions that occur at a larger scale and could impact field scale implementation. Although this FY 2010 investigation is focused primarily on ammonia gas injection into low water content sediments, secondary objectives include: a) complete long-term (1 year) evaluation of 10 potential remediation technologies initiated in FY 2009, b) further investigation of foam injection of phosphate into low water content sediments, and c) further investigation of carbon dioxide gas injection into low water content sediments, d) investigate the effect of ammonia treatment of Tc. In this study, a variety of experiments were conducted at different scales from batch (static) sediment/water/gas systems, to small 1-D columns to large 1-D columns (with a 9 meter length), to 2-D radial flow and 2-D linear flow systems. Larger scale sediment systems incorporated elements which are present at field scale including: a) advection and/or diffusion of gas through sediment, b) influence of layers and discrete physical heterogeneities (gas permeability), c) influence of water content (which affects gas permeability as well as equilibrium partitioning), and d) influence of the combination of different sediment and co-contaminants (i.e., evaluation of $\mathrm{NH}_{3}$ treatment with sediments from different Hanford U-contaminated sites).

Mechanisms that control ammonia gas geochemistry of the uranium-laden sediment minerals can be separated into: a) ammonia gas/liquid partitioning (into pore water), b) $\mathrm{pH}$ and dissolution/precipitation of major sediment minerals, and c) changes in uranium surface phases (U-laden minerals represent a minor fraction of minerals present). Ammonia partitioning was investigated experimentally and compared to equilibrium predictions from Henry's and Rault's Law. Major sediment geochemical changes were also investigated experimentally in both batch, 1-D, and 2-D sediment systems, and compared to equilibrium dissolution and precipitation that is predicted to occur based on geochemical equilibrium modeling. Changes in uranium surface phases were investigated by: a) sequential liquid extractions (i.e., leaching), b) electron microprobe with elemental detectors, c) scanning electron microscope with EDS 
detector, d) Laser induced fluorescence spectroscopy (LIFS), and e) x-ray near edge structure (XANES) for $\mathrm{U}(\mathrm{IV}) / \mathrm{U}(\mathrm{VI})$ in combination with extended $\mathrm{x}$-ray absorption fine structure (EXAFS) for uranium mineralogy. 


\subsection{Background}

\subsection{Uranium Contamination Distribution in the Hanford Vadose Zone}

Uranium occurs naturally in the Hanford Site vadose zone sediments, and also is present from uranium-enrichment processes (i.e., surface and subsurface discharges). Natural minerals that contain uranium include betafite $\mathrm{C}\left[\mathrm{Ca}_{0.92} \mathrm{U}_{1.08}\left(\mathrm{Ti}_{2} \mathrm{O}_{7}\right)\right]$, which most likely are from granitic clasts commonly found in Hanford Site sediments (15\% to 35\% [Zachara et al. 2007]) and uranium coprecipitated with calcite (uranyl tricarbonate). Uranium also is present on sediment surfaces as aqueous and adsorbed $\mathrm{U}^{+6}$ species $\mathrm{Ca}_{2} \mathrm{UO}_{2}\left(\mathrm{CO}_{3}\right)_{3}(\mathrm{aq}), \mathrm{CaUO}_{2}\left(\mathrm{CO}_{3}\right)_{3}{ }^{2-}$ (and to a lesser extent $\mathrm{Mg}$ equivalent phases), with smaller concentrations of $\left(\mathrm{UO}_{2}\right)_{2} \mathrm{CO}_{3}(\mathrm{OH})_{3}{ }^{-}$and $\mathrm{UO}_{2}\left(\mathrm{CO}_{3}\right)_{2}{ }^{2-}$ (Figure 2.1). It should be noted that under natural Hanford Site groundwater/vadose zone pore water $\mathrm{pH}(8.0)$, U(VI) aqueous/adsorbed complexes are neutral or negatively charged, so they exhibit anionic adsorption behavior (i.e., adsorption decreases as the $\mathrm{pH}$ increases from 8.0 to 11 or higher). In addition, $\mathrm{U}(\mathrm{VI})$ aqueous/adsorbed complexes in fieldcontaminated sediments at a $\mathrm{pH}<7$ are predominantly positively charged, so they exhibit cationic adsorption behavior (i.e., as the $\mathrm{pH}$ decreases from 7.0 to more acidic conditions, adsorption decreases).

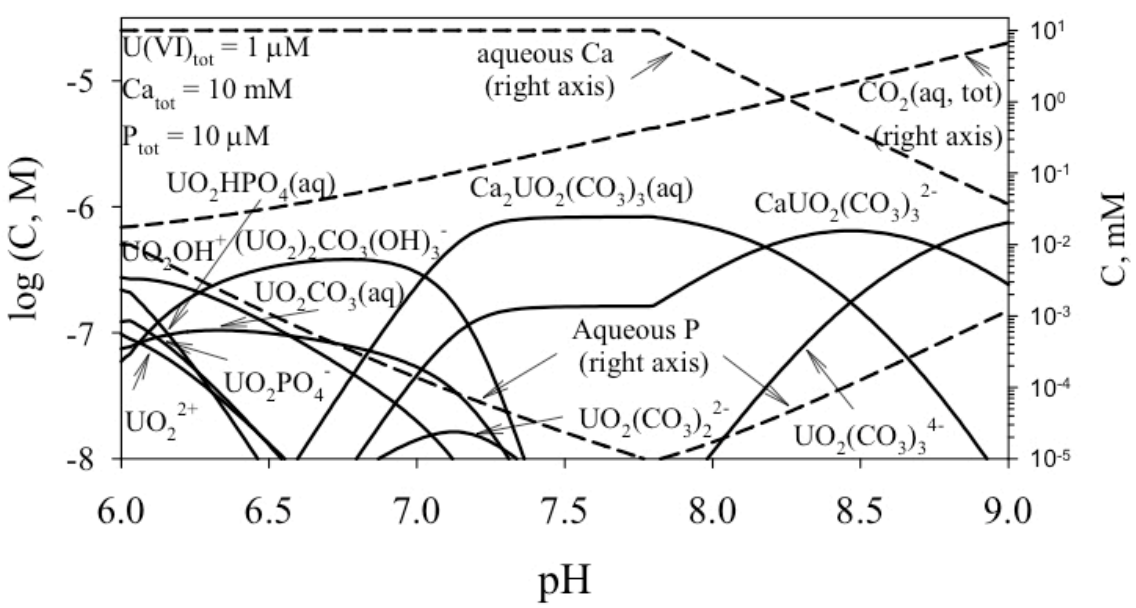

Figure 2.1. Aqueous $\mathrm{U}(\mathrm{VI})$ speciation in the presence of $\mathrm{Ca}(10 \mathrm{mM}), \mathrm{Mg}$ $(10 \mathrm{mM}), \mathrm{CO}_{3}$, and $\mathrm{PO}_{4}$ (Zachara et al. 2007).

Vadose zone contamination at the Hanford Site results from past uranium and plutonium enrichment activities and the intended or unintended release of $202,703 \mathrm{~kg}$ of uranium to the ground surface (Simpson et al. 2006) in a variety of aqueous solutions (i.e., acidic, basic, with organic complexants [citrate, ethylenediaminetetraacetic acid]) and inorganic ligands $\left(\mathrm{CO}_{3}, \mathrm{PO}_{4}\right)$, which would influence the uranium migration behavior. Uranium contamination in shallow 200-Area sediments has been found as a uranium-silicate [Na-boltwoodite; $\mathrm{Na}\left(\mathrm{UO}_{2}\right)\left(\mathrm{SiO}_{4}\right) * 1.5 \mathrm{H}_{2} \mathrm{O}$; Liu et al. 2004)], uranophane $\left[\mathrm{Ca}\left(\mathrm{UO}_{2}\right)_{2}\left(\mathrm{SiO}_{3} \mathrm{OH}\right)_{2}\left(\mathrm{H}_{2} \mathrm{O}\right)_{5}\right]$, and as uranium-calcite coprecipitates (Um et al. 2009). This finding (conceptually illustrated in Figure 2.2) is supported by data from a U105 borehole C5602 (Figure 2.3). Deeper 200-Area sediments show predominantly natural uranium sorbed to silt- and clay-size fractions and calcite. In the 300 Area, uranium also is present as metatorbernite $\left[\mathrm{Cu}\left(\mathrm{UO}_{2}\right)_{2}\left(\mathrm{PO}_{4}\right)_{2} * 8 \mathrm{H}_{2} \mathrm{O}\right]$. Physical transport of aqueous contaminants in the vadose zone is controlled by gravity (i.e., migration proceeds downward) and capillary forces (i.e., migration proceeds in both the vertical and horizontal directions), as shown conceptually in Figure 2.2, with greater lateral spreading in low-K zones and at the interface above high-K zones. 


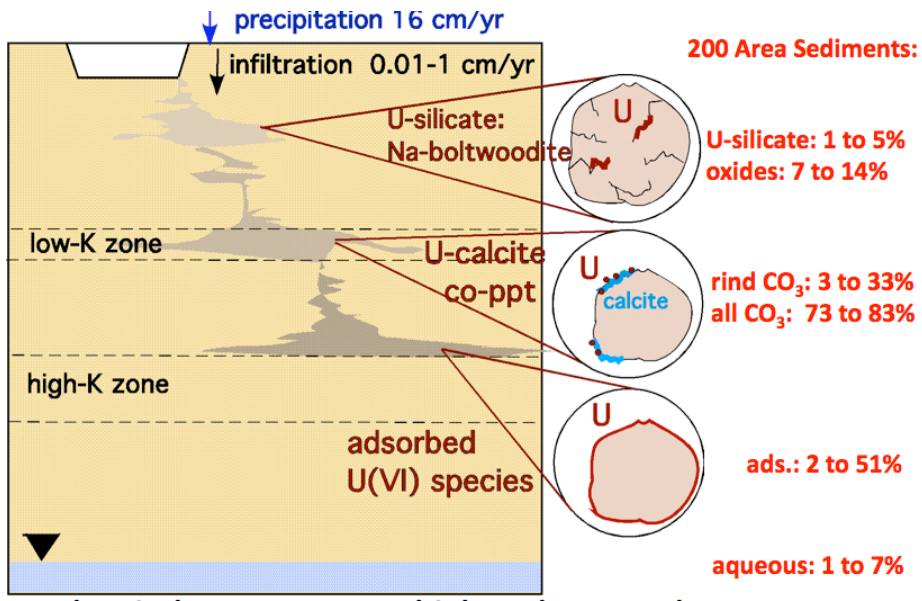

Figure 2.2. Conceptual diagram of $U$ contamination in the vadose zone, as controlled by physical and geochemical processes at multiple scales.
Uranium carbonate aqueous complexes exhibit adsorption to Hanford sediments with a $\mathrm{K}_{\mathrm{d}}$ varying form 0.5 to $28 \mathrm{~mL} / \mathrm{g}$ (Zachara et al. 2007). The natural groundwater (and presumed pore water in the vadose zone) is oversaturated with respect to $\mathrm{Ca}-\mathrm{Mg}$ carbonate. The carbonate concentration significantly controls the uranium adsorption, as all major aqueous complexes present at $\mathrm{pH} 8$ include carbonate (Figure 2.1). A decrease in the pore water carbonate concentration results in an increase in uranium adsorption. Therefore, contaminated sites that differ in $\mathrm{pH}$

and carbonate concentration from natural Hanford conditions can exhibit greatly different uranium transport behavior. The uranium $\mathrm{K}_{\mathrm{d}}$ on sediment for deionized water is, on average $3.1 \pm 1.7$ times greater than Hanford groundwater, due to the presence of U-carbonate solution complexes in groundwater.

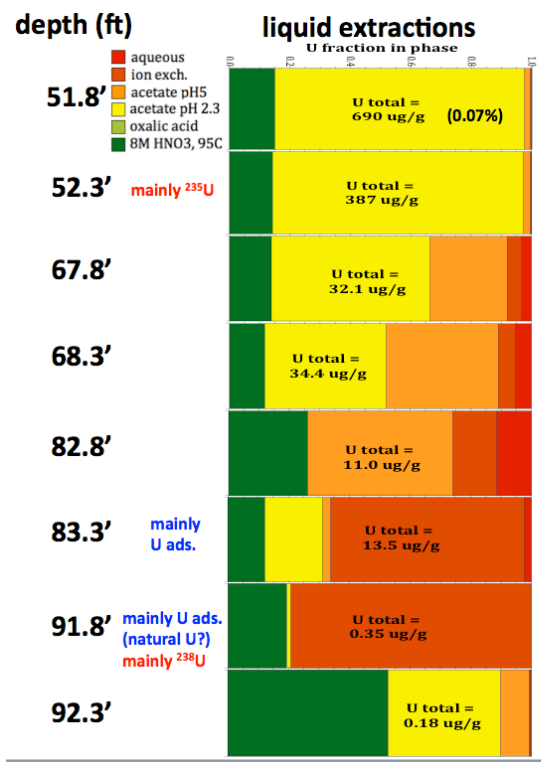

Figure 2.3. Comparison of $U$ surface phase characterization with depth from U105 borehole C5602. Liquid extractions (this study) and solid analysis (Um et al. 2009) shown. solid analysis
Uranium adsorption on

boltwoodite (fluorescence, EXAFS, XANES) [XRD lower limit 0.5\%] boltwoodite, uranophane (fluor.)

U-silicate, U-carbonate, some $\mathrm{U}$ adsorbed (fluor.)

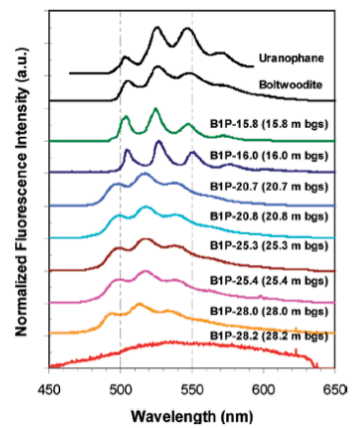
Hanford sediments also exhibits increasing resistance to desorption with longer contact time with sediments, as shown in numerous laboratory and field scale studies. In one laboratory example (Figure 2.4, Smith and Szecsody 2010), U-233 was adsorbed to sediment for 1 week, 1 month, and 1 year, with breakthrough curves of groundwater injection through the sediment shown. Even after 1 month of contact time, significantly less uranium desorbed from the sediment. By one year of uranium-sediment contact time, only $44 \%$ of the uranium desorbed compared with the 1 -week contact time. It is

hypothesized that: a) significant U-carbonate mass can diffuse into sediment microfractures, and b) adsorbed uranium-carbonate complexes can be slowly incorporated into dissolving/reprecipitating carbonates as uranyl tricarbonate. Therefore, carbonates present in these uranium-contaminated Hanford sediments may contain a thin "rind" of uranium-associated carbonate on the surface of carbonates. 
Liquid extractions were specifically conducted in this study to identify how much uranium is present when a small fraction of the carbonate is dissolved and when all of the carbonate is dissolved. Some extractions were also conducted to characterize how much uranium desorbs from sediment after $1 \mathrm{~h}$ of contact time and $1000 \mathrm{~h}$ of contact time in order to account for the $\mathrm{U}$ diffusion out of microfractures, as described in Um (2010).

Stop-flow 1-D column experiments dramatically illustrate the significance of the slow release rate of uranium by sediment (Figure 2.5). In this example, uranium contaminated sediment from the Hanford 300 Area smear zone (31-ft depth) were used. Leaching of the untreated sediment shows a significant fraction of the uranium mass is desorbed by $260 \mathrm{~h}$ (before the first stop flow event), with an initial concentration of $485 \mu \mathrm{g} / \mathrm{L}$ (off the scale of the graph). Groundwater flow was stopped for $190 \mathrm{~h}$, then upon subsequent advection, the untreated sediment shows a significant rise in the effluent uranium concentration. Conversely, a phosphate-treated sediment (data not shown) showed a very small increase during stop-flow events. A second stop-flow event was conducted at $670 \mathrm{~h}$, and a similar increase in uranium concentration for the untreated sediment is observed. These experiments led to the following findings:

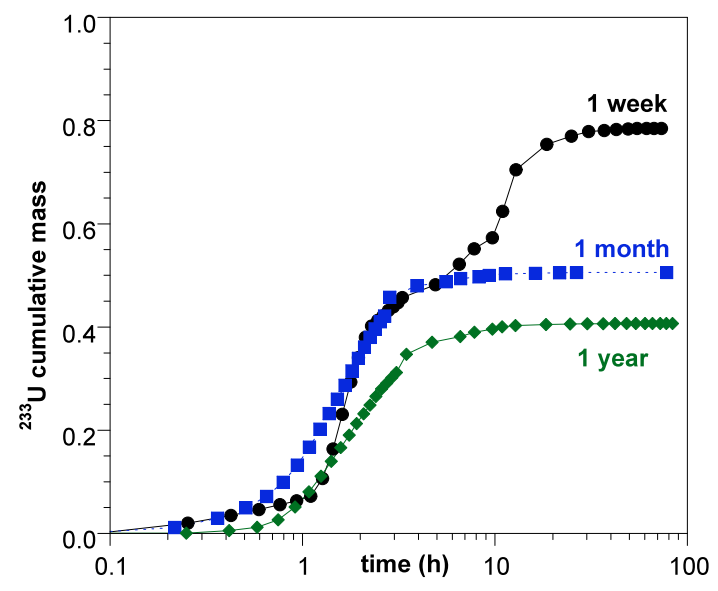

Figure 2.4. 1-D water-saturated column breakthrough of uranium after 1 week, 1 month, or 1 year of ${ }^{233} \mathrm{U}$-sediment aging showing ${ }^{233} \mathrm{U}$ breakthrough (Smith and Szecsody 2009).

- Uranium is slowly released from sediment by one or more mechanisms.

- Phosphate treatment appears effective over the time period tested. These experiments are still in progress and will be reported in detail as part of the 300-Area treatability test study.

- Long-term water leaching experiments such as these are needed to test the effectiveness of the $\mathrm{NH}_{3}$ gas (or other) uranium remediation method, even though the intended application of the technology is the vadose zone and not the saturated zone. 


\subsection{Ammonia Treatment and Aqueous Geochemistry}

Addition of ammonia gas to the vadose zone results in partitioning of ammonia into the pore water, with the following speciation:

$$
\begin{gathered}
\mathrm{NH}_{3}(\mathrm{~g})<=>\mathrm{NH}_{3}(\mathrm{aq}) \quad \mathrm{K}_{\mathrm{h}}=6.58 \times 10^{-4} \\
\mathrm{NH}_{3}(\mathrm{aq})+\mathrm{H}^{+} \Leftrightarrow=\mathrm{NH}_{4}^{+} \mathrm{pK}=9.4
\end{gathered}
$$

This reaction results in a $\mathrm{pH}$ increase, depending on how much $\mathrm{NH}_{3}$ mass is partitioned into the pore water. In Equation 2.1, $\mathrm{K}_{\mathrm{h}}$ is the dimensionless Henry's Law partitioning coefficient. In Equation 2.2, $\mathrm{pK}$ is the $\mathrm{NH}_{3}$ /ammonium dissociation constant. If gas/water equilibrium is reached, the final aqueous $\mathrm{NH}_{3}$ concentration (and $\mathrm{pH}$ ) depends only on the fraction of $\mathrm{NH}_{3}$ in the injection gas as listed in Table 2.1.

Table 2.1. Ammonia gas partitioning to water and resulting $\mathrm{pH}$.

\begin{tabular}{ccc}
\hline$\% \mathbf{N H}_{3} \mathbf{( g )}$ & {$\left[\mathbf{N H}_{3}\right](\mathbf{a q})_{\text {total }}[\mathbf{m o l} / \mathbf{L}]$} & $\mathbf{p H}$ \\
\hline $100 \%$ & 15.7 & 12.52 \\
$30 \%$ & 9.2 & 12.26 \\
$10 \%$ & 6.3 & 12.02 \\
$5 \%$ & 3.1 & 11.87 \\
$1 \%$ & 0.63 & 11.52 \\
$0.3 \%$ & 0.19 & 11.26 \\
$0.1 \%$ & $6.3 \times 10^{-2}$ & 11.02 \\
$0.01 \%$ & $6.3 \times 10^{-3}$ & 10.51 \\
$10^{-3} \%$ & $6.3 \times 10^{-4}$ & 9.99 \\
$10^{-4} \%$ & $6.3 \times 10^{-5}$ & 9.41 \\
$10^{-5} \%$ & $6.3 \times 10^{-6}$ & $8.69^{(\mathrm{a})}$ \\
$10^{-6} \%$ & $6.3 \times 10^{-7}$ & $7.78^{(\mathrm{a})}$ \\
\hline
\end{tabular}

(a) Assumes no other aqueous ions.

Table 2.1 illustrates the significant $\mathrm{pH}$ increase that will occur, starting at a low concentration and increasing, as $\mathrm{NH}_{3}$ gas partitions into pore water. These equilibrium values may not be reached in a laboratory or field system if insufficient $\mathrm{NH}_{3}$ gas is supplied. The amount of gas needed to reach $\mathrm{NH}_{3}$ gas/liquid equilibrium in a sediment/water system is dependent on the total porosity and water content, which defines the gas volume and liquid volume. In general, gas density is two or more orders of magnitude less mass than liquids. These calculations for $\mathrm{NH}_{3}$ gas equilibrium are reported in the results section, but on the order of 200 to 1000 pore volumes of gas are needed to achieve equilibrium (also assuming no kinetic gas/liquid partitioning effect). If these equilibrium values are not achieved, the $\mathrm{pH}$ does not increase as much. 
In a sediment/water system, the pore-water $\mathrm{pH}$ may achieve the hypothetical $\mathrm{pH}$ based on $\mathrm{NH}_{3}$ gas/liquid partitioning, but numerous additional reactions occurring at different rates will buffer this $\mathrm{pH}$ change. In the gas phase, if $\mathrm{CO}_{2}$ is present during $\mathrm{NH}_{3}$ gas injection (i.e., for example, if $5 \% \mathrm{NH}_{3}$ and $95 \%$ air containing $3 \% \mathrm{CO}_{2}$ is used), the carbonate partitioning into pore water (and carbonate already present in the Hanford pore water) will buffer the $\mathrm{pH}$ increase to some extent. After an $\mathrm{NH}_{3}$ gas injection is completed, if this zone of sediment has little gas advection (i.e., advection of gas does not occur and air diffusion is minimal), the $\mathrm{pH}$ will remain high, and mineral precipitation reactions will buffer the system $\mathrm{pH}$. If gas (air or other gas) is advected into the system at some later time period (e.g., 3 months), a portion of the $\mathrm{NH}_{3}$ will be removed because it is somewhat volatile. Carbonate solubility is much higher under these more alkaline conditions, so pore water at $\mathrm{pH} 11$ with the advection (or diffusion) of air (or $\mathrm{CO}_{2}$ gas) will result in a considerable increase in aqueous carbonate, and the $\mathrm{pH}$ will decrease.

As described previously, uranium adsorption will decrease significantly under these highly alkaline conditions, so there will be localized (i.e., grain scale) uranium mobilization (Szecsody et al. 2010; Figure 2.2). Increased carbonate, if occurring, also will decrease uranium adsorption.

The four main fractions of uranium in Hanford sediments include: a) Na-boltwoodite $\left[\mathrm{Na}\left(\mathrm{UO}_{2}\right)\left(\mathrm{SiO}_{4}\right) * 1.5\left(\mathrm{H}_{2} \mathrm{O}\right)\right]$, b) uranophane $\left[\mathrm{Ca}\left(\mathrm{UO}_{2}\right)_{2}\left(\mathrm{SiO}_{3} \mathrm{OH}\right)_{2} * 5\left(\mathrm{H}_{2} \mathrm{O}\right)\right.$; both hydrous U-silicates], c) uranium coprecipitated with carbonates, and d) aqueous/adsorbed uranium carbonate complexes. Under the more alkaline conditions created by $\mathrm{NH}_{3}$ gas partitioning into pore water, carbonates are not more soluble so they should not dissolve, but the hydrous uranium silicates are more soluble under alkaline conditions, especially with increased carbonate (Figure 2.6). Therefore, if the objective of this $\mathrm{NH}_{3}$ gas treatment is to dissolve uranium mineral phases that are somewhat soluble and precipitate lower solubility mineral phases, a mixture of $\mathrm{NH}_{3} / \mathrm{CO}_{2} / \mathrm{N}_{2}$ gas may enhance treatment compared to use of $\mathrm{NH}_{3} / \mathrm{N}_{2}$ gas. The influence of these mixed gases on uranium surface-phase solubility was investigated to a limited extent during FY 2010, with more investigations planned during FY 2011. In addition, after $\mathrm{NH}_{3}$ gas treatment for a few months, injection of a $\mathrm{CO}_{2} / \mathrm{N}_{2}$ gas mixture may enhance treatment. Investigations into using a post- $\mathrm{NH}_{3}$ treatment gas to increase the rate of $\mathrm{pH}$ neutralization were initiated during FY 2010, with plans to continue during FY 2011.

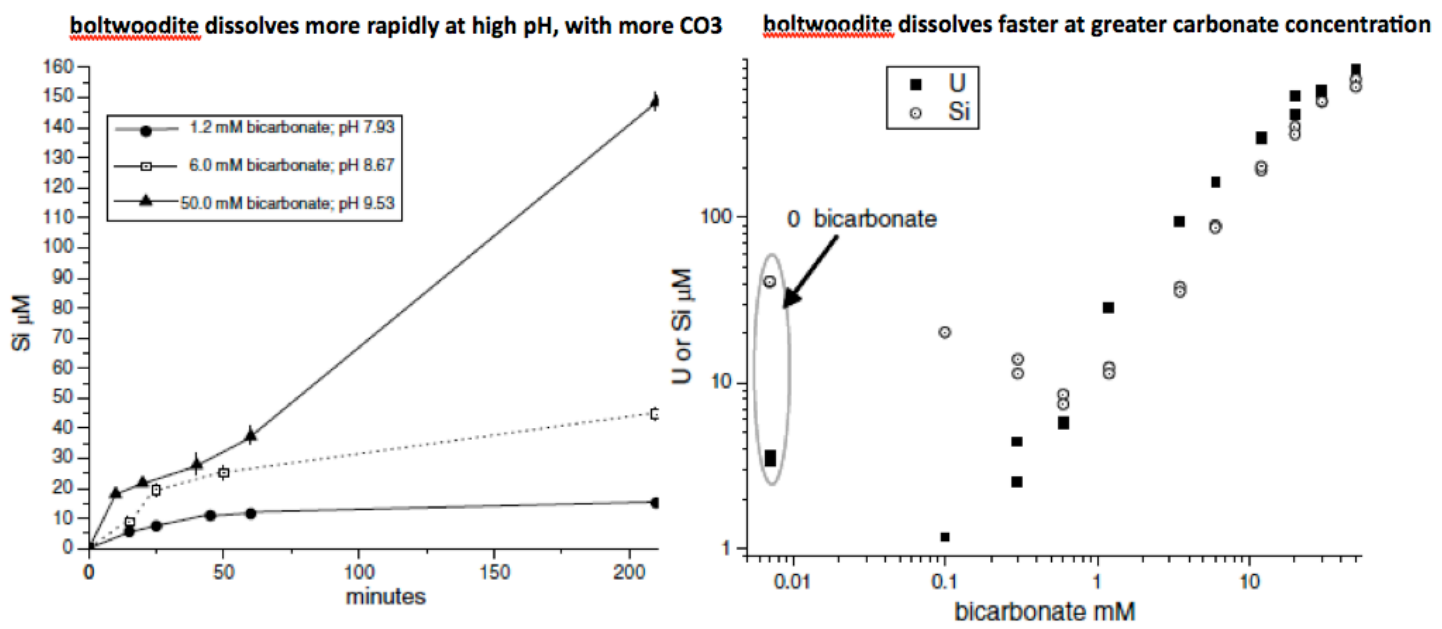

Figure 2.6. Dissolution of Na-boltwoodite with increasing $\mathrm{pH}$ and carbonate (Ilton et al. 2006). 


\subsection{Ammonia Treatment and Sediment Mineralogy}

The significant increase in Hanford sediment $\mathrm{pH}$ from a natural level of 8 to levels in the 11 to 12 range by $\mathrm{NH}_{3}$ gas treatment will cause the dissolution of some aluminosilicate mineral phases. Identification of which mineral phases are more likely to dissolve under these conditions was accomplished using a geochemical equilibrium-modeling program (Geochemist Work Bench). As all 11 major minerals found in the Hanford sediment could not be simulated simultaneously, Hanford groundwater with one mineral phase was simulated over the $\mathrm{pH} 8$ to 11 range to illustrate the relative changes in aqueous concentrations and the minerals that are likely to precipitate. To minimize the complexity of the aqueous species and potential mineral precipitates, minor groundwater species were not included in simulations that did not require those ions. Mineral phases simulated included quartz, plagioclase (anorthite), potassium feldspar (orthoclase), biotite (phlogopite), muscovite, amphibole group (antigorite), illite, montmorillonite (nontronite), kaolinite, calcite, and chlorite (clinochlore). Some of the minerals represent a crystal structure with variable ion substitution (such as montmorillonite, which is a dioctahedral smectite, 2:1 clay); whereas, a specific crystal structure with exact ion substitution was needed for the simulation. Therefore, minerals in parentheses represent the specific mineral phase simulated. Although these simulations do show the extent to which minerals dissolve as the $\mathrm{pH}$ increases, precipitates formed are not representative of the complexity that occurs in the natural sediment because ions from other minerals are not present.

Researchers have spent much time and effort over the last 10 years to understand the processes and reactions that occur in natural heterogeneous terrestrial systems, such as soils, subsoils, vadose zones, and aquifer sediments, when they are exposed to extreme geochemical and relatively high-temperature conditions. Such a unique system was created at the Hanford Site where highly-alkaline, highly-saline and thermally-hot liquid wastes, which were stored in underground single shell waste tanks, accidentally leaked to underground sediments and moved downward through the relatively thick $(\sim 30 \mathrm{~m})$ vadose zone. A research effort sponsored by the DOE via the Office of Environmental Management, the Environmental Management Science Program, the Natural and Accelerated Bioremediation Research Program, and the Environmental Remediation Sciences Program was initiated, with the main objective to understand processes and reactions that may occur under such conditions, which may control or influence the movement of radionuclide and metal contaminants under these extreme conditions. A summary of the findings of some research groups, in terms of the dissolution of existing soil minerals within sediment matrices and formation of the secondary phases, are presented below.

Research conducted at Lawrence Berkeley National Laboratory demonstrated that quartz underwent dissolution, and the following secondary phases were formed: brucite, calcite, cancrinite, and portlandite (Zheng et al. 2008). Experiments were conducted using Hanford formation sediments with a coarse sand texture (more than $87 \%$ sand), which contained quartz, feldspar, and basaltic rock fragments. The clay size fraction of this sediment is composed of $40 \%$ illite, $20 \%$ smectite, $20 \%$ mixed-layer illite and smectite, and $20 \%$ kaolinite with a trace amount of chlorite. In another study, the authors concluded that net precipitation of solids may decrease the porosity and probably the permeability of the sediments (Wan et al. 2004b). Their findings also suggested that silicates, feldspars and mica (e.g., biotite) were the dissolving phases in the Hanford sediments under conditions of high alkalinity. In yet another paper coming out from the same research group, the authors found that quartz underwent dissolution under conditions of high $\mathrm{pH}$ and high temperature, and this process was followed by the precipitation of secondary phases, such as sodium metasilicate, cancrinite, and zeolite (Wan et al. 2004a). 
Research conducted at Pacific Northwest National Laboratory demonstrated that base-induced dissolution of soil minerals was rapid in the first 48 hours as indicated by fast releases of Si and Fe into the soil solution (Qafoku et al. 2003a). Potassium release in the soil solution lagged, and dissolution of potassium-bearing minerals (most likely mica and potassium-feldspar) proceeded faster only after the first 2 to 3 days of experimental time. These batch experiments were conducted at $50^{\circ} \mathrm{C}$ under $\mathrm{CO}_{2}$ - and $\mathrm{O}_{2}$-free conditions. The x-ray diffraction (XRD) results confirmed that two of the most common phyllosilicates in the sediment, smectite and biotite, underwent dissolution, while clinochlore was resistant to weathering under these conditions (Qafoku et al. 2003c). The XRD, scanning electron microscope (SEM), and energy-dispersive x-ray spectroscopy (EDS) analyses and measurements demonstrated the formation of aluminosilicate, such as $\mathrm{NO}_{3}$-cancrinite with a yarn-like morphology (Anthony et al. 1995; Bickmore et al. 2001), sodalite with a cotton-ball like morphology (Barnes et al. 1999b), and zeophyllite (with a platy morphology). Zeophyllite was formed in the presence of high aluminum concentrations. Both sodalite and cancrinite are called "reservoir minerals" because of their large cation-exchange capacities (Buhl and Lons 1996). In addition to providing the mineral with a higher specific surface area, the cages host a complex distribution of extra-frame-work cations and anions (Ballirano et al. 2000). Morphological features of the neophases were found to change with the aqueous silicon/aluminum ratio. These secondary phases were mainly formed on the surfaces of plagioclase with an average chemical composition of approximately $73 \%$ silicon, $16 \%$ aluminum, $6 \%$ calcium, $3 \%$ sodium, and $2 \%$ potassium. Iron precipitates with a sphere-like morphology and $<500 \mathrm{~nm}$ diameter also were formed, but quantitative XRD analysis determined that there was only a small increase in the amount of hematite in the post-treatment sediments. Iron-rich, boll-like structures were observed on the surfaces of mica particles that underwent dissolution. The results from these experiments also indicated that a phase transformation of biotite to hydrobiotite also occurred. Both dissolution and precipitation reactions were kinetically controlled as evidenced from data collected in column experiments (Qafoku et al. 2004). The release of silicon, potassium, and iron into the soil solutions varied with the fluid residence time, which probably indicates that spatially controlled nonequilibrium conditions were created during reactive transport of the highly alkaline and saline liquids. Dissolution was more rapid than precipitation, and fluid residence time had a greater effect on precipitation than dissolution. Biotite and feldspars underwent intensive dissolution in these column experiments. Nitrate cancrinite and sodalite were the newly formed phases. Modeling calculations also suggested the formation of brucite and goethite; the formation of gibbsite also was indicated by the presence of high aluminum concentrations in the leaching solution. Another study demonstrated that goethite and hematite were formed during experiments conducted under similar conditions (Qafoku et al. 2007b). The formation and transformation of iron secondary phases depended on factors such as the ambient temperature and the presence of silicon and aluminum aqueous concentrations. Iron secondary phases were more abundant when sufficient aluminum was present in the aqueous phase. Under these conditions, silicon and aluminum precipitation and formation of felspathoids with a silicon:aluminum 1:1 $\mathrm{M}$ concentration is promoted, but iron follows a different precipitation pathway that leads to the formation of goethite and/or hematite. Finally, two papers were published to demonstrate $\mathrm{Cr}(\mathrm{VI})$ reduction in the sediments exposed to alkaline and saline fluids in batch (Qafoku et al. 2007a) and column experiments (Qafoku et al. 2003b). Szecsody et al. (2001) demonstrated the reduction of technetium under similar conditions. No reports were found in the literature demonstrating $\mathrm{U}(\mathrm{VI})$ reduction and attenuation under these conditions.

Studies conducted at Washington State University demonstrated that the presence of chemical elements such as cesium, potassium, strontium, calcium, and magnesium did not affect the formation of cancrinite and sodalite in the Hanford sediments under highly alkaline conditions (Deng et al. 2006b). A 
general mineral transformation pathway was observed in these studies: poorly crystalline aluminosilicate $\Rightarrow$ Linde Type A zeolite $\Rightarrow$ cancrinite/sodalite, with cancrinite and sodalite being the two stable phases (Deng et al. 2006a). In earlier studies, the same group found that cancrinite, sodalite, LTA zeolite and allophane were identified as the new formation in these sediments (Mashal et al. 2004; Mashal et al. 2005b; Mon et al. 2005). The soil mineral dissolution followed the order of quartz $\Rightarrow$ kaolinite $\Rightarrow$ illite, and although cancrinite, sodalite, and zeolite were formed, the zeolite was not detected after 25 days of reaction time (Mashal et al. 2005a), indicating that this mineral underwent either dissolution or phase transformation. Other relevant references follow: Gerson and Zheng 1997; Hassan 1997; Zheng et al. 1997; Barnes et al. 1999a; Green-Pedersen and Korshin 1999; Park and Englezos 1999; Buhl et al. 2000; Buck and McNamara 2004; Zhao et al. 2004; Bao et al. 2005; Blackford et al. 2007; Chorover et al. 2008; and Leyva-Ramos et al. 2008. 


\subsection{Experimental and Modeling Approach}

In our FY 2009 studies (Szecsody et al. 2010), we investigated 10 different technologies for uranium sequestration by low-water-content geochemical manipulation. Our FY 2010 studies focused primarily on the influence of $\mathrm{NH}_{3}$ gas on sediment mineralogy, uranium mineralogy and leaching, and other side effects. Experiments in this study evaluated the following phenomena:

- $\mathrm{NH}_{3}$ gas/water equilibrium partitioning and kinetics

- $\mathrm{NH}_{3}$ gas/low-water-content sediment major geochemical changes

- $\mathrm{NH}_{3}$ gas and changes in uranium surface phases

- $\mathrm{NH}_{3}$ gas advection in one- and 2-D laboratory systems of increasing the scale and physical complexity (i.e., heterogeneities)

- Planning for a field-scale injection based on laboratory results.

Experiments and analyses for each task are described in the following sections.

\subsection{Sediments Used in Study}

Sediments used in our FY 2010 studies had uranium concentrations that ranged from natural levels $(<2 \mu \mathrm{g} \mathrm{U} / \mathrm{g}$ ) to contaminated sediments (up to $700 \mu \mathrm{g} \mathrm{U} / \mathrm{g}$ ), as described in Table 3.1. Uranium surface phases can be generally classified as hydrous $\mathrm{U}$ silicates (i.e., sodium-boltwoodite $\left[\mathrm{Na}\left(\mathrm{UO}_{2}\right)\left(\mathrm{SiO}_{4}\right)^{*}\right.$ $\left.1.5 \mathrm{H}_{2} \mathrm{O}\right]$, uranophane) or uranium associated with calcite, or adsorbed uranium. The highest uraniumcontaminated sediments (Hanford 200 Area) had sodium-boltwoodite as the primary uranium phase, whereas the lowest U-containing sediment had a mixture of adsorbed and calcite-associated uranium.

Most of the uranium-contaminated sediments were available only in limited quantities $(<50 \mathrm{~g})$, so only small-scale experiments were conducted. The ERDF pit sediments were available in large quantities ( $>200 \mathrm{~kg}$ ), so were used for numerous experiments investigating $\mathrm{NH}_{3}$ gas effects on major minerals in sediments as well as for large scale experiments. For some large-scale experiments in which uraniumcontaminated sediments were desired, pit sediments from the Environmental Restoration Disposal Facility (ERDF) (still Hanford formation, so approximately the same mineralogy) were used in most of the experimental systems, and uranium-contaminated sediments were used in small quantities in specified locations.

The mineralogy in sediments from the BX and TX Tank Farm boreholes were characterized in other studies (Serne et al. 2008a, 2008b). This characterization was conducted in the same BX-102 borehole as sediments 1 and 2 in this study (and similar depths, as shown in Tables 3.1 and 3.2). Characterization also was conducted near where sediments $3 \mathrm{a}$ and $3 \mathrm{~b}$ were collected (near tank TX-104). Table 3.2 shows the mineralogy of samples taken from borehole C4105, which is between tanks TX-106 and TX-109 so it is near tank TX-104. The three sediment samples in the Hanford H2 formation were sandy gravels (Table 3.2), and did not vary significantly in major mineralogy or clay mineralogy. The average moisture content for the Hanford $\mathrm{H} 2$ formation was $6.3 \%$ (in the $2.8 \%$ to $13 \%$ range), with $1.5 \%$ calcite and a total uranium concentration (by $8-\mathrm{M} \mathrm{HNO}_{3}$ ) of $0.5 \mu \mathrm{g} / \mathrm{g}$ to $2.5 \mu \mathrm{g} / \mathrm{g}$ (uncontaminated sediment). In contrast, the fine-grained Cold Creek formation sample contained significant calcite (55\%), but the clay 
mineralogy was similar to the Hanford formation samples. The Cold Creek formation had an average moisture content of $14.2 \%$ (in the $13 \%$ to $23 \%$ range) and an average total uranium concentration of $3.3 \mu \mathrm{g} / \mathrm{g}$. The calcite content in the Cold Creek formation varies considerably with depth. In this study, the calcite content of the mixture of sediments $3 \mathrm{a}$ and $3 \mathrm{~b}$ should average $\sim 1 \%$ (Table 3.2 ), so other than this calcite content, the higher clay content of the Cold Creek and Hanford formation sediments at the TX Tank Farm ( $8 \%$ to $10 \%$, compared to $2.5 \%$ to $5.5 \%$ ) could result in higher reactivity for sediment 3 compared to sediments 1 and 2 .

Table 3.1. Uranium-contaminated sediments used in this study.

\begin{tabular}{|c|c|c|c|c|c|c|c|}
\hline \# & Uranium surface phase & Location & epth (ft) & Sample ID & Formation & $J(u g / g)$ & $\mathrm{CaCO}_{3}(\%)$ \\
\hline 1 & U-silicate: Na-boltwoodite ${ }^{(c)}$ & $\mathrm{BX}-102$ & 131 & SO1014-61 ${ }^{(f)}$ & Hanford & 415 & -- \\
\hline 2 & adsorbed U(VI) species & $B X-102$ & 152 & SO1014-72 ${ }^{(f)}$ & Hanford & $\sim 49^{(\mathrm{b})}$ & -- \\
\hline $3 a$ & U-calcite coprecipitate ${ }^{(\mathrm{d}, \mathrm{e})}$ & TX-104 & 69.3 & C3832-69B & Hanford & 18.4 & $\sim 1.78 \%{ }^{(a)}$ \\
\hline $3 b$ & $\begin{array}{l}\text { ads. } \mathrm{U}(\mathrm{VI})+\mathrm{U} \text {-calcite coppt }{ }^{(\mathrm{d}, \mathrm{e})} \\
\text { boltwoodite } \\
\text { boltwoodite } \\
\text { boltwoodite, uranophane } \\
\text { boltwoodite, uranophane } \\
\text { ads. } \mathrm{U}(\mathrm{VI})+\mathrm{U} \text {-calcite coppt } \\
\text { ads. } \mathrm{U}(\mathrm{VI})+\mathrm{U} \text {-calcite coppt } \\
\text { adsorbed } \mathrm{U}(\mathrm{VI}) \\
\text { adsorbed } \mathrm{U}(\mathrm{VI}) \\
\text { likely ads. } \mathrm{U}(\mathrm{VI})+\mathrm{U} \text {-calcite coppt } \\
\text { likely ads. } \mathrm{U}(\mathrm{VI})+\mathrm{U} \text {-calcite coppt }\end{array}$ & $\begin{array}{c}\text { TX-104 } \\
\text { U105 } \\
\text { U105 } \\
\text { U105 } \\
\text { U105 } \\
\text { U105 } \\
\text { U105 } \\
\text { U105 } \\
\text { U105 } \\
\text { ERDF pit } \\
\text { ERDF pit } \\
\text { IDF Pit } 30 \\
\text { BC Crib } \\
\text { BC Crib } \\
\text { BC Crib }\end{array}$ & $\begin{array}{c}110.3 \\
51.8 \\
52.3 \\
67.8 \\
68.3 \\
82.8 \\
83.3 \\
91.8 \\
92.3 \\
20 \\
40\end{array}$ & $\begin{array}{l}\text { C3832-110B } \\
\text { C5602*4 } \\
\text { C5602 } \\
\text { C5602*4 } \\
\text { C5602 } \\
\text { C5602*4 } \\
\text { C5602 } \\
\text { C5602*4 } \\
\text { C5602 }\end{array}$ & $\begin{array}{c}\text { Cold Creek } \\
\text { Hanford } \\
\text { Hanford } \\
\text { Hanford } \\
\text { Hanford } \\
\text { Hanford } \\
\text { Hanford } \\
\text { Hanford } \\
\text { Hanford } \\
\text { Hanford } \\
\text { Hanford } \\
\text { Hanford } \\
\text { Hanford } \\
\text { Hanford } \\
\text { Hanford }\end{array}$ & $\begin{array}{c}55 \\
690 \\
387 \\
32.1 \\
34.4 \\
11.0 \\
13.5 \\
0.35 \\
0.18 \\
1.1 \\
1.1 \\
3.0 \\
18 \\
0.18 \\
0.18\end{array}$ & ND \\
\hline
\end{tabular}

(a) $1.78 \%$ calcite for sample $69 \mathrm{~A}$

(b) $40 \mathrm{ug} / \mathrm{g}$ for sample $72 \mathrm{~A}$

et al., 2009

(c) Liu et al., 2004

(e) Wellman et al., 2008

(f) borehole 299-E33-45, Serne et al., 2002, 2008

Table 3.2. Sediment grain size and mineralogy characterization. Data from Serne et al. (2008a, 2008b).

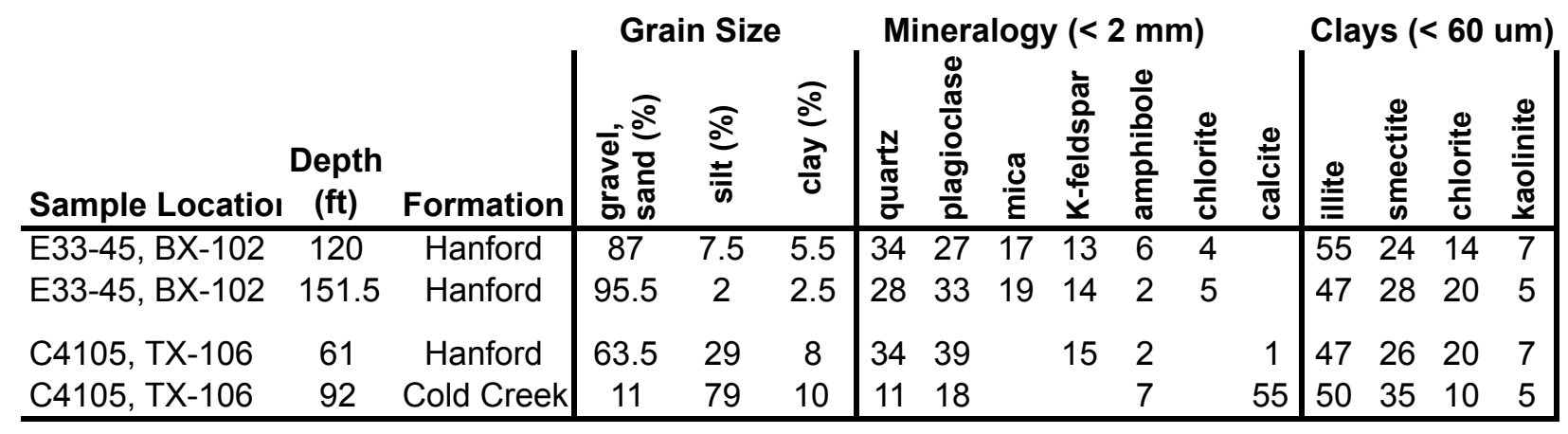




\section{2 $\mathrm{NH}_{3} \mathrm{Gas} /$ Water Experiments}

$\mathrm{NH}_{3}$ gas was used in this study, with a volumetric fraction varying from $100 \%$ to $1 \%$ in different experiments. Most experiments were conducted with anhydrous $\mathrm{NH}_{3}$ mixed with anhydrous nitrogen gas, although some experiments used other gases (see the following section). $\mathrm{NH}_{3}$ gas partitioning between the gas and liquid phases is defined by the Henry's Law partition coefficient of $6.58 \times 10^{-4}$ (dimensionless $\mathrm{K}_{\mathrm{h}}$ ) or $1.61 \times 10^{-5} \mathrm{~atm} \mathrm{m^{3 }} / \mathrm{mol}$. Experiments were conducted to confirm the partitioning of $100 \%$ and $5 \%$ $\mathrm{NH}_{3}$ gas into water as was described by Henry's Law, and to determine the kinetics of the gas-to-liquid partitioning process. Batch gas-to-liquid partitioning experiments consisted of bubbling $\mathrm{NH}_{3}$ gas at a specified rate (i.e., $20 \mathrm{~mL} / \mathrm{min}$ ) into water of a specified volume (100 mL to $1000 \mathrm{~mL}$ ) over time, with continuous monitoring of the $\mathrm{pH}$, electrical conductivity (EC), and temperature of the water. Because the reaction is exothermic, the water temperature increases.

Other physicochemical properties change as $\mathrm{NH}_{3}$ gas partitions into water. The equilibrium concentration of $\mathrm{NH}_{3}$ in water (details described in the results section) is $15.7 \mathrm{~mol} / \mathrm{L}$ for $100 \% \mathrm{NH}_{3}$ gas, and a lower concentration for lower fraction of $\mathrm{NH}_{3}$ in the gas phase $\left(\right.$ at $\left.20^{\circ} \mathrm{C}\right)$. This significant amount of dissolved $\mathrm{NH}_{3}$ increases the liquid volume by $30 \%$ (at $15.7 \mathrm{~mol} / \mathrm{L}$ ). The water solubility of $\mathrm{NH}_{3}$ increases with decreasing temperature, so at $0^{\circ} \mathrm{C}, 43 \%$ to $47 \% \mathrm{NH}_{3}\left(\mathrm{NH}_{3}\right.$ weight/total) can partition into water, compared with $33.1 \%$ at $20^{\circ} \mathrm{C}$ (Brinblecombe and Dawson et al. 1984). In addition, the viscosity of the liquid decreases from 78 dynes/cm (with no $\mathrm{NH}_{3}$ ) to 20 dynes/cm at $15.7 \mathrm{~mol} / \mathrm{L}$ (Yoo et al. 1984; Bloch and Luecke 1970).

\section{3 $\mathrm{NH}_{3}$ Gas/Sediment/Water Batch Experiments}

$\mathrm{NH}_{3}$ gas treatment of sediments that contained some pore water was conducted in batch vials and in small-to-large columns. Batch treatments enabled precise control of the amount of $\mathrm{NH}_{3}$ mass relative to the pore water, but were at a low sediment:gas volume ratio not found in field sediments (i.e., essentially at a very high porosity), whereas $\mathrm{NH}_{3}$ gas treatment in columns enabled advection of a number of pore volumes of gas to treat the sediment. Batch and column studies were conducted with dried sediment that had a specified amount of groundwater added to reach $1 \%, 4 \%, 8 \%$, and $16 \%$ water content $(\mathrm{g} / \mathrm{g})$. A typical batch treatment consisted of $2 \mathrm{~g}$ to $5 \mathrm{~g}$ of sediment in a $25 \mathrm{~mL}$ tube, so if filled with $5 \%$ to $100 \%$ $\mathrm{NH}_{3}$ gas, the equivalent treatment is approximately 40 pore volumes of $\mathrm{NH}_{3}$ gas. A series of these batch treatments were conducted in separate vials for time periods ranging from 10 seconds to 1 year to quantify the rate at which $\mathrm{NH}_{3}$ partitions into pore water (as defined by the pore water $\mathrm{pH}$ change), sediment mineral dissolution (as defined by the increase in aqueous cations and anions) that occurs over a short time period, and mineral precipitation (as defined by the subsequent decrease in aqueous cation and anion concentrations). A series of highly controlled batch experiments were conducted in which 50 pore volumes, 300 pore volumes, and 1000 pore volumes of $\mathrm{NH}_{3}$ :nitrogen gas mixtures were reacted with sediments for specified time periods ranging from 1 hour to 800 hours.

A large number of batch experiments received $\mathrm{NH}_{3}$ gas treatment in 1-D columns. Small 1-D column experiments consisted of the sediment at specified water contents $(1 \%$ to $16 \% \mathrm{w} / \mathrm{w})$ packed into a $1.1-\mathrm{cm}$ diameter by $12-\mathrm{cm}$-long stainless steel column. The gas-filled pore volume of the system was calculated and the $\mathrm{NH}_{3}$ gas treatment consisted of injecting the $\mathrm{NH}_{3}$ gas mixture (1\% to $100 \% \mathrm{NH}_{3}$ with balance being nitrogen) at $2.0 \mathrm{~mL} / \mathrm{min}$ to $150 \mathrm{~mL} / \mathrm{min}$ through the sediment column for a specified time to receive the equivalent number of pore volumes of gas treatment. The batch experiments then consisted of 
allowing this $\mathrm{NH}_{3}$-treated sediment to react (i.e., remain in a sealed column) for a specified amount of time (ranging from minutes to 1 year) before uranium, cation, or anion analysis of the pore water and/or solid-phase analysis (see Sections 3.7 and 3.8). As described in the following section, $\mathrm{NH}_{3}$ gas partitioning into sediment pore water occurs rapidly (initially in seconds), so the batch gas treatments described above (with a specified gas volume equivalent to a number of pore volumes) and the batch experiments with column gas treatments (with a specified gas volume advected through the column) are equivalent to $<200$ pore volumes. For high $\mathrm{NH}_{3}$ gas treatment ( $>200$ pore volumes), the rate at which $\mathrm{NH}_{3}$ gas partitions into pore water slows considerably (with a half-life ranging from minutes to hours), so column treatments at a high gas flow rate would not allow sufficient time for the $\mathrm{NH}_{3}$ to partition into the pore water. Therefore, batch treatments at $>200$ pore volumes are considered more accurate.

At specified time periods in batch (and column) experiments, sediments were treated to extract pore water for analysis of aqueous and adsorbed cations, anions, and some uranium surface phases. This involves taking apart the batch or small 1-D column to extract the sediment. Because the sediment is at a high $\mathrm{pH}$ (i.e., 10 to 13), once the sediment pore water is exposed to air (containing $3 \% \mathrm{CO}_{2}$ ), there can be increased $\mathrm{CO}_{2}$ partitioning into water (increased solubility), and the carbonate concentration in the pore water can increase. Most small-batch systems were manipulated in an anaerobic chamber during disassembly to eliminate this potential $\mathrm{CO}_{2}$ effect. However, the one- and 2-D column systems (described in the following two sections) are large, so it was not possible to take sediment samples from these systems in an anaerobic chamber. It should be noted that, once the gas has been injected for a field $\mathrm{NH}_{3} /$ nitrogen gas injection, most of the sediment will not be exposed to air for months (time for diffusion to re-equilibrate soil gas) unless a new gas mixture is introduced on purpose. This effect of air (or $\mathrm{CO}_{2}$ gas) exposure after $\mathrm{NH}_{3}$ gas treatment was investigated in a few batch experiments in which the sediment was exposed to $5 \% \mathrm{NH}_{3}$ gas for 200 hours, and then exposed to either air or $100 \% \mathrm{CO}_{2}$ gas for 200 hours before the sediment was analyzed for cations/anions, and uranium surface phases.

Separation of pore water from low-water-content sediment was accomplished by several different methods, each of which has limitations. The predominant water extraction consisted of addition of deionized water (1:1 ratio) to sediment, followed by centrifuging and $0.45-\mathrm{m}$ filtering to obtain sufficient pore water for analysis. For sediments in which additional liquid volume was needed for multiple analyses but for which there was a very limited mass of sediment, a higher liquid:solid ratio was used $(10 \mathrm{~mL}: 2 \mathrm{~g})$. While this process is straightforward, ion concentrations in diluted pore water are not exactly representative of pore water geochemistry. At a higher liquid:solid ratio, some adsorbed ions will desorb, so this deionized water extraction process tends to produce somewhat elevated cation:anion aqueous concentrations and lower adsorbed cation:anion concentrations.

An alternate extraction method consisted of centrifuging low-water-content sediments in a special tube with a filter so that pore water could be extracted. Although no water is added to the sediment, only a fraction of the pore water was extracted. We believe that this pore water likely was located far from sediment surfaces, so it contains a lower ion concentration (i.e., ions in the double diffuse layer near sediment surfaces are probably not extracted). This centrifuge process also is time consuming, and considerably more sediment is needed to extract a small mass of water. In addition, this centrifuge process could only be used for water contents of $8 \%$ or higher for the Hanford sediment used.

A third method for extracting pore water was injection of an immiscible liquid (hexane) into lowwater-content sediment packed into a small column, which advects some of the pore water from the sediment. The liquid extracted from the system consists of a combination of water and hexane, but 
because the liquids are immiscible, the water is then easily separated. Because the capillary forces holding water in small sediment pores are much stronger than for hexane, only a portion of the pore water is extracted. Several experiments were conducted to compare $\mathrm{pH}$, electrical conductivity, cation, and anion concentrations for the different extraction methods.

In addition to sediments, several mineral phases were treated with $\mathrm{NH}_{3}$ gas to evaluate the dissolution rate. These minerals were the 11 most commonly identified minerals in the Hanford and Cold Creek formations and included biotite, chlorite, illite, montmorillonite, microcline, hornblende, kaolinite, muscovite, and quartz. Two rocks (i.e., granite and basalt) also were treated with $\mathrm{NH}_{3}$ gas, as the Hanford and Cold Creek formations consist of clasts of these two rocks. Experiments involved grinding the minerals or rocks, reacting the solids (with $4 \%$ water content added as groundwater) with $10 \% \mathrm{NH}_{3}$ gas for 30 days, and then adding deionized water, centrifuging, and filtering for cation/anion analysis. Parallel liquid extractions were done with untreated ground mineral sediments.

Two additional mineral phases (uranium substituted in calcium carbonate and Na-boltwoodite) were used for evaluating the set of six sequential liquid extractions (see Section 3.7).

\section{4 $\mathrm{NH}_{3}$ Gas Injection into 1-D Sediment Columns}

A number of 1-D column experiments were conducted in which ammonia/nitrogen gas was advected through the sediment column, with in situ real time measurements of $\mathrm{pH}$, temperature, and reaction front, and later analysis of sediments at specified distances. These 1-D column experiments were conducted to evaluate effects of reactions between ammonia gas and sediment geochemistry and uranium surface phases in systems in which the gas was advected (as in the field) rather than batch reacted. Sediment was generally packed uniformly in these sediment columns. Influence of heterogeneities was evaluated in 2-D flow systems, as described in the following section. The 1-D columns used for these experiments consisted of $1.25 \mathrm{~cm}$ internal diameter clear PVC (schedule 80$)$ of varying length [50 cm $(1.6 \mathrm{ft}), 160 \mathrm{~cm}(5 \mathrm{ft}), 305 \mathrm{~cm}$ $(10 \mathrm{ft}), 610 \mathrm{~cm}(20 \mathrm{ft})$, and $915 \mathrm{~cm}(30 \mathrm{ft})]$. Experiments varied from ammonia gas injection in a $30 \mathrm{ft}$ long column with temperature monitoring every $10 \mathrm{ft}$ (Figure 3.1), to ammonia gas injection in a $20 \mathrm{ft}$ column (separated into two 10-ft pieces) with automated data logging of temperature at 10 and $20 \mathrm{ft}$ (Figure 3.2a).

During $\mathrm{NH}_{3}$ gas injection, the reaction front is typically sharp (Figure 3.2b) for high $\mathrm{NH}_{3}$ gas concentrations $\left(100 \% \mathrm{NH}_{3}\right.$ advection shown), but is more diffuse for lower $\mathrm{NH}_{3}$ gas concentration advection, as described in detail in the results section. The approximate sediment pore water $\mathrm{pH}$ could be monitored in situ using $\mathrm{pH}$ indicator paper, as shown

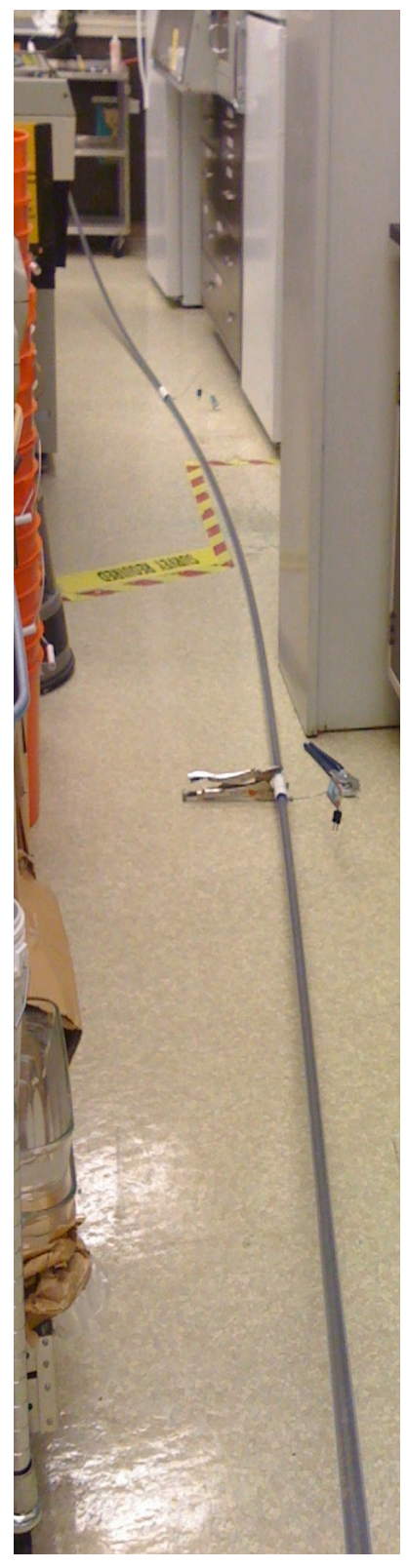

Figure 3.1. $30-\mathrm{ft}$ long 1-D column of $100 \% \mathrm{NH}_{3}$ injection. 
in Figure 3.2c where a pH of 11 is shown at the feed end of the column, and a pH of 8 is shown at the 20 -ft location because the reaction front had not yet advected to this location. In many of the experiments, the $\mathrm{NH}_{3}$ gas advection was terminated while the reaction front was still in the column. This enabled collection of sediments in front of, within, and behind the reaction front to evaluate $\mathrm{NH}_{3}$ reactions with the sediment.
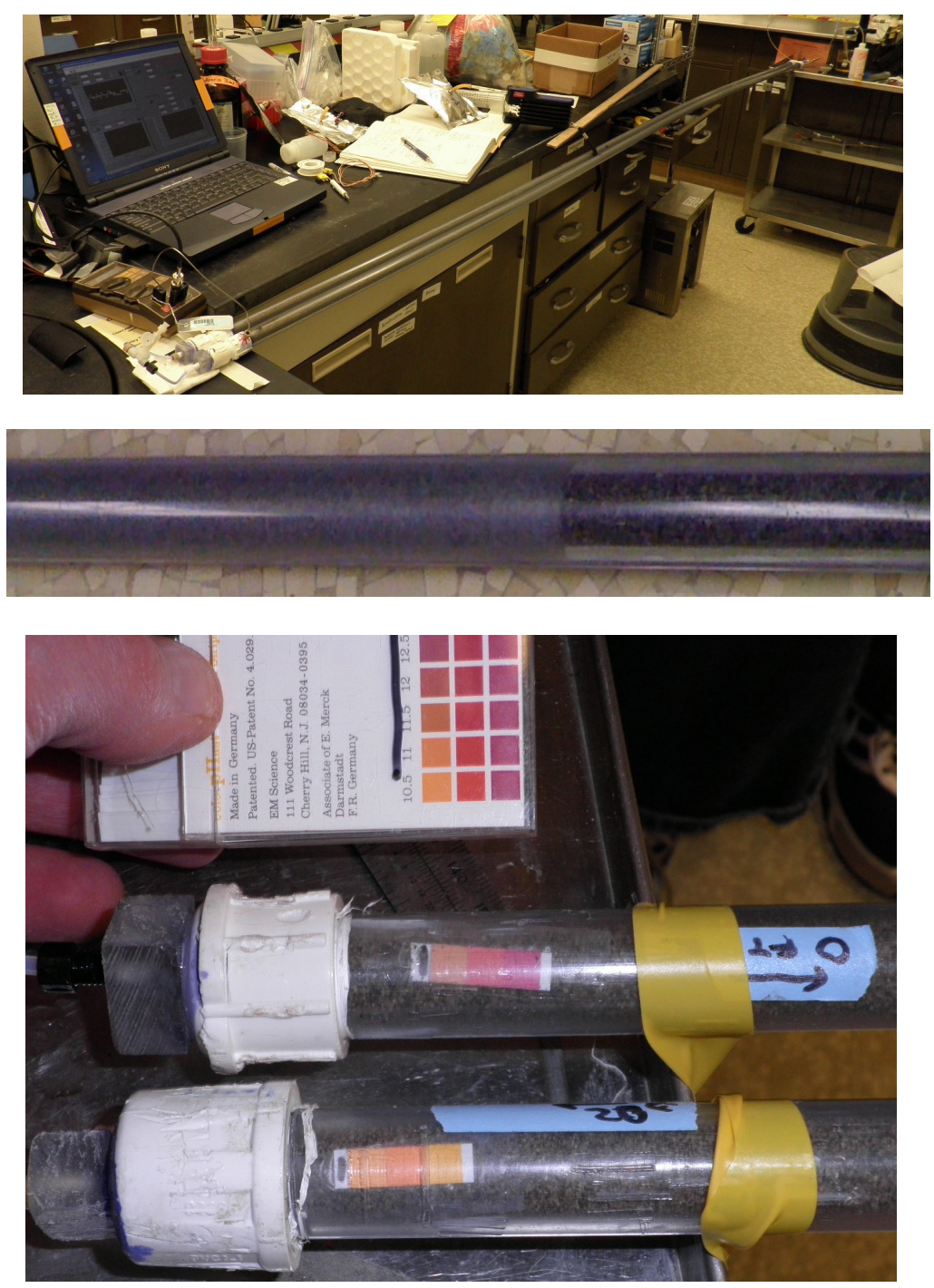

Figure 3.2. Ammonia gas injection into a 20 -ft long $1-\mathrm{D}$ column with data logging of temperature (a), reaction front visually shown (b), and $\mathrm{pH}$ indicator paper (c).

The ammonia gas phase concentration was periodically measured in 1-D and 2-D flow systems by taking a 10 to $20 \mathrm{~mL}$ gas samples, which were analyzed using and UV absorption or colormetric test, as described in Section 3.6. 


\section{5 $\mathrm{NH}_{3}$ Gas Injection into 2-D Experiments}

Several different 2-D flow systems were used in experiments to evaluate the injection of ammonia gas or foam into heterogeneous sediment. For ammonia gas injection, a 2-D wedge-shaped system was used (Figure 3.3). This flow system is $50 \mathrm{~cm}$ high by $122 \mathrm{~cm}$ in length, and a 10 degree radial angle, such that the injection side is $1.5 \mathrm{~cm}$ in width at $0 \mathrm{~cm}$ length), and the outlet side (at $122 \mathrm{~cm}$ length) is $50 \mathrm{~cm}$ in width. The volume of the system is 155 liters, so contained $280 \mathrm{~kg}$ of sediment. The length and vertical dimension of this flow system enables the evaluation of a density-influenced liquid or gas injection. Ammonia gas was injected at the narrow end at 2.1 liters/minute, simulating well injection, and the experiment ended when the reaction front was partially through the flow system. The entire wedge shaped flow system was placed in a hood for the experiment. The system was packed with four layers of sediment. The center two layers of sediment were packed with a Hanford formation gravely sand, and initially at $1 \%$ or $4 \%$ water content. The upper and lower layers were packed with Hanford formation silty sand at $4 \%$ and $8 \%$ water content. The permeability and water content heterogeneities were emplaced to evaluate different advection and pore water partitioning rates, as described in detail in the result section. In addition, 16 small discontinuous layers were emplaced in the center two layers. These discontinuous lenses consisted of eight zones of a Hanford formation silt at 1\%, 4\%, 8\%, and 16\% water content, and eight layers of a fine silica sand (\#70) at the same water contents. For this experiment, pictures were taken at different times to qualitatively track the progress of the reaction and drying fronts.

Imposed flow differences in this system were from different water contents where higher water content has lower air permeability. In addition, with higher the water content, more mass of ammonia gas is needed to saturate the pore water (i.e., a greater number of pore volumes needed to reach equilibrium). These conditions are similar to having low-permeability layers/lenses in the field (with lower total hydraulic conductivity and higher natural water content) where it will likely take longer to reach $\mathrm{pH}$ equilibrium from an ammonia gas injection compared with surrounding coarser material at lower water content.

A second wedge-shaped flow system was built during FY 2010. This system is $6.0 \mathrm{~m}$ (20 ft) in length by $5.1 \mathrm{~cm}$ ( $2 \mathrm{in}$.) high, and is constructed at a 4.5-degree angle, so it varies from $1.0 \mathrm{~cm}$ at the injection end to $61 \mathrm{~cm}$ in width at the outlet end (Figure 3.4). This flow system was built to evaluate advection of $\mathrm{NH}_{3}$ gas at a length scale similar to field scale. The flow system is built in four $5-\mathrm{ft}(1.5-\mathrm{m})$ long pieces so that $\mathrm{NH}_{3}$-gassed sediment can be unpacked in a hood. This also enables 5 -ft, 10 -ft, 15 -ft, or 20-ft long radial injection experiments to be conducted. The total volume of this flow system is $5.4 \mathrm{~L}$ (to $5 \mathrm{ft}$ ), $25 \mathrm{~L}$ (to $10 \mathrm{ft}$ ), $51 \mathrm{~L}$ (to $15 \mathrm{ft}$ ), and $147 \mathrm{~L}$ (to $20 \mathrm{ft}$ ). The entire 20 -ft-long system requires $250 \mathrm{~kg}$ of sediment. To evaluate the influence of $\mathrm{NH}_{3}$ gas on field sediments that are contaminated with uranium, the system will be initially packed with Hanford formation sediment that is not contaminated with uranium. Then, through 0.9 -cm-diameter ports tapped at different distances on the top plate of the flow cell, a sediment core will be extracted and uranium-contaminated sediment emplaced. This approach also enables retrieval of sediments during the experiment, rather than just at the end of the experiment. 

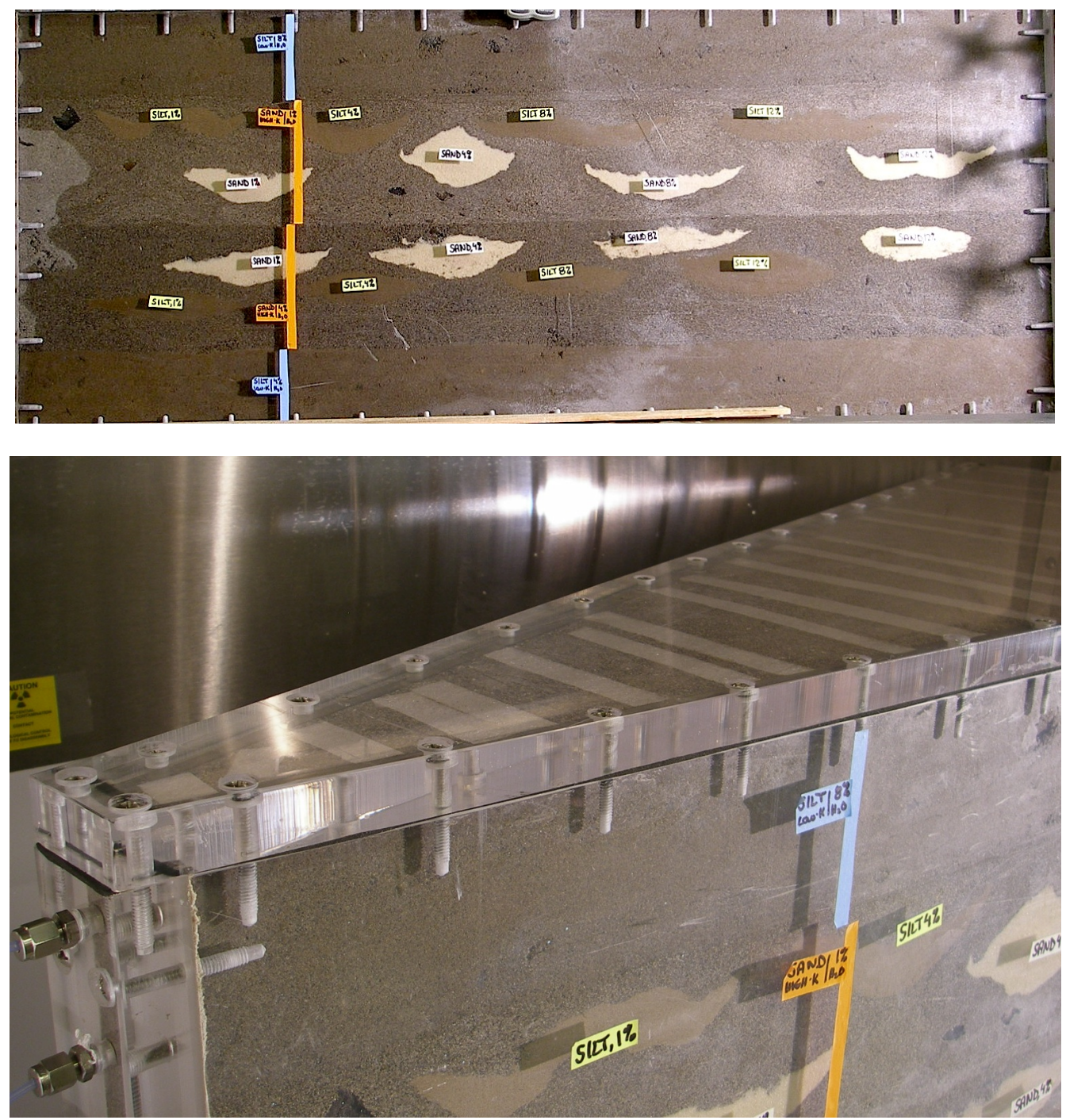

Figure 3.3. 2-D wedge-shaped flow system ( $1.2 \mathrm{~m}$ long) used for ammonia gas injection into a radial flow system containing layers and discontinuous low-K lenses.

\subsection{Ammonia Gas Concentration Measurement and Flow Control}

Two different methods were used to measure the ammonia gas concentrations in experiments. One system used a Perkin Elmer ultraviolet (UV) absorbance detector with 10-cm long gas cell and absorbance at $204 \mathrm{~nm}$. This involved filling the cell with $30 \mathrm{~mL}$ of gas at a concentration of $1.5 \%$ ammonia or less (Figure 3.5a), which resulted in an absorbance of 2.5 absorbance units (AU) at a ammonia concentration of $1.4 \%$. Although the calibration curve was fairly linear to $2.5 \mathrm{AU}$, ammonia concentrations were kept below $0.5 \%$ in order to maintain the absorbance below 1.0 AU (Figure 3.5b). A typical experiment used 5\% ammonia gas concentration, so $3.0 \mathrm{~mL}$ of $5 \%$ ammonia gas injected into the $30 \mathrm{~mL}$ measurement cell resulted in a 10 times dilution or $0.45 \%$. 

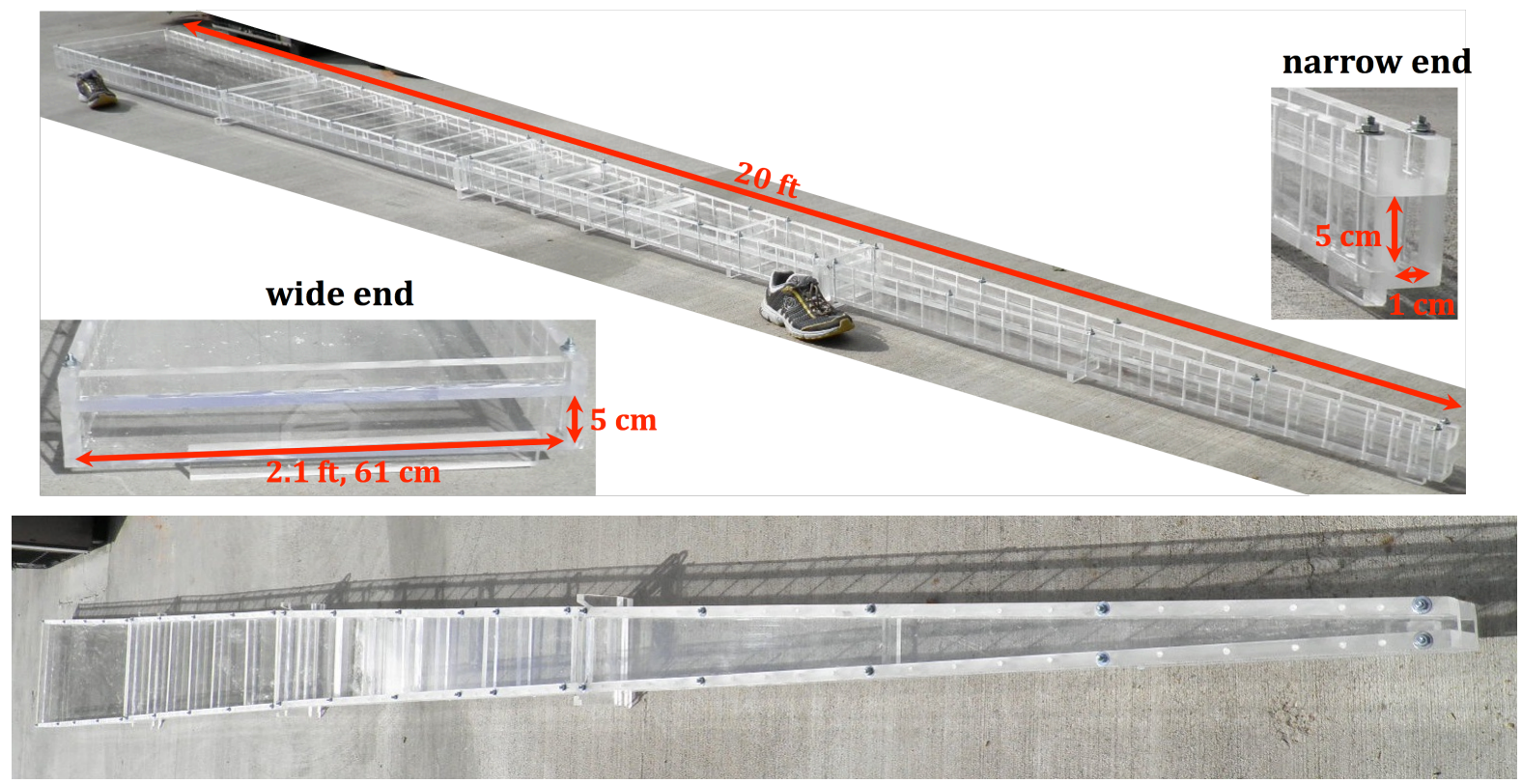

Figure 3.4. 2-D wedge-shaped flow system (6 $\mathrm{m}$ or $20 \mathrm{ft}$ in length) built for approximating field scale ammonia gas injection processes.
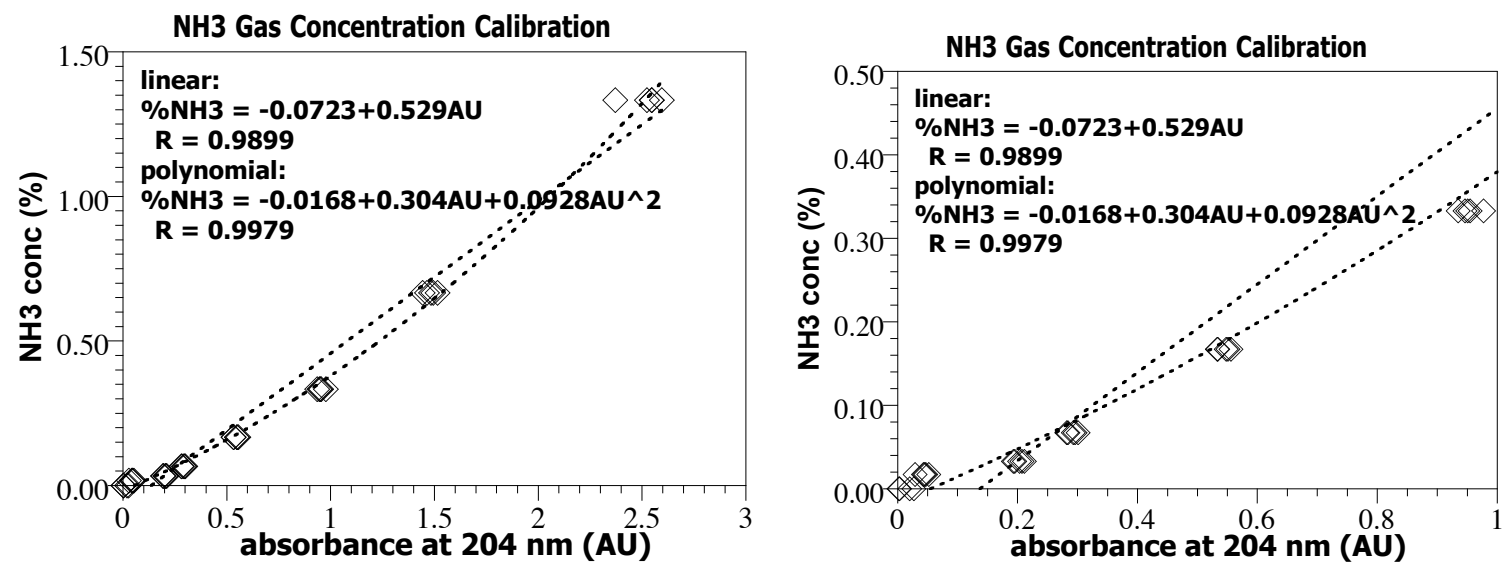

Figure 3.5. Ammonia gas phase concentration calibration by UV absorption at $204 \mathrm{~nm}$.

This analysis method was accurate and used only a small volume of gas; however, it was not possible to measure $\mathrm{NH}_{3}$ gas samples rapidly with this method. Therefore, so for some experiments, gas phase samples were collected in septa-top glass vials for later analysis.

A simpler $\mathrm{NH}_{3}$ gas-phase concentration method was used for rapid measurements. This method consisted of a Drager gas sampler $(100 \mathrm{~mL})$ and colormetric tubes designed for $\mathrm{NH}_{3}$ gas in the $0.5 \%$ to $10 \%$ range. The accuracy of this method was $0.5 \%$ and a $100-\mathrm{mL}$ gas sample was needed for the measurement. This level of accuracy was sufficient for most experiments. Using this method, a gas concentration measurement required 20 seconds. 
Batch experiments requiring specified volumes of $\mathrm{NH}_{3}$ gas mixtures (at standard temperature and atmospheric pressure) were conducted by filling flexible metalized gas-sampling bags (5-L volume) with the appropriate gas mixture ( $5 \%$ ammonia, $95 \%$ nitrogen, for example). The fraction $\mathrm{NH}_{3}$ concentration was verified using an $\mathrm{NH}_{3}$ concentration measurement. Specified volumes from this bag $(10 \mathrm{~mL}$ to $600 \mathrm{~mL}$ ) then were removed using a $250-\mathrm{mL}$ syringe with a gas-tight luer valve, and the sample was injected into the batch experiment through a septa.

For experiments in which $\mathrm{NH}_{3}$ gas was advected into a column, control of the gas flow rate was necessary. Although an electronic control valve specifically designed for $\mathrm{NH}_{3}$ gas was tested, it failed over time and was not used. Several manual diaphragm valves also specifically designed for use with $\mathrm{NH}_{3}$ gas were tested, but they failed over time and were not used. It appeared that minute amounts of water vapor resulted in the anhydrous $\mathrm{NH}_{3}$ gas partitioning to the extent that a small droplet of $\mathrm{NH}_{4} \mathrm{OH}$ was formed, and subsequently it dehydrated, leaving crystals that prevented proper functioning of the flow controllers.

A bubble flow meter also was tested. This meter, which consists of emplacing a detergent bubble film in a glass tube with marks at $1 \mathrm{~mL}, 10 \mathrm{~mL}$, and $100 \mathrm{~mL}$ (and measuring the time required to reach those volumes for use in flow rate calculations), also did not work because the $\mathrm{NH}_{3}$ gas rapidly partitioned into the water film in the bubble (so the bubble did not move when the flow rate was low). Simple plastic-ball flow meters (cone shaped tubes containing a plastic ball with calibration marks) did measure the $\mathrm{NH}_{3}$ gas flow rate consistently over the long time periods needed for the experiments; however, they required calibration.

$\mathrm{NH}_{3}$ gas flow rate was ultimately measured using hydraulic oil and a graduated cylinder $(10 \mathrm{~mL}$ to $100 \mathrm{~mL}$ ). The cylinder was filled with oil, turned upside down, and placed in a beaker containing oil. $\mathrm{NH}_{3}$ gas was bubbled into the cylinder until the oil was displaced to exactly the same level inside the cylinder as in the open beaker. At that point, the $\mathrm{NH}_{3}$ gas pressure in the cylinder was at atmospheric pressure. The flow rate then was calculated using the time required to fill the cylinder. $\mathrm{NH}_{3}$ did not partition into the oil over short periods of time; however, over time periods of days to weeks, the volume of $\mathrm{NH}_{3}$ trapped in the cylinder decreased, indicating a slow partitioning into the oil, which likely contained a small amount of water.

\subsection{Aqueous Characterization: pH, EC, Cations, Anions, U Liquid Extractions}

Sediment samples from batch, 1-D, or 2-D experiments were collected to characterize the pore water $\mathrm{pH}$, electrical conductivity, cations (aqueous and adsorbed), anions (aqueous) and $U$ surface phases (aqueous, adsorbed, and additional crystalline phases). As described in Section 3.3 above, pore water was either centrifuged out of sediment samples or deionized water was added and filtered $(0.45 \mu \mathrm{m})$.

The pore water $\mathrm{pH}$ was measured using a glass $\mathrm{pH}$ electrode ( $2 \mathrm{~mm}$ diameter) or micro electrode (which needed $0.3 \mathrm{~mL}$ liquid sample). This measured $\mathrm{pH}$ value was adjusted to account for the dilution with deionized water dilution, although there is some uncertainty with this calculation. The pore water electrical conductivity measurement was made with a flow-through electrical conductivity electrode, with 20 microliter internal volume. Aqueous cations/elements $\left(\mathrm{Ca}^{2+}, \mathrm{Mg}^{2+}, \mathrm{Na}^{+}, \mathrm{Fe}^{3+}, \mathrm{Si}, \mathrm{Sr}^{2+}, \mathrm{K}^{+}, \mathrm{Ba}^{2+}\right.$, and $\mathrm{Al}^{3+}$ ) were measured using an inductively coupled plasma optimal emission spectrometer (ICP-OES, 
Perkin-Elmer Optima 2100DV). These elements were present as predominantly ( $>99 \%)$ cations except for $\mathrm{Si}$, which is present as $\mathrm{SiO}_{2}$ (aq) (at $\mathrm{pH} 8$, dominant species) and mixed $\mathrm{SiO}_{2}$ (aq) and $\mathrm{H}_{3} \mathrm{SiO}_{4}{ }^{-}$ $(\mathrm{pH} 11)$. Adsorbed cations were also measured by ICP-OES, after sediment/liquid extraction using $0.5 \mathrm{~mol} / \mathrm{L} \mathrm{Mg}\left(\mathrm{NO}_{3}\right)_{2}$ (ion exchange solution). The aqueous ammonia concentration was determined via a colormetric method, HACH method 10031, using a HACH DR-2010 UV-VIS spectrophotometer. Six anions were measured using a Dionex ion chromatograph $\left(\mathrm{F}^{-}, \mathrm{Cl}^{-}, \mathrm{NO}_{2}{ }^{-}, \mathrm{Br}^{-}, \mathrm{SO}_{4}{ }^{-}, \mathrm{NO}_{3}{ }^{2-}\right)$. Aqueous carbonate was measured on a Shimatzu carbon analyzer. For some foam injection experiments, the sodium lauryl sulfate (surfactant) concentration was extracted (separated) from sediment samples with a water/acetonitrile solution (Martin et al. 2006), then measured colormetrically (Hach crystal violet method, 8028). Phosphate (as precipitates) was extracted from sediment samples with a $0.5 \mathrm{M} \mathrm{HNO}_{3}$ acid then measured colormetrically (Hach 8078).

A series of six sequential liquid extractions were used to measure uranium surface phases. The first two phases (aqueous and adsorbed uranium) were clearly identified by these extractions. The remaining four extractions were used to determine U mass distribution in four operationally-defined pools dissolved by increasing aggressive liquids. The six liquid extractions used in our FY 2010 studies consisted of 1) aqueous uranium by addition of natural Hanford groundwater, 2) adsorbed uranium by $0.5-\mathrm{M} \mathrm{Mg}\left(\mathrm{NO}_{3}\right)_{2}$ (1 hour), 3) 1-M sodium acetate (1 hour) to dissolve some uranium carbonates ("rind uranium carbonate" extraction), 4) acetic acid at $\mathrm{pH} 2.3$ (5 days) to dissolve most uranium carbonates and boltwoodite/uranophane (hydrous uranium silicates), 5) 0.1-M ammonium oxalate and 0.1-M oxalic acid ( 1 hour) to dissolve oxides, and 6) 8 -M nitric acid at $95^{\circ} \mathrm{C}$ ( 2 hours) to dissolve hard-to-extract uranium phases. Each extraction was placed in a shaker for the designated amount of time, centrifuged at $3000 \mathrm{rpm}$ for 10 minutes (Sorvall Instruments, Model RC5C), and then filtered $(0.45 \mathrm{~m})$ before analysis. The uranium concentration was determined for each extract via kinetic phosphorescence analysis (Chemchek, Model KPA-11), which is consistent with the method used by Brina and Miller (1992).

The set of six sequential liquid extractions for uranium analysis was modified near the end of FY 2010 to include 1) aqueous uranium by addition of synthetic groundwater (SGW-1), 2) adsorbed uranium by $0.0144-\mathrm{M} \mathrm{NaHCO}_{3}$ and $0.0028-\mathrm{M} \mathrm{Na}_{2} \mathrm{CO}_{3}$ (pH 9.45, 1 hour), 3) 1-M sodium acetate (1 hour) to dissolve some uranium carbonates ("rind uranium carbonate" extraction), 4) acetic acid at $\mathrm{pH} 2.3$, (5 days) to dissolve most uranium carbonates and a hydrated uranium silicate, boltwoodite, and 5) 8 - $\mathrm{M}$ nitric acid at $95^{\circ} \mathrm{C}$ ( 2 hours) to dissolve hard-to-extract uranium phases. In addition, the 14.4-mM carbonate solution at $\mathrm{pH} 9.45\left(0.0144-\mathrm{M} \mathrm{NaHCO}_{3}\right.$ and $\left.0.0028-\mathrm{M} \mathrm{Na}_{2} \mathrm{CO}_{3}\right)$ was reacted with sediment for 1000 hours in a parallel extraction to measure long-term labile uranium, as some fraction of the uranium mass can slowly diffuse from sediment microfractures. It should be noted that the second sequential extraction and this long-term extraction use the same liquid, so they provide an indication of the significance of diffusion kinetics on mobilizing adsorbed uranium mass from the sediment because the extractions differ only in the extraction time (1 hour versus 1000 hours).

\subsection{Major Mineralogy Surface Phase Characterization}

Different techniques were used to evaluate dissolution of minerals that occur over short time periods (time periods ranging from minutes to tens of hours) during $\mathrm{NH}_{3}$ gas treatment of low-water-content sediments, and the subsequent precipitation of mineral phases over long periods of time. XRD analysis was used for selected pure mineral phase dissolution experiments, as the sample-mass fraction required for this technique is limited to a phase being $0.5 \%$ or greater. 
A SEM with an EDS detector was used for numerous untreated and treated sediment samples to evaluate changes in minerals. This technique involves selecting specific mineral phases and then conducting an EDS scan of that surface to determine the chemical composition of the solid. SEM micrographs also were taken, and can illustrate weathering processes that occur during $\mathrm{NH}_{3}$ gas treatment ( $\mathrm{pH}$ increase). Over a few hours, many EDS scans and pictures can be taken of sediment minerals to obtain a measure of the influence of $\mathrm{NH}_{3}$ gas on different major minerals. The concentrations of the uranium mineral phases generally are too low a concentration to be detected by this technique.

An electron microprobe was also used to evaluate changes in sediment mineralogy. This technique uses thin sections made from the sediment (i.e., sediment grains encased in epoxy and then sectioned) and automated scans with multiple elemental detectors targeting specified elements (aluminum, sulfur, uranium, iron, silicon, phosphorus, and calcium). Using a beam width of 10 microns and scan time of 500 milliseconds per point, a $200 \times 200$ grid was scanned on each sample (i.e., 40,000 points, $2 \mathrm{~mm} \times$ $2 \mathrm{~mm}$ ), which took $\sim 20$ hours per sample. A second series of scans was conducted with a scan time of 1 second per point; a $280 \times 280$ grid on 10 -micron centers was scanned on each sample (i.e., 78,000 points, $2.8 \mathrm{~mm} \times 2.8 \mathrm{~mm}$ ), which took $\sim 48$ hours per sample. This technique is advantageous because the elemental detectors are more sensitive than the EDS detector (some to orders of magnitude, depending on element), and a statistical description of minerals is obtained rather than a few dozen points. This technique is best suited for identifying changes that occur over the entire particle. For this $\mathrm{NH}_{3}$ gas treatment, we believe that a small amount of dissolution/precipitation occurs on different mineral surfaces, so thin-section analysis by electron microprobe is not the best technique for evaluating the surface phase changes. Several adjustments to this technique will be considered for future efforts.

\subsection{Uranium Surface Phase Characterization}

Different techniques were used to evaluate changes in uranium mineral phases including 1) the electron microprobe described above, 2) laser induced x-ray fluorescence spectroscopy (LIFS), 3) x-ray adsorbed near edge spectroscopy (XANES), and 4) extended x-ray absorbed fine structure (EXAFS). The electron microprobe technique was used to identify uranium surface phases in the sediment before and after $\mathrm{NH}_{3}$ gas treatment. Use of this technique has limitations for identifying small changes in surface phases (described in the previous section) as the technique identifies elemental distributions on the surface and the interior of the sediment mineral grain surfaces. In addition, the low total uranium concentration in the sediment prevents identification of uranium minerals because the uranium mineral peak is near one iron peak. Iron generally is present in high concentrations so the small uranium peak is difficult to quantify on the shoulder of the large iron peak.

Laser induced fluorescence spectroscopy (LIFS) also was used to examine the elemental composition of the uranium surface mineral phases on selected untreated and $\mathrm{NH}_{3}$-treated sediments. Multiple spectra were taken at different fluorescence delay times (between excitation and emission) because different delay times are more sensitive to specific minerals. Three Hanford sediments were analyzed:

1) U-105/C5602 at a 52.3-ft depth, 2) TX-104 at a 110-ft depth, and 3) BX-102 at a 152-ft depth. The U-105 untreated sediment contained a total of $690 \mu \mathrm{g} \mathrm{U} / \mathrm{g}$, and was primarily sodium-boltwoodite (Um et al. 2009). The TX104 untreated sediment contained a total of $41.7 \mu \mathrm{g} \mathrm{U} / \mathrm{g}$, and was a mixture of uranyl oxyhydroxide, a small amount of uranophane, and uranyl-tricarbonate. The BX-102 untreated sediment contained a total of $28 \mu \mathrm{g} \mathrm{U} / \mathrm{g}$, and was primarily boltwoodite and uranophane. Although we wanted to identify uranium surface phase changes for the three primary different phases (uranophane/boltwoodite, 
uranyl-tricarbonate, and adsorbed uranium) with $\mathrm{NH}_{3}$ gas treatment, adsorbed uranium tended to be present at low concentration so was difficult to identify. Future studies will include the use of added uranium (i.e., a high concentration of aqueous and adsorbed uranium added to the sediment as well as a high concentration of added uranyl tricarbonate) to evaluate the sequestration processes.

For one sediment sample with the highest total uranium concentration (U-105/C5602 at a 52.3-ft depth, $690 \mu \mathrm{g} \mathrm{U} / \mathrm{g}$ ), additional surface phase analysis was conducted to identify any surface phase changes caused by the $\mathrm{NH}_{3}$ gas treatment. The oxidation state of the uranium minerals [i.e., a mixture of primarily U(VI) phases with possibly some U(IV) phases] were identified by XANES analysis at the $\mathrm{U} \mathrm{L}_{\text {III }}$ edge $(17.166 \mathrm{keV})$. The molecular structure around the uranium molecules (i.e., uraniumcontaining minerals or minerals precipitated on uranium minerals) was quantified with EXAFS. The XANES and EXAFS beamline analysis and interpretation was conducted at the Stanford Synchrotron Radiation Lightsource.

\subsection{Geochemical Equilibrium Modeling}

Geochemical equilibrium modeling was used to identify which mineral phases in Hanford sediments are most likely to dissolve with the $\mathrm{NH}_{3}$ gas treatment, and which mineral phases are likely to precipitate once ions present in pore water at elevated $\mathrm{pH}$ are $\mathrm{pH}$ equilibrated back to neutral conditions. This equilibrium modeling was conducted with Geochemist Workbench 5.0. Baseline simulations were major cations/anions present in Hanford groundwater (presumed in natural pore water in vadose zone sediments) buffered with pore water $\mathrm{CO}_{2}$. The relative dissolution mass of sediment minerals with increasing $\mathrm{pH}$ was assessed by simulations with 11 of the most common sediment minerals (average percentage in Hanford formation sediment indicated for each): 1) quartz (32\%), 2) plagioclase (25\%, end members anorthite and albite), 3) biotite (8\%), 4) muscovite (9\%), 5) microcline (13\%, K-spar), 6) pyroxenes $(6 \%$, hornblende), 7$)$ montmorillonite $(1.2 \%), 8)$ illite $(2.75 \%), 9)$ calcite $(2 \%), 10)$ chlorite $(0.7 \%)$, and 11$)$ kaolinite $(0.35 \%)$. Simulations conducted in FY 2010 to determine minerals phases that may precipitate used aqueous cation/anion concentrations measured in $\mathrm{NH}_{3}$-treated sediments at low water saturation fixed at the measured $\mathrm{pH}$ and also set to $\mathrm{pH} 8$ (i.e., the natural Hanford sediment $\mathrm{pH}$ level).

\subsection{1-D/2-D Foam Advection Experiments with $\mathrm{PO}_{4}$}

A few 1-D and one 2-D experiments were conducted in which foam containing a phosphate solution was injected into the flow system. The 1-D column experiments were conducted to evaluate the following processes during advection: a) relative retardation of the foam front, surfactant concentration, phosphate relative to gas advection, and the associated pressure distribution, b) advection of uranium in unsaturated sediments by foam (no $\mathrm{PO}_{4}$ ) relative to groundwater injection (no $\left.\mathrm{PO}_{4}\right)$, advection of uranium in unsaturated sediments by foam with $\mathrm{PO}_{4}$ relative to foam with no phosphate (b, above) and groundwater injection with $\mathrm{PO}_{4}$. These column experiments were conducted in 2.5 -cm-diameter by 20 -cm-long columns. A 2-D experiment was conducted in a $1.2-\mathrm{m}$ by $54-\mathrm{cm}$ by $1.1-\mathrm{cm}$ rectangular flow system packed with discontinuous layers of fine, medium, and coarse Hanford sediments. The objective of this foam $/ \mathrm{PO}_{4}$ injection experiment was to assess: a) foam $/ \mathrm{PO}_{4}$ transport processes in different layers (advection in coarse grained sediment and advection plus capillary water movement in fine grained sediment), and b) the relative mass of $\mathrm{PO}_{4}$ deposition in different layers in comparison to a previously investigated unsaturated treatment process - infiltration of the phosphate solution. 
The 2-D experiment was conducted at a foam injection rate of $60 \mathrm{~mL} / \mathrm{min}$ (primarily air) with $1 \%$ liquid (i.e., foam quality $99 \%$ ) containing $0.5 \%$ surfactant and $47 \mathrm{mM}$ phosphate buffered to $\mathrm{pH} 7.5$. Injection was along a $60 \mathrm{~cm}$ long porous well placed inside one side of the 1.2-meter system. A withdrawal well was placed along the other side of the flow system and air suction was maintained during the experiment. Pictures were taken during the experiment to qualitatively describe transport processes. The foam/PO4 injection was terminated when some moisture content from the foam had advected across most of the 2-D system. Approximately 140 sediment samples were taken at the end of the experiment for analysis of water content, phosphate concentration, and surfactant concentration. 


\subsection{Results}

The primary focus of experiments was on $\mathrm{NH}_{3}$ gas technology development for remediation of uranium present in the Hanford vadose zone. In Section 4.1, we summarize uranium surface phase changes by sequential liquid extractions. As a link to our previous experiments, this section also represents our FY 2009 results (data to 3 months) and the additional 1-year results. The sequence of processes that occur when $\mathrm{NH}_{3}$ gas is injected into sediment proceeds as follows: 1) $\mathrm{NH}_{3}$ gas partitions into the pore water (described in Section 4.2); 2) aqueous $\mathrm{NH}_{3}$ phases form and the pore water $\mathrm{pH}$ increases (over a seconds-to-minutes time frame, described in Section 4.3) and the EC increases (Section 4.4); 3) some minerals dissolve (clays, feldspars, and silicates, described in Section 4.5); 4) by forced advection with air and/or sediment $\mathrm{pH}$ buffering, the $\mathrm{pH}$ neutralizes over time; and 4) uranium surface phases are altered (described in Section 4.6). The understanding of the geochemical changes developed in these small scale experiments is then scaled up to evaluate processes that occur at the field scale, including 1) $\mathrm{NH}_{3}$ gas advection through sediment (1-D column tests, described in Section 4.7), 2 ) the influence of physical and water content heterogeneities during $\mathrm{NH}_{3}$ gas advection (2-D systems, described in Section 4.8), and 3) the significance of $\mathrm{NH}_{3}$ gas diffusion for low-K layers (described in Section 4.9). Because technetium is another mobile contaminants at Hanford, the effect of $\mathrm{NH}_{3}$ gas treatment of sediment on pertechnetate $\left(\mathrm{TcO}_{4}{ }^{-}\right)$was evaluated (see Section 4.10). Finally, results of an alternate technology $\left(\mathrm{PO}_{4}\right.$ advection using foam) are presented (Section 4.11).

\subsection{Short-Term Geochemical Performance: Change in Uranium Mobility for All Tested Technologies}

A comparison of the uranium surface phase changes observed by sequential extractions reported in the previous study (Szecsody et al. 2010) was conducted for time intervals ranging from 1 to 3 months. Additional treatments were conducted, with an additional time interval of 12 months for a final uranium sequential extraction (Figure 4.1). The $\mathrm{NH}_{3}$ gas treatment results (Figure 4.1a) obtained at 12 months were similar to those at obtained at 2 and 3 months. The $\mathrm{CO}_{2}$ gas treatment results obtained at 12 months (Figure 4.1e) were somewhat less favorable when compared with the results obtained at 3 months, possibly indicating some changes in carbonate coatings. Ferric nitrate (delivered by mist injection, Figure 4.1g) did show decreased uranium mobility (i.e., considerably less aqueous and adsorbed uranium) for short times of 1 to 3 months, but by 12 months, the results were less favorable. This may indicate the amorphous iron-uranium oxides formed were not stable in the geochemical environment. Phosphate addition to sediment by low-water-content mist injection (Figure 4.1j) or low-water-content foam injection (Figure 4.1k) led to lower uranium mobile phases at 12 months compared to shorter time intervals. These results are not surprising, as phosphates initially precipitate as amorphous phases and take time periods of months to years to crystallize. Both of these treatments show very little aqueous or adsorbed uranium after 12 months. Phosphate treatment of BX-102 sediment (sediment 2, not shown but discussed and shown in Szecsody et al. 2010) did show greatly increased aqueous and adsorbed uranium after phosphate treatment for 1 to 3 months (in contrast with results for this TX-104 sediment). The TX-104 sediment contains primarily uranium co-precipitated with carbonates, whereas the BX-102 sediment contains primarily uranium in sodium-boltwoodite. Liquid extractions were also conducted on sodium-boltwoodite and uranium-carbonate (Section 4.5.3). 

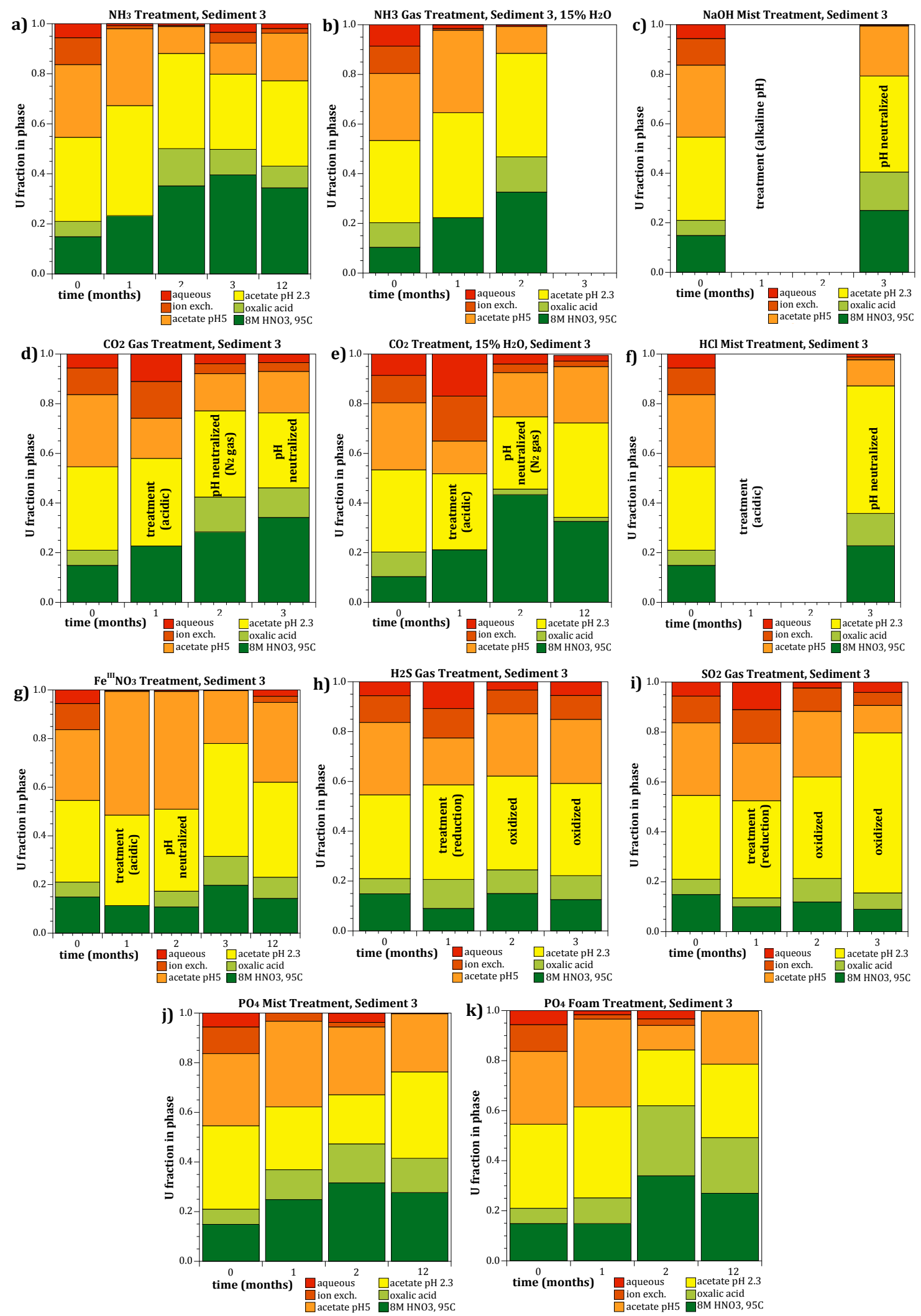

Figure 4.1. Sequential U liquid extractions results of differing low water content treatments of sediment TX-104 (69 ft + $110 \mathrm{ft}$, sediment 3). 
These results show decreased uranium mobility for uranium present in the sediment as aqueous uranium, adsorbed uranium, and uranium-carbonate (TX-104, 69-ft and 110-ft sediment 3, Table 3.1). For sediments containing uranium as primarily sodium-boltwoodite (BX-102, U105 shallow sediments), results presented in Section 4.5.2 also show decreased mobility.

\subsection{Ammonia Gas - Water Partitioning: $\mathrm{pH}$ and Electrical Conductivity}

Because $\mathrm{NH}_{3}$ gas has low volatility (dimensionless Henry's Law partition coefficient $=6.58 \times 10^{-4}$ ), anhydrous $\mathrm{NH}_{3}$ gas additions to water (and sediment with some pore water) partitions to a significant extent into water. The calculated fraction of $\mathrm{NH}_{3}$ in sediments with different water contents (Figure 4.2a) shows that at $4 \%$ water content (nominal value for the Hanford vadose zone) $0.274 \%$ of the $\mathrm{NH}_{3}$ remains in the gas phase $(99.726 \%$ partitions into water), which is an equivalent retardation factor of 363 . The propensity for $\mathrm{NH}_{3}$ gas to partition into water is easily observed by bubbling $\mathrm{NH}_{3}$ into a beaker of water and at the same rate into a beaker of oil. At a moderate flow rate $(20 \mathrm{~mL} / \mathrm{min}), \mathrm{NH}_{3}$ bubbles are seen in the oil, but no bubbles are observed in the water because the $\mathrm{NH}_{3}$ is rapidly partitioned into the water. The rate of $\mathrm{NH}_{3}$ partitioning into water (and the resulting $\mathrm{pH}$ ) was characterized by bubbling differing fractions of $\mathrm{NH}_{3}$ into water (Figure $4.2 \mathrm{~b}$ and Figure 4.2c).
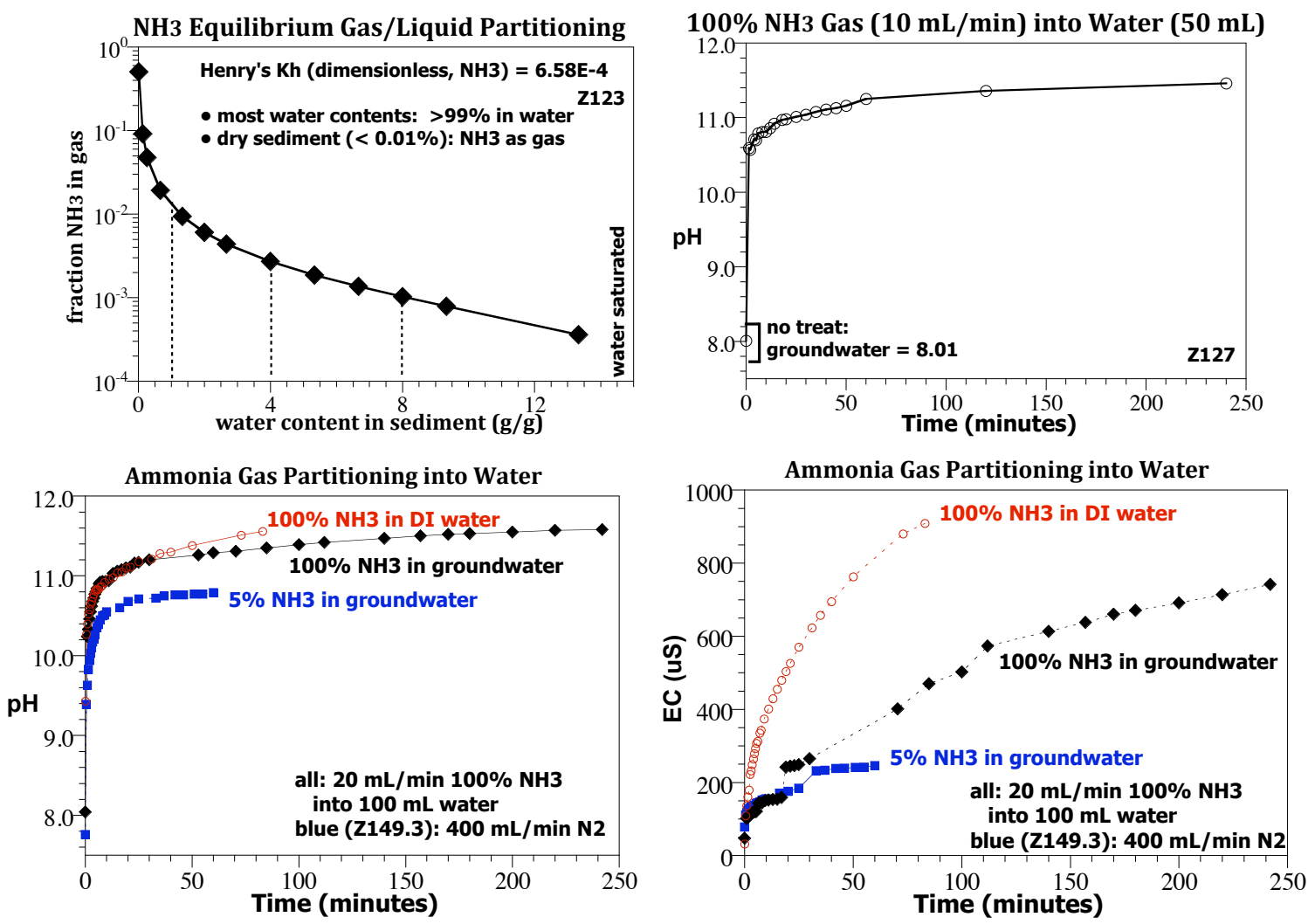

Figure 4.2. Ammonia gas partitioning into water shown by equilibrium calculation (a), pH increase in batch system (b, c), and electrical conductivity increase (d). 
With $100 \% \mathrm{NH}_{3}$ added to deionized water (Figure 4.2, top right, and red line in Figure 4.2c, bottom left), the $\mathrm{pH}$ increased from 8.0 to 11 (aqueous $\mathrm{NH}_{3}=0.1 \mathrm{~mol} / \mathrm{L}$, Table 2.1) within 2 minutes. The rate of $\mathrm{pH}$ increase then slowed considerably; by 100 to 250 minutes, the $\mathrm{pH}$ increased to only 11.5 . A pH of 11.5 is equivalent to an aqueous $\mathrm{NH}_{3}$ concentration of $0.6 \mathrm{~mol} / \mathrm{L}$. It is likely that the reduced gas-toliquid partitioning is the result of 1) the aqueous system being closer to equilibrium compared to initially being far from equilibrium and 2) the aqueous speciation of $\mathrm{NH}_{3} . \mathrm{NH}_{3}$ aqueous species $\left[\mathrm{NH}_{3}(\mathrm{aq})+\mathrm{H}^{+}\right.$ $\Leftrightarrow \mathrm{NH}_{4}{ }^{+} \mathrm{pK}=9.4$; Figure 4.3, left] results in some buffering capacity at $\mathrm{pH} 9.4$. Simulation of $\mathrm{NH}_{3}$ addition to water (Figure 4.3, right) shows that, at a $\mathrm{pH}<9.4$, the predominant aqueous species is $\mathrm{NH}_{4}{ }^{+}$, and at higher $\mathrm{pH}$ levels, the predominant species is $\mathrm{NH}_{3}(\mathrm{aq})$.
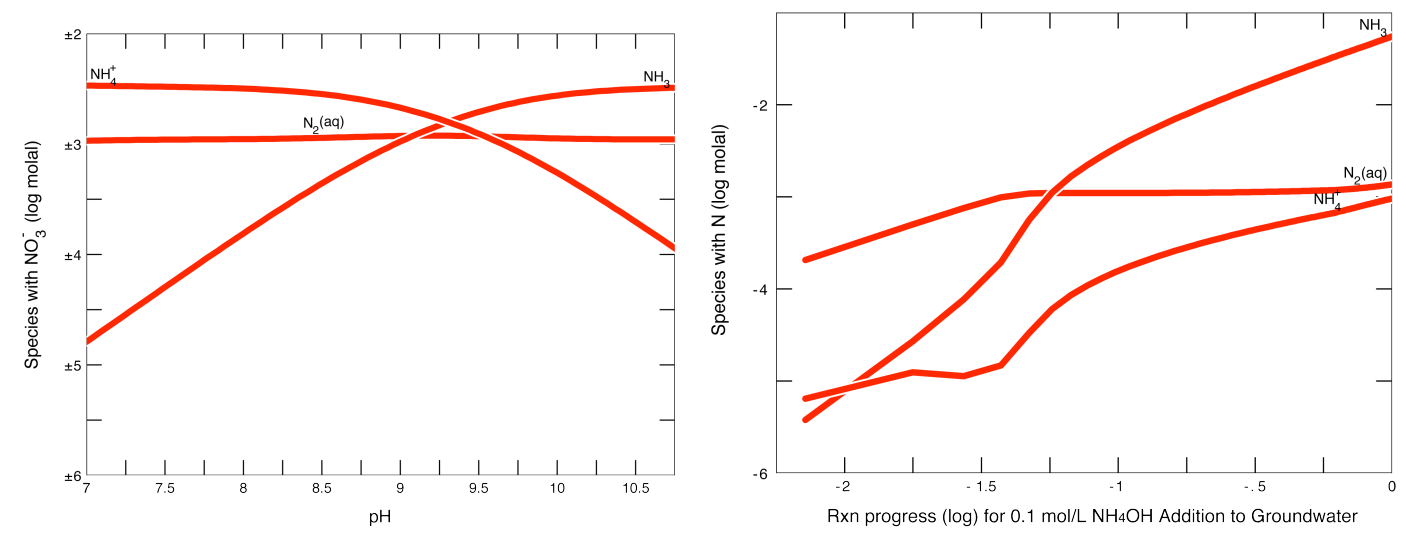

Figure 4.3. Calculated aqueous ammonia speciation over $\mathrm{pH}$ (a) and aqueous species concentrations during ammonia addition to water (b).

Partitioning of $100 \% \mathrm{NH}_{3}$ gas into Hanford groundwater (Figure 4.2, bottom left) shows a slower $\mathrm{pH}$ increase compared partitioning into deionized water, probably because of the additional $\mathrm{pH}$ buffering of the carbonate in the groundwater. Finally, partitioning of $5 \% \mathrm{NH}_{3}$ (with $95 \%$ nitrogen) gas into groundwater (Figure 4.2, bottom left) shows an even slower $\mathrm{pH}$ increase. In this case, the actual $\mathrm{NH}_{3}$ gas flux rate is the same as in previous experiments $(20 \mathrm{~mL} / \mathrm{min})$, but with the additional flow of nitrogen gas (at $400 \mathrm{~mL} / \mathrm{min}$ ), some $\mathrm{NH}_{3}$ gas is advected out of the system before it can partition into the water. Therefore, the kinetics of gas/liquid partitioning was partially exceeded by the gas advection. In Section 4.8, this same effect is noted, as injection of $100 \% \mathrm{NH}_{3}$ into a sediment column produces a sharp observed front, whereas injection of $5 \% \mathrm{NH}_{3}$ produces a more diffused front.

The fraction of $\mathrm{NH}_{3}$ gas in the mixed gas injection is proportional to the resulting $\mathrm{pH}$ (calculated in Table 2.1). Batch experiments with different percentages of $\mathrm{NH}_{3}$ gas almost reached the calculated $\mathrm{pH}$ (Figure 4.4, left); however, a large amount of $\mathrm{NH}_{3}$ gas had to be injected. The total mass of $\mathrm{NH}_{3}$ gas also influences the resulting $\mathrm{pH}$, as injection of differing volumes ( 0.01 to 10 pore volumes) of $\mathrm{NH}_{3}$ gas into the same amount of water (Figure 4.4, left) leads to an initial rapid $\mathrm{pH}$ increase, but then $\mathrm{pH}$ increase slows down, which is similar to previous results (Figure 4.2, bottom left). The $\mathrm{pH}$ increase also is similar to calculated values ( $\mathrm{pH} 2.1$ ).

Although the pore water $\mathrm{pH}$ initially increases rapidly with $\mathrm{NH}_{3}$ gas treatment and then slows (Figure 4.2, top right, and bottom left), the EC of the water increases in a more linear rate (Figure 4.2, bottom right). Although pore water EC is not a primary variable that defines the system geochemical 
conditions, the results our studies indicate that it is a better measure of the increased $\mathrm{NH}_{3}$ gas treatment over time when compared with $\mathrm{pH}$. Our results also indicate that total sediment EC may be a valuable in situ measurement.
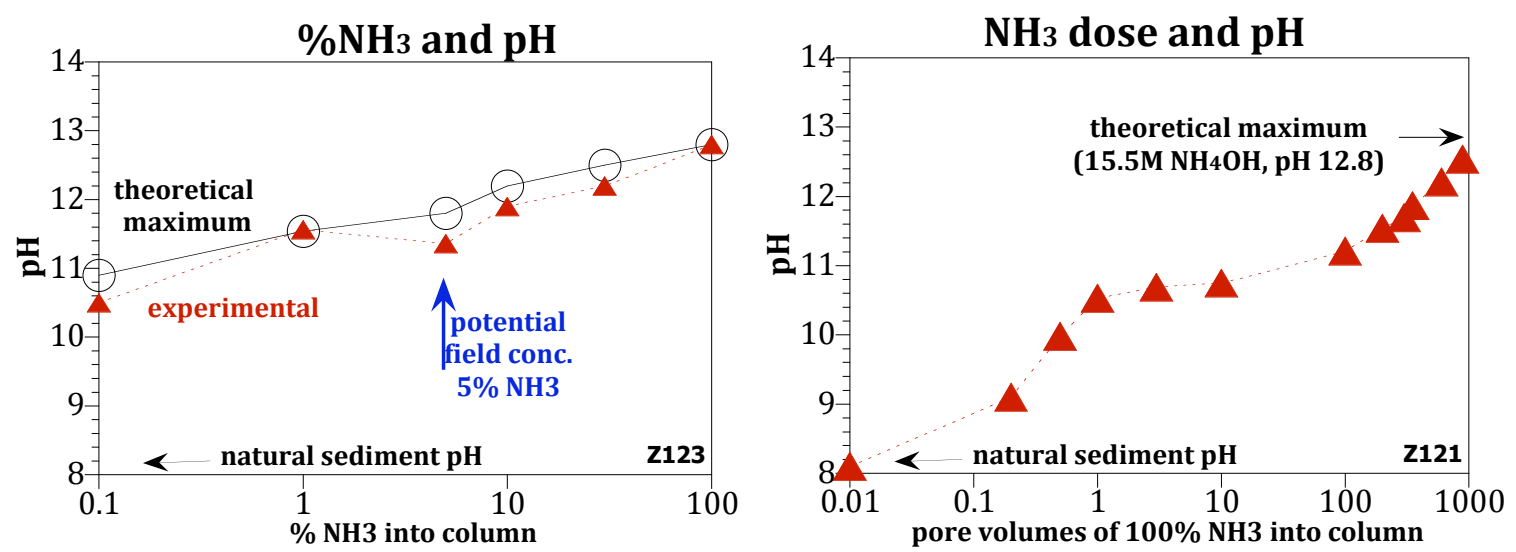

Figure 4.4. Sediment pore water reaction with: a) different fraction of ammonia/nitrogen gas and b) different pore volumes of $100 \%$ ammonia gas.

Other physicochemical changes that occur as $\mathrm{NH}_{3}$ gas is partitioned into water include increased temperature, increased liquid volume, decreased water viscosity, and desiccation of pore water at very high anhydrous $\mathrm{NH}_{3}$ gas treatments (near injection well, see Section 4.3). The partitioning or speciation reaction is exothermic, so there is a temperature increase in the pore water. For injection of $100 \% \mathrm{NH}_{3}$ gas into a sediment column, the measured temperature increase was as much as $30^{\circ} \mathrm{C}$ (Figure 4.5). For injection of $5 \% \mathrm{NH}_{3}$ gas, the temperature increase was $4^{\circ} \mathrm{C}$. The dynamic viscosity of the water decreases from 9.1 centipoise $\left(25^{\circ} \mathrm{C}\right)$ to 2.3 centipoise for $15.7 \mathrm{~mol} / \mathrm{L} \mathrm{NH}_{4} \mathrm{OH}$ (maximum solubility of $100 \% \mathrm{NH}_{3}$ gas). The $\mathrm{NH}_{3}$ in water also increases the liquid volume in water by approximately $30 \%$ at $15.7 \mathrm{~mol} / \mathrm{L} \mathrm{NH}_{4} \mathrm{OH}$. The density of the concentrated $\mathrm{NH}_{4} \mathrm{OH}$ is $0.898 \mathrm{~g} / \mathrm{mL}$ (Weast et al. 1988). The combination of the viscosity decrease and liquid volume increase leads to the formation of larger liquid droplets at the reaction front during $\mathrm{NH}_{3}$ gas injection (shown in Section 4.10).

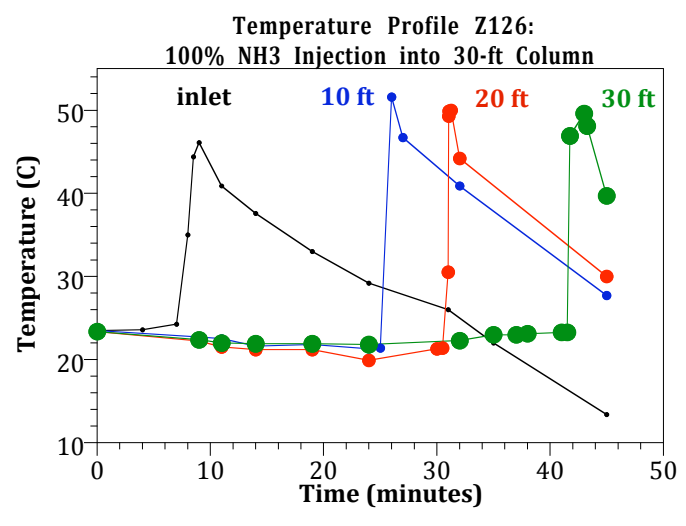

Figure 4.5. Sediment temperature during $\mathrm{NH}_{3}$ gas injection in a 1-D column. 


\subsection{Ammonia Gas: Sediment Pore Water Partitioning and pH, EC Change}

\subsubsection{Sediment Pore Water $\mathrm{pH}$}

\subsubsection{Batch Experiments at Low Water Content $(<8 \%)$}

The sequence of processes that occurs when $\mathrm{NH}_{3}$ gas is injected into sediment proceeds as follows: 1) $\mathrm{NH}_{3}$ gas partitions into the pore water; 2) aqueous $\mathrm{NH}_{3}$ phases form and the pore water $\mathrm{pH}$ increases (over a time period of seconds to minutes); 3) some minerals dissolve (clays, feldspars, silicates, described in Section 4.3); 4) by forced advection with air and/or sediment $\mathrm{pH}$ buffering, the $\mathrm{pH}$ neutralizes over time (described in Section 4.4), and 5) uranium surface phases are altered (described in Section 4.5). As shown in the previous section, $\mathrm{NH}_{3}$ gas initially partitions rapidly (within seconds to minutes) into water (see Figure 4.2) to $\mathrm{pH} \mathrm{9.5,} \mathrm{and} \mathrm{then,} \mathrm{rate} \mathrm{of} \mathrm{the} \mathrm{partitioning} \mathrm{slows.} \mathrm{The} \mathrm{pore} \mathrm{water} \mathrm{pH}$ and $\mathrm{EC}$ of sediments was measured in systems at differing initial water content to assess the influence of $\mathrm{NH}_{3}$ partitioning. Hanford vadose zone sediments have water contents (measured as $\mathrm{wt} \%$ ) that vary from $1 \%$ or less to a nominal value of $4 \%$ in the Hanford Formation to a nominal value of $12 \%$ for the Cold Creek Unit to water saturation (20\% to $25 \%$ ) near groundwater. It should be noted that the water in sediments with low water content ( $1 \%$ to $16 \%$, described below) differs from water in a beaker in that the surface area of the water in sediments is spread in a thin film on mineral grains, so is able to more rapidly partition ammonia.

Measured $\mathrm{pH}$ in sediments in which $10 \% \mathrm{NH}_{3}(90 \%$ nitrogen) was injected at $1 \%, 4 \%, 8 \%$, and $16 \%$ initial water content show initial $\mathrm{pH}$ values quickly reach the maximum expected levels (Figure 4.6). Two experiments in which the $\mathrm{pH}$ was measured at time intervals ranging from 30 seconds to hundreds of hours (Figure 4.6, left) show a pH of 12 for samples with $4 \%$ and $8 \%$ initial water content, and this $\mathrm{pH}$ level did not vary for 200 hours. The $\mathrm{pH}$ in these experiments was measured by diluting the pore water with deionized water (in approximately a $1 \mathrm{~g}$ pore water to $1 \mathrm{~mL}$ deionized water ratio). The dilution factor was accounted for in the reported $\mathrm{pH}$ values. This appears to indicate the equilibrium $\mathrm{pH}$ was reached rapidly. For somewhat greater times ranging from 1 hour to 6 months (Figure 4.6, right), the pH was higher for lower water contents, but also did not change for times $<100$ hours. Over longer time periods, the $\mathrm{pH}$ decreases because mineral-precipitation reactions buffer the $\mathrm{pH}$. The higher $\mathrm{pH}$ levels observed in the lower-water-content experiments are an artifact of these batch experiments in which a fixed volume of $\mathrm{NH}_{3}$ (i.e., added by mass, not by concentration) reacted with a fixed mass of sediment at different water contents. Sediments with lower water contents have lower water volumes, so the $\mathrm{pH}$ levels reached in these samples is higher. During $\mathrm{NH}_{3}$ gas injection at field scale, the resulting $\mathrm{pH}$ at equilibrium is only a function of the fraction of $\mathrm{NH}_{3}$ gas (i.e., gas concentration).

At higher water contents (i.e., $>8 \%$ ), sufficient pore water exists to allow its extraction by centrifuging, and the $\mathrm{pH}$ (and cations/anions) of the extracted water can be measured with no dilution. A comparison of the $\mathrm{pH}$ at $8 \%$ water content with the centrifuge method (Figure 4.7) to the dilution method (Figure 4.6, right, violet data points) shows a somewhat elevated $\mathrm{pH}$ level in the sample that was diluted with deionized water. It is assumed that the introduction of water in the sediment/water system dilutes and desorbs some ions, so some level of error is introduced (described later in this section). 

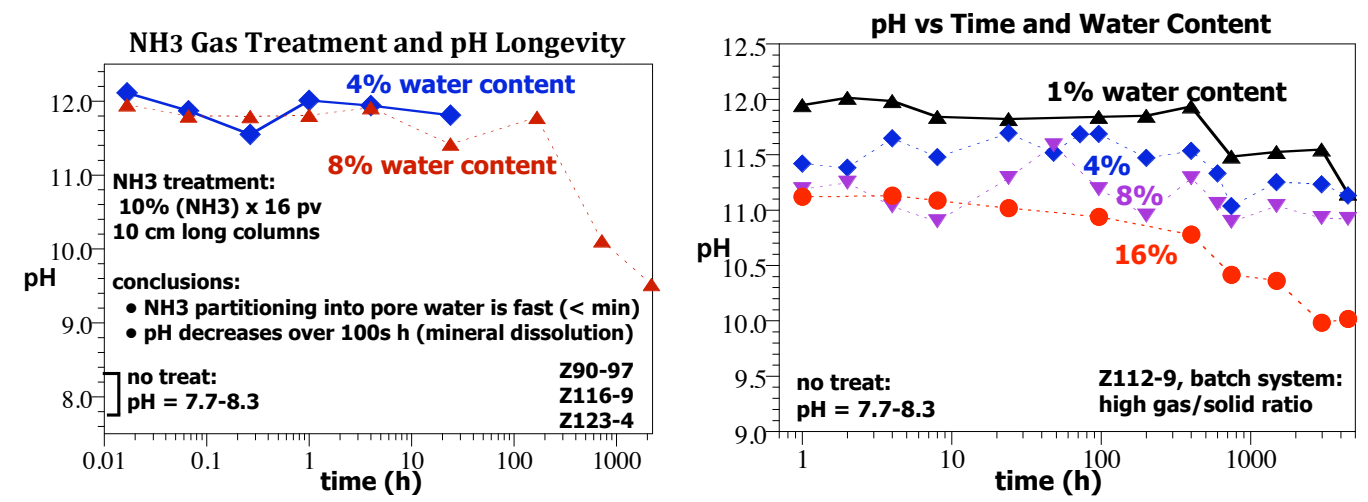

Figure 4.6. Sediment $\mathrm{pH}$ over time during ammonia gas treatments, as measured by dilution.
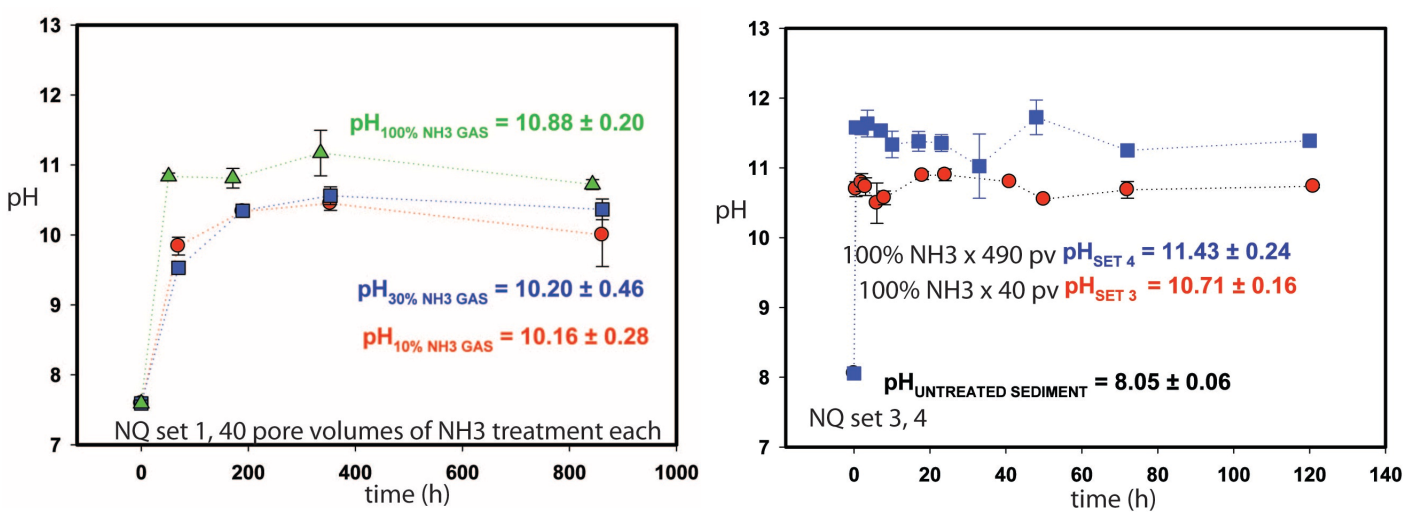

Figure 4.7. Sediment pore water $\mathrm{pH}$ over time during ammonia gas treatments, as measured by centrifuging (no water added): a) differing $\mathrm{NH}_{3}$ concentration, b) differing $\mathrm{NH}_{3}$ mass.

\subsubsection{Batch Experiments at $>8 \%$ Water Content}

Additional batch experiments were conducted in which sediment pore water was removed from the sediment by centrifuging (not diluted). For sediment from the ERDF pit (20-ft depth), this could only be accomplished at a water content of $8 \%$ or higher. A few centrifuge experiments were conducted at $15 \%$, $10 \%$, and $5 \%$ initial water content (see Figure 4.9), but this required significant effort to remove the water at $5 \%$ water content $(20,000 \mathrm{RSG} \times 30$ minutes $)$, so there is significant $\mathrm{pH}$ change due to $\mathrm{NH}_{3}$ volatilization.

Experiments included varying 1) the $\mathrm{NH}_{3}$ gas concentration, 2) the $\mathrm{NH}_{3}$ gas dose (i.e., small to large mass of gas, reported in pore volumes), and 3 ) the water content from two unsaturated systems ( $8 \%$ water content or $0.08 \mathrm{~g} / \mathrm{g}), 19 \%$ water content, and water saturated $(2 \mathrm{~g} / \mathrm{g})$. As shown previously (Figure 4.4, left), increasing the $\mathrm{NH}_{3}$ concentration $(10 \%, 30 \%, 100 \%)$ resulted in $\mathrm{pH}$ increases $\left(\mathrm{pH}_{10 \%}=10.16 \pm\right.$ $\left.0.28 ; \mathrm{pH}_{30 \%}=10.20 \pm 0.46 ; \mathrm{pH}_{100 \%}=10.88 \pm 0.20\right)$, as shown in Figure 4.7. The initial $\mathrm{pH}$ measured in the untreated sediment with an $8 \%$ moisture content (the liquid phase was again separated via centrifugation) was $7.59 \pm 0.05$. These $\mathrm{pH}$ values are somewhat lower than previously reported, possibly because 
some $\mathrm{NH}_{3}$ volatilized during centrifuging. Increasing the mass of $\mathrm{NH}_{3}$ for the same mass of sediment (i.e., pore volumes of gas) also increased the $\mathrm{pH}$ (Figure 4.7, right), as previously shown (Figure 4.4, right).

A change in the initial water content from $8 \%(\mathrm{pH}=11.43 \pm 0.24)$ to $19 \%(\mathrm{pH}=11.34 \pm 0.21)$ for the same $\mathrm{NH}_{3}$ dose (i.e., 40 pore volumes of $10 \% \mathrm{NH}_{3}$ ) also is consistent with previous results (Figure 4.6, right) in which water was used to dilute samples for $\mathrm{pH}$ measurements.

Two water-saturated dissolution experiments were conducted at a liquid/solid ratio of $2.0 \mathrm{~g} / \mathrm{g}$, or 25 times greater than $8 \%$ water content (i.e., $0.08 \mathrm{~g} / \mathrm{g}$ ). In these experiments, the water added contained different $\mathrm{NH}_{4} \mathrm{OH}$ solutions. At $0.01 \mathrm{~mol} / \mathrm{L} \mathrm{NH}_{4} \mathrm{OH}$, the final $\mathrm{pH}$ was $10.39 \pm 0.03$, whereas at $1.0 \mathrm{~mol} / \mathrm{L}$ $\mathrm{NH}_{4} \mathrm{OH}$, the final $\mathrm{pH}$ was $11.54 \pm 0.03$. These values are consistent with calculated $\mathrm{pH}$, based on the $\mathrm{NH}_{4} \mathrm{OH}$ concentration (Table 2.1). Therefore, the low (40 pore volumes of $10 \% \mathrm{NH}_{3}$ ) dose experiments conducted at $8 \%$ water content with an initial $\mathrm{pH}$ of 11.43 by inference has almost $1.0 \mathrm{~mol} / \mathrm{L} \mathrm{NH} \mathrm{NH}_{4} \mathrm{OH}$, which was later measured in the systems (Section 4.8). In terms of reactivity of this alkaline pore water with sediment minerals, a striking difference between water-saturated sediments and sediments at low saturation is the much lower mass (by a factor of 25) of $\mathrm{NH}_{4} \mathrm{OH}$ at low water saturation. In other words, dissolution of minerals will tend to decrease the $\mathrm{pH}$ to a greater extent at low water saturation.

\subsubsection{3 pH Distribution in 1-D and 2-D Systems}

The $\mathrm{pH}$ of sediment pore water was also measured in a number of 1-D columns ( 20 to $30 \mathrm{ft}$ length) and 2-D sediment systems in which a large number of pore volumes of ammonia was injected. Visually, there is a sharp "reaction" front noted in flowing systems (pictures shown in a later section), which is caused by the initial rapid partitioning of $\mathrm{NH}_{3}$ gas into pore water (Figure 4.2), so little gas is ahead of the front. The $\mathrm{pH}$ front is sharper for $100 \% \mathrm{NH}_{3}$ than $5 \% \mathrm{NH}_{3}$, similar to Figure $4.3 \mathrm{c}$. This visual "reaction" front in a clear plastic column or flow system is the result of the exothermic reaction causing some water evaporation, with condensation on the plastic wall. This visual reaction front corresponds to the sediment $\mathrm{pH}$, which is also a sharp front, as shown for a 1-D column (Figure 4.8a) and 2-D radial flow system (Figure 4.8b). The $\mathrm{x}$-axis of both systems is distance in the flow system with a secondary $\mathrm{x}$-axis accounting for the number of pore volumes of injected gas at that location. For the 1-D flow system, the $\mathrm{pH}$ front at $13 \mathrm{ft}$ (Figure $4.8 \mathrm{a}$ ) received 231 pore volumes of $5 \%$ ammonia gas. In this experiment, the ammonia gas concentration was also measured, and this provided evidence that very little ammonia gas is ahead of the reaction front (i.e., nearly all partitions into pore water).

For the 2-D radial flow system, approximately 100 pore volumes of $100 \%$ ammonia gas were injected to the location of the reaction front (Figure 4.8b). Some desiccation of sediments near the inlet of the 1-D columns and the 2-D flow cell was observed. Desiccation during ammonia treatment would only be expected very near the injection well. It requires about 25,000 pore volumes of dry gas to remove $5 \mathrm{wt} \%$ of water from a sediment using dry air (Oostrom et al. 2010). The 1-D column experiments (Section 4.7, Table 4.6) showed 8600 pore volumes of anhydrous ammonia/nitrogen gas were needed to dry $4 \%$ water content using anhydrous ammonia. In contrast, ammonia treatment will only require a few hundred to a few thousand pore volumes of gas addition. 

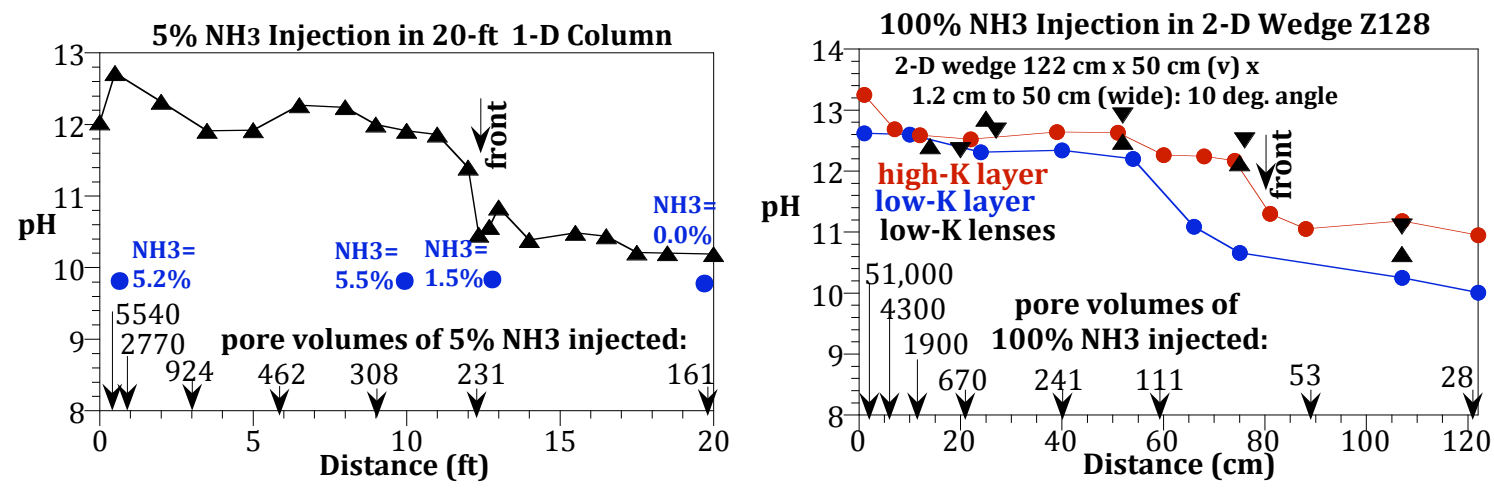

Figure 4.8. Pore water $\mathrm{pH}$ in: a) 20 -ft long 1 -D column with $5 \% \mathrm{NH}_{3}$ injection and b) $1.3 \mathrm{~m}$ long 2-D wedge shaped flow system with sediment layers and $100 \% \mathrm{NH}_{3}$ injection.

\subsubsection{Pore Water pH Measurement Methods and Scaleup Issues}

Ammonia gas treatments in batch experiments in which $\mathrm{pH}$ was measured in diluted samples (Figure 4.6) and in centrifuged samples (Figure 4.7) also differ to some extent, so the data may not be directly comparable. Additional experiments were conducted to compare $\mathrm{pH}$ measurements using different methods to extract pore water. These experiments (Figure 4.9), which received exactly the same ammonia gas treatment, show that diluting sediment pore water results in an error in the pore water $\mathrm{pH}$ such that the reported value (corrected for dilution) is higher than the actual (or centrifuge) value. The greater the amount of dilution (Figure $4.9 \mathrm{~b}$ ), the greater the difference compared with the actual pore water $\mathrm{pH}$. For $1: 1$ water extractions, the $\mathrm{pH}$ was 0.3 units greater than the centrifuge method. Therefore, this $\mathrm{pH}$ error was accounted for in $\mathrm{pH}$ values reported in later sections in 1-D columns and 2-D systems. A third method using addition of an immiscible organic liquid to displace pore water, was inefficient, and not used in subsequent studies.
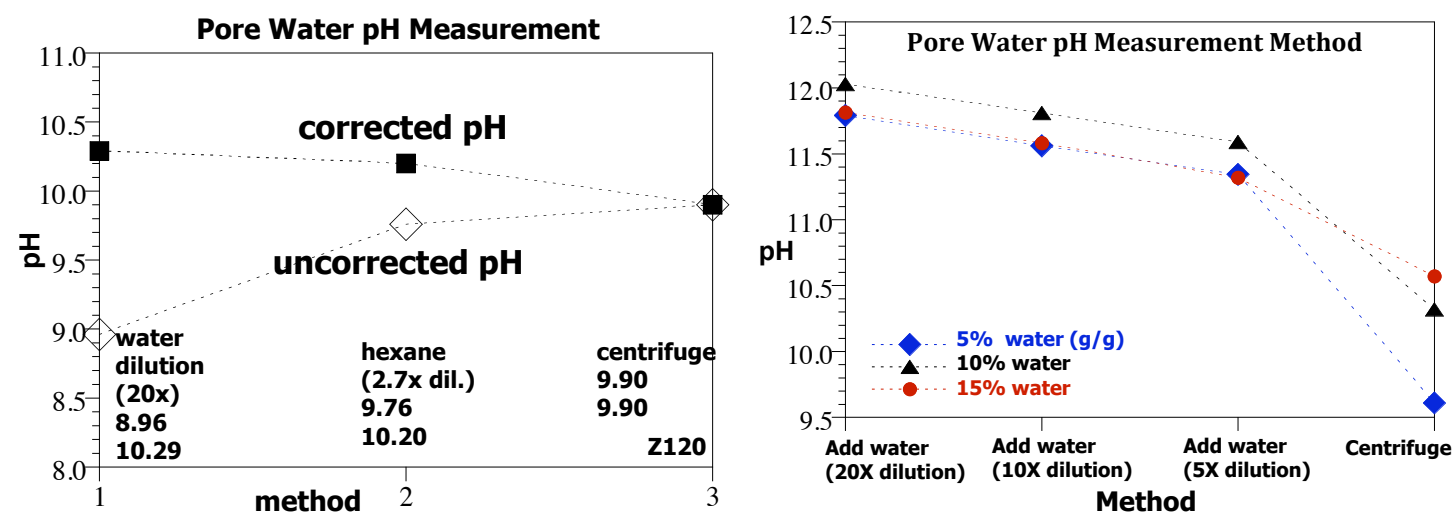

Figure 4.9. Sediment pore water $\mathrm{pH}$, as pore water was extracted by different methods. 


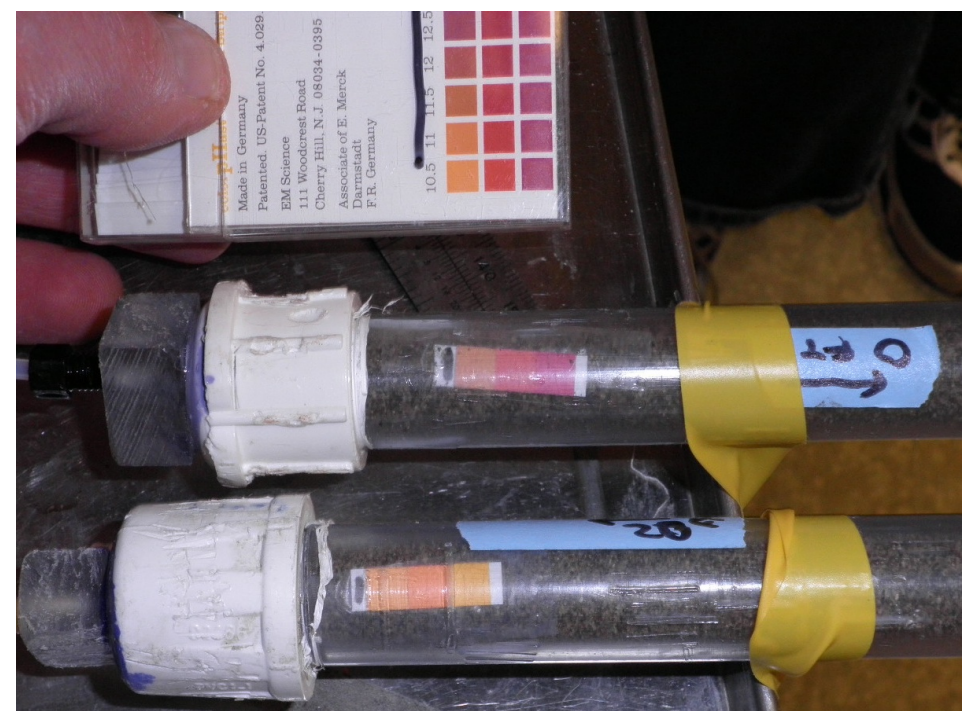

Figure 4.10. Use of $\mathrm{pH}$ indicator paper for in situ measurement during ammonia gas injection into sediment.
During ammonia gas injections in some 1-D columns, the use of $\mathrm{pH}$ indicator paper also provided evidence that the $\mathrm{pH}$ front was sharp. The $\mathrm{pH}$ indicator paper absorbs some moisture from the sediment, and this appears to be sufficient to result in a reflected light change to indicate $\mathrm{pH}$ as ammonia partitions into the $\mathrm{pH}$ paper. As shown in Figure 4.10, the $\mathrm{pH}$ at $0.0 \mathrm{ft}$ in the column has a $\mathrm{pH}>10.5$ (right most indicator paper is red), whereas at $20 \mathrm{ft}$ (lower indicator paper), the indicator paper on the right is still yellow $(\mathrm{pH}<9)$. During the ammonia injection, the $\mathrm{pH}$ paper turns colors rapidly, indicating a $\mathrm{pH}$ shift from 8 to 10.5 in minutes. The color of the indicator

paper (indicating $\mathrm{pH}$ ) is reversible, as demonstrated in subsequent batch experiments. This may be possible because during subsequent advection of nitrogen, ammonia mass partitions out of the $\mathrm{pH}$ paper pore water into the gas phase.

Because the sediment grain size distribution may influence the $\mathrm{pH}$ levels resulting from $\mathrm{NH}_{3}$ gas treatments, experiments were conducted to evaluate the significance of this effect. While small-scale laboratory experiments used a $<4 \mathrm{~mm}$ to $<12 \mathrm{~mm}$ sieved fraction of different Hanford formation sediments, sediments used in field-scale injection tests can have a significant fraction of gravel (the average particle size Hanford formation sediments average is $32 \%<4 \mathrm{~mm}$ ). Five different grain size distributions from $<53$ micron, $<425$ micron, $<2 \mathrm{~mm},<16 \mathrm{~mm}$, and the entire size distribution were treated with 250 pore volumes of $5 \% \mathrm{NH}_{3}$ for 24 hours, and then the $\mathrm{pH}$ and $\mathrm{EC}$ was measured. The resulting $\mathrm{pH}$ uncorrected for the grain size distribution (Figure 4.11 [left]) did not show a trend with smaller grain size, but the EC did show the expected trend of increasing reactivity with the smaller grainsize fraction. The smaller grain-size fraction has a higher surface area and is assumed to have nearly all of the reactivity (i.e., adsorption of metals, ions and other reactions). It is generally assumed that the larger grain-size fraction (i.e., gravel) has no distributions from $<53$ micron, $<425$ micron, $<2 \mathrm{~mm}$, $<16 \mathrm{~mm}$, and the entire size distribution were treated with 250 pore volumes of $5 \% \mathrm{NH}_{3}$ for 24 hours, and then the $\mathrm{pH}$ and $\mathrm{EC}$ was measured.

The resulting $\mathrm{pH}$ uncorrected for the grain size distribution (Figure 4.11 [left]) did not show a trend with smaller grain sizes, but the EC did show the expected trend of increasing reactivity with the smaller grain-size fraction. The smaller grain-size fraction has higher surface area, and is assumed to have almost all of the reactivity (i.e., adsorption of metals, ions and other reactions). It is generally assumed that the larger grain-size fraction (i.e., gravel) has no reactivity, and the reactivity associated with the smaller grain-size fraction can be corrected by assuming zero reactivity of the gravel fraction. This assumption has been previously shown to result in a systematic error for uranium adsorption to sediment (Gamerdinger et al. 1998), as there is some adsorption of uranium on the grain coatings of the gravel. For this study, corrected $\mathrm{pH}$ and electrical conductivities assuming zero reactivity of the larger grain-size 
fraction was a reasonably valid assumption, and did correct for the shift in electrical conductivity. This also shows that the EC of the $<2 \mathrm{~mm}$ grainsize fraction (or the $<4 \mathrm{~m}$ or $<12 \mathrm{~mm}$ fractions) is not too different from the full grain-size electrical conductivity, so any error in the correction is minimal.

\subsubsection{Sediment Pore Water Electrical Conductivity}

As ammonia gas partitions into pore water, the $\mathrm{pH}$ increase is nonlinear (Figure $4.2 \mathrm{~b}, \mathrm{c}$ ), yet the pore water electrical conductivity increase is much closer to linear (Figure 4.2d). Although $\mathrm{pH}$ is a primary geochemical parameter that is directly linked to the $\mathrm{NH}_{3}$ (aq) concentration in these systems, the pore water electrical conductivity cannot be directly related to a single ions, and will change with both ammonia gas partitioning as well as sediment dissolution/ precipitation. In batch systems, as the pore water $\mathrm{pH}$ decreased over $100 \mathrm{~s}$ to 1000 s of hours by approximately 0.7 to $1.2 \mathrm{pH}$ units (Figure 4.6b), the corresponding electrical conductivity decrease was much greater (Figure 4.12a), which is a general (though imperfect) indicator that tri-and divalent cations are more likely to have precipitated compared with monovalent cations (which exhibit lower electrical conductivity for the same ionic strength). The $1 \%$ and $4 \%$ water content experiments (Figure 4.12a) showed a 50\% decrease in EC, whereas the $8 \%$ and $16 \%$ water content experiments showed a $30 \%$ decrease.

In 1-D columns, the pore water electrical conductivity clearly showed the reaction front (Figure 4.12b) as clearly or better than the corresponding pH (Figure 4.8a). Many of these column results showed a decreased EC with increasing distance behind the reaction front (i.e., the highest EC was at the reaction front), which may be caused by some precipitation reactions. In a 2-D radial (i.e., wedge) system, the shape of the electrical conductivity measured at $5100 \mathrm{~h}$ in samples (Figure 4.12d, i.e., high only near the inlet) was significantly different from the shape of the reaction front or $\mathrm{pH}$ at $7 \mathrm{~h}$ (Figure $4.12 \mathrm{c}$, i.e., change at $80 \mathrm{~cm}$ ), but was consistent with the $\mathrm{pH}$ front shape at $5100 \mathrm{~h}$ (i.e., minimal change over most of the system). These results indicate that electrical conductivity may be a useful field scale tool for a general indicator of the slow change in sediment geochemistry over 100s to 1000s of hours, if there is sufficient sensitivity and resolution in cross borehole measurements. Electrical conductivity measurements are likely more reliable than $\mathrm{pH}$ at field scale due to the difficulty in calibration of remote $\mathrm{pH}$ electrodes. 

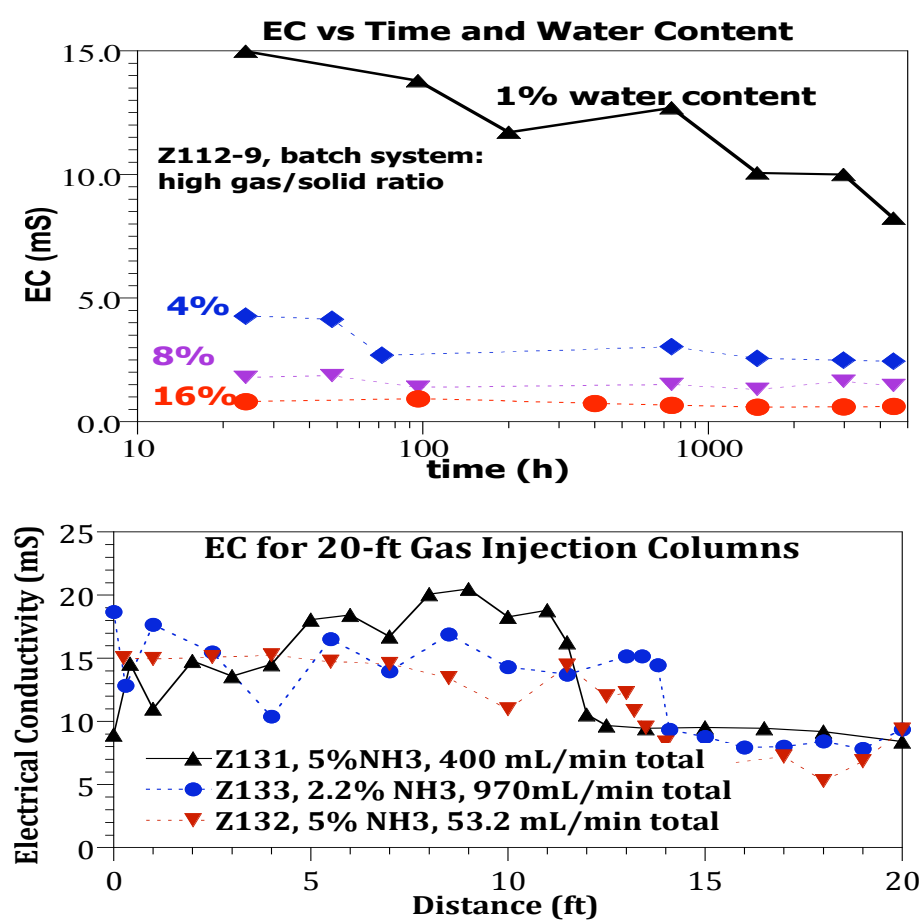

pH for $100 \%$ NH3 Injection in 2-D Wedge Z128
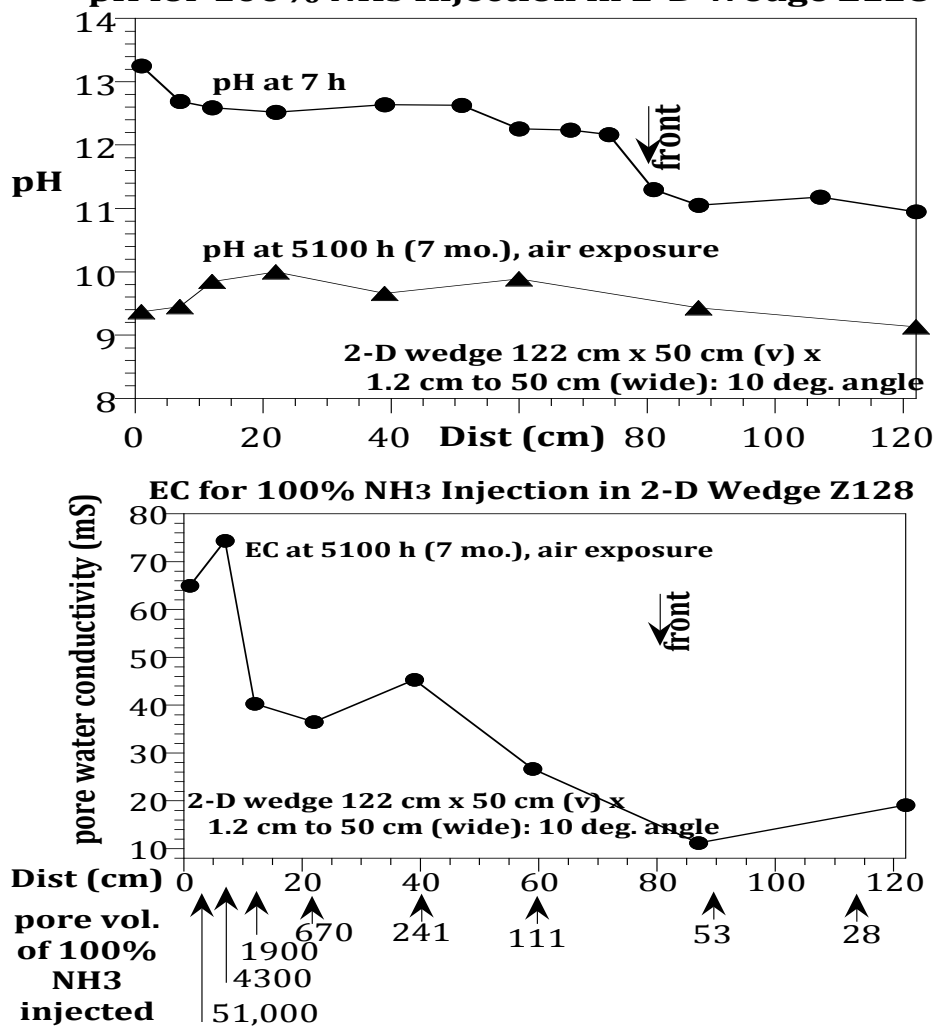

Figure 4.12. Sediment pore water EC over time during ammonia gas treatments in: a) batch, b) 1-D column, c) 2-D system $\mathrm{pH}$, and d) 2-D system EC.

\subsection{Ammonia Gas Treatment: Mineral Dissolution and Precipitation}

\subsubsection{Predicted Aqueous Ions Based on Geochemical Equilibrium Modeling}

The aqueous groundwater composition of 12 major cations/anions was simulated as the $\mathrm{pH}$ was increased from 8.0 (natural pore-water $\mathrm{pH}$ ) to 11 to characterize changes in solution complexes and determine which mineral phases would precipitate. $\mathrm{NH}_{3}$ gas treatment of sediment results in a pH increase from 8.0 to 11 to 12.5 (depending on the $\mathrm{NH}_{3}$ concentration used). Additional simulations described later in this section incorporated the dissolution of minerals found in Hanford sediments. If the reactions are close to equilibrium, solution species and precipitated species predicted from this equilibrium modeling may be measured in the experimental systems described in the following sections. Some phases, specifically carbonates, can exist in supersaturated state (i.e., ions that should precipitate remain in solution). Aqueous speciation shown (Figure 4.13) is separated into species containing major cations or anions for simplicity compared to the complete system with $>100$ species.

These simulations show that silica aqueous species decrease with increasing $\mathrm{pH}$, but aluminum aqueous species increase slightly. Calcium and magnesium are predominantly present as cations, but carbonate and silicate aqueous complexes decrease in 
concentration with increasing $\mathrm{pH}$ (Figure $4.13 \mathrm{c}$ and $\mathrm{d}$ ). The carbonate complexes in this simulation decrease in overall mass (Figure 4.13e) because this simulation is a closed system (i.e., it predicts what would occur with $\mathrm{NH}_{3}$ gas treatment of pore water when no mixing occurs with air containing $\mathrm{CO}_{2}$ ). In an open system with exposure to $\mathrm{CO}_{2}$, additional carbonate would partition into the pore water. Iron aqueous complexes (not shown) are present in low concentration $\left(<10^{-12} \mathrm{~mol} / \mathrm{L}\right)$ as hydroxides and increase slightly with increasing $\mathrm{pH}$. Uranium aqueous species (Figure 4.13f) are present primarily as carbonates $\left(<10^{-26} \mathrm{~mol} / \mathrm{L}\right.$ in this simulation, with $20 \mathrm{ppb}$ initial uranium concentration), and they decrease by three orders-of-magnitude as the $\mathrm{pH}$ increases.
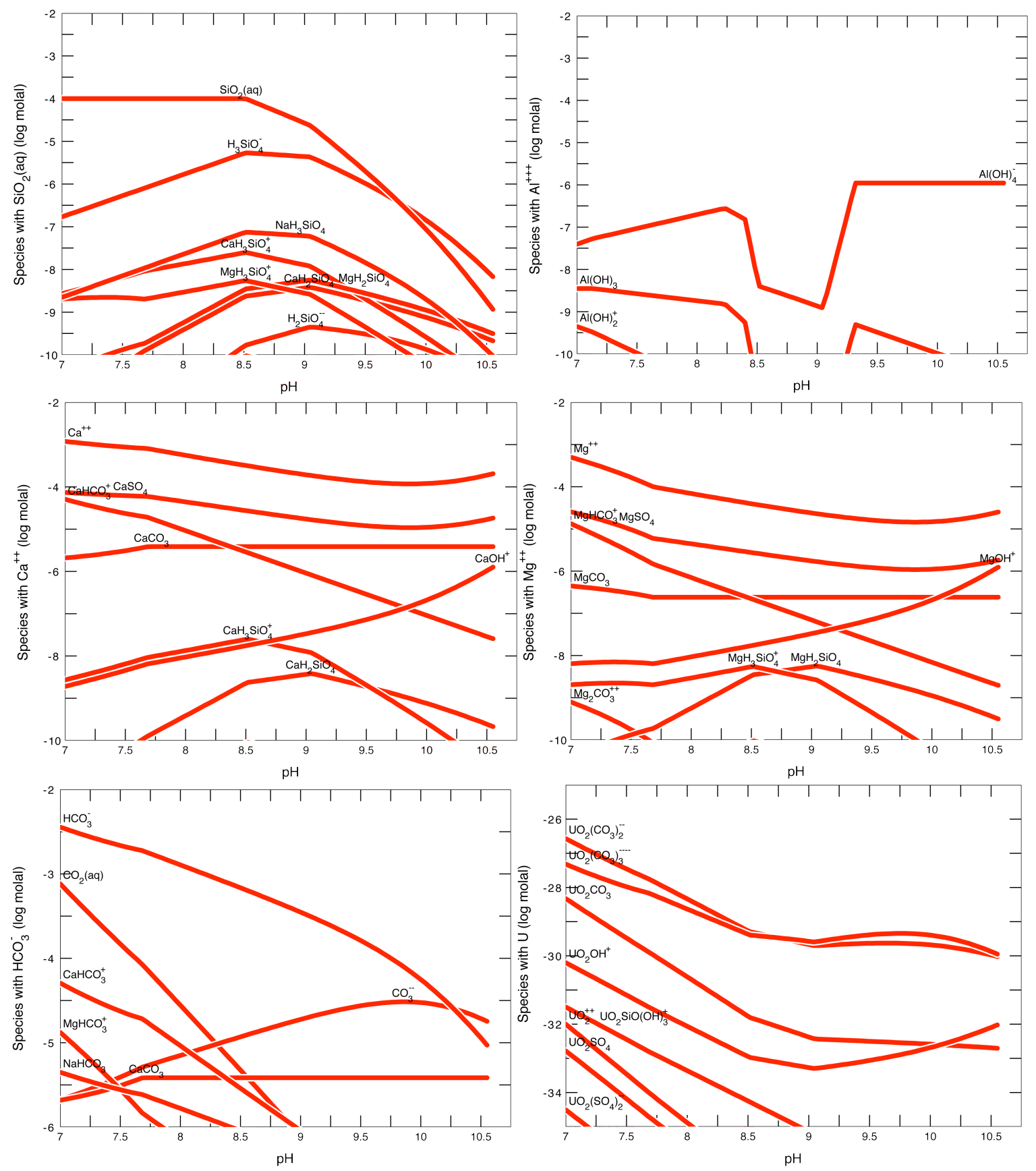

Figure 4.13. Predicted aqueous complexation as Hanford groundwater $\mathrm{pH}$ is varied from 8 to 11 . 
The corresponding solid phase composition (Figure 4.14a) shows a corresponding increase in carbonate precipitation, and changes in silicate mineral phases (i.e., dissolution of one phase, and precipitation of a second phase). The elemental composition of the solid phases (Figure 4.14b) show increases in silicon, aluminum, magnesium, calcium, and strontium indicating that at equilibrium, ions present in groundwater at $\mathrm{pH} 8$ would be present partially as precipitates at $\mathrm{pH} 11$. Limitations to these simulations include: a) mineral phase dissolution not shown, b) no effects of kinetics of precipitation.
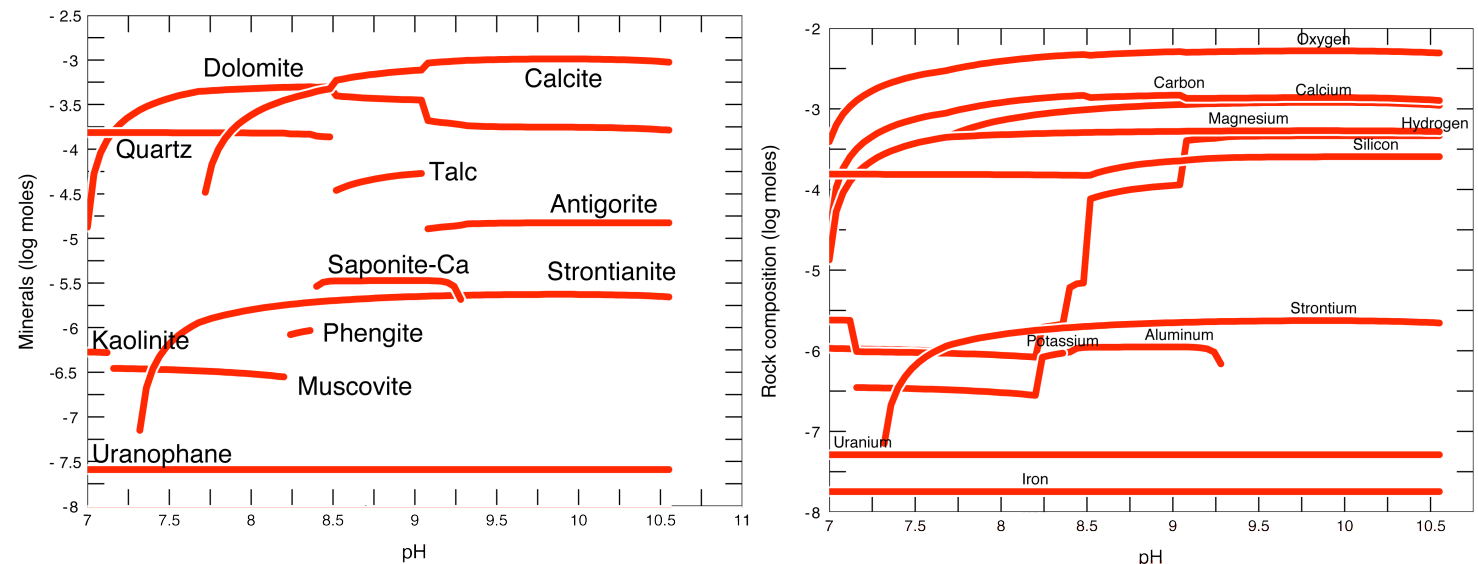

Figure 4.14. Predicted solid phase composition as Hanford groundwater $\mathrm{pH}$ is varied from 8 to 11 (no minerals initially present).

Simulations of single minerals present in the Hanford formation in groundwater as the $\mathrm{pH}$ is increased from 8 to 11 were also conducted to predict aqueous speciation. The nine major minerals present in the Hanford formation (average percentage indicated) included: quartz (32\%), plagioclase $(25 \%$, end members anorthite and albite), biotite $(8 \%)$, muscovite $(9 \%)$, microcline $(13 \%, \mathrm{~K}$-spar), pyroxenes $(6 \%$, hornblende), montmorillonite (1.2\%), illite (2.75\%), calcite $(2 \%)$, chlorite $(0.7 \%)$, and kaolinite $(0.35 \%)$. Individual mineral phase simulations were conducted, as only a few mineral phases can be simulated at the same time (with a simple aqueous composition). With the full Hanford groundwater composition, with one mineral phase, some simulations had 130 mineral phases included in the simulation and up to 250 aqueous species. Therefore, these simplified simulations only provide a general indication of the aqueous species that should be present. Although the actual dissolution of multiple mineral phases that occurs in the natural sediment (with ammonia gas treatment) can produce a pore water composition that may cause precipitation, these ions present from dissolution of different minerals were not simulated.

Quartz in contact with groundwater as the $\mathrm{pH}$ increases from 8 to 11 resulted in a decrease in aqueous silicon, as quartz precipitated (Figure 4.15a). The corresponding solid phase composition (Figure 4.15b) shows quartz is stable to $\mathrm{pH} 10.5$, but at higher $\mathrm{pH}$ a different silicate (Wollastonite, $\mathrm{CaSiO}_{3}$ ) is stable. Calcite in contact with groundwater as the $\mathrm{pH}$ increases from 8 to 11 also showed a corresponding decrease in aqueous carbonate (aqueous speciation similar to that shown in Figure 4.15a). Calcite stability decreases at $\mathrm{pH}>10.5$, but simulations were conducted only to $\mathrm{pH} 11$. Two feldspars were considered in simulations, a plagioclase ( $\mathrm{Na}$ end member) and orthoclase (K-spar). 

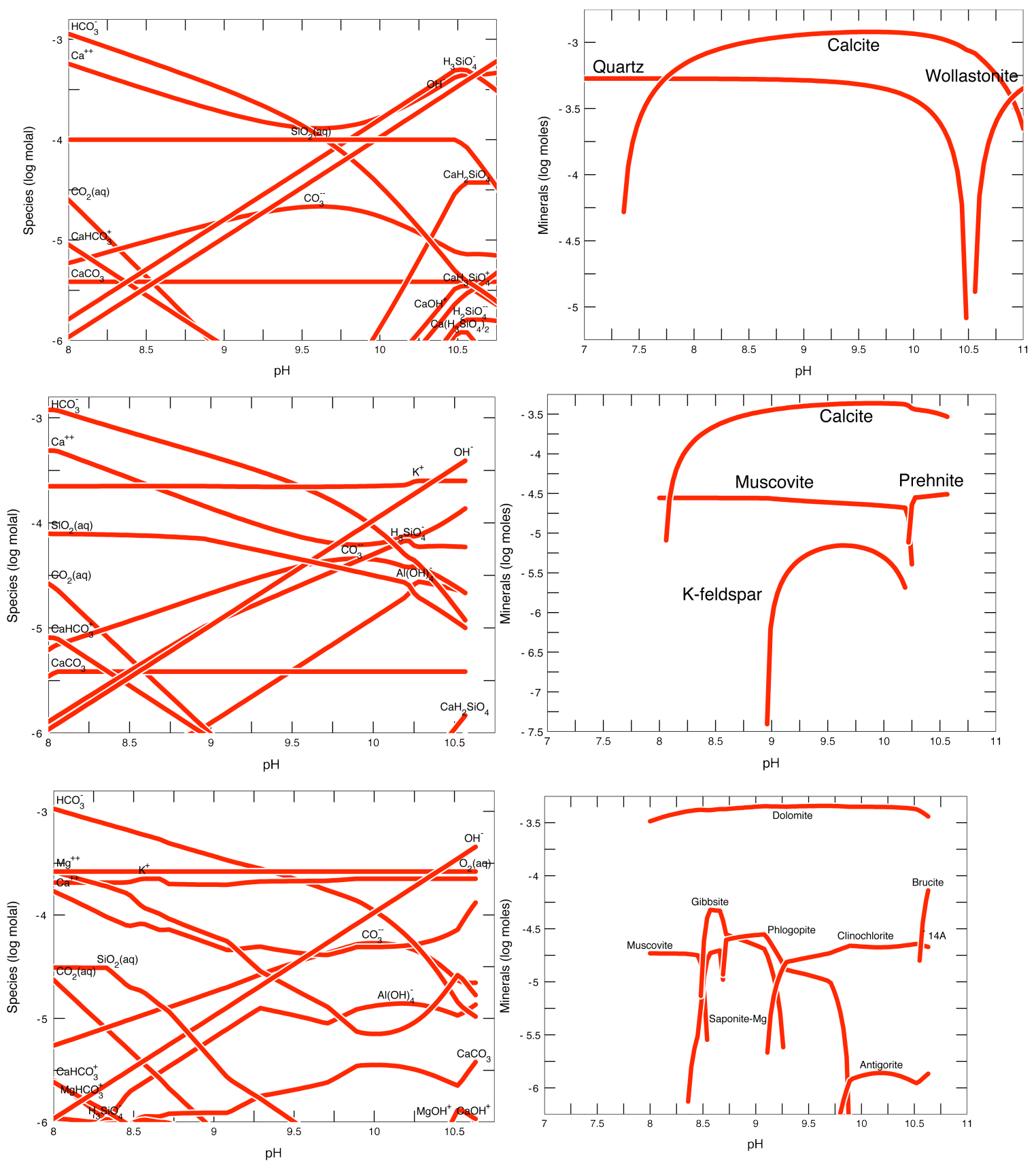

Figure 4.15. Predicted mineral phase dissolution or precipitation as individual mineral phases in contact with Hanford groundwater $\mathrm{pH}$ changes from 8 to 11: quartz aqueous species (a), precipitates (b), orthoclase aqueous species (c), and precipitates (d), and muscovite aqueous species (e), and precipitates (f).

Reaction of orthoclase over this $\mathrm{pH}$ range showed the limited $\mathrm{pH}$ stability (9-10.5), and corresponding formation of different mineral phases (Figure 4.15d). The aqueous concentrations of Si remained the same, but $\mathrm{K}+$ increased with increasing $\mathrm{pH}$ (Figure 4.15c). Reaction of the Na-plagioclase (anorthite) with groundwater over the same $\mathrm{pH}$ range showed similar results (not shown). Clays play a significant role in sediment systems, as these secondary mineral phases present at low mass fraction have high 
surface areas and adsorb significant cations. Six different clays were simulated individually, with muscovite shown for aqueous species (Figure 4.15e) and precipitates (Figure 4.15f). Aqueous speciation changes for these clays over the $\mathrm{pH}$ range all show decreasing cation concentrations, but there are complex changes in the most stable mineral phase, as shown in Figure 4.15f. Simulations do not include adsorbed cations, which upon mineral phase dissolution (and precipitation of a different phase) will also influence the phase formed. Since Hanford groundwater is Ca-Mg-carbonate saturated, cations present as adsorbed phases (molar basis) average $77 \% \mathrm{Ca}^{+2}, 17 \% \mathrm{Mg}^{+2}, 4.2 \% \mathrm{~K}^{+}, 2.7 \% \mathrm{Na}^{+}$, and $2.4 \% \mathrm{Sr}^{2+}$. Dissolution of other clays showed somewhat different results in terms of mineral phases formed, but aqueous cation concentrations generally decreased with increasing $\mathrm{pH}$. As some results shown in this and the following sections show increased cation concentrations, this may be a result of the kinetics of the dissolution/reprecipitation process (i.e., there was not sufficient time for ions to precipitate; simulations assume equilibrium) or may be partially a result of the desorption/ion exchange of cations due to the large ammonia concentration.

\subsubsection{Aqueous Cation Concentrations for Individual Mineral Dissolution}

Mineral samples of the nine most common minerals in Hanford sediment and two rocks (granite and basalt) were treated with $\mathrm{NH}_{3}$ gas to evaluate cation dissolution. $\mathrm{NH}_{3}$ gas treatment consisted of using the freshly ground mineral, adding groundwater to achieve $4 \%$ moisture content, and then reacting 40 pore volumes of $10 \% \mathrm{NH}_{3} / 90 \% \mathrm{~N}_{2}$ for 1 month. Cations from untreated minerals also were evaluated. As described in the previous section, although it is expected that many of these minerals are less stable at elevated $\mathrm{pH}$ (i.e., most clays, orthoclase K-spar), the concentrations of aqueous cations at elevated $\mathrm{pH}$ levels generally are greater than at natural pore-water $\mathrm{pH} 8$ (at geochemical equilibrium). Therefore, it is expected that aqueous cation concentrations of $\mathrm{NH}_{3}$-treated minerals (at $\mathrm{pH} 11$ ) would be equal to or less than aqueous concentrations of the untreated sediments ( $\mathrm{pH} 7$ to 8). Elevated cation concentrations would indicate a state of nonequilibrium (i.e., some kinetic limitation to expected precipitation reactions).

Measured cation concentrations in mineral phases for $\mathrm{NH}_{3}$ treated minerals were slightly elevated (by a factor of less than two), and, for a few phases, somewhat elevated (by a factor of less than 10) compared with untreated minerals (Figure 4.16, Table 4.1). Biotite, chlorite, illite, microcline, hornblende, and quartz are minerals that showed similar total cation concentrations. Montmorillonite and muscovite are minerals that showed somewhat elevated aqueous cation concentrations. However, all minerals (and rocks) showed a change in the major mineralogy from a calcium-magnesium-dominated pore water to silicon-potassium-calcium-dominated pore water, so cations were desorbing from some surfaces (clays) and the mineral phase was dissolving. Sediment minerals that did show substantial dissolution (as defined by pore water cation concentrations being 1.5 to six times greater for $\mathrm{NH}_{3}$ treated sediment relative to untreated sediment) were phyllosilicates (montmorillonite, muscovite, kaolinite). This increasing cation concentration was mainly from dissolution (i.e., elevated silicon, potassium, calcium), but also to a lesser extent, from desorption of cations. The dissolution of quartz at elevated $\mathrm{pH}$ is expected, and did produce predominantly silica, whereas the dissolution of basalt produced predominantly silicon and calcium. Results were, therefore, consistent with expected cations based on geochemical equilibrium modeling. 


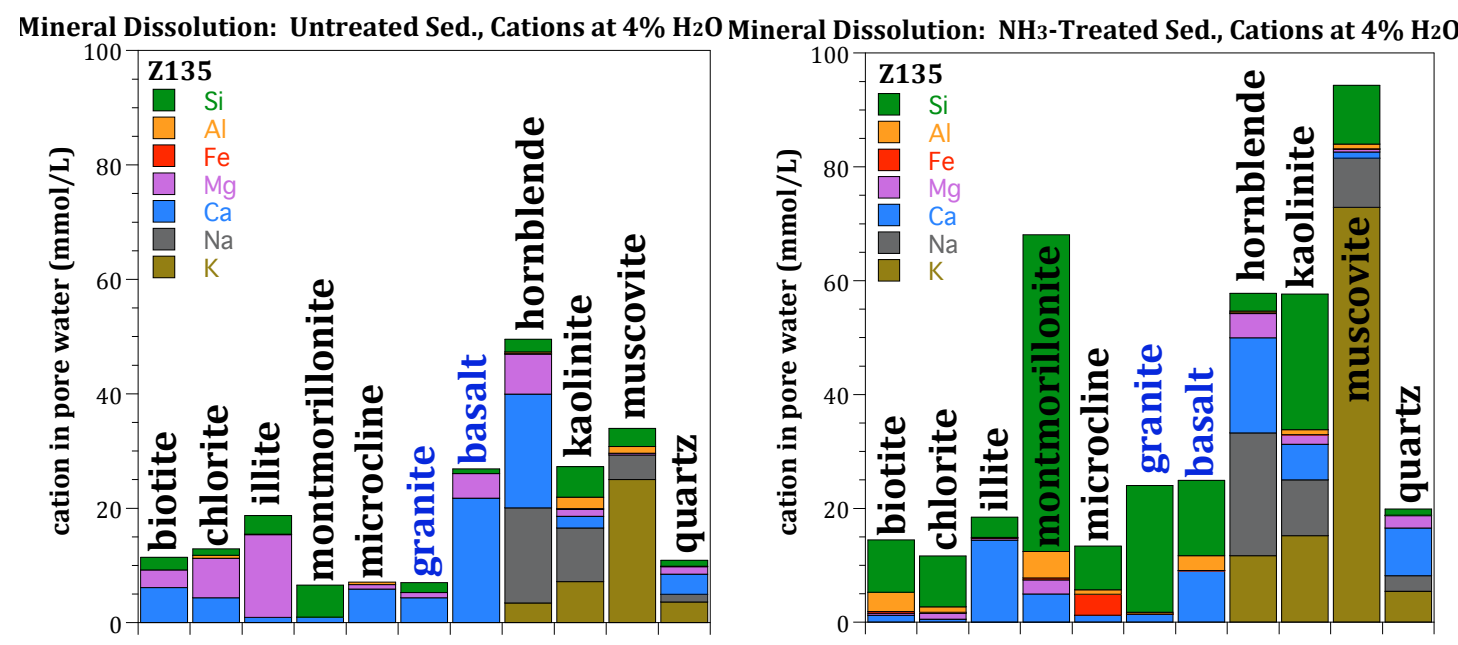

Figure 4.16. Pore water aqueous cations for untreated minerals (a) and $\mathrm{NH}_{3}$-treated minerals (b).

Table 4.1. Pore water cations from mineral dissolution.

\begin{tabular}{|c|c|c|c|c|c|c|c|c|}
\hline Mineral & Treatment & $\underset{(\mathrm{mmol} / \mathrm{L})}{\mathbf{S i}}$ & $\underset{(\mathrm{mmol} / \mathrm{L})}{\mathrm{Al}^{3+}}$ & $\underset{(\mathrm{mmol} / \mathrm{L})}{\mathrm{Fe}^{3+}}$ & $\underset{(\mathrm{mmol} / \mathrm{L})}{\mathrm{Mg}^{2+}}$ & $\underset{(\mathrm{mmol} / \mathrm{L})}{\mathrm{Ca}^{2+}}$ & $\underset{(\mathrm{mmol} / \mathrm{L})}{\mathrm{Na}^{+}}$ & $\underset{(\mathrm{mmol} / \mathrm{L})}{\mathbf{K}^{+}}$ \\
\hline \multirow[t]{2}{*}{ biotite } & untreated & 2.21 & 0.00 & 0.00 & 3.10 & 6.13 & & \\
\hline & NH3 treated* & 9.21 & 3.38 & 0.30 & 0.38 & 1.22 & & \\
\hline \multirow[t]{2}{*}{ chlorite } & untreated & 1.14 & 0.53 & 0.00 & 6.87 & 4.38 & & \\
\hline & NH3 treated* & 8.91 & 0.96 & 0.19 & 1.03 & 0.56 & & \\
\hline \multirow[t]{2}{*}{ illite } & untreated & 3.28 & 0.00 & 0.00 & 14.43 & 0.95 & & \\
\hline & NH3 treated* & 3.57 & 0.09 & 0.03 & 0.33 & 14.45 & & \\
\hline \multirow{2}{*}{ montmorillonite } & untreated & 5.60 & 0.00 & 0.00 & 0.00 & 0.99 & & \\
\hline & NH3 treated* & 55.7 & 4.64 & 0.34 & 2.48 & 4.98 & & \\
\hline \multirow[t]{2}{*}{ microcline } & untreated & 0.00 & 0.43 & 0.00 & 0.76 & 5.89 & & \\
\hline & $\mathrm{NH3}$ treated* & 7.66 & 0.77 & 3.71 & 0.04 & 1.20 & & \\
\hline \multirow[t]{2}{*}{ granite } & untreated & 1.73 & 0.00 & 0.00 & 0.92 & 4.38 & & \\
\hline & NH3 treated* & 22.3 & 0.29 & 0.03 & 0.08 & 1.36 & & \\
\hline \multirow[t]{2}{*}{ basalt } & untreated & 0.86 & 0.00 & 0.00 & 4.28 & 21.76 & & \\
\hline & NH3 treated* & 13.21 & 2.61 & 0.02 & 0.04 & 9.04 & & \\
\hline \multirow{2}{*}{ hornblende } & untreated & 2.21 & 0.28 & 0.10 & 6.98 & 19.87 & 16.64 & 3.45 \\
\hline & $\mathrm{NH} 3$ treated* & 3.12 & 0.32 & 0.13 & 4.26 & 16.69 & 21.58 & 11.70 \\
\hline \multirow[t]{2}{*}{ kaolinite } & untreated & 5.32 & 2.02 & 0.10 & 1.26 & 2.02 & 9.38 & 7.17 \\
\hline & $\mathrm{NH} 3$ treated* & 23.81 & 0.86 & 0.02 & 1.68 & 6.25 & 9.81 & 15.23 \\
\hline \multirow[t]{2}{*}{ moscovite } & untreated & 3.15 & 1.18 & 0.00 & 0.30 & 0.00 & 4.28 & 25.04 \\
\hline & $\mathrm{NH} 3$ treated* & 10.31 & 0.86 & 0.06 & 0.47 & 1.10 & 8.64 & 72.90 \\
\hline quartz & $\begin{array}{l}\text { untreated } \\
\text { NH3 treated* }\end{array}$ & $\begin{array}{l}1.05 \\
1.09\end{array}$ & $\begin{array}{l}0.10 \\
0.08\end{array}$ & $\begin{array}{l}0.00 \\
0.00\end{array}$ & $\begin{array}{l}1.30 \\
2.18\end{array}$ & $\begin{array}{l}3.52 \\
8.37\end{array}$ & $\begin{array}{l}1.31 \\
2.70\end{array}$ & $\begin{array}{l}3.64 \\
5.47\end{array}$ \\
\hline
\end{tabular}




\subsubsection{Sediment Aqueous and Adsorbed Cation Concentration Changes}

\subsubsection{Range of Sediments and Water Content}

Treating Hanford formation sediment with ammonia gas increases the $\mathrm{pH}$ significantly (Figure 4.6), which also results in significant mineral dissolution and precipitation of alternate phases. Results shown in the previous section demonstrated that although some minerals are highly unstable under alkaline conditions (and dissolve), precipitation reactions also occur, leaving nearly the same or only somewhat elevated aqueous species. At differing initial water content, ammonia gas treatment of Hanford formation sediment (ERDF pit, 20-ft depth) show cation concentrations that are proportional to the resulting $\mathrm{pH}$, and

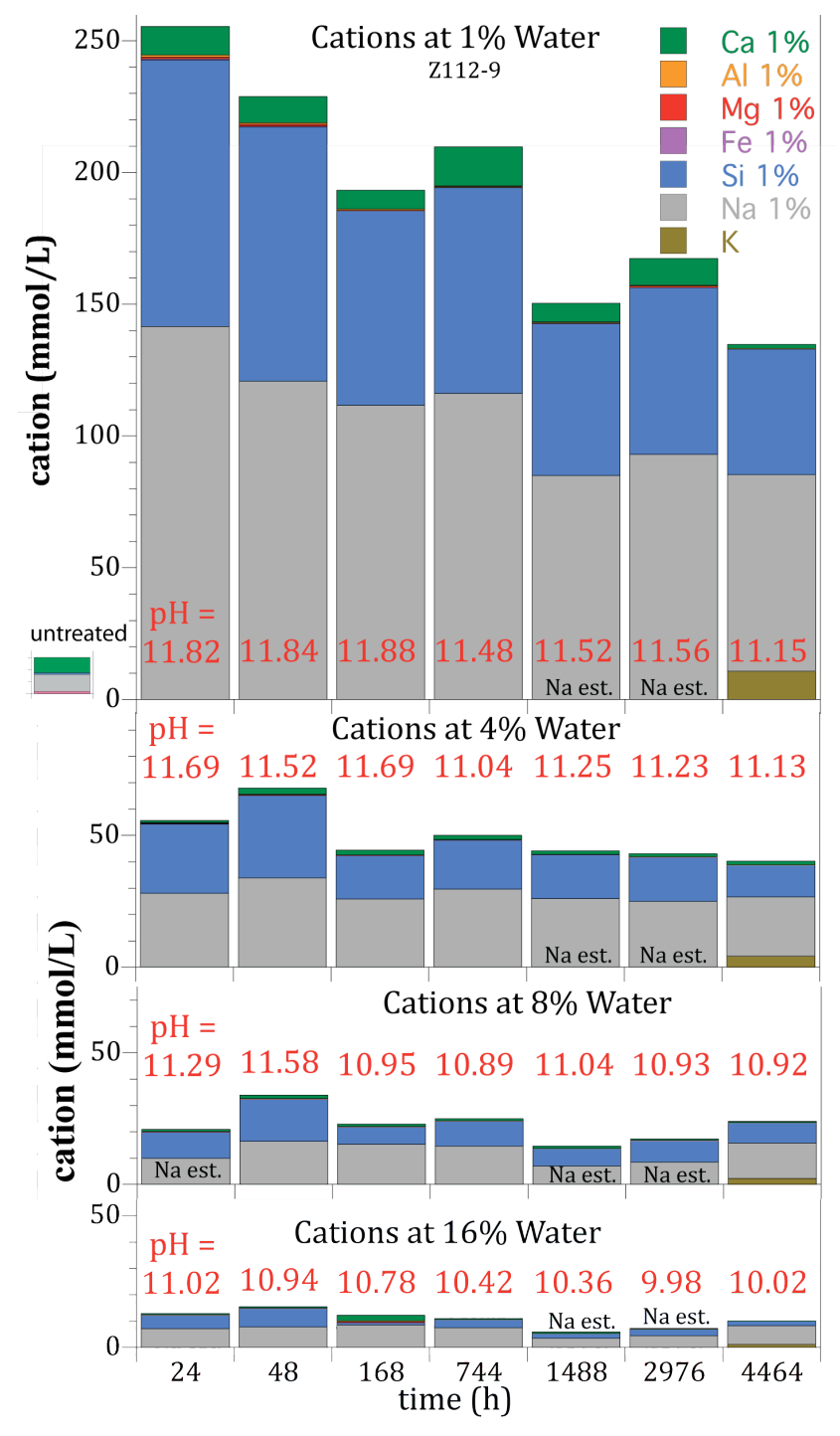

Figure 4.17. Sediment pore water cation concentrations over time during ammonia gas treatments (Hanford formation sediment from the ERDF pit, 20-ft depth). lower initial water content experiments have higher initial $\mathrm{pH}$ and EC (Figure 4.6b). Results are presented as stack bar graphs (Figure 4.17), which show the changes in major species, and also as individual cation graphs (Figure 4.18), which are on different scales, to show the trends of minor species better. The dominant cations present as a result of $\mathrm{NH}_{3}$ treatment of sediment is silica and sodium (Figure 4.17), which as the $\mathrm{pH}$ decreases over hundreds to thousands of hours decreases only a limited extent. In these experiments, the $\mathrm{NH}_{3}$ gas treatment resulted in a high $\mathrm{pH}$, and 40 pore volumes of the $10 \% \mathrm{NH}_{3}$ gas was kept in contact with sediment for the duration of the experiment. Therefore, the $\mathrm{pH}$ decreased only a limited amount $(\mathrm{pH}$ values indicated in Figure 4.17, $\mathrm{pH}$ graph is Figure 4.6b). The corresponding EC of the pore water (Figure 4.12a) shows a more significant decrease over time, which is a general indicator of pore water speciation changes. It should also be noted that the focus of this study is on uranium mineral changes as well as the fate of adsorbed/aqueous uranium species in terms of whether uranium-containing precipitates form or non-uranium precipitates coat surface uranium phases. Therefore, the change in uranium mobility in these multiple surface phases may be dependent on specific pore-water ions such as $\mathrm{Al}^{3+}$, which precipitates quickly (Figure 4.18) or be largely dependent on silica, which appears to not precipitate quickly.

The aqueous silica concentration in pore water decreases over thousands of hours (Figure 4.18a) by half, which is less than the 
orders-of-magnitude decrease predicted assuming equilibrium conditions (Figure 4.13a), indicating that kinetics exert some influence. Equilibrium simulations did not include the final complexity of all mineral phases present, but they are useful for predicting general trends of ions over the $\mathrm{pH}$ range that occurs with $\mathrm{NH}_{3}$ gas treatment. In contrast, the concentration of $\mathrm{Al}^{3+}$ in pore water decreased more than an order of magnitude over time in all experiments (Figure 4.18b). The concentrations of $\mathrm{Ca}^{2+}$ and $\mathrm{Mg}^{2+}$ in the pore water decreased an order of magnitude for the most alkaline $\mathrm{pH} 12$ (i.e., $1 \%$ initial water content, Figures $4.18 \mathrm{c}$ and d), but experiments in which the $\mathrm{pH}$ was initially lower (11 to 11.7, Figure 4.17), aqueous concentrations showed little change. These results were consistent with predicted change (Figure $4.14 \mathrm{c}$ and d). The $\mathrm{Na}^{+}$pore water concentration also decreased by $<50 \%$ over thousands of hours (Figure 4.18e). Finally, the $\mathrm{Fe}^{3+}$ concentration decreased two or more orders of magnitude (Figure 4.18f).
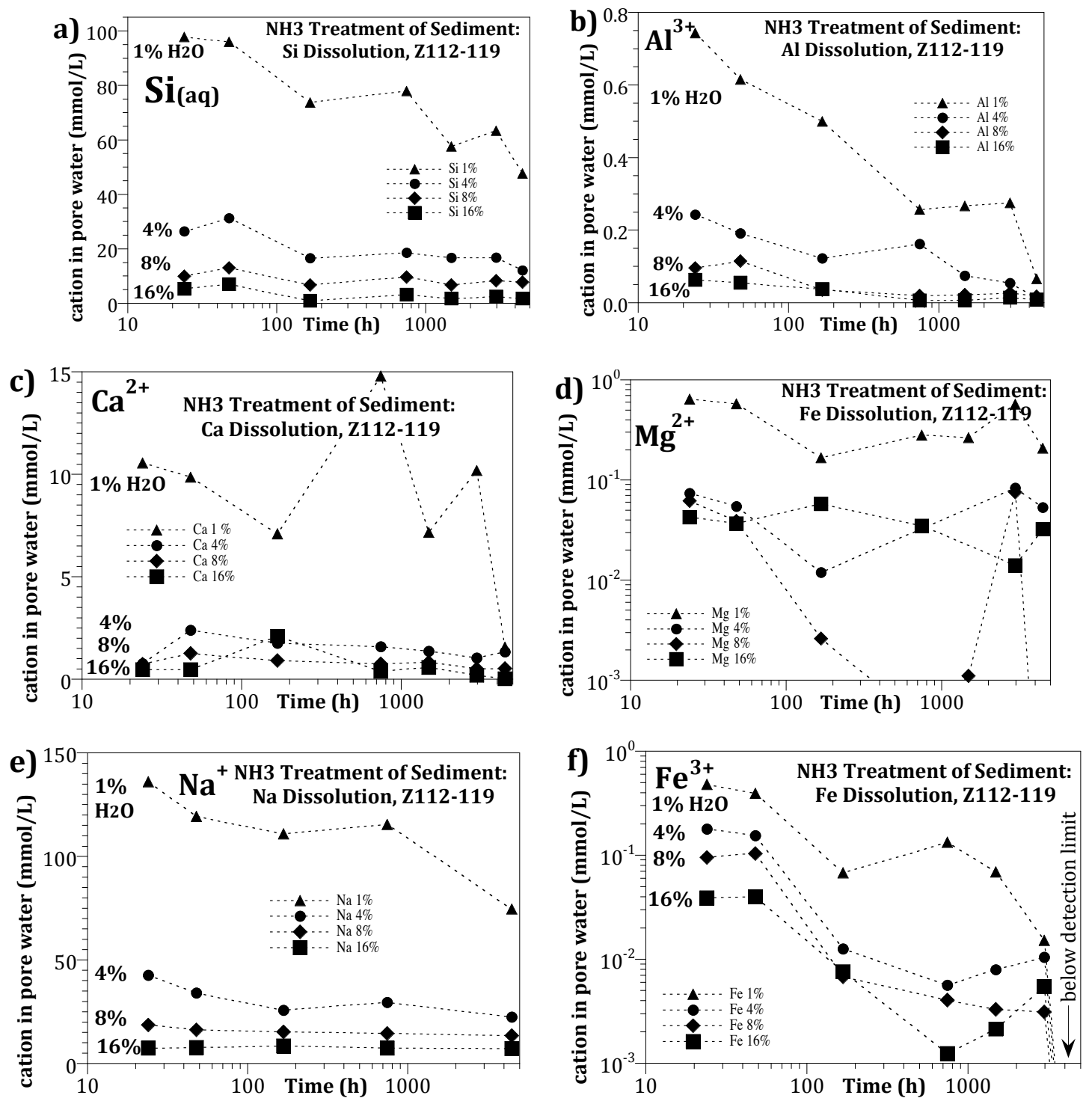

Figure 4.18. Sediment pore water cation concentration change over time during $\mathrm{NH}_{3}$ treatment (Hanford formation ERDF pit sediment, 20-ft depth). 
Cation data were also collected after $10 \% \mathrm{NH}_{3}$ treatment of a range of Hanford subsurface sediments from different sites (Figure 4.19a). Sediments were initially at 4\% water content. Ammonia gas treatment of these sediments showed predominantly $\mathrm{Si}$ and $\mathrm{Ca}^{2+}$ cations in the pore water with some $\mathrm{Na}^{+}$. The ferric iron concentration (Figure 4.19b) was similar to that previously observed for the ERDF pit sediment (Figure 4.18f), as was the $\mathrm{Al}^{3+}$ concentration (Figure 4.19c). High ionic strength at the BC cribs is likely from co-contaminants, as described in greater detail in Section 4.8
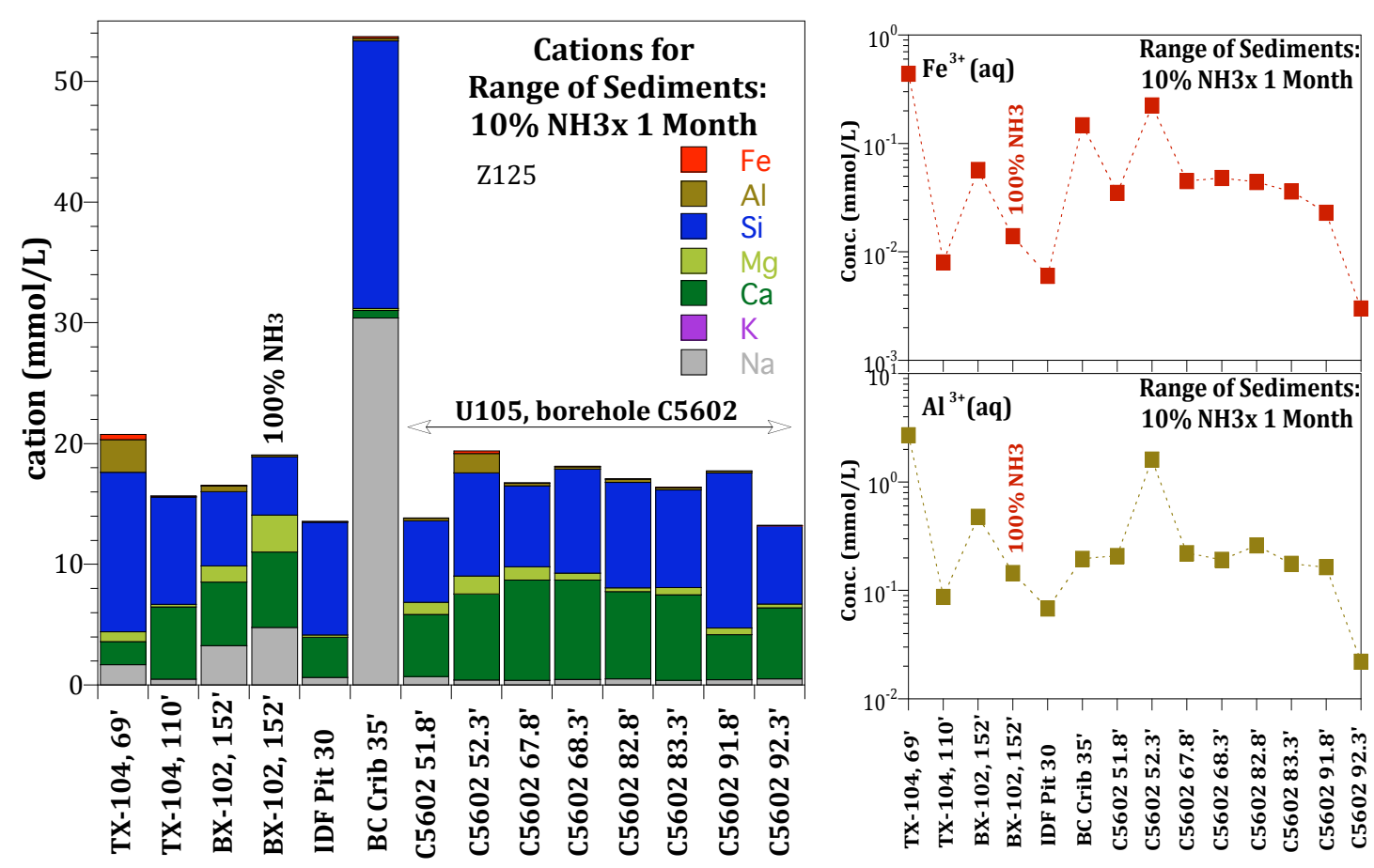

Figure 4.19. Sediment pore water cation concentrations for Hanford sediments after $10 \% \mathrm{NH}_{3}$ gas treatment.

Pore water cation data during ammonia gas treatment in a larger scale (2-D) system shows somewhat different results from the previous batch experiments, as: a) $100 \%$ ammonia gas at differing pore volumes of treatment was used, b) sediment samples taken at different locations in the flow system were exposed to air, and c) cation analysis is also at 7 months (5100 h, Figure 4.20).

Greater ammonia treatment did result in a higher $\mathrm{pH}$, as shown at the bottom of the bar graphs (Figure 4.20) and graphically (Figure 4.12c). After 7 months, much of the early aqueous cations had precipitated, and there was a nearly uniform cation concentration (30 to $70 \mathrm{mM}$ total), as compared with $25 \mathrm{mM}$ for the untreated sediment (small graph on the left, Figure 4.20). The point at $1 \mathrm{~cm}$ that received the highest ammonia treatment ( $\mathrm{pH}$ 13.2), which was also desiccated (from the anhydrous ammonia), did remain at a high (presumed) ionic strength of the pore water. Results for this point are an artifact of the experiment, as the desiccated sediment results in precipitates that would not normally occur, and during rewetting (dilution) to obtain a sample for analysis, these precipitates are dissolved. During ammonia gas treatment in the field, a small volume near the injection well is likely to be temporarily desiccated (see 2-D experiment, Results Section 4.10), but over time this volume will equilibrate with pore water from surrounding sediment. 
There is additional pore water aqueous and adsorbed cation data in Results Section 4.8, in which a $\mathrm{BC}$ crib sediment was used. This sediment is has high concentrations of $\mathrm{Na}-\mathrm{NO}_{3}$ as a result of contaminant spread in the field.

\subsubsection{ERDF Pit Sediment at Differing $\mathrm{NH}_{3}$ Concentration}

Dissolution experiments were conducted at $10 \%, 30 \%$, and $100 \%$ $\mathrm{NH}_{3}$ (40 pore volumes) initially at $8 \%$ water content. The average concentrations of relevant chemical elements measured in different ammonia treatments calculated with data collected in the timeframe of 69 to 861 hours, are presented in Table 4.2. The changes in the concentrations of selected elements with time during these experiments are presented in Figure 4.21.

Clearly, the gas treatment significantly changed the chemical composition of the liquid phase in contact with the sediment matrix. The chemical elements relevant to this study can be divided into groups based on the way they responded to an increase in the $\mathrm{NH}_{3}$ gas concentration and based on the measured changes in their aqueous concentrations with time in response to an increasing $\mathrm{NH}_{3}$ gas concentration (Table 4.2 and Figure 4.21).

Table 4.2. Changes in liquid phase elemental composition after sediment exposure to three $\mathrm{NH}_{3}$ gas concentrations $(10 \%, 30 \%$, and $100 \%)$.

\begin{tabular}{lcccc}
\hline Element & $\begin{array}{c}\text { Initial Concentration } \\
(\text { no treatment } \\
\left.\mathrm{mmol} \mathrm{L}^{-1}\right)\end{array}$ & $\begin{array}{c}\text { Concentration } \\
(69-861 \text { hours } \\
\left.10 \% \mathrm{NH}_{3} \mathrm{mmol} \mathrm{L}^{-1}\right)\end{array}$ & $\begin{array}{c}\text { Concentration } \\
(69-861 \text { hours } \\
\left.30 \% \mathrm{NH}_{3} \mathrm{mmol} \mathrm{L}^{-1}\right)\end{array}$ & $\begin{array}{c}\text { Concentration } \\
(69-861 \text { hours } \\
\left.100 \% \mathrm{NH}_{3} \mathrm{mmol} \mathrm{L}^{-1}\right)\end{array}$ \\
\hline $\mathrm{Al}$ & $0.039 \pm 0.000$ & $0.078 \pm 0.071$ & $0.060 \pm 0.034$ & $0.028 \pm 0.056$ \\
$\mathrm{Ba}$ & $0.001 \pm 0.000$ & $0.001 \pm 0.000$ & $0.002 \pm 0.001$ & $0.002 \pm 0.001$ \\
$\mathrm{Ca}$ & $6.339 \pm 0.214$ & $4.198 \pm 0.906$ & $5.404 \pm 2.302$ & $12.454 \pm 2.884$ \\
$\mathrm{Fe}$ & $0.051 \pm 0.000$ & $0.114 \pm 0.086$ & $0.063 \pm 0.046$ & $0.036 \pm 0.031$ \\
$\mathrm{~K}$ & $0.848 \pm 0.068$ & $2.175 \pm 0.440$ & $3.230 \pm 0.833$ & $3.745 \pm 0.644$ \\
$\mathrm{Na}$ & $7.047 \pm 0.187$ & $11.353 \pm 4.620$ & $13.416 \pm 5.330$ & $20.129 \pm 2.981$ \\
$\mathrm{Si}$ & $0.694 \pm 0.000$ & $1.166 \pm 0.241$ & $1.066 \pm 0.118$ & $0.870 \pm 0.140$ \\
$\mathrm{Sr}$ & $0.011 \pm 0.000$ & $0.008 \pm 0.006$ & $0.013 \pm 0.006$ & $0.032 \pm 0.005$ \\
$\mathrm{pH}$ & $7.59 \pm 0.05$ & $10.16 \pm 0.28$ & $10.20 \pm 0.46$ & $10.88 \pm 0.20$ \\
\hline
\end{tabular}



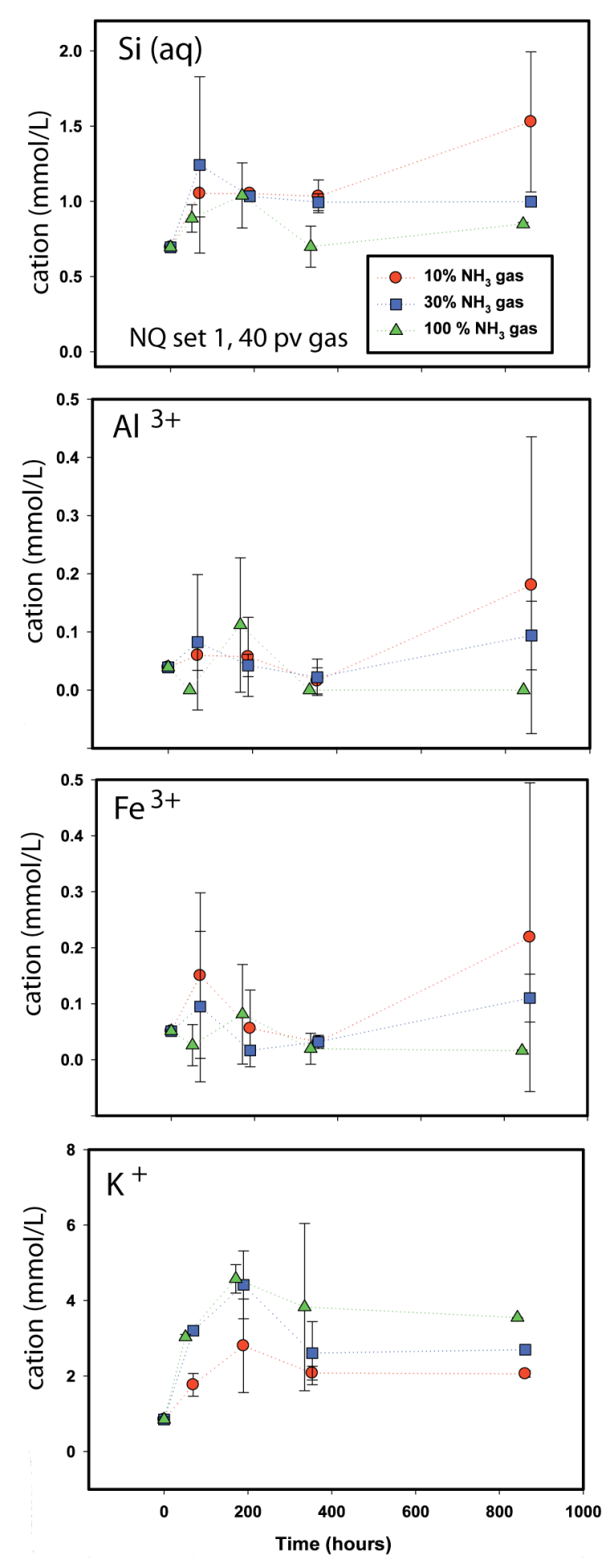

Figure 4.21. Changes in pore water cations with $\mathrm{NH}_{3}$ gas treatment.
The aqueous concentrations of the first group of elements, i.e., $\mathrm{Ca}, \mathrm{K}, \mathrm{Na}$, and $\mathrm{Sr}$, initially increased (i.e., from the no treatment concentration, Table 4.2), and also increased with increasing $\mathrm{NH}_{3}$ gas concentrations in the interval $10 \%-100 \%$.

The aqueous concentrations of the other group of elements, i.e., $\mathrm{Al}, \mathrm{Ba}$, and $\mathrm{Fe}$ did not change significantly after the sediment was exposed to the $\mathrm{NH}_{3}$ gas. In addition, their aqueous concentrations did not respond to the two variables investigated in these experiments: the $\mathrm{NH}_{3}$ gas concentration and experimental time, although an increasing (yet not significant) concentration trend was observed.

The silicon concentration increased significantly in the exposed sediments to the $\mathrm{NH}_{3}$ gas treatment, but changed little or decreased with time.

There are at least three possible geochemical processes that might affect and/or control the aqueous concentrations of these elements in these systems, namely soil mineral dissolution, precipitation (neophase formation), and cation/anion exchange reactions. The aqueous concentration of these elements increases when soil mineral dissolution occurs. This will continue until the aqueous phase becomes oversaturated with respect to one or more secondary phases that might subsequently precipitate causing a decrease in the aqueous concentrations of the elements that make up the structure of the neophases. In addition, since a cation, i.e., $\mathrm{NH}_{4}^{+}$, is introduced into the system during gas injection, cation exchange reactions may be also promoted. Finally, the atmospheric $\mathrm{CO}_{2}$ gas will be driven and get dissolved in the basic solution increasing the concentration of carbonates and/or bicarbonates anions, which might get involved in anion exchange reactions.

Soil mineral dissolution may occur under alkaline conditions as it is clearly demonstrated in previous studies (Qafoku et al. 2004). As a result, the chemical elements of the soil mineral matrices may be released in the aqueous phase when these minerals undergo dissolution. Past research has shown that the most likely dissolving soil mineral in these sediments are quartz $\left[\mathrm{SiO}_{2}\right]$, feldspars $\left[\mathrm{KAlSi}_{3} \mathrm{O}_{8}-\mathrm{NaAlSi}_{3} \mathrm{O}_{8}-\mathrm{CaAl}_{2} \mathrm{Si}_{2} \mathrm{O}_{8}\right]$, micas (such as 
biotite) $\left[\mathrm{K}(\mathrm{Mg}, \mathrm{Fe})_{3} \mathrm{AlSi}_{3} \mathrm{O}_{10}(\mathrm{~F}, \mathrm{OH})_{2}\right]$, and chlorite (most likely clinochlore: $\left(\mathrm{Mg}_{5} \mathrm{Al}\right)\left(\mathrm{AlSi}_{3}\right) \mathrm{O}_{10}(\mathrm{OH})_{8}$ or ferroan clinochlore $\left[(\mathrm{MgFeAl})_{6}(\mathrm{SiAl})_{4} \mathrm{O}_{10}(\mathrm{OH})_{8}\right]$.

All these minerals were present in the sediment sample used in $\mathrm{NH}_{3}$ gas studies. However, the results presented above demonstrated that with some exceptions, such as in the case of the calcium and sodium concentrations that may be controlled by exchange reactions, the concentrations of the chemical elements changed little with increasing $\mathrm{NH}_{3}$ gas concentration and liquid phase $\mathrm{pH}$. Most likely, the apparent invariability or even decrease in aqueous-phase concentrations observed for some elements (e.g., silicon) and the apparent zero effect of $\mathrm{NH}_{3}$ gas concentration on silicon release (i.e., silicon-bearing phase dissolution) could be the result of precipitation of secondary phases that might have formed in the sediments exposed to harsher basic conditions created by the larger (i.e., $30 \%$ or $100 \%$ ) $\mathrm{NH}_{3}$ gas concentrations. Because of the higher $\mathrm{pH}$ levels measured in these experiments, dissolution should have occurred at a greater extent in the experiments where the sediments were exposed to $30 \%$ or $100 \% \mathrm{NH}_{3}$ gas concentrations (as compared to the ones where the sediments were exposed to $10 \%, \mathrm{NH}_{3}$ gas concentration).

The importance of the sediment moisture content in controlling the magnitude of elemental concentration was clearly shown in the comparison of experiments conducted at low water saturation $(8 \%$ water or $0.08 \mathrm{~g} / \mathrm{g})$ to experiments conducted in water saturated conditions $(2 \mathrm{~g} / \mathrm{g})$. The aqueous cation concentration in watersaturated experiments increased over time, whereas at low water saturation, pore water cation concentrations increased for a short period of time, then decreased. Shown is silica (Figure 4.22, green points are 8\% water content experiment), but a similar trend was observed with $\mathrm{Ca}, \mathrm{Na}$, and $\mathrm{Mg}$ (not shown), but observed in other experiments (Figure 4.18).

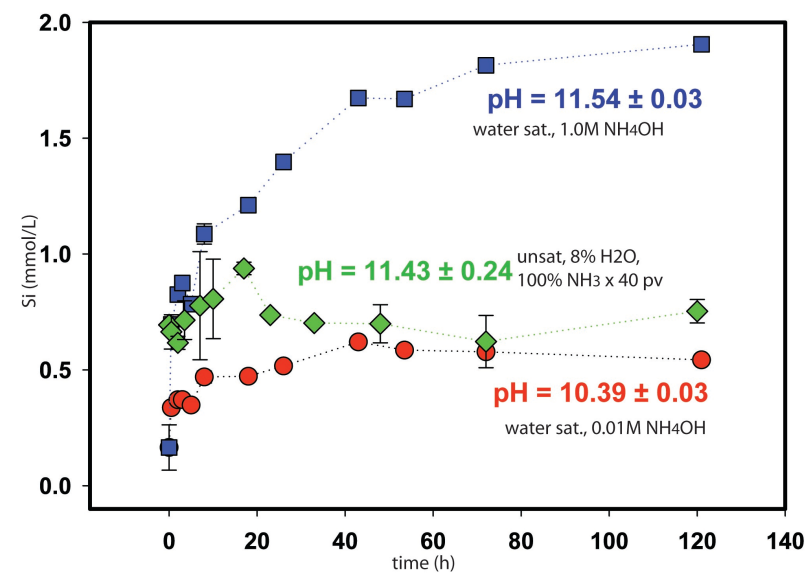

Figure 4.22. Aqueous silica in water saturated and unsaturated (pore water, $8 \% \mathrm{H}_{2} \mathrm{O}$ ) systems.

One can clearly see in the trend obtained in the experiments conducted with the $1 \mathrm{~mol} \mathrm{~L}^{-1} \mathrm{NH}_{4} \mathrm{OH}$ solution; in those experiments, an initial rapid dissolution reaction occurred, followed by a slower dissolution reaction (change in slope). Invariant silicon concentrations then plateaued over time, most likely indicating that one (or more) simultaneous precipitation reactions were occurring. Additional evaluations will include a calculation of the initial dissolution rates based on the changes in silicon concentration over time in the experiments conducted with the $1 \mathrm{~mol} \mathrm{~L}^{-1}$ and $10 \mathrm{mmol} \mathrm{L}^{-1} \mathrm{NH}_{4} \mathrm{OH}$ solutions. In addition, initial dissolution rates will be calculated for calcium and sodium. Modeling work to fit the experimental data (calcium, silicon, sodium, and magnesium) to a cation exchange or dissolution model also will be conducted. The rate of hydroxide consumption in the $10 \mathrm{mmol}$ system also will be calculated.

\subsubsection{Comparison of Pore Water Cations for Extraction Methods}

Two different methods (i.e., diluting and centrifuging) were used to extract pore water from lowwater-content sediment. Comparisons of the pore water cation concentrations for the samples extracted 
using the two methods are shown in Figure 4.23. Hanford formation sediment from the ERDF pit (20-ft depth) was used in both sets of experiments, and initially, the water content in both samples was $8 \%$. The $\mathrm{NH}_{3}$ gas treatment differed to some extent, but cation concentrations showed that the overall ionic strength was the about the same in both samples. The $\mathrm{Na}^{+}, \mathrm{Mg}^{+2}, \mathrm{Al}^{+3}$, and $\mathrm{Fe}^{+3}$ concentrations were comparable; however, in the sample extracted by dilution, the $\mathrm{Si}$ concentration was larger, and the $\mathrm{Ca}^{2+}$ concentration was smaller. In the dilution method, deionized water at a $1 \mathrm{~g} / 1 \mathrm{~mL}$ ratio was added to sediment. Aqueous ions and some adsorbed cations are collected with this method, and because of the lower sediment/water ratio, a higher fraction of the adsorbed cations partition into the diluted water (compared with cations present in the pore water). Adsorbed cations were not measured in these experiments, but a comparison of aqueous and adsorbed cations is shown in the Section 4.9. Alternatively, the centrifuge method can only be used in higher-water-content sediments ( $>8 \%$ water content for the Hanford formation $<4 \mathrm{~mm}$ sediment fraction), and a larger mass of sediment is needed in experiments to produce sufficient water for analysis. It also is not clear what fraction of cations is eluded. Because the water contents of sediments in the Hanford formation and the Cold Creek formation (with its much finer grained particles) average $4 \%$ and $12 \%$, respectively, the only method that can be used to extract pore water is dilution.
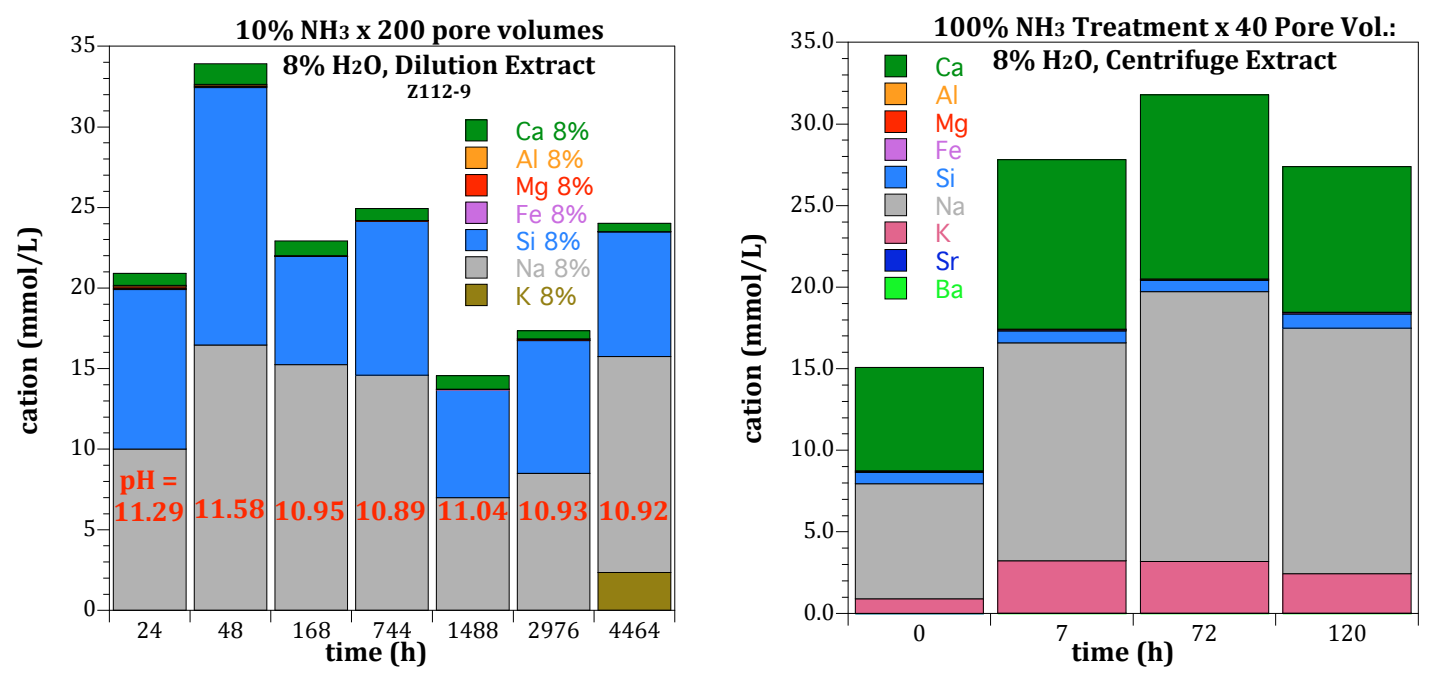

Figure 4.23. Sediment pore water cation concentration for Hanford formation ERDF pit sediment (20-ft depth) at $8 \%$ initial water content with: a) dilution method and b) centrifuge method.

\subsubsection{Sediment Aqueous Anion Concentration Changes}

Ammonia gas treatment of sediment also results in an increase in pore water anion concentrations. In batch experiments with Hanford formation sediment from the ERDF pit (20-ft depth), the predominant anion that increased was chloride (data not shown). In a 2-D system using the same sediment, a better trend is shown (Figure 4.24) with varying amounts of $\mathrm{NH}_{3}$ gas treatment from very few (points furthest from the injection at the left, or a small number of pore volumes of treatment) to thousands of pore volumes of $100 \% \mathrm{NH}_{3}$ gas treatment for the left-most point. These results also show increasing amounts of chloride and fluoride with increasing $\mathrm{NH}_{3}$ treatment. In addition, nitrate increases with $\mathrm{NH}_{3}$ treatment, and there was a trace of nitrate in the sample with highest $\mathrm{NH}_{3}$ gas treatment. Carbonate was present in the pore water, but at a lower concentration than the untreated sediment. 
These results do show that, while $\mathrm{NH}_{3}$ gas injection can result in nitrogen reduction for a zone of sediment that receives thousands of pore volumes of $100 \% \mathrm{NH}_{3}$ treatment, this area is likely to be small at field scale with $5 \% \mathrm{NH}_{3}$ gas injection. In addition, the calculated $\mathrm{NH}_{3}$ concentration in the sediment (Table 2.1) is $1 \mathrm{~mol} / \mathrm{L}$ to $4 \mathrm{~mol} / \mathrm{L}$, so $50 \mathrm{mmol} / \mathrm{L}$ nitrate (highest observed value) represents $1.2 \%$ to $5 \%$ of the nitrogen mass (as $\mathrm{NH}_{3}$ ) being reduced to nitrate. Actual measured values of $\mathrm{NH}_{3}$ in pore water (see Section 4.9) are as high as $2 \mathrm{~mol} / \mathrm{L}$.

\subsubsection{Mineral Dissolution/ Precipitation: Solid Phase Analysis}

To identify mineral phases dissolving and precipitating, solid phase analysis of pre- and post-

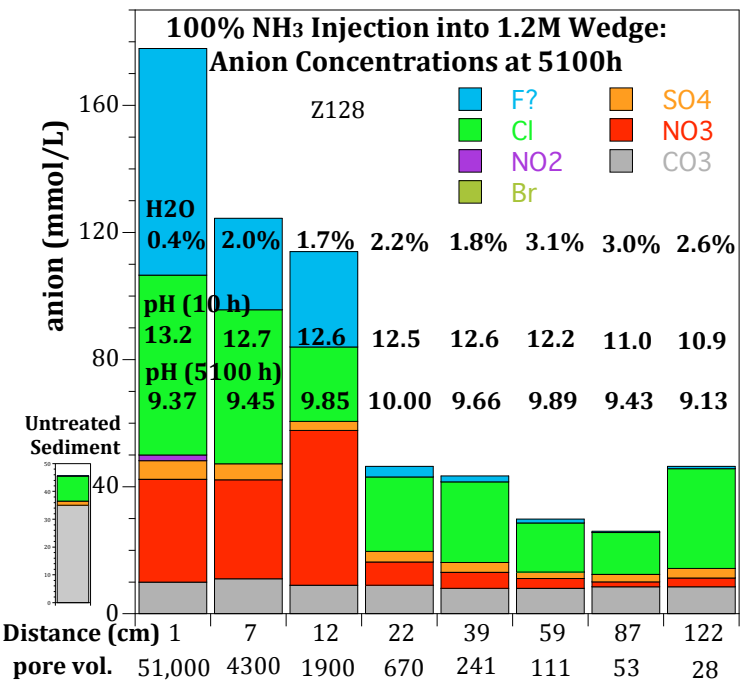

Figure 4.24. Sediment pore water anion concentrations for Hanford formation ERDF pit sediment (20-ft depth) at $8 \%$ initial water content in a 2-D flow system. ammonia treated sediments were analyzed by scanning electron microscopy and an electron microprobe. Three post-treatment sediment samples were subjected to careful inspections with scanning electron microscopy (SEM). In addition to studying morphological features of soil minerals and their surfaces, the chemical composition of soil minerals and coatings was also determined with EDS in many areas of interest. Electron microbe analysis was conducted on thin sections of epoxy-encased untreated and $\mathrm{NH}_{3}$-treated TX-104 (69 ft $\left.+110 \mathrm{ft}\right)$ sediment. Analysis of five elements (Fe, Si, Al, U, Ca) and the electron backscatter was conducted at a high density (10 micron spot, 280 points $\times 280$ points $=78,400$ points). It was hypothesized that mineral phases would be identified in the untreated sediment that would show a rind of a different mineral phase for the $\mathrm{NH}_{3}$-treated sediment. Results (Appendix A, Figures A.1 to A.4), unfortunately, show little difference in mineralogy. Future microprobe analysis will be conducted on specific minerals (grain, submicron scale).

Scanning electron microbe studies were conducted on sediment samples that received high $\mathrm{NH}_{3}$ treatment (490 pore volumes of $100 \% \mathrm{NH}_{3}$ ). The first sediment sample (sample 7, Set 4) was exposed to the $100 \% \mathrm{NH}_{3}$ gas inside a column. The sediment had an $8 \%$ moisture content and reacted with the $\mathrm{NH}_{3}$ gas for $120 \mathrm{~h}$. The other two sediment samples were from the experimental Set 5 (samples 1 and 26). These samples were exposed to the $1 \mathrm{~mol} \mathrm{~L}^{-1}$ and $10 \mathrm{mmol} \mathrm{L}^{-1} \mathrm{NH}_{4} \mathrm{OH}$ solutions, respectively, in batch experiments (1: 2 solid: solution ratio) conducted for $121 \mathrm{~h}$ (Figure 4.25 to 4.27 ).

Surface coatings were present in many soil minerals inspected in the three sediment samples (Figures 4.25 through 4.27); however, their origin was difficult to determine. The coatings may have had a diagenic/pedogenic origin, or they may have formed during the $120 \mathrm{~h}$ of sediment exposure to the alkaline solutions when accelerated dissolution of soil minerals should have occurred, followed by precipitation and formation of stable neophases. These neophases may have morphological features similar to the coatings observed in these sediments samples. 

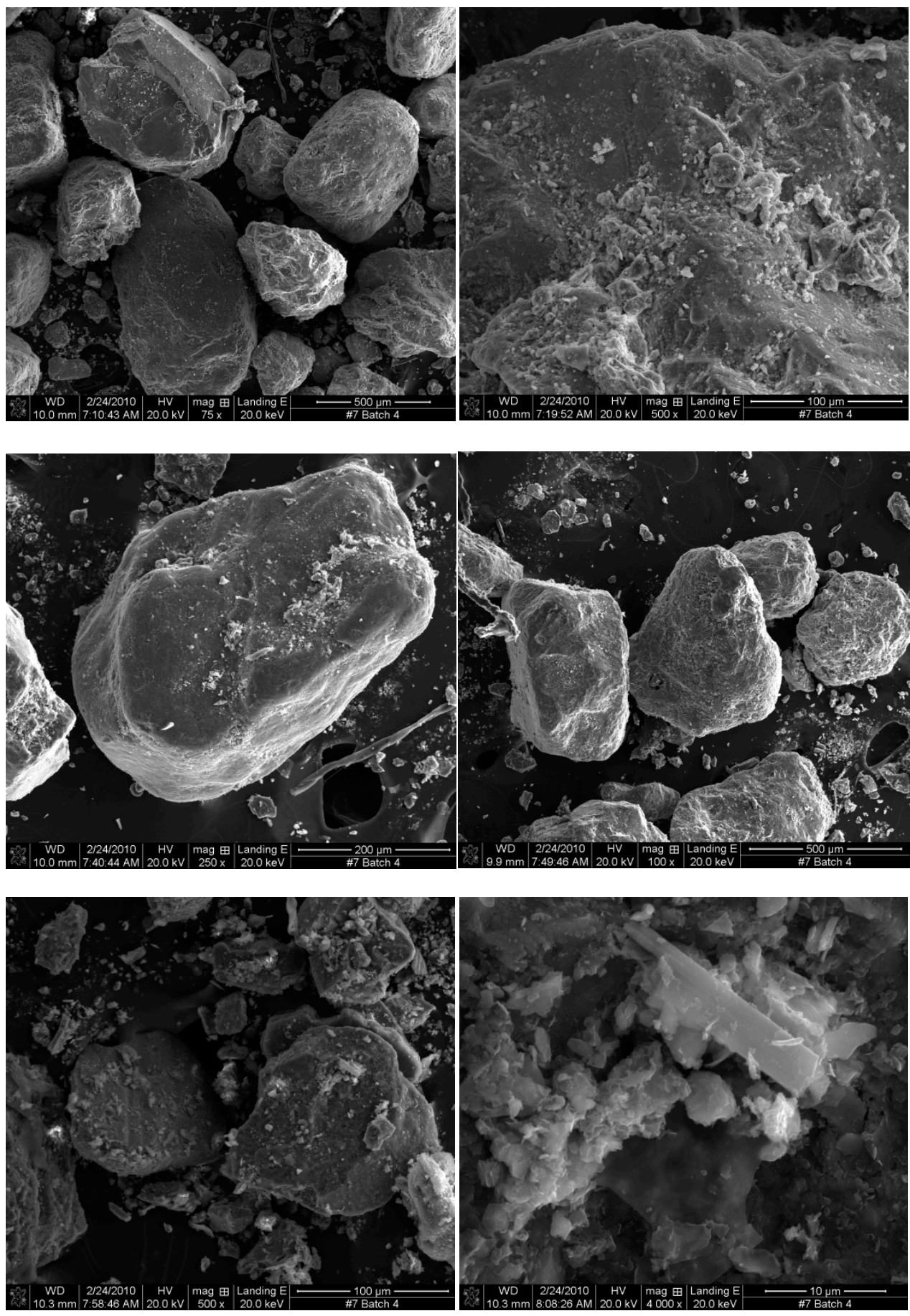

Figure 4.25. SEM images of soil particles and surface coatings from sediments ( $8 \%$ water content) with 490 pore volumes of $100 \%$ ammonia treatment (NQ set 4). 

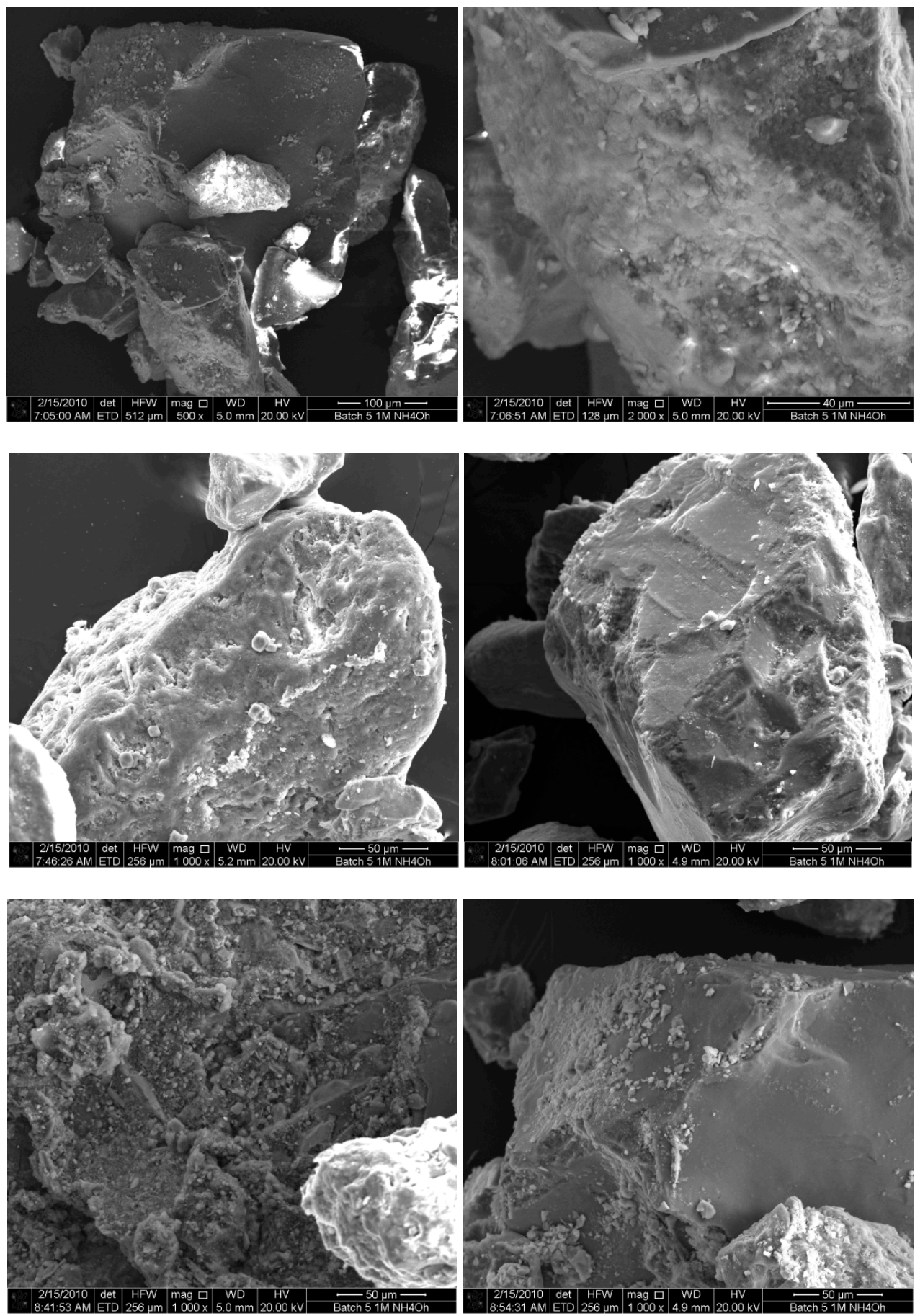

Figure 4.26. SEM images from water-saturated samples $\left(1 \mathrm{~mol} \mathrm{~L}^{-1} \mathrm{NH}_{4} \mathrm{OH}\right)$. 

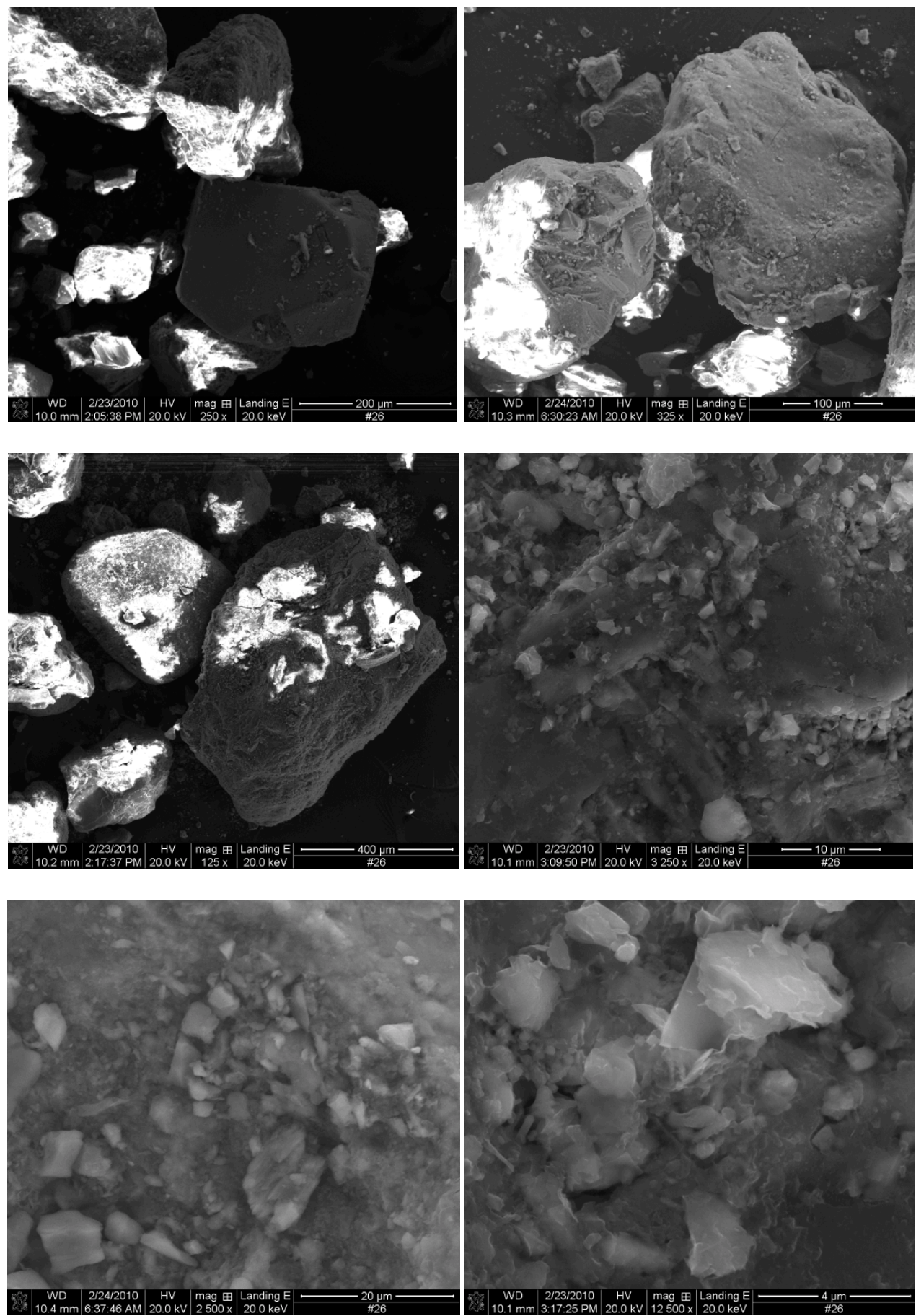

Figure 4.27. SEM images from water-saturated samples $\left(0.01 \mathrm{~mol} \mathrm{~L}^{-1} \mathrm{NH}_{4} \mathrm{OH}\right)$. 
An attempt will be made to determine the origin of these coatings by carefully inspecting an untreated sediment sample, which will be subjected to the same SEM and EDS analyses and measurements as the treated sediment samples. Hopefully, we will be able to compare the morphological features and chemical composition of the coatings in the nontreated and treated sediment samples and gather evidence to determine the origin of the coatings observed in all treated sediments. Soil minerals in the groups of cancrinite, sodalite, and zeolite, which were formed during similar experiments conducted with the same sediment exposed to $1 \mathrm{~mol} \mathrm{~L}^{-1}$ to $4 \mathrm{~mol} \mathrm{~L}-1 \mathrm{NaOH}$ and aluminum-rich $\left(0.055 \mathrm{~mol} \mathrm{~L}^{-1} 0.22 \mathrm{~mol} \mathrm{~L}^{-1}\right)$ solutions (Qafoku et al. 2003c, 2003b, 2004), were not observed in these sediment samples.

The conditions created in the sediment as a result of their exposure to $\mathrm{NH}_{3}$ gas or $\mathrm{NH}_{4} \mathrm{OH}$ liquid were not as harsh (in terms of $\mathrm{pH}$ values) as the ones created when the sediment was exposed to $\mathrm{NaOH}$ liquids ( $1 \mathrm{M}$ to $4 \mathrm{M}$ ). The maximum $\mathrm{pH}$ value measured in $\mathrm{NH}_{3}$ experiments was $\sim 13$, while the $\mathrm{pH}$ values measured in the $\mathrm{NaOH}$ experiments were close to $\sim 14$. In addition, it also appears that the amounts of silicon and aluminum released during the $\mathrm{NH}_{3}$ experiments were small, and it was not sufficient for the formation of minerals in the zeolite, cancrinite, and sodalite groups (which all have a 1:1 Si:Al molar ratio). The amount of aluminum released was small, and this probably would have been the limiting factor for the formation of these minerals. Numerous EDS measurements also were performed in these three sediment samples to determine the chemical composition of surface coatings and that of discrete soil mineral particles that may have been formed during the experiment (Appendix B, Figures B.1 to B.9). Analysis of this data is in progress.

\subsection{Uranium Surface Phase Changes}

\subsubsection{Predicted Uranium Mineral Phase Changes}

Geochemical equilibrium simulations were conducted using Hanford groundwater $(\mathrm{pH} 8)$ with a single uranium mineral (uranophane) that was reacted with $0.1 \mathrm{~mol} / \mathrm{L} \mathrm{NH}_{4} \mathrm{OH}$. Simulation results are shown in Figure 4.28 in terms of reaction progress (i.e., $1 \%, 10 \%$, and $100 \%$ of the $\mathrm{NH}_{3}$ reacted with the solution). This roughly corresponds to previous simulations of increasing $\mathrm{pH}$, as the final $\mathrm{pH}$ is 10.1 . Uranophane is stable in the $\mathrm{pH} 8$ to 10 range (Figure 4.28a), but there is an increase in aqueous uranium complexes (Figure 4.28b). These uranium aqueous complexes are present at low concentrations from uranophane equilibrium dissolution. Major ions present in solution (Figure 4.28c) correspond to changes previously noted, with decreasing concentrations of aqueous carbonate and silicate. Although uranophane was used in this simulation, there are other uranium precipitates that could be used and may form if the uranophane was less stable under the geochemical conductions compared with these other phases. A plot of the saturation index of uranium containing phases (Figure 4.28d) shows that uranophane is the most stable uranium phase, with uraninite and coffinite being the next most stable mineral phases. Sodiumboltwoodite is significantly less stable under these geochemical conditions, so under these equilibrium conditions (i.e., no kinetic limitations), it should dissolve and a more stable uranium precipitate should form. 

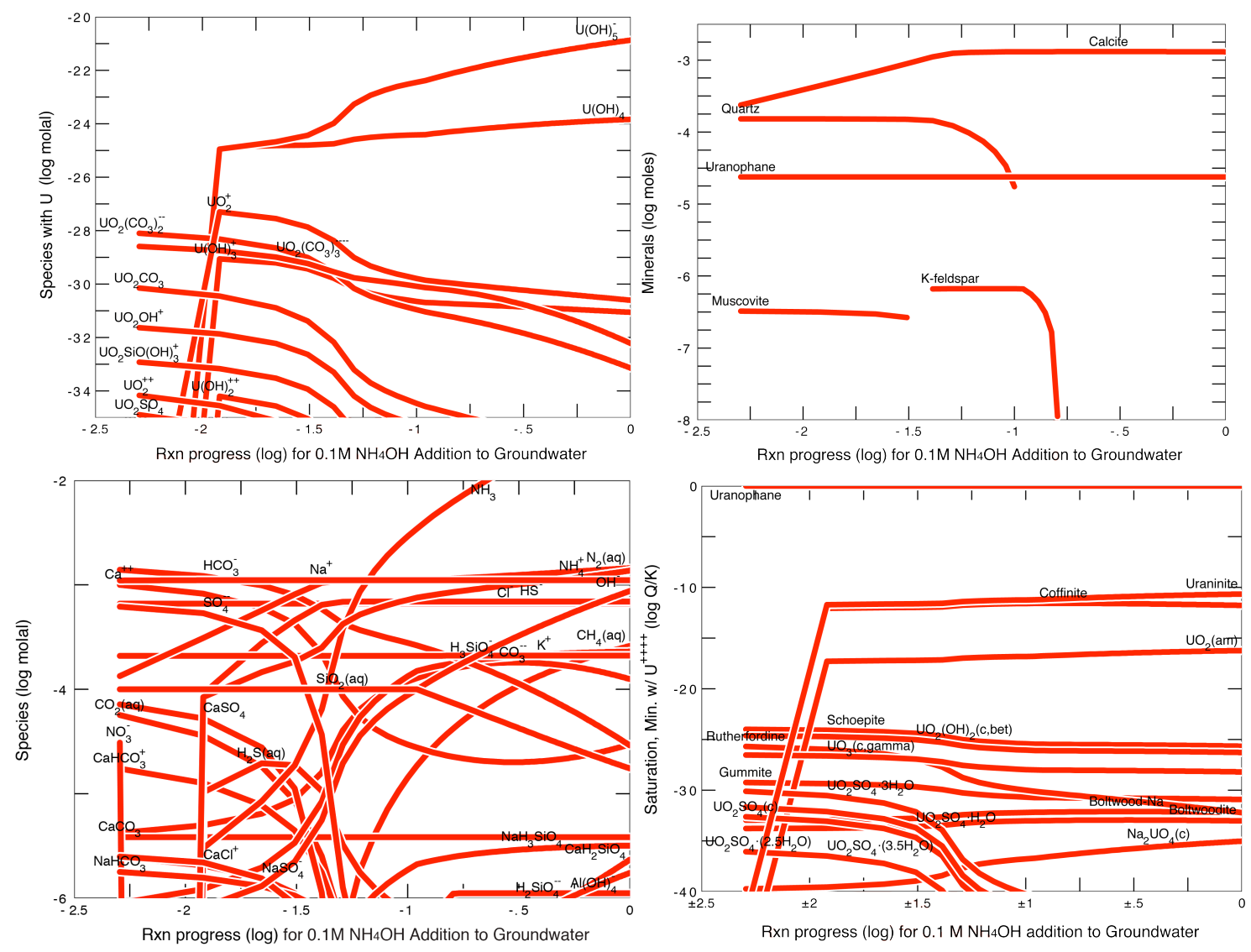

Figure 4.28. Predicted speciation of reaction of Hanford groundwater with $0.1 \mathrm{~mol} / \mathrm{L} \mathrm{NH}_{4} \mathrm{OH}$. Shown are (a) U aqueous species, (b) mineral phases, (c) major aqueous species, and (d) uranium mineral saturation index.

\subsubsection{Sequential Liquid Extractions to Estimate U Mobility}

Sequential liquid extractions were used as a measure of the changes in uranium surface phases for sediments that were treated with $\mathrm{NH}_{3}$ gas. Although liquid extractions characterize the aqueous and adsorbed phases well, precipitated uranium phases (carbonates, oxides, phosphates, silicates, etc.) are operationally defined by more aggressive liquids use, which dissolve one or more of these surface phases. Following is a description of the sequence used for liquid extractions during FY 2010:

1. Aqueous uranium by Hanford groundwater (or synthetic groundwater) for $1 \mathrm{~h}$

2. Ion exchangeable uranium by $0.5-\mathrm{M} \mathrm{Mg}\left(\mathrm{NO}_{3}\right)_{2}$ for $1 \mathrm{~h}$, which will be changed to a $0.01-\mathrm{M} \mathrm{Na}-\mathrm{CO}_{3}$ solution at $\mathrm{pH} 9.3$

3. Dissolution of a small portion of carbonates using Na-acetate at $\mathrm{pH} 5.0$ for $1 \mathrm{~h}$

4. Dissolution of most carbonates using acetic acid at $\mathrm{pH} 2.3$ for $120 \mathrm{~h}$, which also appears to dissolve hydrous silicates such as sodium-boltwoodite

5. Dissolution of various (iron, magnesium, aluminum) oxides by oxylic acid for $1 \mathrm{~h}$

6. Dissolution of some remaining hard-to-extract uranium phases using $8-\mathrm{M} \mathrm{HNO}_{3}$ at $95^{\circ} \mathrm{C}$ for $2 \mathrm{~h}$. 
Identification of the crystalline $U$ phases is described in the following section.

For ammonia gas injection into vadose zone sediments to be successful as a uranium remediation technology, it needs to show decreases $U$ mobility in a variety of field conditions including the following: a) different sediments (mineralogy), b) different $U$ surface phases, c) different $U$ concentration, d) presence of different co-contaminants, and e) possible to inject/react with a homogeneous/ heterogeneous sediment zone at a reasonably large scale. For the liquid extractions described in this section, the target is to cause a significant decrease in the most mobile $\mathrm{U}$ phases, namely, aqueous $\mathrm{U}$, adsorbed $\mathrm{U}$, and possibly the $\mathrm{pH} 5$ acetate extracted $\mathrm{U}$ (primarily $\mathrm{U}$ carbonates, some Na-boltwoodite).

Sequential reactions were tested on two U-bearing minerals: Na-boltwoodite $\left(\mathrm{Na}\left(\mathrm{UO}_{2}\right)\left(\mathrm{SiO}_{4}\right) * 1.5 \mathrm{H}_{2} \mathrm{O}\right)$ and $\mathrm{U}$-substituted carbonate. Na-boltwoodite $(409 \mathrm{~g} / \mathrm{mol})$ is $57.4 \%$ uranium by weight. The U-substituted carbonate has $<1 \% \mathrm{U}$ substitution. The $\mathrm{U}$-carbonate is expected to completely dissolve by the third (acetate) or fourth (acetic acid) extraction. Although Na-boltwoodite dissolves under alkaline conditions with excess carbonate (Ilton et al. 2006, Figure 2.5), it was not known how readily it dissolves under acidic conditions of the various extractions. Experimental data showed that Na-boltwoodite dissolves predominantly ( $84 \%$ of the $\mathrm{U}$ ) by the fourth (acetic acid pH 2.3) extraction (Figure 4.29), with some of the dissolution occurring in the $\mathrm{pH} 5$ acetate extraction $\# 3$ (13\% of $U$ mass). The specific Na-boltwoodite sample used (same crystals used in the Ilton et al. [2007] study) may not have been entirely pure Na-boltwoodite, as only $41.5 \%$ of the mass was $U$ (significantly less than the theoretical $57.4 \%$ ). The U-substituted carbonate (courtesy of D. Wellman, PNNL) mainly dissolved in the $\mathrm{pH} 5$ acetate extraction \#3 (84\% of U mass), and was completely dissolved by the $\mathrm{pH} 2.3$ acetic acid extraction \#4 (15\% of the U mass), as expected. These results are very useful as they show

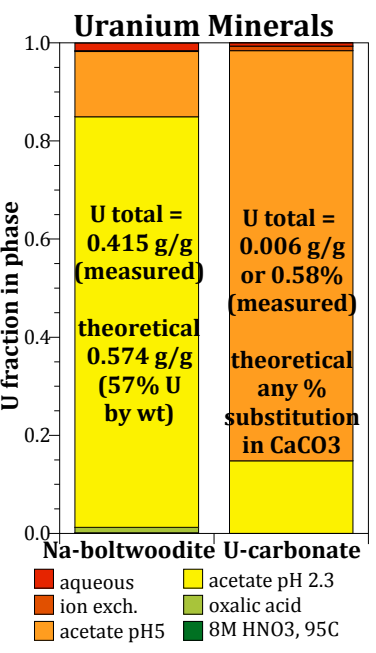

Figure 4.29. U Mineral dissolution. extractions \#3 (pH 5 acetate) and \#4 (pH 2.3 acetic acid) dissolve $U$ in carbonates as expected, but also dissolve Na-boltwoodite. Therefore, sediments that are known to contain high Na-boltwoodite concentration (BX-102, U105 sediments reported below) with high U mass in the acetic acid extraction is from the dissolution of Na-boltwoodite. Sequential extractions are also needed for uranophane.

Results of the sequential liquid extractions show that the ammonia gas treatment of sediment appears to reduce uranium mobility, but the extent to which this occurs is dependent mainly on the surface phases that uranium is initially present in. For the TX-104 sediment (mixed 69-ft and 110-ft depth, Figure 4.30), $\mathrm{U}$ has been previously identified as predominantly coprecipitates with calcite (Table 3.1). Sequential liquid extractions of this untreated sediment (Figure 4.30, left most bar in each series is for the untreated sediment) show $65 \%$ of the $U$ extracted is associated with carbonates (or other phases extracted with the acetic acid), and 15\% aqueous/adsorbed $U$ (most mobile phases), and $20 \%$ more recalcitrant phases. It should also be noted that there is likely additional mobile uranium leaching off the sediment as a result of diffusion of the more mobile phases out of sediment microfractures, so future extractions will include a 1000 -h carbonate (ion exchangeable) extraction. Ammonia gas treatment of the sediment initially at $5 \%$ water content over the course of a year (Figure 4.30a) shows a significant decrease in the most mobile $\mathrm{U}$ phases, and an increase in the hard-to-extract $\mathrm{U}$ phases (dark green, $8 \mathrm{M} \mathrm{HNO}_{3}$ ). 

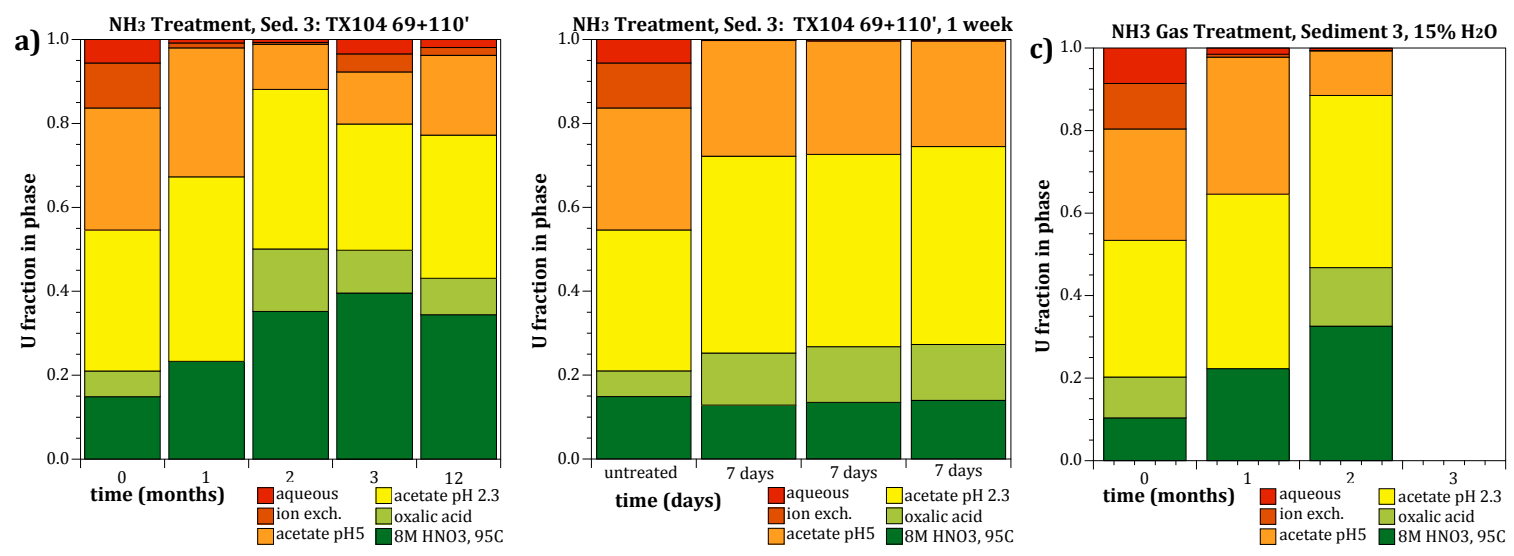

Figure 4.30. Sequential liquid extractions and $\mathrm{U}$ analysis for $\mathrm{NH}_{3}$-treated $\mathrm{TX}-104$ sediment, which contains primarily U coprecipitated with calcite. Initial water content is $4 \%$ for (a) and (b).
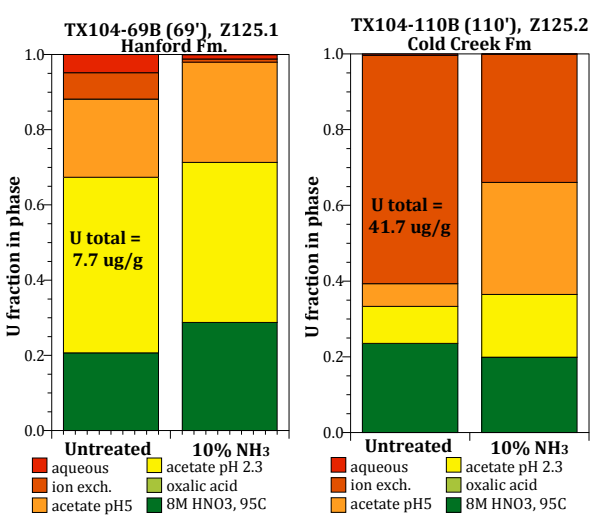

Figure 4.31. Sequential liquid extractions and $U$ analysis on TX-104 sediments from different depth.
Ammonia gas treatments were repeated at 1 month to confirm results (Figure 4.30b), and repeated at an initial water content of $15 \%$, all of which show similar results. $\mathrm{NH}_{3}$ gas treatments for 1 month also were conducted separately on sediments from the Hanford formation (69-ft depth) and Cold Creek formation (110-ft depth)

(Figure 4.31). The Hanford formation results were similar to those for the mixed sediment. The uranium distribution in the sediment from the Cold Creek formation had considerably more adsorbed uranium (high carbonate concentration in this sediment), but still showed decreased mobile uranium phases.

The BX-102 sediment (152-ft depth) has U primarily in Na-boltwoodite. Extraction \#4 (yellow bar, Figure 4.32; acetic acid, $\mathrm{pH}$ 2.3) contained the largest fraction of uranium. Separate liquid extractions with Na-boltwoodite do show a high fraction of the boltwoodite is dissolved in the acetic acid. Ammonia gas treatment of this sediment also appears to reduce mobile $U$ phases, as three times more $U$ is extracted with extraction \#6 $\left(8 \mathrm{M} \mathrm{HNO}_{3}\right)$. We hypothesize that the ammonia gas treatment is dissolving some of the Na-boltwoodite, as alkaline conditions lead to dissolution of this mineral phase (Figure 2.7). The ammonia gas treatment is not as effective for decreasing the total $\mathrm{U}$ mobility for this Na-boltwoodite compared with $\mathrm{U}$ associated with carbonates (Figure 4.30). Ammonia gas treatment for Na-boltwoodite may require more alkaline conditions (i.e., higher percentage of ammonia gas results in a higher pore water $\mathrm{pH}$ ) or the additional presence of carbonate (described in Section 4.6).

Other Hanford sediments from the IDF pit and BC Crib (Figure 4.33) show an unusual distribution of uranium initially present in the sediment (as a thin rind of $U$ associated with carbonate), although surface $\mathrm{U}$ phases have not been identified. Ammonia gas treatment showed mixed results, with slightly more mobile $\mathrm{U}$ for the IDF pit, and less mobile $\mathrm{U}$ for the $\mathrm{BC}$ crib sediment. The BC crib sediment was studied in greater detail in Section 4.8. 
It should be noted that while the distribution of $U$ in surface phases (adsorbed or crystalline) may primarily control how effective the ammonia gas treatment is, other factors such as sediment mineralogy and co-contaminants may also influence the outcome. While most sediments tested were in the Hanford formation with similar mineralogy (Table 3.2), the Cold Creek formation of the TX104 110-ft depth sample (Figure 4.33b) showed a significantly different initial U surface phase distribution. Mineralogy may play a significant role as one strong hypothesis for the reduction of $U$ mobility is $\mathrm{U}$ mineral phases are being coated by aluminosilicate precipitates, which may be from the dissolution of specific clays. In addition, cation and anion analysis of BC Crib sediments (see Section 4.8) show a high ionic strength of co-contaminants (Na-nitrate), which may influence the U surface phases. Certainly there should be less adsorbed $\mathrm{U}$, as other ions are displacing the U-carbonate anion complexes.

Ammonia gas treatment also was conducted on a series of sediment samples from U105 tank borehole C5602 (Figure 4.34). Untreated sediments are well characterized (Um et al. 2009), and have a high uranium concentration $(690 \mu \mathrm{g} \mathrm{U} / \mathrm{g})$ at a $52-\mathrm{ft}$ depth that is primarily sodiumboltwoodite (confirmed by LIFS). The concentration decreases to $\sim 30 \mu \mathrm{g} / \mathrm{g}$ at a depth of $67 \mathrm{ft}$, and the uranium is a mixture of uranium-silicates and uranium-carbonates, and then decreases to nearly background levels $(0.35 \mu \mathrm{g} / \mathrm{g})$ at a depth of $92 \mathrm{ft}$. The left-side panels in Figure 4.34 show the uranium extraction results for untreated sediment, and the right-side panels show the uranium extraction results after the sediment was treated with 40 pore volumes of $10 \% \mathrm{NH}_{3}$ for 1 month. At nearly all depths, a significant decrease in uranium mobility was observed, except the 67.8 -ft depth, which actually shows an increase in the uranium associated with a thin layer of carbonates. This series of extractions also shows a higher fraction of uranium surface phase change for the carbonate/adsorbed uranium and a smaller fraction for the sodiumboltwoodite (i.e., shallow two depths).
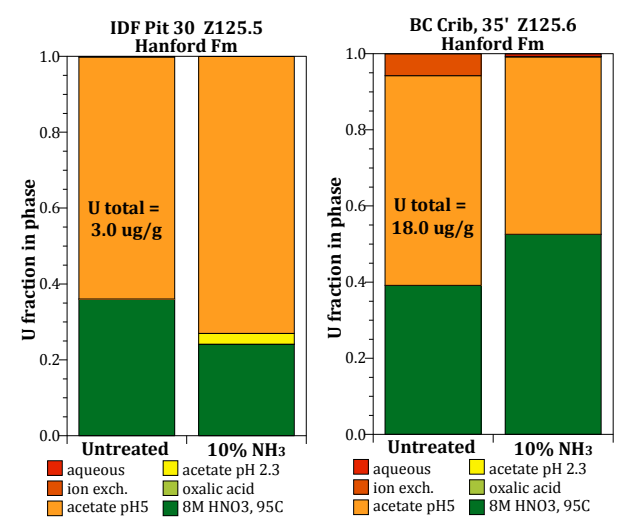

Figure 4.33. Sequential liquid extractions and $\mathrm{U}$ analysis on Hanford sediments that received $\mathrm{NH}_{3}$ treatment for 1 month. The U surface phases of these sediments are not characterized. 


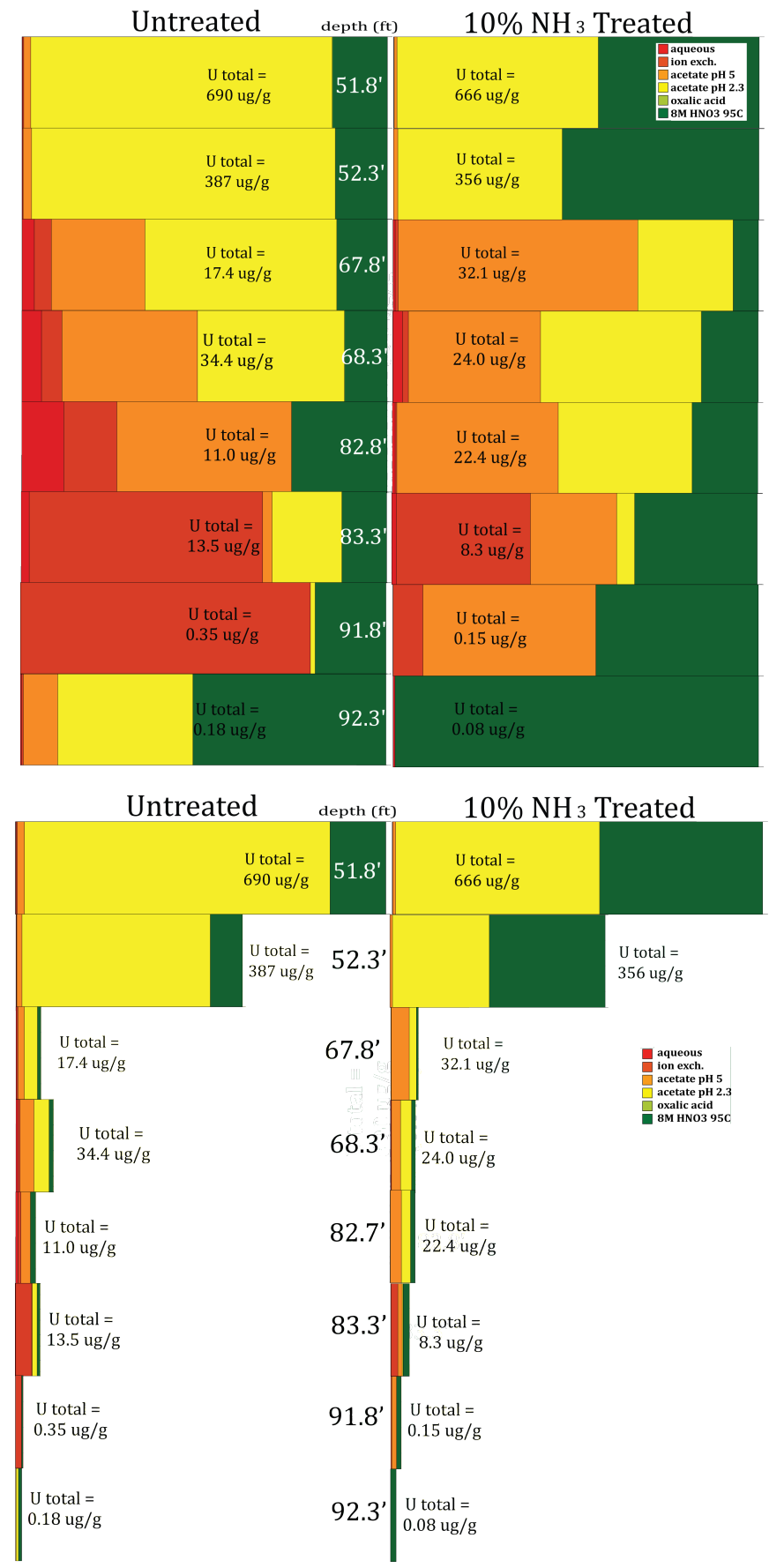

Figure 4.34. Sequential liquid extractions and $\mathrm{U}$ analysis on U105 sediments in borehole C5602 (depth listed) that received $\mathrm{NH}_{3}$ treatment for 1 month. This sediment contains $U$ primarily in Na-boltwoodite at 52-ft depth, U-carbonates at 60- to 70-ft depth. Upper bar graphs show percent $U$ in different phases; lower bar graph size is proportional to total $\mathrm{U}$ mass.
The same results are presented with the fraction $U$ phases proportional to the $\mathrm{U}$ fraction in the sample $(\mu \mathrm{g} / \mathrm{g}$ values listed, lower panels, Figure 4.34). These more clear emphasize that most of the uranium in the sediment is in the shallow sediment (as Na-boltwoodite), although deeper uranium is closer to groundwater. The intent of a future field treatment is to lower the risk of $U$ transport to groundwater, so deeper treatment of the lower concentration uranium may be the primary focus. The total uranium mass values reported for untreated and $\mathrm{NH}_{3}$-treated sediments (Figure 4.35) also show differences. Six sediments show less $U$ for treated sediments and two show greater U. There may be several different sources for this difference, including: a) small sediment sample size, b) $\mathrm{NH}_{3}$ gas treatment in columns advects some fines out of system, and c) reproducibility of the liquid extractions. For these extractions, 2 to $10 \mathrm{~g}$ samples were used, and small sample size results in greater variability. These sediments were treated in small 1-D columns, and during ammonia gas injection, some of the sediment fines are advected out of the column, resulting in less total U. Liquid extraction reproducibility is described later in this section (averages 11.2\% standard deviation).

The C5602 borehole sediment samples at differing depth covered a range of total U concentration from $0.18 \mu \mathrm{g} / \mathrm{g}$ to $690 \mu \mathrm{g} / \mathrm{g}$. As previously stated, high $\mathrm{U}$ concentration samples are generally Na-boltwoodite (or uranophane), moderate $U$ concentrations (10 to $100 \mu \mathrm{g} / \mathrm{g}$ ) have a large fraction of $U$ associated with carbonate, whereas low $\mathrm{U}$ concentration (natural $\mathrm{U},<10 \mu \mathrm{g} / \mathrm{g}$ ) are a mixture of aqueous/adsorbed, U-carbonates, and $\mathrm{U}$ in oxides/silicates. Ammonia gas treatment on sediments tested appear to show greater changes for low and moderate U concentrations, but less change for high $U$ concentrations (i.e., Na-boltwoodite). A plot of the 
fraction change relative to the total (Figure 4.35a) graphically shows some general trends. A second plot is the fraction change within each extraction (Figure 4.35b). Over a wide concentration range, aqueous $\mathrm{U}$ and adsorbed $\mathrm{U}$ decreased (top two plots) in $\sim 85 \%$ of cases. Concentrations with no data plotted had a zero concentration for that extraction in the untreated sample. This aqueous and adsorbed $U$ extraction data indicates these phases are being incorporated (or coated) by precipitates. The second obvious trend is the large increase in the $8 \mathrm{M} \mathrm{HNO}_{3}$ extraction for $79 \%$ of the samples over a wide concentration range. This extraction dissolves multiple surface phases, so it is not possible to understand what $U$ surface phase(s) is being precipitated. In addition, this data (i.e., an increase in this $8 \mathrm{M} \mathrm{HNO}_{3}$ extractable $\mathrm{U}$ ) is consistent with precipitation of non-U-bearing minerals (i.e., coatings) on existing $U$ surface phases. The acetate (both pH 5 and 2.3) extractions show mixed results, with both increases and decreases at all concentrations. As described earlier, acetic acid extractions dissolve multiple U phases including U-carbonates and Na-boltwoodite. In general, Na-boltwoodite is present in sediments with a high $(>100 \mu \mathrm{g} / \mathrm{g})$ total $\mathrm{U}$ concentration, and mixed $\mathrm{U}$ surface phases are present at lower U concentration (U solid phase identification described in Section 4.5.3). The two highest $U$ concentrations (386, $690 \mu \mathrm{g} / \mathrm{g}$ total U, Figure 4.35) show a decrease in both acetate extractions. Trends in individual extractions due to the $\mathrm{NH}_{3}$ treatment shown in Figure 4.35b (i.e., as a fraction change relative to each individual extraction for the untreated sediment) is grouped (Figure 4.36). There is no clear trend of
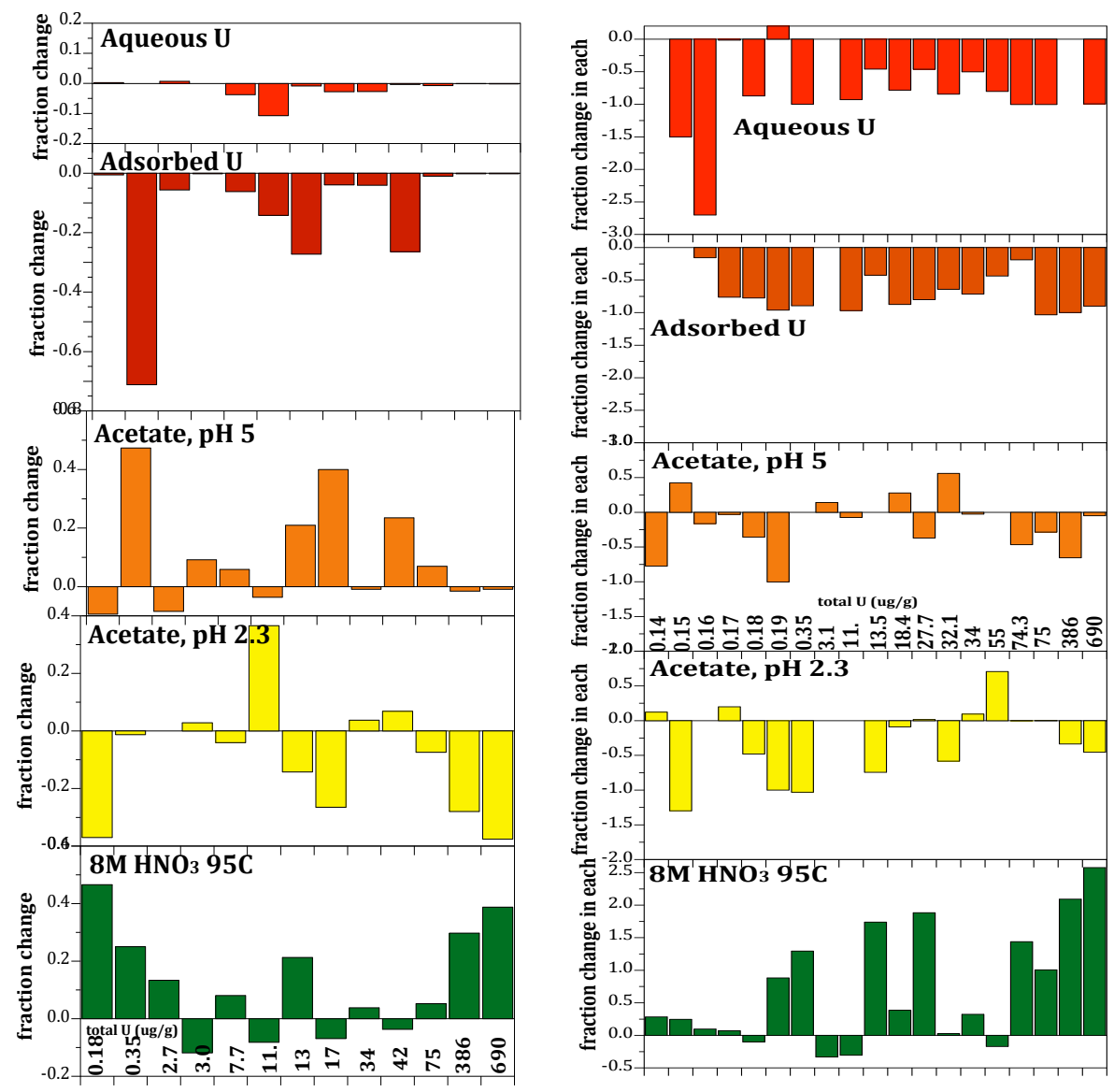

Figure 4.35. Fraction change in $U$ liquid extractions over $U$ concentration as a fraction of the total $\mathrm{U}(\mathrm{a})$ or fraction change in each extraction (b). 


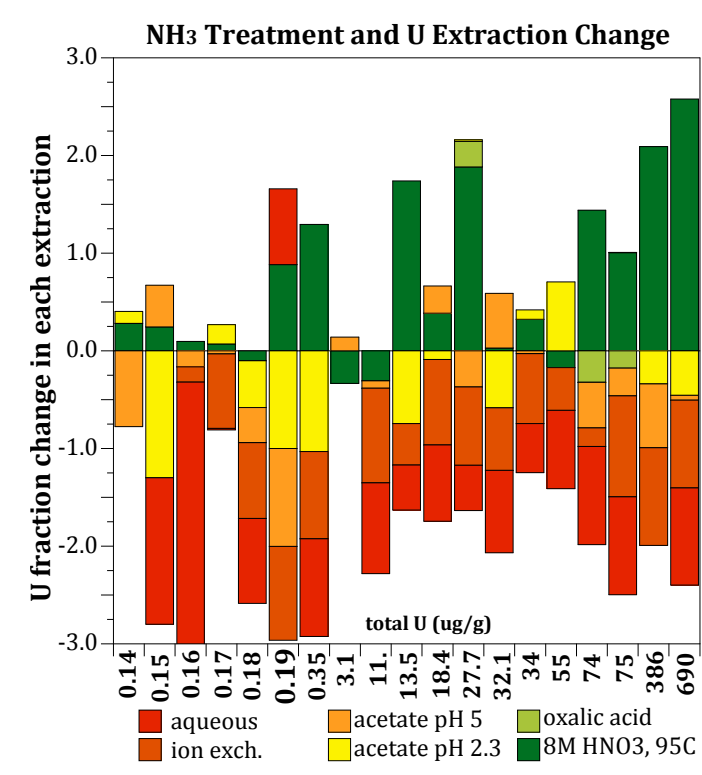

Figure 4.36. Fraction change in $U$ for each extraction. difference in treatment effect with total U concentration, even though the $U$ phases present at different concentration change (i.e., lowest $\mathrm{U}<10 \mu \mathrm{g} / \mathrm{g}$ is predominantly aqueous and adsorbed $\mathrm{U}$, mid concentrations are carbonate- $\mathrm{U}$ and aqueous/adsorbed $\mathrm{U}$, and the highest concentrations are generally Na-boltwoodite.

Two boreholes currently being cored at the $\mathrm{BC}$ Crib site (boreholes C7534, C7540) were characterized for uranium and Tc-99 contamination. Uranium contamination was characterized by three liquid extractions that included groundwater, acetate ( $\mathrm{pH} 5$ ), and the $8 \mathrm{M} \mathrm{HNO}_{3}$ for 15 samples in each borehole. Results showed very small amounts (background) of uranium at all depths (Figure 4.37). Tc-99 distribution with depth is reported in Section 4.11.

The reproducibility of the uranium liquid extractions was addressed with replicate extractions on four different samples (Table 4.3). Three different untreated sediments had three to six replicate extractions conducted and one $\mathrm{NH}_{3}$-treated sediment had three replicate extractions. The average standard deviation of all extractions was $11.2 \%$. The standard deviation of the total $U$ was $3.1 \%$.

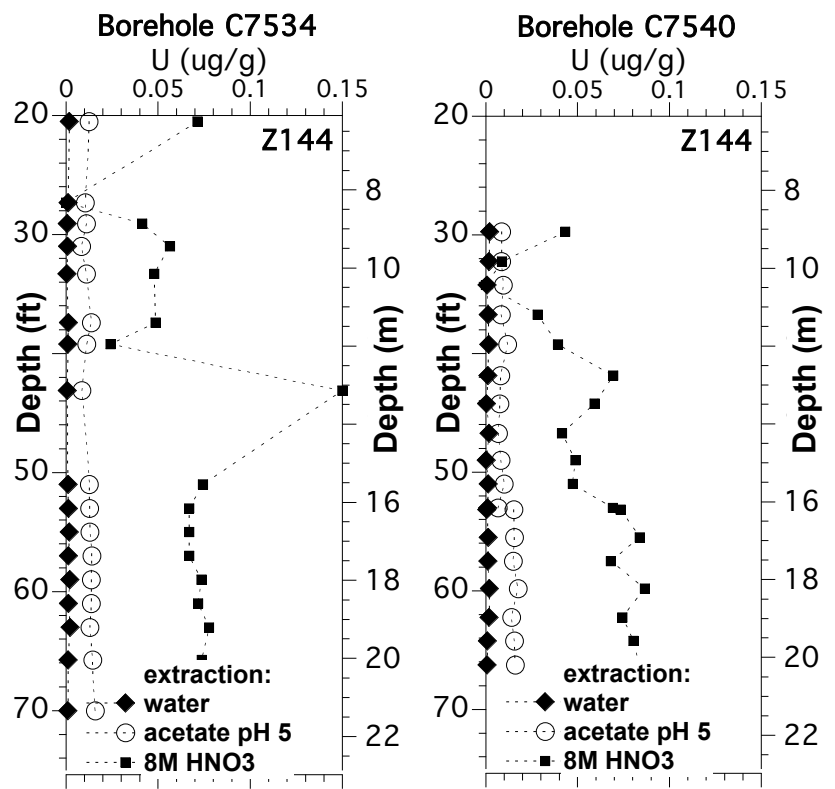

Figure 4.37. U characterization of $\mathrm{BC}$ Crib boreholes with groundwater, Na-acetate, and $8 \mathrm{M} \mathrm{HNO}_{3}$ liquid extractions.
Some extractions exhibited greater variability, which may reflect a differing fraction of $U$ surface phases dissolved in the short time of most extractions $(1 \mathrm{~h})$, and that the extraction time chosen may be insufficient. Extraction \#4 (acetic acid, pH 2.3, $120 \mathrm{~h}$ extraction time) had low variability (4.2\% standard deviation). In contrast,

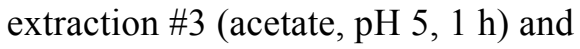
extraction \#5 (oxalic acid, $1 \mathrm{~h}$ ) had standard deviations of $8.1 \%$ and $11.1 \%$ respectively. The ion exchangeable $U$ extraction (\#2) had a standard deviation of $17.6 \%$. This extraction liquid is currently being changed from $0.5 \mathrm{M} \mathrm{Mg}\left(\mathrm{NO}_{3}\right)_{2}$ (standard extraction for cations/anions) to a $0.01 \mathrm{M} \mathrm{Na}$-carbonate (specific for uranium-carbonate complexes). Along with a $1 \mathrm{~h}$ extraction, a $1000 \mathrm{~h}$ extraction using this solution will be conducted with future extractions, which should show the influence of any kinetic-limited $\mathrm{U}$ desorption. The high standard deviation 
of the aqueous extraction (16.3\%) may also reflect kinetic limitations of immobile pore water. Finally, the $8 \mathrm{M} \mathrm{HNO}_{3}$ extraction $(2 \mathrm{~h})$ had an $18.2 \%$ standard deviation.

Table 4.3. Uranium liquid extraction reproducibility.

\begin{tabular}{lcccccccc} 
Sediment & $\begin{array}{c}\text { number } \\
\text { of samples }\end{array}$ & $\begin{array}{c}\text { total U } \\
\text { (ug/g) }\end{array}$ & $\begin{array}{c}\text { Extr. \#1 } \\
\text { (ng/g) }\end{array}$ & $\begin{array}{c}\text { Extr. \#2 } \\
\text { (ng/g) }\end{array}$ & $\begin{array}{c}\text { Extr. \#3 } \\
\text { (ng/g) }\end{array}$ & $\begin{array}{c}\text { Extr. \#4 } \\
\text { (ng/g) }\end{array}$ & $\begin{array}{c}\text { Extr. \#5 } \\
\text { (ng/g) }\end{array}$ & $\begin{array}{c}\text { Extr. \#6 } \\
\text { (ng/g) }\end{array}$ \\
\hline 1, untreated & 3 & $376.6 \pm 6.15$ & $5731 \pm 672$ & $3897 \pm 480$ & $10443 \pm 920$ & $301400 \pm 4169$ & $30821 \pm 72.1$ & $24340 \pm 5780$ \\
2, untreated & 5 & $74.34 \pm 2.32$ & $929 \pm 61.4$ & $781.7 \pm 38.4$ & $2716 \pm 261$ & $55540 \pm 2086$ & $10362 \pm 1004$ & $4012 \pm 529$ \\
3, untreated & 6 & $28.14 \pm 1.75$ & $2051 \pm 435$ & $3027 \pm 312$ & $7835 \pm 817$ & $9466 \pm 924$ & $2230 \pm 649$ & $3541 \pm 1070$ \\
3, 1 week NH3 & 3 & $23.23 \pm 0.34$ & $57.1 \pm 14.6$ & $1.93 \pm 0.83$ & $6189 \pm 228$ & $10831 \pm 228$ & $3024 \pm 160$ & $3129 \pm 174$ \\
\hline std deviation (\%) & all & 3.12 & 16.3 & 17.6 & 8.1 & 4.2 & 11.1 & 18.2 \\
\hline \multicolumn{7}{c}{ * some additional variability due to different water contents used } \\
average deviation of liquid extractions: $11.2 \%$
\end{tabular}

\subsubsection{Solid Phase Analysis}

The liquid extractions described in the previous section directly characterize aqueous and adsorbed uranium, but amorphous and/or crystalline $U$ phases are operationally characterized by the remaining four liquid extractants. Because multiple $U$ phases are present, a single liquid extractant can dissolve one or more U minerals (example: U substituted carbonate and Na-boltwoodite are both dissolved by both of the acetate extractions). In addition, some secondary mineral phases on sediment coat primary mineral phases, and extractant liquids may not be able to dissolve the secondary phase even though it should dissolve the primary phase (example, a phosphate or silicate coating on carbonate). Several different techniques were used to characterize $U$ solid phases including electron microprobe (described in Section 4.4.5), scanning electron microscope, X-ray fluorescence, and XANES/EXAFS. At low uranium concentrations, none of these techniques could identify mineral phases, so sediment samples used tended to have high $\mathrm{U}$ concentration, which was generally uranium present as Na-boltwoodite. A typical $\mathrm{U}$ vertical profile in sediment (U105, Figure 4.26, 4.38) was high $(>100 \mu \mathrm{g} / \mathrm{g}) \mathrm{U}$ in shallow sediment as uranophane/ Na-boltwoodite, somewhat more mobile $U$ present associated with carbonates (lower $20-100 \mu \mathrm{g} / \mathrm{g}$ ), then the most mobile $\mathrm{U}$ present at the greatest depth as a mixture of multiple phases including aqueous and adsorbed $U$ (and $<30 \mu \mathrm{g} / \mathrm{g}$ ). Although the bulk of the $\mathrm{U}$ contamination is Na-boltwoodite, it is also the least mobile, so $\mathrm{NH}_{3}$ treatments are focused on all different U surface phases.
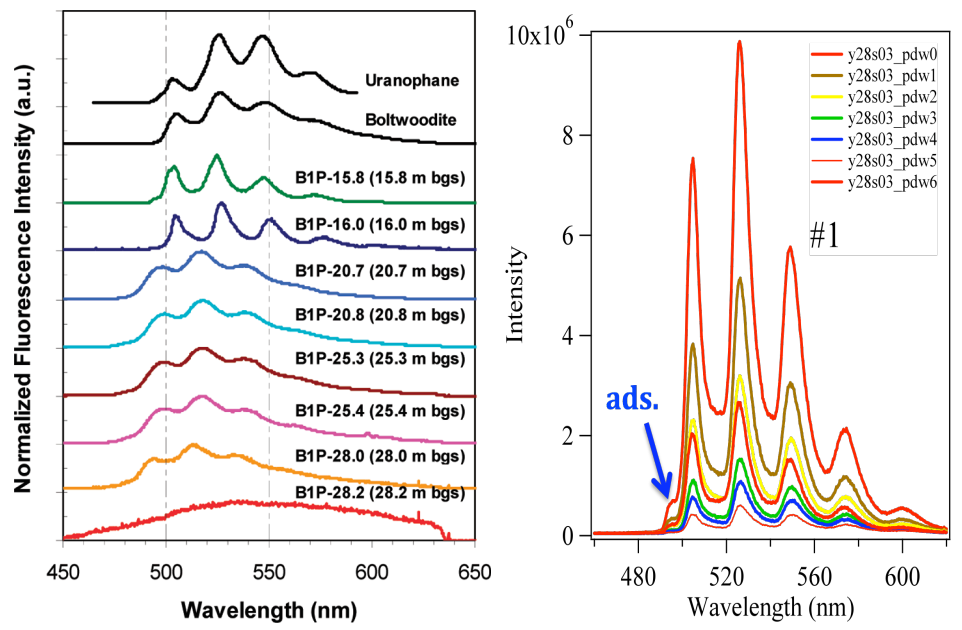

Figure 4.38. $\mathrm{X}$-ray fluorescence of untreated and $\mathrm{NH}_{3}$-treated C5602, 52.3-ft sediment. 


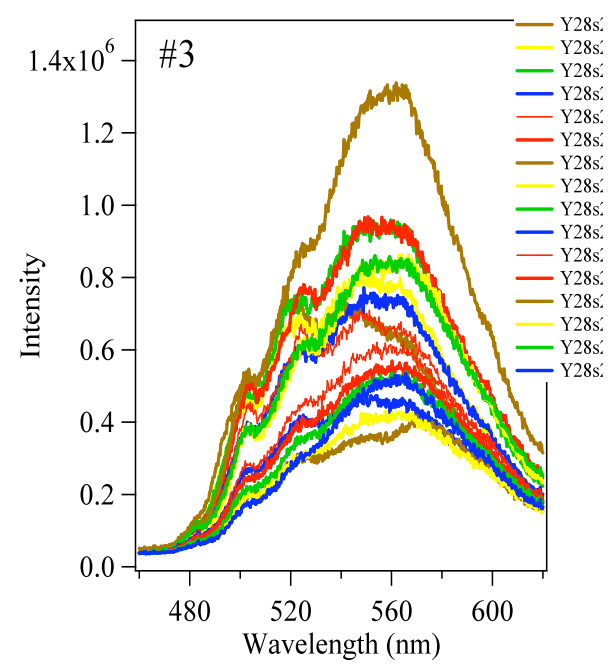

Figure 4.39. X-ray fluorescence of $\mathrm{NH}_{3}$-treated C5602, 52.3-ft sediment.
Fluorescence scans (LIFS) were conducted on three different sediments. The first sediment was the U105 sediment from borehole C5602, 52.3-ft depth $(690 \mu \mathrm{g} / \mathrm{g} \mathrm{U}$, Na-boltwoodite). The untreated sediment scan (green line, Figure 4.38a) does show primarily Na-boltwoodite. The $\mathrm{NH}_{3}$-treated sediment (40 pore volumes of $100 \% \mathrm{NH}_{3}$ ) also shows primarily Na-boltwoodite, but with some adsorbed $\mathrm{U}$ (Figure 4.38b).

Fluorescence scans (LIFS) on the TX104, $110 \mathrm{ft}$ (Cold Creek Fm) sediment was also conducted on the untreated and $\mathrm{NH}_{3}$-treated sediment. This sediment has $\mathrm{U}$ primarily as U-calcite coprecipitate (at $55 \mu \mathrm{g} / \mathrm{g}$, Table 2.1), as confirmed by XRF on the untreated sediment (not shown). The ammonia-treated sediment (Figure 4.39) shows uranyl oxyhydroxide, small boltwoodite/uranophane, and uranyltricarbonate, or a mixture of U surface phases.
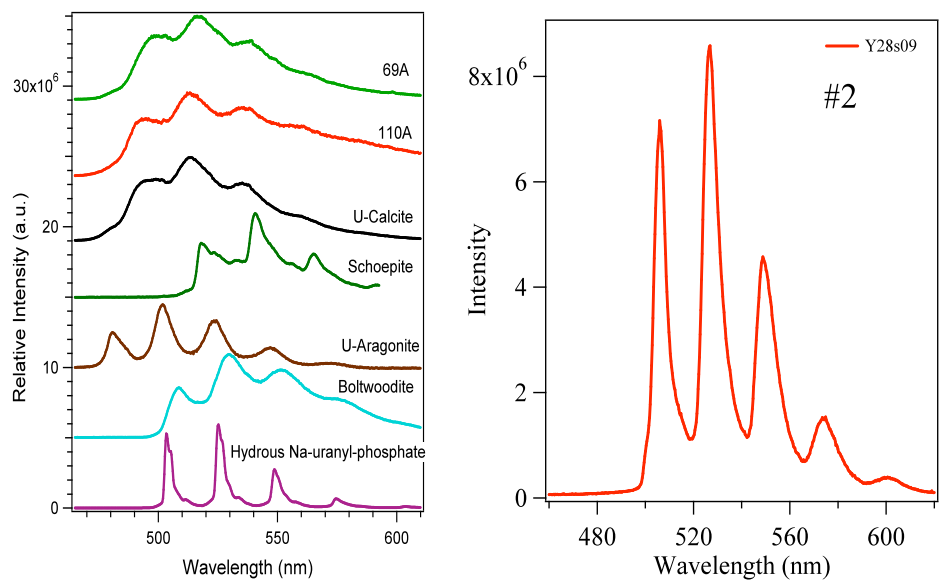

Figure 4.40. $\mathrm{X}$-ray fluorescence of untreated and $\mathrm{NH}_{3}$-treated TX-104, 152-ft depth sediment.
Finally, fluorescence scan (LIFS) of the untreated BX-102, 152-ft depth sediment $(28 \mu \mathrm{g} / \mathrm{g})$ shows primarily uranophane and Na-boltwoodite (Figure 4.40a). Fluorescence scans of the $\mathrm{NH}_{3}$ treated sediment is completed (Figure 4.40b) and interpretation is in progress. Preliminary analysis shows primarily Na-boltwoodite.

\section{Additional analysis was} conducted on the C5602 (52.3-ft depth) untreated and $\mathrm{NH}_{3}$-treated sediment to identify changes in

U solid phases that included XANES, and EXAFS analysis conducted by John Bargar at the Stanford Linear Accelerator. X-ray near edge structure (XANES) is used to identify the U valence state [i.e., fraction $\mathrm{U}(\mathrm{VI})$ and $\mathrm{U}(\mathrm{IV})$ ], whereas the extended x-ray adsorption structure (EXAFS) is used to identify the elements that $U$ is associated with (i.e., carbonates, silicates, oxides). The treated sediment sample received 40 pore volumes of $100 \%$ ammonia gas treatment. This sample was chosen due to the high uranium content $(690 \mu \mathrm{g} / \mathrm{g})$, and most was previously identified as Na-boltwoodite, as described above. Preliminary analysis of the scans (Figure 4.41) show little to no change in the EXAFS by the $\mathrm{NH}_{3}$ treatment, so there is little change in the local molecular structure around U. Changes in the $\mathrm{U}$ release rates from sediment (as shown by sequential liquid extractions) may be due to changes in porosity, or coating by other precipitates on top of the U mineral phases. Additional EXAFS/XANES analysis will be conducted on $\mathrm{NH}_{3}$-treated sediment that received higher treatment (and possibly on U minerals). 


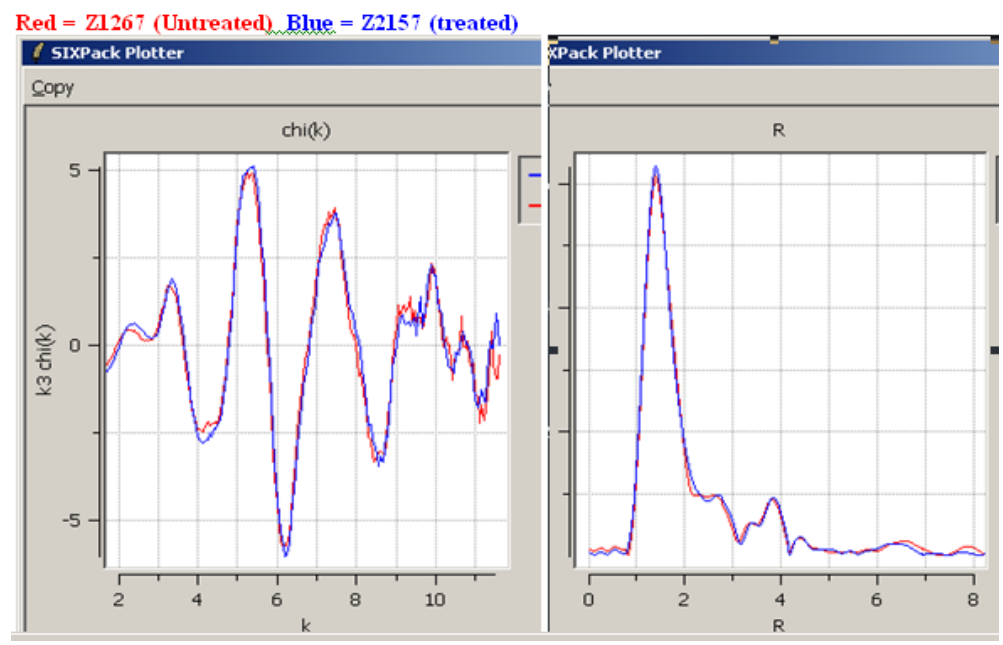

Figure 4.41. XANES/EXAFS analysis on untreated (red) and $\mathrm{NH}_{3}$-treated (blue) $\mathrm{C} 5602,52.3$-ft depth sediment.

\subsection{Mixed Ammonia/Carbon Dioxide Gas Treatments}

Sequential and parallel mixed-gas treatments were evaluated for two different purposes: 1) $\mathrm{pH}$ neutralization after $\mathrm{NH}_{3}$ gas treatment, and 2) increased sodium-boltwoodite dissolution during $\mathrm{NH}_{3}$ gas treatment. $\mathrm{NH}_{3}$ gas treatment elevates the $\mathrm{pH}$ of the sediment pore water, leading to mineral phase dissolution and precipitation. If a high concentration of $\mathrm{NH}_{3}$ gas is used and the gas is not flushed from the system, the $\mathrm{pH}$ remains elevated for months (Figure 4.6), and then gradually decreases. Alternatively, if the $\mathrm{NH}_{3}$ gas is flushed with air $\left(3 \% \mathrm{CO}_{2}\right)$, the $\mathrm{pH}$ drops more rapidly, as shown in Figure 4.12c. Experiments were conducted in which air $\left(3 \% \mathrm{CO}_{2}\right)$ or $100 \% \mathrm{CO}_{2}$ was used as secondary gas treatment after the $\mathrm{NH}_{3}$ had reacted with the sediment pore water for 1 month. Our hypothesis for evaluating mixed $\mathrm{NH}_{3} / \mathrm{CO}_{2}$ treatments is that sodium-boltwoodite dissolves to a greater extent under alkaline conditions with higher carbonate concentration, as shown in aqueous systems in a previous study (Ilton et al. 2006, Figure 2.6).

Sequential $\mathrm{NH}_{3}$ gas, then air or $\mathrm{CO}_{2}$ gas treatments were conducted in a series of batch experiments with a BC crib subsurface sediment from borehole C7534 (52-ft depth), which contains a moderate concentration of technetium-99 (results reported in Section 4.11) and a low uranium concentration (no Na-boltwoodite). The experiments are designed to evaluate a different $\mathrm{NH}_{3}$ treatment (called treatment 1 , Table 4.4), and a different $\mathrm{CO}_{2}$ treatment (called treatment 2).

To date, only some experiments are completed. The influence of the differing ammonia treatment (i.e., none, 100 pore volumes of $5 \%, 1000$ pore volumes of $5 \%$, and 1000 pore volumes of $100 \% \mathrm{NH}_{3}$ ) shows only minor differences in treatment (Figure 4.42). The high ammonia mass treatments had less ion exchangeable $\mathrm{U}$, but a greater mass of acetate-extractable $\mathrm{U}$. The total $\mathrm{U}$ mass was very low $(0.15 \mu \mathrm{g} / \mathrm{g}$ or less), so near detection limits. This sediment contains significant concentrations of co-contaminants (described below and in Section 4.8). The sediment contained a moderate amount of Tc-99 (570 pCi/g), and as described in Section 4.11, these ammonia treatments (to date, data for secondary treatment not available) showed little change in Tc mobility. A second series of sequential gas treatments were conducted, but with mixed gasses for the first treatment (described below). 
The use of different mixtures of ammonia and carbon dioxide gas were investigated to a limited extent in batch experiments to determine if uranium surface phases were better immobilized by the presence of the carbon dioxide, based on two reasons. First, Na-boltwoodite is dissolved more quickly under alkaline conditions in the presence of excess carbonate (Figure 2.6), so differing parallel $\mathrm{NH}_{3} / \mathrm{CO}_{2}$ treatments were conducted. Second, $\mathrm{CO}_{2}$ should neutralize $\mathrm{pH}$ more quickly (as a secondary gas treatment after the initial $\mathrm{pH}$ increase from $\mathrm{NH}_{3}$ ), so sequential $\mathrm{NH}_{3}$, then $\mathrm{CO}_{2} /$ air treatments were conducted. Experiments were conducted with $5 \% \mathrm{NH}_{3}$ and either $95 \%$ air $\left(3 \% \mathrm{CO}_{2}\right)$ or $95 \% \mathrm{CO}_{2}$ (Table 4.5) for $200 \mathrm{~h}$. Sediments were initially at $4 \%$ water content. Additional experiments (i.e., treatment 2) was then conducted with $100 \%$ air or $100 \% \mathrm{CO}_{2}$.

Table 4.4. Sequential gas treatments for $U$ and Tc-99.

\begin{tabular}{|c|c|c|}
\hline \# & Treatment 1 & Treatment 2 \\
\hline$Z 162$ & $\begin{array}{c}\text { none } \\
\end{array}$ & none \\
\hline$\overline{\mathrm{Z163}}$ & $5 \% \mathrm{NH} 3 / 95 \% \mathrm{~N} 2 \times 100$ pore vol., 1 month & none \\
\hline Z164 & $5 \% \mathrm{NH} 3 / 95 \% \mathrm{~N} 2 \times 100$ pore vol., 1 month & $100 \%$ air x 100 pore vol., 1 month \\
\hline Z165 & $5 \% \mathrm{NH} 3 / 95 \% \mathrm{~N} 2 \times 100$ pore vol., 1.5 month & $100 \%$ CO2 $\times 100$ pore vol., 1 month \\
\hline$\overline{Z 166}$ & $5 \% \mathrm{NH} 3 / 95 \% \mathrm{~N} 2 \times 1000$ pore vol., 1 month & none \\
\hline Z167 & $5 \% \mathrm{NH} 3 / 95 \% \mathrm{~N} 2 \times 1000$ pore vol., 1 month & $100 \%$ air x 100 pore vol., 1 month \\
\hline Z168 & $5 \% \mathrm{NH} 3 / 95 \% \mathrm{~N} 2 \times 1000$ pore vol., 1.5 month & $100 \%$ CO $2 \times 100$ pore vol., 1 month \\
\hline$\overline{\mathrm{Z} 169}$ & $100 \%$ NH3 x 1000 pore vol., 1 month & none \\
\hline $\mathrm{Z} 170$ & $100 \%$ NH3 $\times 1000$ pore vol., 1 month & $100 \%$ air x 100 pore vol., 1 month \\
\hline Z171 & $100 \%$ NH3 x 1000 pore vol., 1.5 month & $100 \%$ CO2 x 100 pore vol., 1 month \\
\hline
\end{tabular}

initial moisture content $2.5 \%$

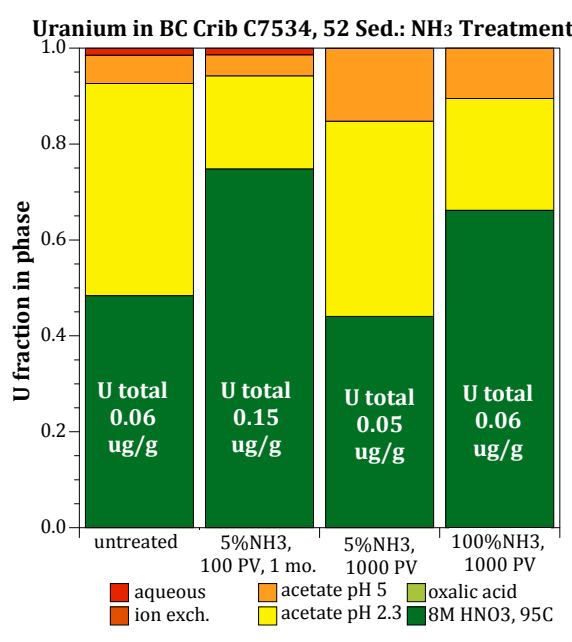

Figure 4.42. Sequential gas treatments showing $\mathrm{U}$ extractions just after $\mathrm{NH}_{3}$ treatment.
The use of different mixtures of ammonia and carbon dioxide gas were investigated to a limited extent in batch experiments to determine if uranium surface phases were better immobilized by the presence of the carbon dioxide. The basis for conducting these experiments was that Na-boltwoodite is dissolved more quickly under alkaline conditions in the presence of excess carbonate (Figure 2.6). Experiments were conducted with $5 \% \mathrm{NH}_{3}$ and either $95 \%$ air $\left(3 \% \mathrm{CO}_{2}\right)$ or $95 \% \mathrm{CO}_{2}$ (Table 4.5 ) for $200 \mathrm{~h}$. Sediments were initially at $4 \%$ water content. Additional experiments (i.e., treatment 2) was then conducted with $100 \%$ air or $100 \% \mathrm{CO}_{2}$.

The sediment chosen for these experiments (BC crib sediment from $\mathrm{C} 7534,52-\mathrm{ft}$ depth), had a low total $\mathrm{U}$ content $(0.15 \mu \mathrm{g} / \mathrm{g})$, which is likely a mixture of natural surface phases and does not contain Na-boltwoodite. This sediment is also has a high ionic strength likely from co-contaminants (see Section 4.11), which may have advected aqueous and adsorbed $U$ to greater depth. Results after the initial treatment (i.e., treatment 1 in Table 4.5) show nearly identical $U$ surface phases for $\mathrm{NH}_{3}$ /air mixture (Figure 4.43), but more aqueous and adsorbed $\mathrm{U}$ for the $\mathrm{NH}_{3} / \mathrm{CO}_{2}$ mixed gas, which is expected, based on previous 
results with $100 \% \mathrm{CO}_{2}$ treatment (see Figure 4.1). Cations present in the pore water include $400 \mathrm{mmol} / \mathrm{L}$ $\mathrm{Na}^{+}$and $500 \mathrm{mmol} / \mathrm{L} \mathrm{Mg}^{2+}$. Anions include $2 \mathrm{~mol} / \mathrm{L}$ nitrate and $0.6 \mathrm{~mol} / \mathrm{L}$ sulfate (see Section 4.11). These very high ion concentrations create unusual pore water conditions, so uranium surface phase changes that take place in more natural conditions may not occur.

Table 4.5. Mixed gas treatments for U surface phase change.

\begin{tabular}{cll}
$\#$ & \multicolumn{1}{c}{ Treatment 1 } & \multicolumn{1}{c}{ Treatment 2} \\
\hline $\mathrm{Z} 180.1$ & \multicolumn{1}{c}{ none } & \multicolumn{1}{c}{ none } \\
\hline $\mathrm{Z} 180.25 \% \mathrm{NH} 3 / 95 \%$ air $\times 50$ pore vol., $200 \mathrm{~h}$ & none \\
$\mathrm{Z} 180.35 \% \mathrm{NH} 3 / 95 \%$ CO2 $\times 100$ pore vol., $200 \mathrm{~h}$ & none \\
\hline $\mathrm{Z} 181.15 \% \mathrm{NH} 3 / 95 \%$ air $\times 50$ pore vol., $200 \mathrm{~h}$ & $100 \%$ air $\times 50$ pore vol., $200 \mathrm{~h}$ \\
$\mathrm{Z} 181.25 \% \mathrm{NH} 3 / 95 \%$ air $\times 50$ pore vol., $200 \mathrm{~h}$ & $100 \%$ CO2 $\times 50$ pore vol., $200 \mathrm{~h}$ \\
\hline $\mathrm{Z} 181.35 \% \mathrm{NH} 3 / 95 \% \mathrm{CO} 2 \times 100$ pore vol., $200 \mathrm{~h}$ & $100 \%$ air $\times 50$ pore vol., $200 \mathrm{~h}$ \\
$\mathrm{Z} 181.45 \% \mathrm{NH} 3 / 95 \% \mathrm{CO} 2 \times 100$ pore vol., $200 \mathrm{~h}$ & $100 \% \mathrm{CO} 2 \times 50$ pore vol., $200 \mathrm{~h}$ \\
\hline
\end{tabular}
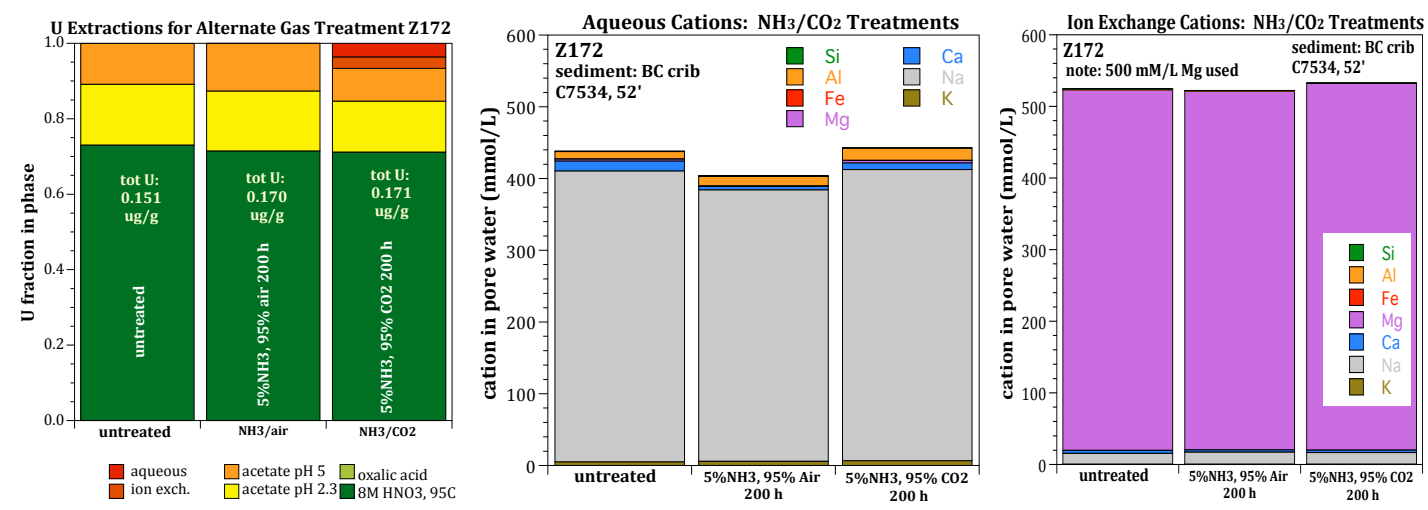

Figure 4.43. Results of mixed gas treatments with: a) U extractions, b) aqueous cations, and c) adsorbed cations.

After $200 \mathrm{~h}$ of the mixed gas treatments (Table 4.5), a second treatment of either air $\left(3 \% \mathrm{CO}_{2}\right)$ or $100 \% \mathrm{CO}_{2}$ was flushed through vials (after vacuum to remove the ammonia/ $\mathrm{CO}_{2}$ mixed gas). Although these treatments were of short time interval, treatments that contained high carbon dioxide in either treatment 1 or 2 resulted in a large increase in aqueous and adsorbed $U$ (Figure 4.44), which indicates that $\mathrm{U}$ surface phases present (likely $\mathrm{U}$ associated with carbonates) were solubilized to some extent with the additional pore water carbonate from the $\mathrm{CO}_{2}$ gas. It is likely that additional time with $\mathrm{pH}$ neutralization would result in precipitation of the uranium surface phases, as shown with $100 \% \mathrm{CO}_{2}$ treatment over the long term (Figure 4.1).

With just carbon dioxide treatment for 1 month, then flushing with air (Figure 4.1e), the pH was slightly acidic (PNNL-18879, Szecsody et al. 2010, Figure 4.7) at pH 5.5, and U surface phases were mobile after 1 month, yet precipitated after 2 and 3 months to show a U surface phase distribution of less mobile surface phases compared with untreated sediment. The increased $U$ mobilization after a short period of time shown in these current mixed gas treatments show similar short term U mobilization, but 


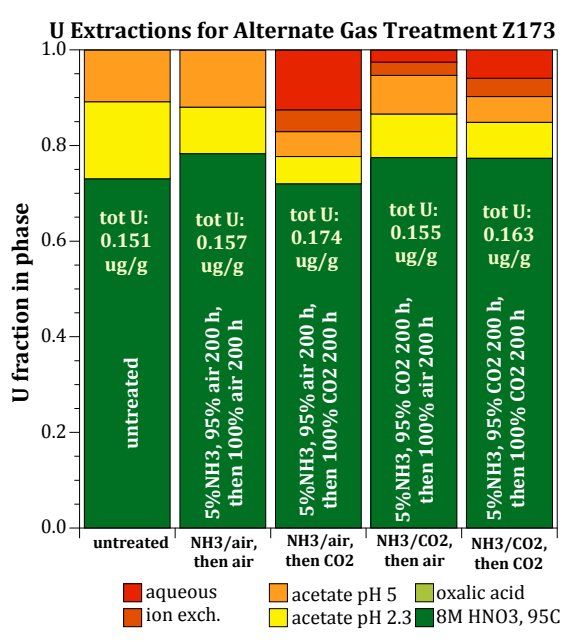

Figure 4.44. Sequential gas treatments showing: a) $U$ extractions just after $\mathrm{NH}_{3}$ treatment, and b) sequential treatments of differing gasses. under alkaline conditions created by the ammonia. Future experiments will focus on mixed $\mathrm{NH}_{3} / \mathrm{CO}_{2} / \mathrm{N}_{2}$ treatments followed by longer term treatment with air or $\mathrm{N}_{2}$ in order to evaluate precipitates that form.

\subsection{Influence of $\mathrm{NH}_{3}$ Gas Advection on Geochemical Changes: 1-D Columns}

To upscale batch results to field advective systems, five 20-ft long and one 30-ft long 1-D column experiments were conducted primarily to evaluate ammonia gas reactivity during advection, to compare to previous batch studies. The focus of these 1-D columns included: a) fraction of ammonia gas injected and reaction front advance, b) rate of ammonia gas injection and reaction front advance, and c) desiccation front advance. The fraction of ammonia gas was varied from $100 \%$ to $5 \%$ (most experiments) to $1 \%$, with nitrogen as the inert gas. Both gasses were anhydrous. Gas injection rates were chosen based on an analysis of rates that would occur at field scale (Figure 4.45). Assuming cylindrical injection in a 15 -ft vertical section, while velocities decrease with distance from the well, a 100- to 1000-liter/h injection rate gives interstitial velocities of 10 to $1000 \mathrm{~cm} / \mathrm{min}$ at a 5- to 15-ft radius. Therefore, 1-D column experiments injecting $5 \% \mathrm{NH}_{3}$ were conducted at 11.3 to $2200 \mathrm{~cm} / \mathrm{min}$ (Table 4.6).

Most 1-D columns were conducted where the $\mathrm{NH}_{3}$ gas was injected only part way through the column so that the reactivity (ammonia gas

concentration, $\mathrm{pH}$, electrical conductivity) ahead, at, and behind the observed reaction front could be quantified. One $30-\mathrm{ft}$ long column was initially conducted with $100 \%$ ammonia gas injection. The reaction front was clearly visible (Figure 4.46a), which results from very rapid ammonia gas partitioning into the pore water along a sharp reaction front (with some water vapor produced). In contrast, injection of 5\% ammonia results in a more diffuse front (also in Figure 4.46a), which is similar to the difference between bubbling $100 \%$ versus $5 \% \mathrm{NH}_{3}$ into a beaker of water (Figure 4.5 ). The exothermic reaction resulted in a $30^{\circ} \mathrm{C}$ temperature rise (Figure 4.46b), compared with a $4^{\circ} \mathrm{C}$ temperature rise for $5 \% \mathrm{NH}_{3}$ injection. For this 1-D experiment, the ammonia gas was injected until it reached the outlet, so the $\mathrm{pH}$ of the sediment was close to uniform (Figure $4.46 \mathrm{c}$ ). 
Table 4.6. $\mathrm{NH}_{3}$ mass balance in 1-D columns.

\begin{tabular}{lccccccccc} 
& $\begin{array}{c}\text { total } \\
\text { length (ft) }\end{array}$ & \%NH3 & $\begin{array}{c}\text { final } \\
\text { velocity } \\
\text { (cm/min) }\end{array}$ & $\begin{array}{c}\text { final } \\
\text { reaction } \\
\text { front (cm) }\end{array}$ & $\begin{array}{c}\text { desiccation } \\
\text { front (cm) }\end{array}$ & $\begin{array}{c}\text { final } \\
\text { pH }\end{array}$ & $\begin{array}{c}\text { NH3 } \\
\text { inj. (mol) }\end{array}$ & $\begin{array}{c}\text { NH3 in } \\
\text { sed. (mol) }\end{array}$ & $\begin{array}{c}\text { NH3 moles } \\
\text { in/out }\end{array}$ \\
\hline Z130p & 1.6 & 5 & 9.64 & 1.5 & -- & 11.41 & 0.012 & 0.011 & 1.12 \\
Z131 & 20 & 5 & 960 & 11.00 & 0.52 & 11.36 & & & \\
Z131A & 20 & 5 & 953 & 16.79 & 0.43 & 11.45 & 2.16 & 3.35 & 0.643 \\
Z132 & 20 & 5 & 127 & 13.2 & 0.35 & 11.21 & 1.29 & 1.52 & 0.851 \\
Z133 & 20 & 2.2 & 2196 & 13.8 & 0.27 & 11.45 & 2.8 & 2.76 & 1.02 \\
Z134 & 20 & 5 & 11.3 & 3.70 & -- & 11.24 & 0.36 & 0.456 & 0.789 \\
\hline
\end{tabular}
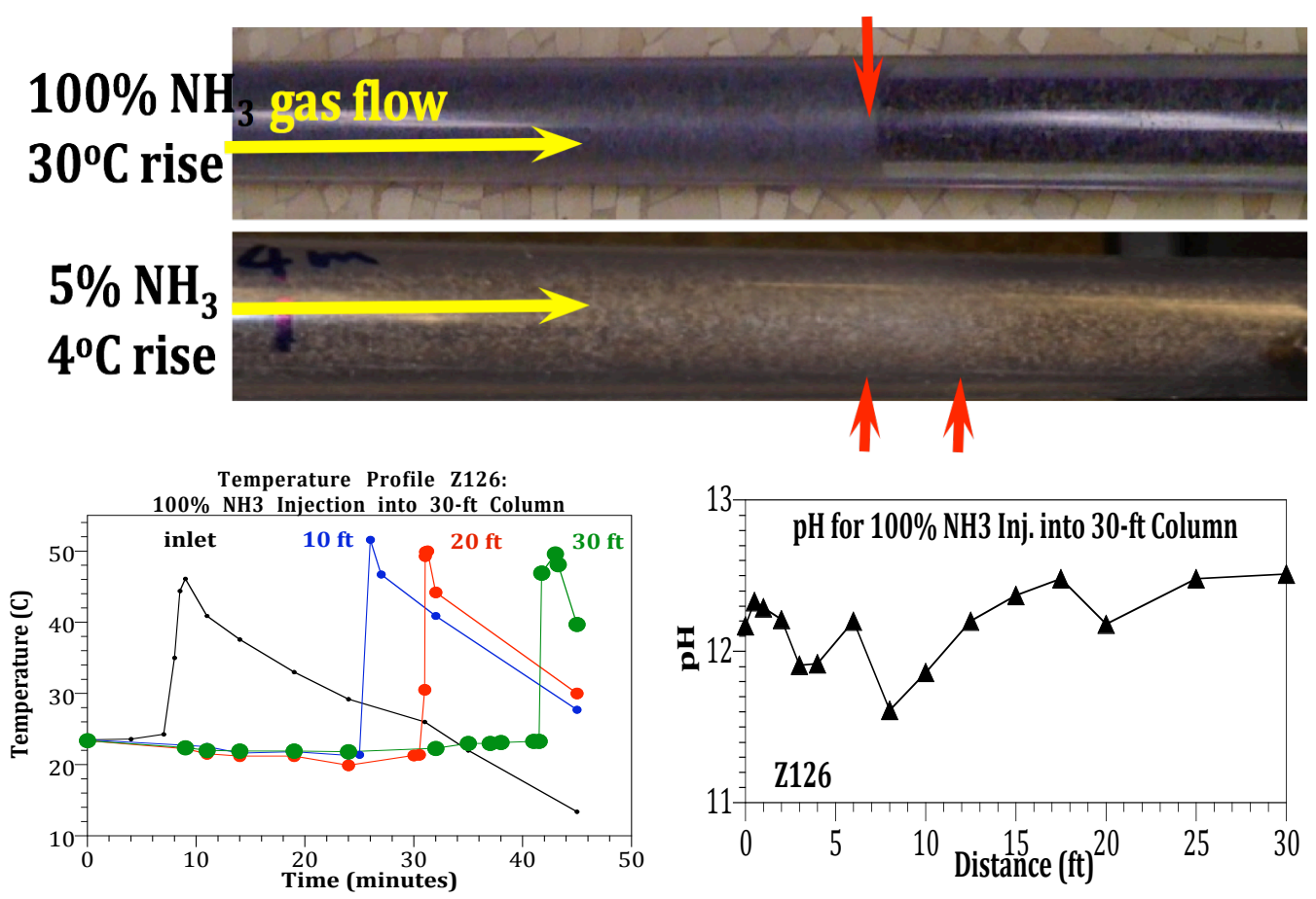

Figure 4.46. $100 \%$ ammonia gas injection: a) reaction front, b) temperature, and c) $\mathrm{pH}$ distribution in sediment.

Most of the 20-ft long columns (Table 4.6) were conducted with the reaction front ending within the sediment column so that subsequent sediment samples taken from the column could be used for $\mathrm{pH}$ and electrical conductivity measurements. From the $\mathrm{pH}$ in the sediment (Figure 4.47a), the mass of ammonia present in the sediment pore water can be calculated. This mass was then compared to the ammonia mass injected (Table 4.6), which showed a reasonable mass balance with mass out was $12 \%$ lower than mass injected. It should be noted that sediment samples were taken from the column within 30 minutes of extracting the ammonia-laden sediment into a fume hood. This method does result in the volatilization of some ammonia. The sediment extraction method was refined to contain the sediment within a few seconds of extraction from the column (described in the following section), which resulted in a significantly sharper $\mathrm{pH}$ front. Therefore, it is likely that the ammonia mass balance could be refined. 

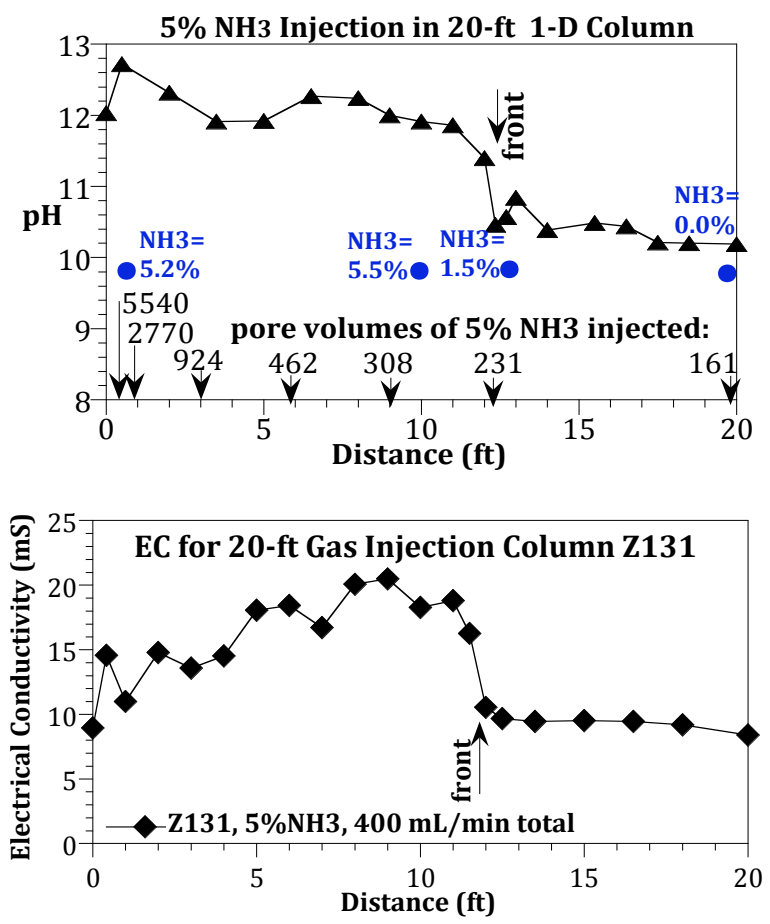

Figure 4.47. $5 \% \mathrm{NH}_{3}$ injection into $20-\mathrm{ft}$ 1-D column with resulting: a) $\mathrm{pH}$ and b) EC.
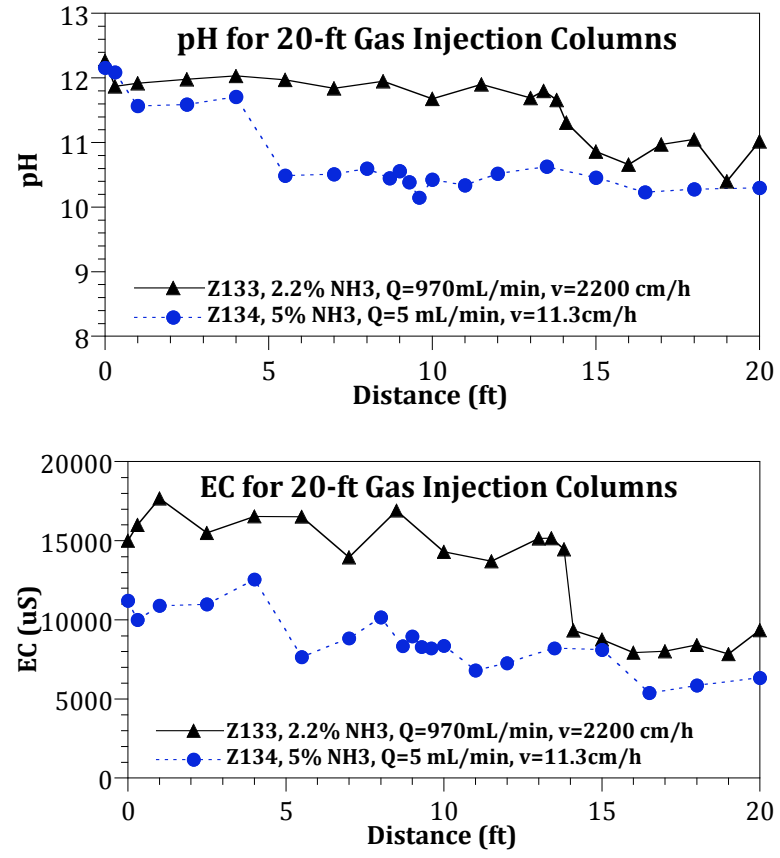

Figure 4.48. $\mathrm{NH}_{3}$ injection at different flow rate with resulting: a) $\mathrm{pH}$ and b) $\mathrm{EC}$.
The 1-D columns of ammonia injection at different velocity did not show a difference in the sharpness of the resulting $\mathrm{pH}$ or electrical conductivity front (Figure 4.48), even though the data shown is for experiments in which there is two orders of magnitude difference in the injection velocity. Again, refinement of the method to extract the slightly volatile samples and higher density sampling may refine this conclusion.

These 1-D columns conducted at different velocity did, however, show that $202 \pm 31$ pore volumes of $5 \%$ ammonia was needed at lower velocities (Figure 4.49) and 363 pore volumes needed at a higher velocity. The theoretical number of pore volumes needed to achieve $\mathrm{pH}$ equilibrium at this porosity $(0.350)$ is 465 . The desiccation front moved 37 times more slowly than the ammonia reaction front, so averaged 8600 pore volumes of gas to desiccate the sediment initially at $4 \%$ water content (Table 4.6). A separate desiccation study showed 25,000 pore volumes of a dry gas are needed to dry sediment initially at $5 \%$ water content (Oostrom et al. 2010).

In conclusion, 1-D injection of ammonia gas into long columns did show that reactivity could be achieved at field scale distances. Although reactivity defined by $\mathrm{pH}$ and $\mathrm{EC}$ changes are described in this section, an additional 1-D experiment was conducted (in the following section) in which sediments were analyzed for cations, anions, and $U$ surface phase changes.

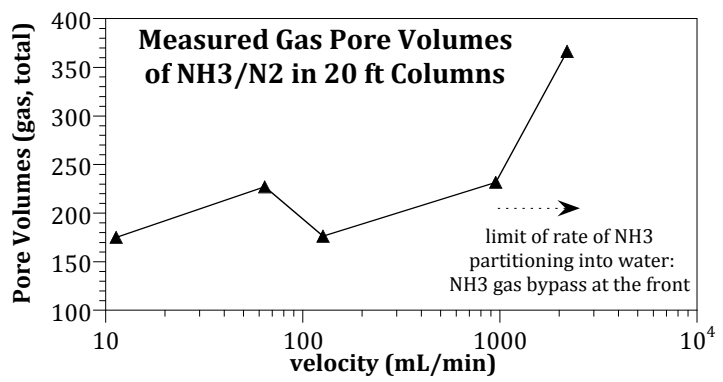

Figure 4.49. Pore volumes of $\mathrm{NH}_{3}$ injection for 1-D columns at different velocity. 


\subsection{Scale Up of Reactivity: Batch to 1-D Columns with Co-Contaminants}

Previous batch and 1-D column experiments have shown that ammonia gas treatment of sediment increases pore water $\mathrm{pH}$, which over time dissolves some minerals. Uranium surface phases are also altered, either by dissolution/precipitation and/or coating by non-U-bearing precipitates. Experiments described in this section were conducted on a field-contaminated BC Crib sediment (borehole C7534, 52-ft depth) in which highly controlled batch and 1-D column experiments were conducted under the same ammonia gas treatment conditions to determine if batch results can be used to predict behavior observed in columns. Data that is compared includes: a) $\mathrm{pH}$, electrical conductivity, b) aqueous cations, c) adsorbed cations, d) aqueous anions, and e) U surface phases as identified by liquid extractions. Previous batch studies have used two methods to apply ammonia gas treatment to sediment: batch treatment and column treatment. Batch treatments were applied by using a small mass of sediment in a large vial (i.e., gas volume equivalent to 50 to 100 pore volumes), and ammonia gas was used to saturate the headspace for a specified amount of time (10 minutes to 30 minutes) with the vial lid open. Because ammonia gas partitions quickly to sediment pore water, the actual $\mathrm{NH}_{3}$ dose received by the sediment is likely larger than just calculated from the head space volume (i.e., 50 to 100 pore volumes). Column treatments involve packing sediment into a small column (volume 5 to $10 \mathrm{~cm}^{3}$ ), and ammonia/nitrogen gas is advected through the column. In some cases, some sediment fines are advected out of the column during this process.

In this series of experiments, a small quantity of sediment $(5 \mathrm{~g})$ is placed in a large glass septa bottle with 1-cm thick septa. The gas volume is evacuated (with vacuum), then a syringe filled with 30 to $450 \mathrm{~mL}$ of $5 \% \mathrm{NH}_{3} / 95 \% \mathrm{~N}_{2}$ gas (at atmospheric pressure) is injected into the vial. The ratio of sediment to gas volume was chosen to be equivalent to 125,300 , and 1000 pore volumes of the mixed gas. The 1-D column results (previous results Section 4.7) showed that 200 to 300 pore volumes of ammonia gas was needed to be close to ammonia saturated values in the pore water, and 465 pore volumes is the calculated number of pore volumes of ammonia needed to reach saturation. Therefore, 125 pore volumes represents insufficient $\mathrm{NH}_{3}$ treatment (i.e., $\mathrm{pH}$ is less than equilibrium $\mathrm{pH}$ calculated using $5 \% \mathrm{NH}_{3}$ ), 300 pore volumes represents close to $\mathrm{NH}_{3}$-saturated values, and 1000 pore volumes represents an excess of $\mathrm{NH}_{3}$. Because of the limited quantity of field-contaminated sediment, the parallel 1-D column was not fully packed with this sediment. Instead, the C7534, 52-ft depth sediment was packed at specified locations in the 20-ft long 1-D column and uncontaminated Hanford formation sediment (all initially at $4 \%$ water content) was packed in most of the column. The $5 \% \mathrm{NH}_{3} / 95 \% \mathrm{~N}_{2}$ gas flow rate and reaction time was chosen to achieve close to 125,300 , and 1000 pore volumes of treatment at specified locations that contained the C7534, 52-ft depth sediment.

The use of a "field-contaminated" sediment was chosen to evaluate whether the presence of co-contaminates would influence the geochemical changes. It should be noted that a field site for ammonia gas treatment is not finalized, and so the distribution of co-contaminates could be significantly different from the sediment used in these experiments.

\subsubsection{Reactivity in Static (Batch) Sediment/Water/Gas Systems}

Ammonia gas treatment of sediment in batch systems at the equivalent of 125, 300, and 1000 pore volumes resulted in $\mathrm{pH}$ values (Figure 4.50a) varying from 10.7 (125 pore volumes), 11.1 (300 pore 
volumes), and 11.4 (1000 pore volumes), which is similar to that previously observed (Figure 4.6). Over the next $800 \mathrm{~h}$, the $\mathrm{pH}$ remained constant for the first $200 \mathrm{~h}$, then decreased to some extent. The electrical conductivity of all samples (Figure $4.50 \mathrm{~b}$ ) of $130 \mathrm{mS}$ was nearly the same for all treatments and $\sim 10$ times that previously observed (Figure 4.48), as a result of a high concentration of ions initially present in the sediment (i.e., co-contaminants). The significance for field injections is it may render the use of real time resistivity ineffective in monitoring the movement of the $\mathrm{pH}$ front for sediments with high ionic strength (i.e., the increase in pore water ionic strength by the ammonia gas injection is fairly minor in this case).

The concentration of ammonia was measured in these systems as aqueous ammonia (Figure 4.50c) and adsorbed ammonia (Figure $4.50 \mathrm{~d}$ ), as desorbed by $0.5 \mathrm{M} \mathrm{Mg}\left(\mathrm{NO}_{3}\right)_{2}$. The aqueous ammonia increased over days, indicating partitioning between aqueous species may take some time. Both aqueous and adsorbed ammonia concentrations decreased substantially by $800 \mathrm{~h}$.
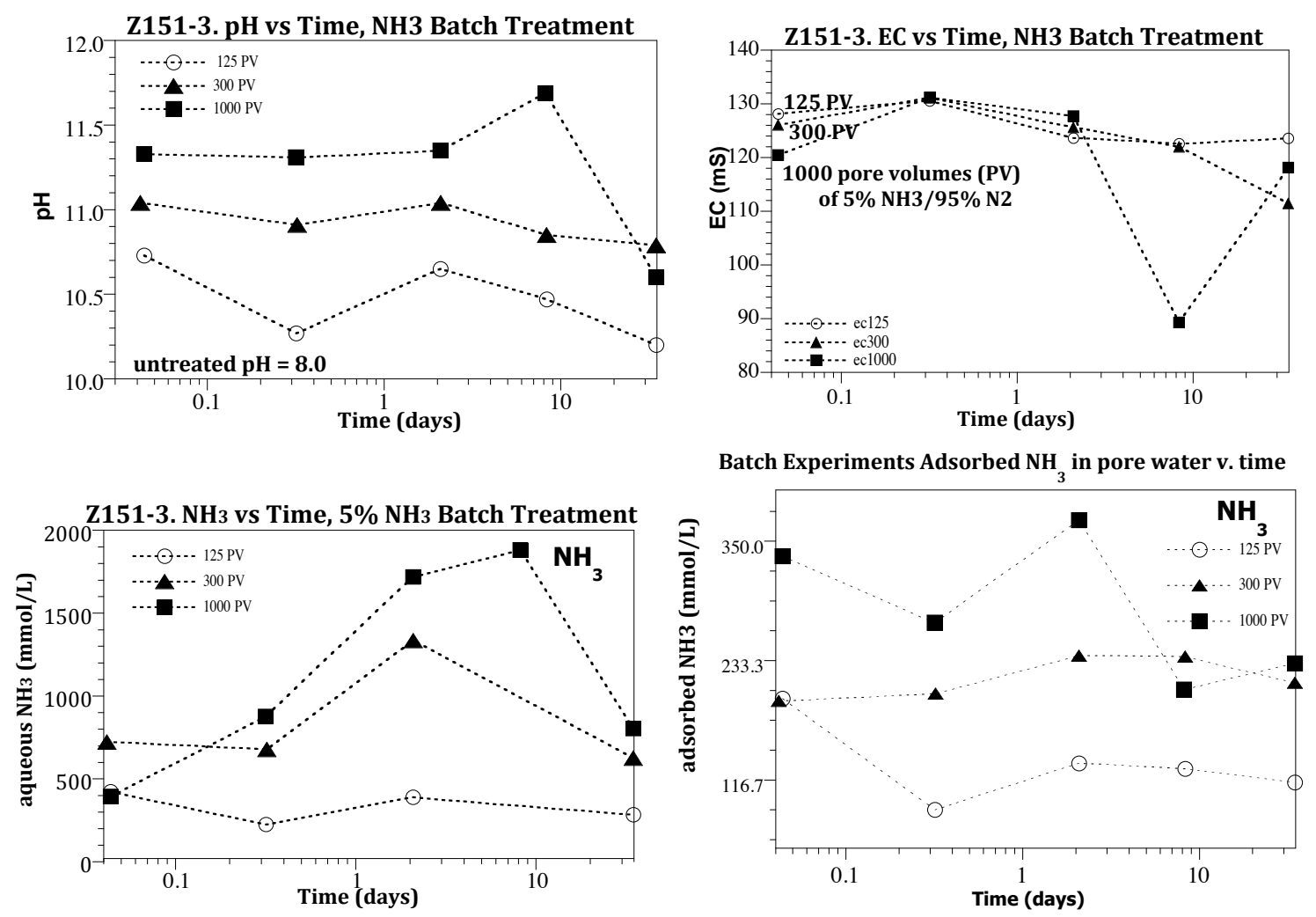

Figure 4.50. Batch $\mathrm{NH}_{3}$ treatments showing: a) $\mathrm{pH}$, b) EC, c) $\mathrm{NH}_{3}$ (aq), and d) $\mathrm{NH}_{3}$ (ads).

Cation concentrations in sediment were measured over time in the aqueous pore water (Figure 4.51a-c), and adsorbed on the sediment (Figure 4.51d-f). Ammonia was included as a cation, even though nearly all of the ammonia mass at this $\mathrm{pH}(>\mathrm{pH} 9.4)$ is $\mathrm{NH}_{3}$ (aq) and not $\mathrm{NH}_{4}^{+}$(primary species at $\mathrm{pH}<9.4)$, shown in Figure 4.3. Prior to ammonia gas treatment, this field-contaminated sediment contained $2.2 \mathrm{~mol} / \mathrm{L} \mathrm{Na}^{+}, 0.4 \mathrm{~mol} / \mathrm{L} \mathrm{Ca}^{2+}, 2 \mathrm{~mol} / \mathrm{L} \mathrm{NO}_{3}{ }^{-}$, and $0.7 \mathrm{~mol} / \mathrm{L} \mathrm{SO}_{4}{ }^{2-}$. These high co-contaminant concentrations tend to mask any changes in cations/anions previously observed of increasing $\mathrm{Na}, \mathrm{Si}$, and $\mathrm{Ca}$ (Figure 4.18) and increasing $\mathrm{Cl}, \mathrm{F}, \mathrm{NO}_{3}$ concentrations (Figure 4.21). Bar 
graphs of cations (Figure 4.51a-f) do show that increasing ammonia treatment from 125 to 300 to 1000 pore volumes increases the measured ammonia concentration as well as $\mathrm{Na}+$. At this high of an ionic strength, the adsorbed cation concentrations were approximately $1 / 4$ of that in solution (graphs are the same scale). There was relatively good cation/anion mass balance, as both showed totals that were nearly the same. There were few changes in any major cation observed.

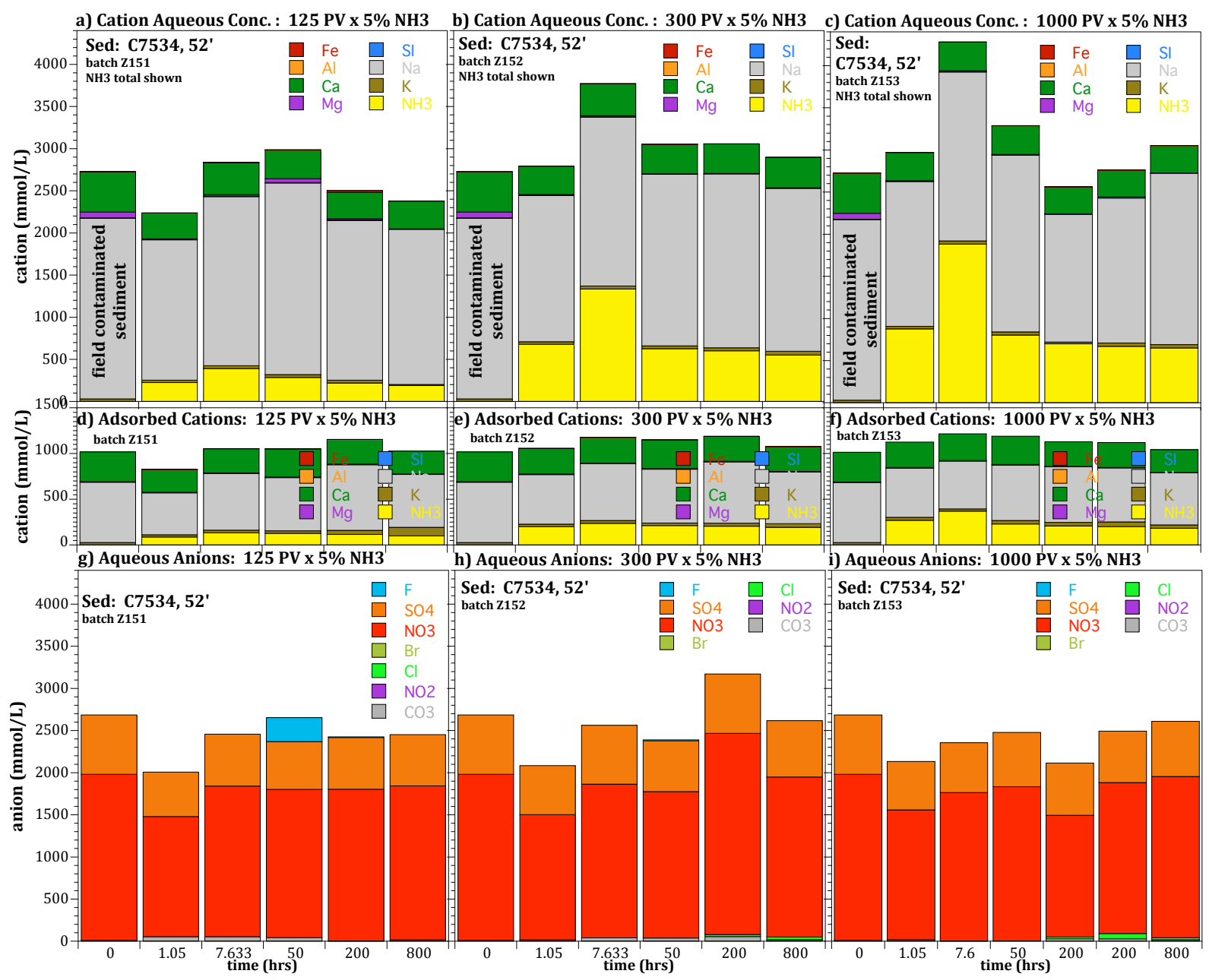

Figure 4.51. Batch $\mathrm{NH}_{3}$ treatments showing aqueous cations $(\mathrm{a}-\mathrm{c})$, adsorbed cations $(\mathrm{d}-\mathrm{f})$, and aqueous anions $(\mathrm{g}-\mathrm{i})$. Treatments for 125,300 , and 1000 pore volumes of $5 \% \mathrm{NH}_{3}$ gas.

Plots of individual cations/elements (Figure 4.52) show similar changes observed in previous batch experiments. The pore water silica concentration (Figure 4.52a) was initially higher for higher $\mathrm{NH}_{3}$ treatment, and over time the concentration in all treatments decreased a small amount (20\% to $\left.50 \%\right)$. In contrast, the $\mathrm{Al}^{3+}$ concentration decreased to a greater extent (Figure 4.52b), similar to that previous observed (Figure 4.17b). The aqueous ferrous iron concentration was highest for the lowest ammonia treatment (also previously observed, Figure 4.17f), and decreased $90 \%$ over time. The aqueous $\mathrm{Mg}^{2+}$ concentration (Figure 4.52d) showed similar changes to that of Fe3+, with a $90 \%$ decrease over $800 \mathrm{~h}$. 

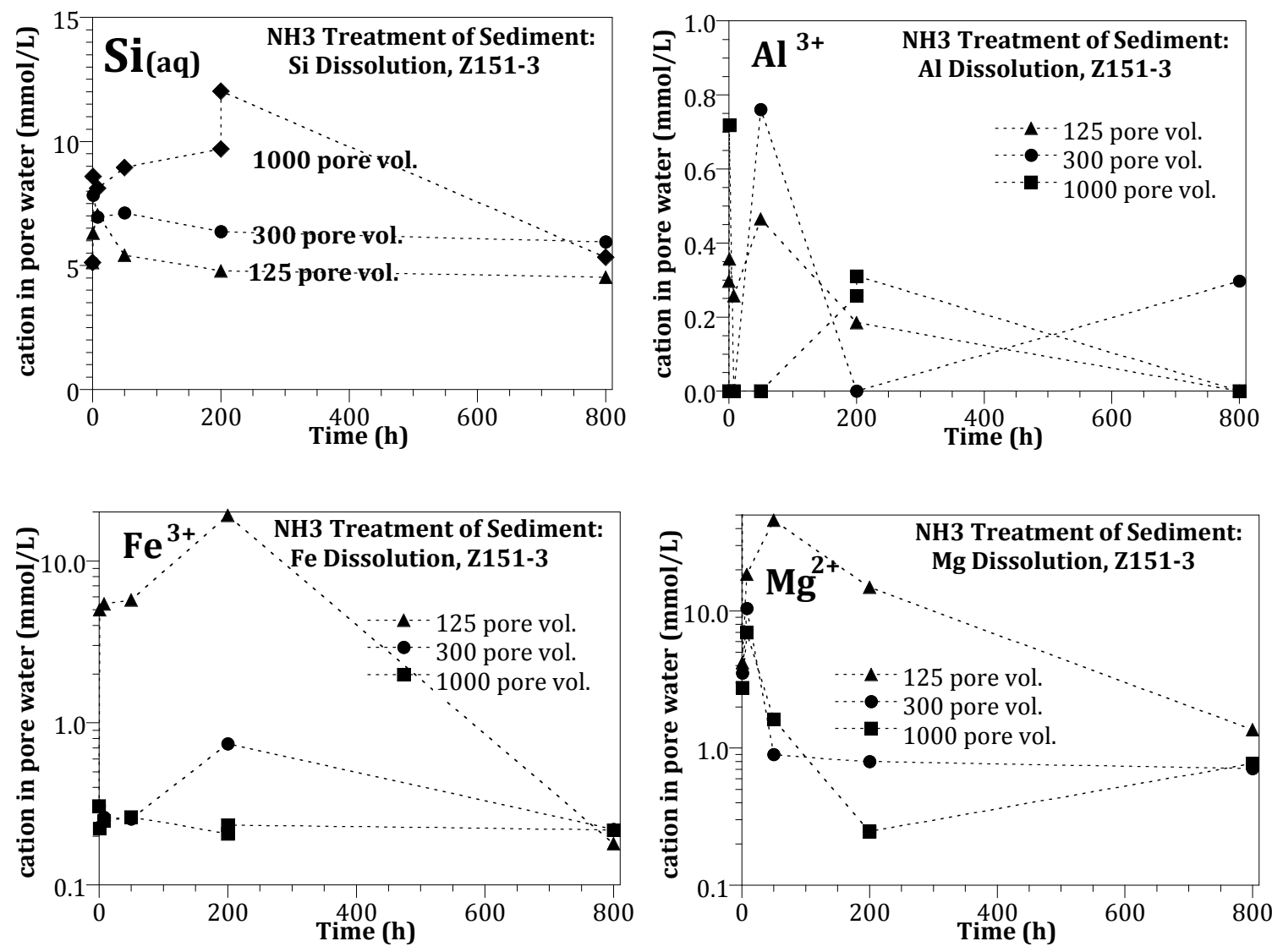

Figure 4.52. Batch $\mathrm{NH}_{3}$ treatments showing changes in aqueous a) $\left.\mathrm{Si}, \mathrm{b}\right) \mathrm{Al}$, c) Fe, and d) $\mathrm{Mg}$.

The uranium surface phase changes were evaluated using sequential liquid extractions. This sediment initially contained low extractable uranium (average for 17 extractions is $0.165 \pm 0.017$ ). Ammonia gas treatment with the equivalent of 125 pore volumes of $5 \%$ ammonia (Figure $4.53 \mathrm{a}$ ) showed a slight decrease in the acetate (i.e., $\mathrm{U}$ associated with a small rind of carbonate, orange color on bar graph) extraction, and a slight increase in the $8 \mathrm{M} \mathrm{HNO}_{3}$ (hard to extract $\mathrm{U}$ surface phases) extraction. With 300 pore volumes of $5 \%$ ammonia treatment (Figure $4.53 \mathrm{~b})$, there was a larger $(\sim 15 \%)$ increase in the $8 \mathrm{M} \mathrm{HNO}_{3}$ (hard to extract $\mathrm{U}$ surface phases) extraction for 200 and $800 \mathrm{~h}$. With 1000 pore volumes of $5 \%$ ammonia treatment (Figure 4.53c), there was no change in the $8 \mathrm{M} \mathrm{HNO}_{3}$ extraction, but the acetate extraction (orange) decreased significantly and the acetic acid (yellow) extractable U increased significantly. Because the total uranium in this sediment was very small, these $U$ surface phase changes are close to detection limits. 


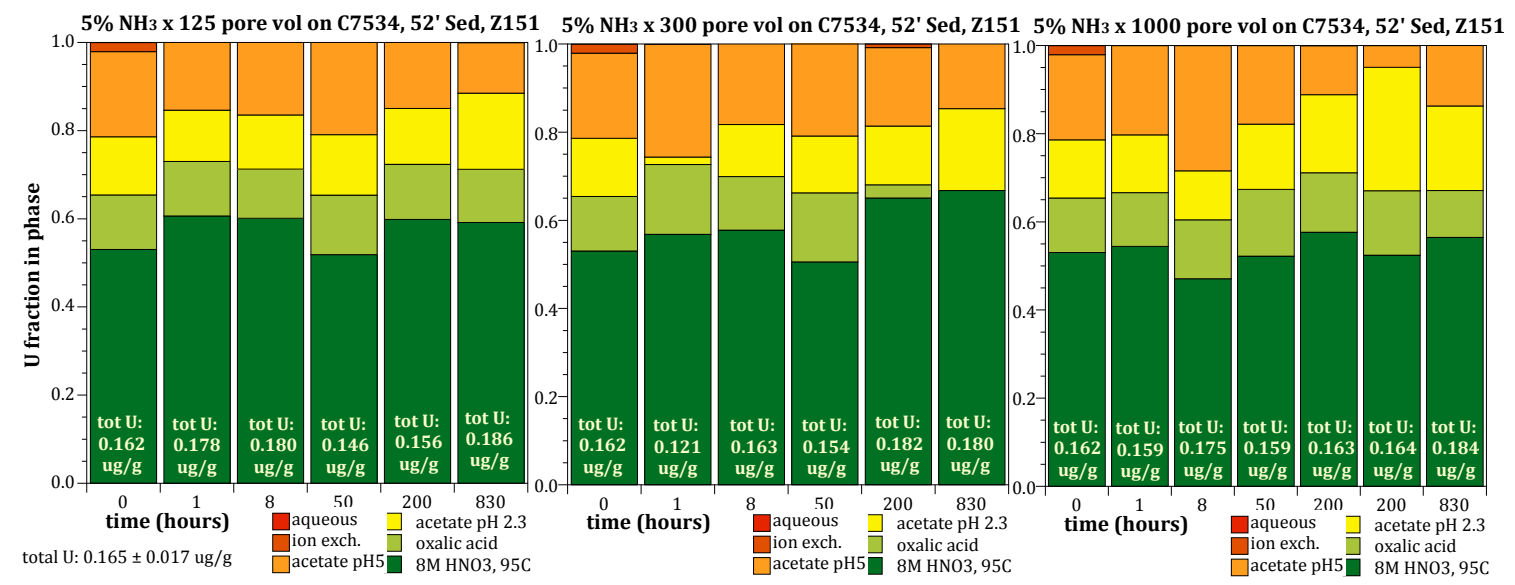

Figure 4.53. Batch $\mathrm{NH}_{3}$ treatments showing changes in $\mathrm{U}$ surface phases (by liquid extractions).

\subsubsection{Reactivity in a 1-D Column}

Injection of $5 \% \mathrm{NH}_{3}\left(95 \% \mathrm{~N}_{2}\right.$, anhydrous $)$ gas at a fast flow rate (interstitial velocity $960 \mathrm{~cm} / \mathrm{min}$, similar to previous experiments Z131, Z131a in Table 4.5) resulted in a high concentration of $\mathrm{NH}_{3}$ in the pore water (Figure $4.42 \mathrm{c}$, as high as $950 \mathrm{mmol} / \mathrm{L}$ ). The $\mathrm{pH}$ front was sharp (Figure 4.54a), as was the electrical conductivity front (Figure 4.54b). The highest $\mathrm{NH}_{3}$ concentration was not at the inlet, but a few centimeters into the column. This may be an artifact of the desiccation that occurs near the inlet. The $\mathrm{pH}$ front was sharper than any previous 1-D column (Figure 4.36a, 4.37a), likely due to the much more rapid sediment sampling that was conducted (limiting $\mathrm{NH}_{3}$ volatilization).
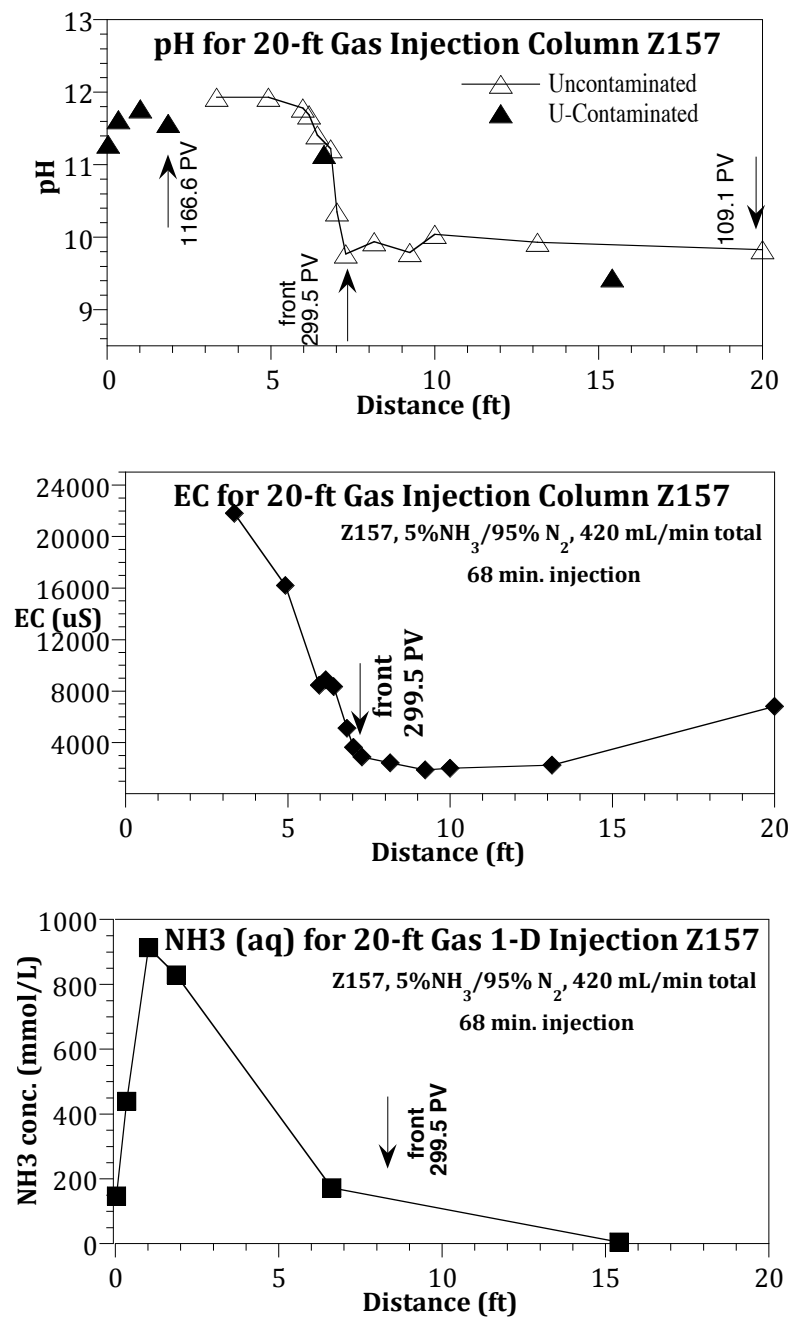

Figure 4.54. $\mathrm{NH}_{3}$ injection into a 20 -ft column, showing: a) $\mathrm{pH}, \mathrm{b}) \mathrm{EC}$, and c) $\mathrm{NH}_{3}$ concentration. 

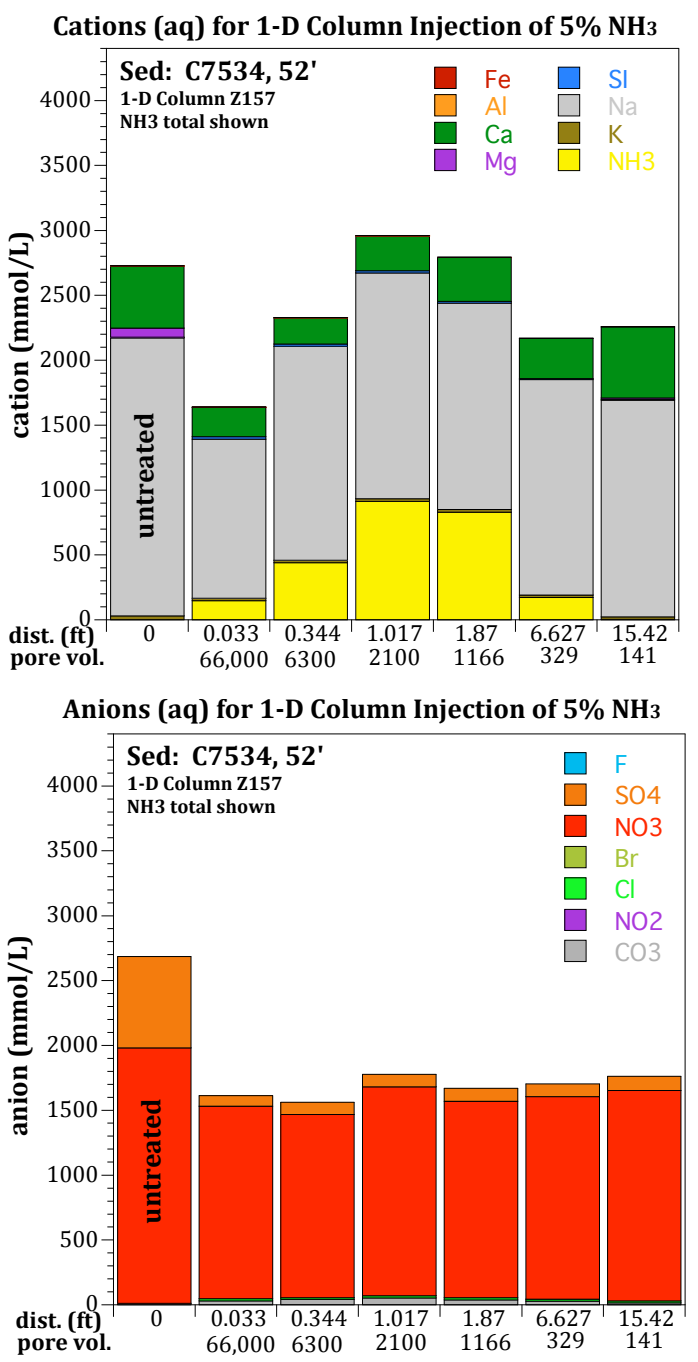

Figure 4.55. $\mathrm{NH}_{3}$ injection into a $20-\mathrm{ft}$ column, showing a) aqueous cations, and b) aqueous anions.
The aqueous cation and anion concentrations (Figure 4.55) at 141, 329, and 1166 pore volumes were similar to previous observed in batch systems at 125 , 300 , and 1000 pore volumes (Figure $4.51 \mathrm{a}-\mathrm{c}, 1 \mathrm{~h}$ data). Individual plots of $\mathrm{Si}, \mathrm{Al}, \mathrm{Fe}$, and $\mathrm{Mg}$ (Figure 4.56) from the 1-D column injection are compared to individual plots from the batch experiments at $1 \mathrm{~h}$ (Figure 4.40). Silica concentration in the batch experiments at 125,300 , and 1000 pore volumes were $6,7.8$, and $9.1 \mathrm{mmol} / \mathrm{L}$, and were similar to that observed in the 1-D column at 141, 329, and 1166 pore volumes of $5.4,7.6$, and $13.8 \mathrm{mmol} / \mathrm{L}$. Silica concentrations were higher nearer the injection end of the column, as these locations received higher ammonia gas treatment.

The pore water aqueous $\mathrm{Al}^{3+}$ concentrations in batch experiments $(125,300$, and 1000 pore volumes) were $0.36,0.0$, and $0.72 \mathrm{mmol} / \mathrm{L}$ were similar to that observed in the 1-D column $(141,329$, and 1166 pore volumes) of $1.0,0.0$, and $0.0 \mathrm{mmol} / \mathrm{L}$. The column experiment had additional sediment that was subjected to higher treatments. These locations (equivalent pore volumes shown in Figure 4.55) had higher Al concentrations.

The pore water aqueous $\mathrm{Fe}^{3+}$ concentrations in batch experiments $(125,300$, and 1000 pore volumes) were $5.0,0.23$, and $0.25 \mathrm{mmol} / \mathrm{L}$ were similar to that observed in the 1-D column $(141,329$, and 1166 pore volumes) of $1.0,0.0$, and $0.0 \mathrm{mmol} / \mathrm{L}$. The ferrous iron concentration also increased slightly for zones nearer the injection inlet that received higher treatment.

The pore water aqueous $\mathrm{Mg}^{2+}$ concentrations in batch experiments (125, 300, and 1000 pore volumes) were $4.1,3.5$, and $2.7 \mathrm{mmol} / \mathrm{L}$ were also similar to that observed in the 1-D column $(141,329$, and 1166 pore volumes) of $11.8,0.0$, and $0.0 \mathrm{mmol} / \mathrm{L}$. Pore water $\mathrm{Mg}^{2+}$ was highest for the untreated sediment.

Sequential liquid extractions were used for field-contaminated sediment located at six locations in the 1-D column to quantify uranium surface phases. Previous batch experiments at 125, 300, and 1000 pore volumes ( $1 \mathrm{~h}$ data, Figure 4.53) do show a decrease in aqueous $\mathrm{U}$, and a slight to moderate increase in the $8 \mathrm{M} \mathrm{HNO}_{3}$ extraction. Results were similar in the 1-D column for 141, 329, and 1166 pore volumes (Figure 4.57). Greater ammonia treatment in the column (points near the column inlet) showed a more significant increase in the $8 \mathrm{M} \mathrm{HNO}_{3}$ extraction (18\%), and corresponding decrease in carbonateassociated $\mathrm{U}$. 
Overall, this series of highly controlled batch and 1-D column experiments did demonstrate that geochemical changes ( $\mathrm{pH}, \mathrm{EC}$, cations, anions, U surface phases) observed in batch studies can be representative of that observed in a 1-D column. The specific sediment used for this study had a high ionic strength (mainly Na-nitrate) and a low $U$ mass, so results of $U$ surface phase changes may not be applicable to high-U contaminated sediments that contain predominantly Na-boltwoodite. However, comparison of the cation changes (Figure 4.56) to ammonia treatment in uncontaminated Hanford formation sediments (Figure 4.17) do show similar results of pore water: a) $\mathrm{Si}$ increases with $\mathrm{NH}_{3}$ treatment, decreases a small extent over time, b) $\mathrm{Al}^{3+}$ increases with $\mathrm{NH}_{3}$ treatment, decreases a moderate extent over time, c) ferrous iron concentration increases with $\mathrm{NH}_{3}$ treatment and decreases a large amount over time, and d) $\mathrm{Mg}^{2+}$ concentration increases with $\mathrm{NH}_{3}$ treatment and decreases a large amount over time. These results indicate that similar dissolution and precipitation reactions may be occurring in these sediments with widely different initial ionic strength, so ammonia treatment may be effective in a range of geochemical conditions.

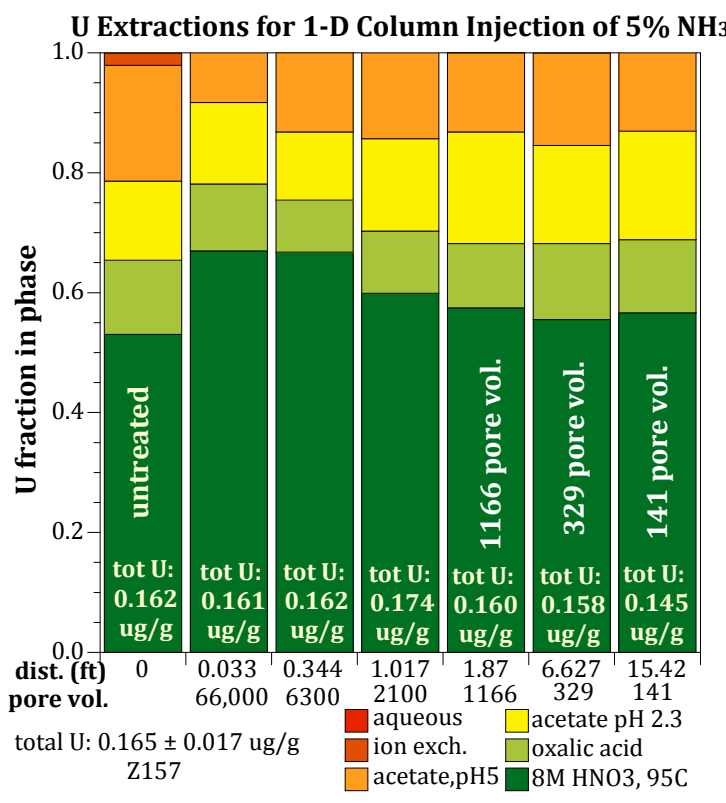

Figure 4.57. $\mathrm{NH}_{3}$ injection into a 20 -ft column, showing $\mathrm{U}$ concentrations in liquid extractions.

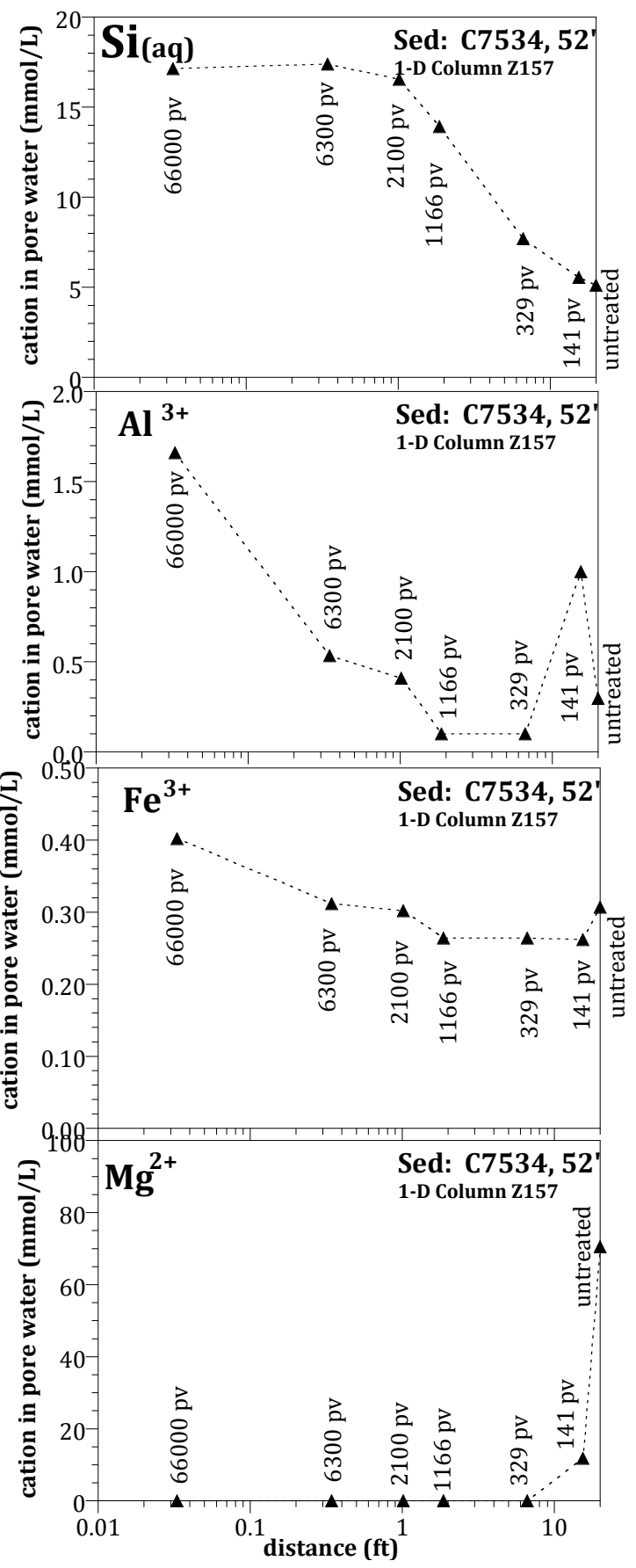

Figure 4.56. $\mathrm{NH}_{3}$ injection into a $20-\mathrm{ft}$ column, showing aqueous: a) $\mathrm{Si}, \mathrm{b}) \mathrm{Al}, \mathrm{c}$ ) $\mathrm{Fe}$, and d) $\mathrm{Mg}$. 


\subsection{Influence of $\mathrm{NH}_{3}$ Gas Diffusion on Geochemical Changes: 1-D Columns}

The rate of $\mathrm{NH}_{3}$ diffusion into sediment was characterized by four 1-D column experiments. These column experiments were conducted using a 5-L flexible metallized bag connected at one end that contained $100 \%$ or $5 \% \mathrm{NH}_{3}$. Over time, as $\mathrm{NH}_{3}$ gas diffused into the sediment pore water, $\mathrm{pH}$ indicator paper located at different distances from the diffusion end provided a qualitative indicator of the movement of the $\mathrm{NH}_{3}$ reaction front. The experiment was concluded when the reaction front was approximately half way through the column, at which time the column was disassembled and sediment samples were taken for $\mathrm{pH}$ and $\mathrm{EC}$ measurements. The first two columns received diffused $100 \% \mathrm{NH}_{3}$ for 170 hours. Two different sediment were used; one contained fine sand from Hanford formation from the 200 Area ERDF pit (20-ft depth), and the other was from the Hanford formation in the 300 Area. The resulting $\mathrm{pH}$ front (Figure 4.58a) did show a more diffuse $\mathrm{pH}$ front compared with advection of $\mathrm{NH}_{3}$ gas into sediment (Figure 4.54a). The EC fronts (Figure 4.47c) also were diffuse. These data will be used to simulate $\mathrm{NH}_{3}$ diffusion. Both sediments had the same water content, and approximately the same porosity. There appeared to be little difference in diffusion between the fine sand and silt/clay, even though the air permeability should be lower in the silt/clay. Diffusion of $5 \% \mathrm{NH}_{3}(95 \%$ nitrogen) into similar sediment columns showed treatment to occur approximately over the same distance and the same amount of time. The $\mathrm{pH}$ fronts (Figure $4.58 \mathrm{~b}$ ) showed very little $\mathrm{pH}$ change, but the EC (Figure 4.58d) showed more significant changes. Overall, these diffusion experiments showed that EC measurements are useful for assessing $\mathrm{NH}_{3}$ gas reactivity.
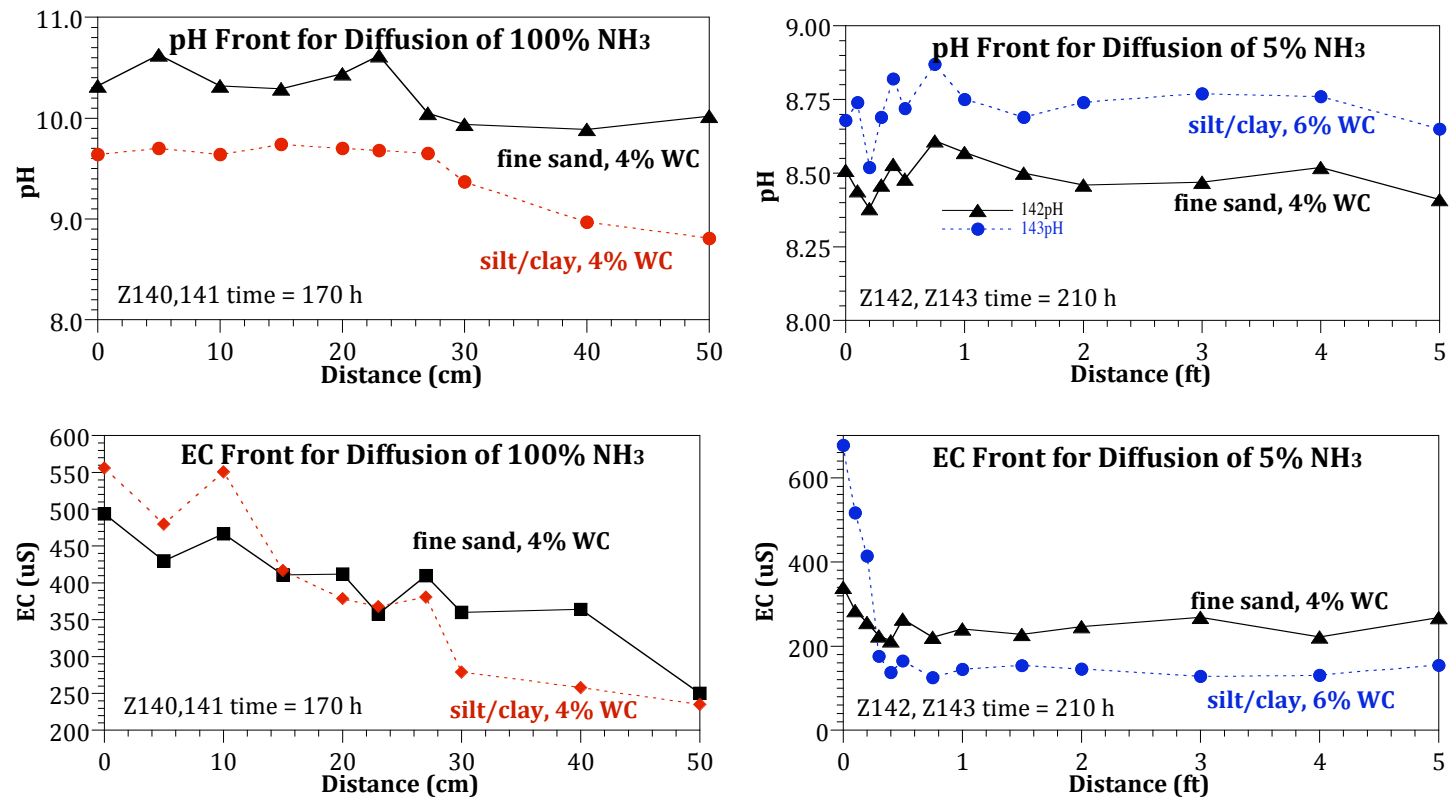

Figure 4.58. $\mathrm{NH}_{3}$ diffusion into 1-D columns: a) $\mathrm{pH}$ for $100 \% \mathrm{NH}_{3}$, b) $\mathrm{pH}$ for $5 \% \mathrm{NH}_{3}$, c) $\mathrm{EC}$ for $100 \% \mathrm{NH}_{3}$, and d) $\mathrm{EC}$ for $5 \% \mathrm{NH}_{3}$. 


\subsection{Influence of Heterogeneities: $\mathrm{NH}_{3}$ Gas Advection in 2-D Systems}

An $\mathrm{NH}_{3}$ gas injection experiment was conducted in a 1.2-m-long, wedge-shaped flow system to evaluate the reactive front advection during radial injection, which would occur at the field scale. As the cross-sectional area increases with distance from the well, the reaction front slows (i.e., in contrast to constant reaction front advection in a linear flow system such as a 1-D column), so prediction of reaction front movement depends on an accurate gas/liquid partition rate. This wedge-shaped flow system also contained heterogeneities in sediment grain size (Figure 4.59) and water content. Four layers were incorporated into the system with silt layers ( $4 \%$ and $8 \%$ water content) and gravely sand layers ( $1 \%$ and $4 \%$ moisture content). It was expected that the $\mathrm{NH}_{3}$ gas front would advect fastest in the higherpermeability, lower-water-content sediment. In addition, there were eight silt lenses in the high-K sand (at $1 \%, 4 \%, 8 \%$, and $16 \%$ initial water content) and eight fine-sand lenses (at 1\%, 4\%, 8\%, and 16\% initial water content). Slower penetration of the $\mathrm{NH}_{3}$ gas into higher-water-content lenses was expected.
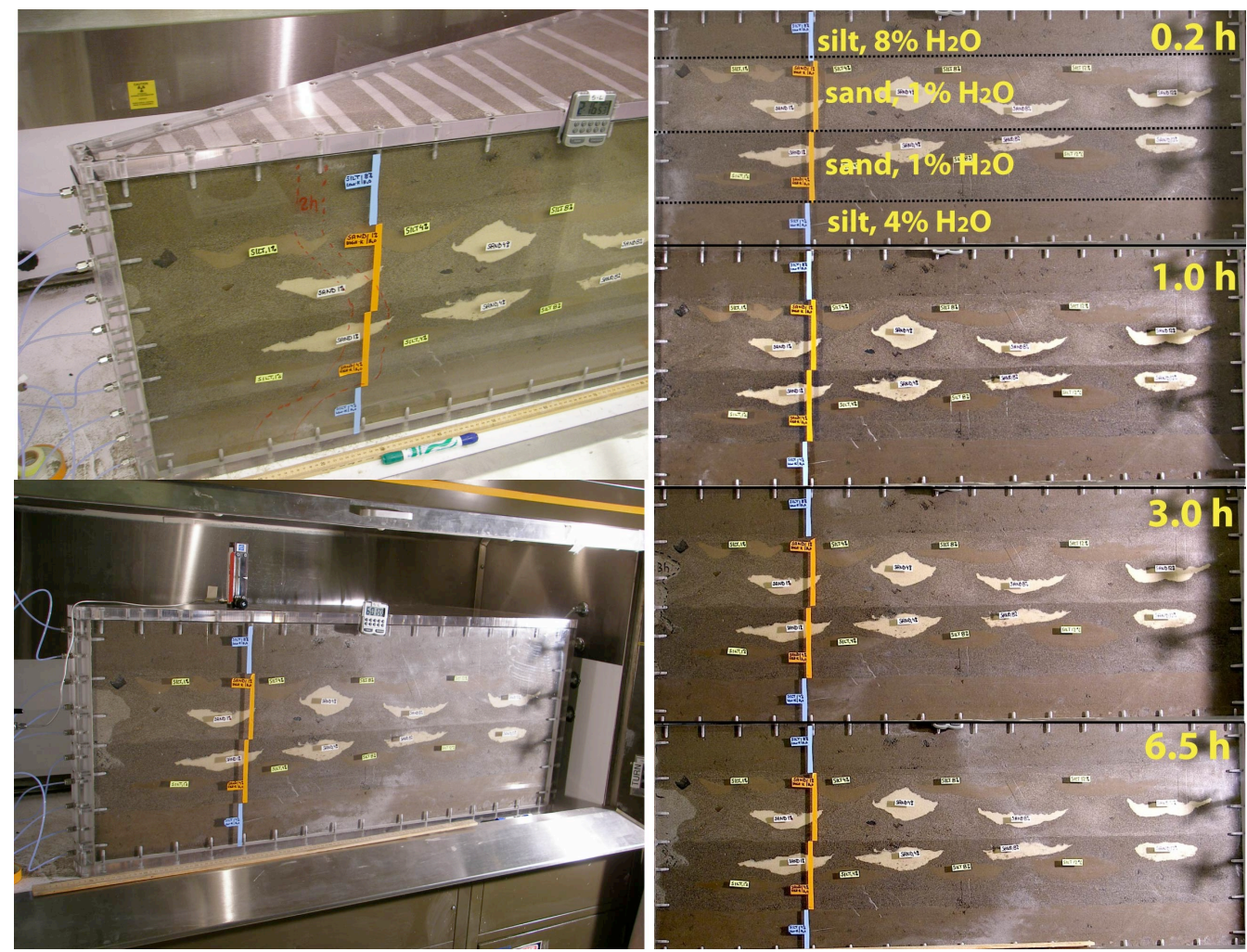

Figure 4.59. $\mathrm{NH}_{3}$ injection into a 2-D radial flow system containing continuous layers and lenses. Reaction front movement shown at four time intervals.

Ammonia gas (100\%) was injected into the narrow end of the 2-D wedge (Figure 4.59a) at 5.0 liters/minute for $6.5 \mathrm{~h}$ until the reaction front was part way through the system. Pictures taken at different times (Figure 4.59c) show the advance of the reaction front. This experiment was run in a fume hood, which limited pictures of the back side (which did not contain discontinuous lenses) showed a more pronounced front advance in the gravel sand zones and a slower movement in the silt layers. The reaction front advection was somewhat more rapid in the gravel sand (center two layers) compared with the silt layers (Figure 4.59c). A close up of the reaction front (Figure 4.60) shows the formation of larger 
condensate droplets. These droplets form due to the combination of: a) increase in liquid volume by $\mathrm{NH}_{3}$ gas to liquid partitioning, b) decrease (by $4 \mathrm{x}$ ) in the liquid viscosity as the ammonia concentration increases, and c) exothermic $\mathrm{NH}_{3}$ gas to liquid partitioning reaction evaporates some water, which then condenses. A small area near the injection (left) side shows desiccation of the sediment for a few centimeters. The desiccation front in this wedge shaped system was highly variable, as there was gravel in the gravely sand layers (center two layers). In 1-D columns (Table 4.6), the desiccation front moved on average 37 times more slowly, so in terms of pore volumes of anhydrous ammonia, the reaction front retardation averaged 232 pore volumes and the desiccation front retardation averaged 8600 pore volumes.

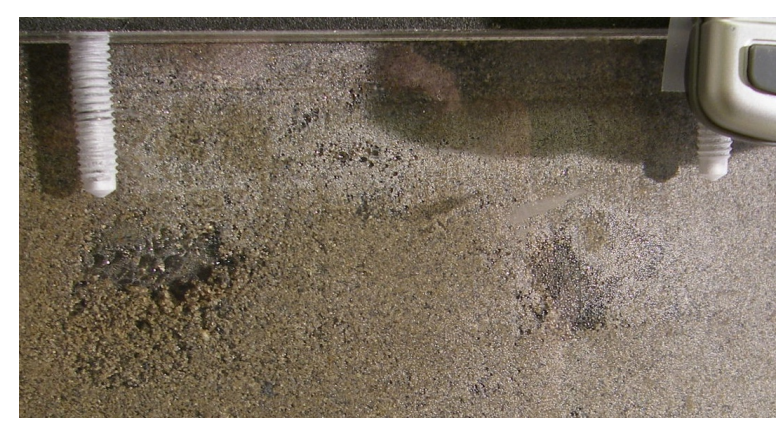

Figure 4.60. $\mathrm{NH}_{3}$ reaction front droplets.

The water content in sediment after the experiment (Figure 4.61a) showed desiccation near the inlet, and water contents in layers were similar to initial conditions. Water content in the lenses (triangles) redistributed with the surrounding gravely sand. Measurements of $\mathrm{pH}$ in the low-K (silt) and high-K (gravely sand) layers

(Figure 4.61b) confirm the location of the reaction front and the slower $\mathrm{NH}_{3}$ advection in the low-K layer. The $\mathrm{pH}$ in discontinuous lenses (black triangles, Figure 4.61b) had approximately the same $\mathrm{pH}$ as the surrounding high-K gravely sand.

Over the course of 7 months with exposure to air, the sediment $\mathrm{pH}$ decreased from 12 to 13 (at 7 hours) to 9 to 10 (Figure 4.61c). The EC of the pore water (Figure 4.61d) shows precipitation has occurred in most of the sediment, except near the inlet (with remaining high EC).

Sediment dissolution/precipitation reactions as a result of the $\mathrm{NH}_{3}$ gas are shown by pore water cation and anion concentrations (Figure 4.62a, b) and changes in uranium surface phases by liquid extractions (Figure 4.62c). These samples were analyzed on sediment samples that had limited exposure to air after 7 months, so they represent long term changes (although air was not flushed through samples). Cation and anion concentration changes at different distances in the box represent differing amount of treatment, as many more pore volumes of $\mathrm{NH}_{3}$ was reacted with sediment near the wedge inlet. The initial (7 hour) and final (7 month) $\mathrm{pH}$ values (in Figure 7.61) are shown in Figure 4.62, as well as the number of pore volumes of $100 \% \mathrm{NH}_{3}$ for each sediment sample.

By 7 months, most aqueous (pore water) cations had decreased to a total of $40 \mathrm{mmol} / \mathrm{L}$ to $80 \mathrm{mmol} / \mathrm{L}$, with predominantly sodium and silicon (Figure 4.62b). Anion concentrations remained higher (Figure 4.62a), with a significant $\mathrm{Cl}^{-}$and $\mathrm{F}^{-}$concentration. There was observed nitrate for three samples at $1 \mathrm{~cm}, 7 \mathrm{~cm}$, and $12 \mathrm{~cm}$ from the inlet, so for very high treatment (i.e., $>1900$ pore volumes of $100 \%$ $\mathrm{NH}_{3}$,, $\mathrm{NH}_{3}$ oxidation can occur. 


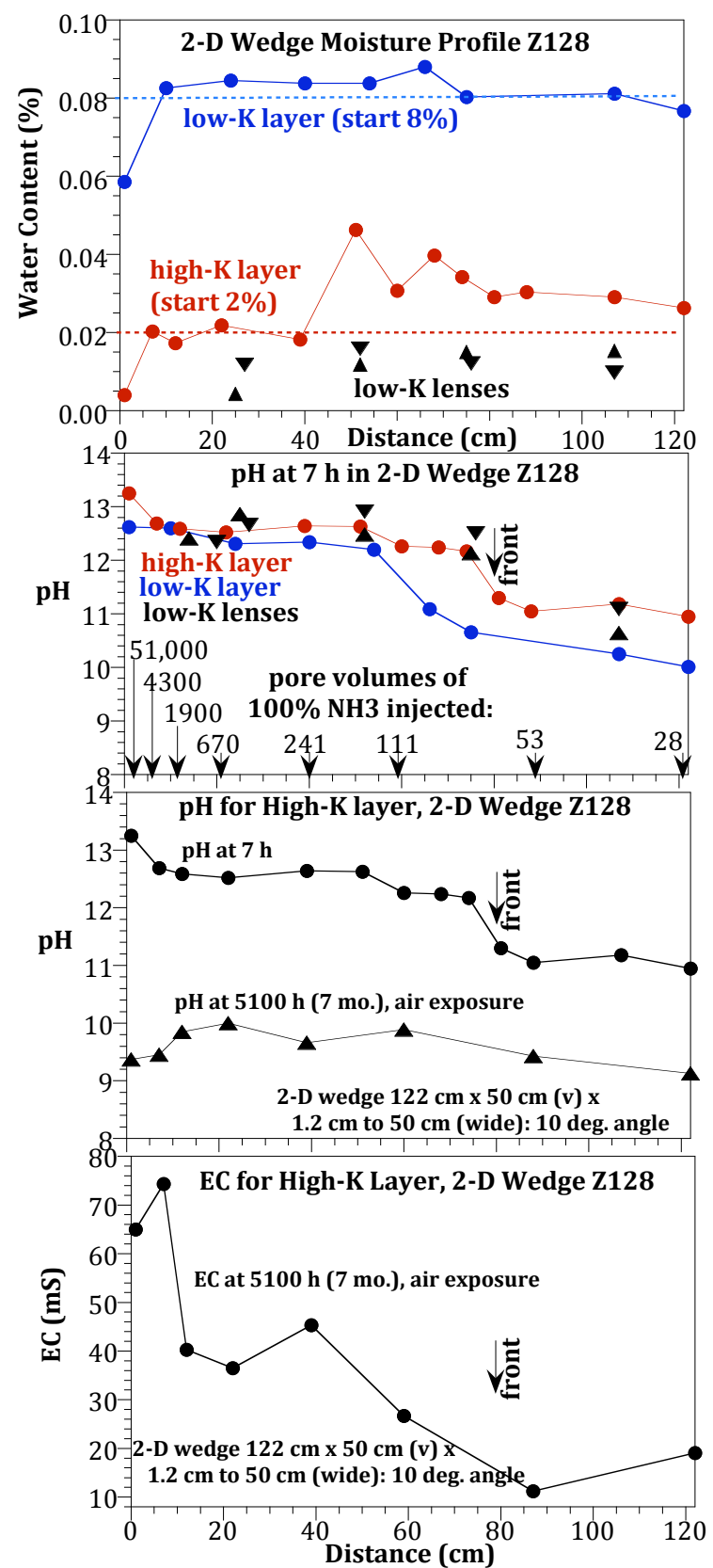

Figure 4.61. $\mathrm{pH}$ and $\mathrm{EC}$ in $2-\mathrm{D}$ wedge system.

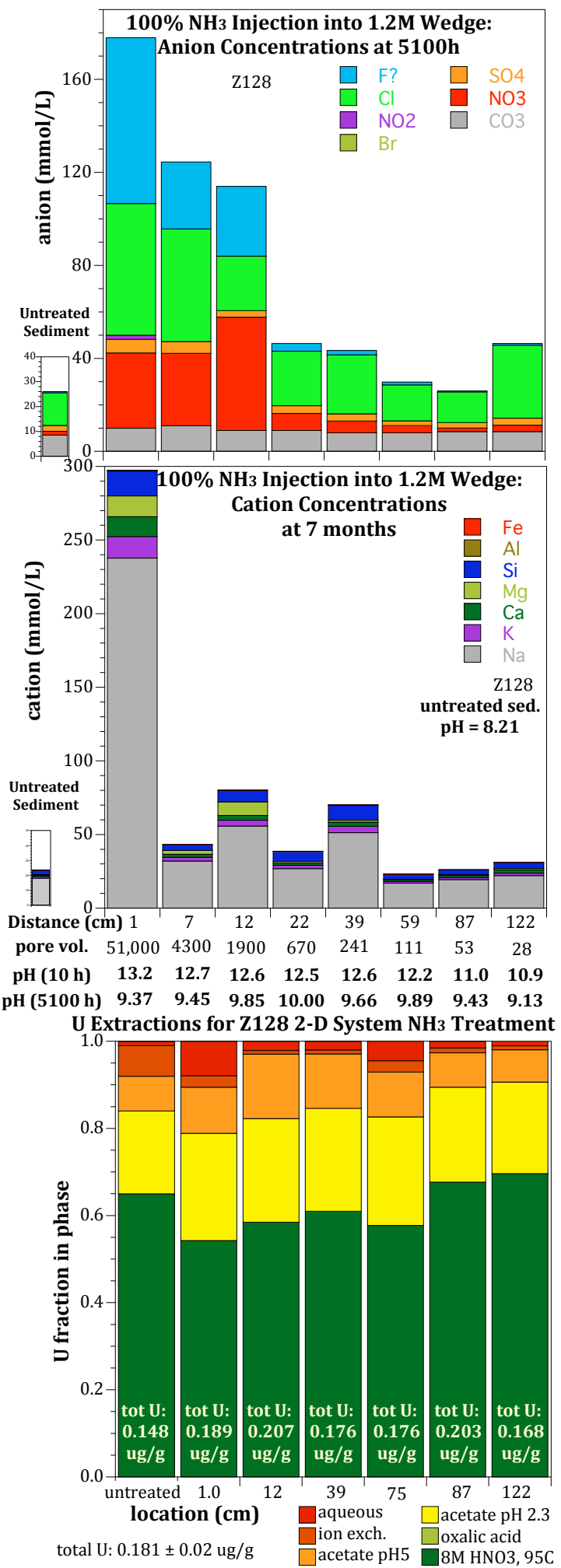

Figure 4.62. $\mathrm{NH}_{3}$ reactions with sediment shown by: a) anions, b) cations, and c) $\mathrm{U}$ extraction. 
Liquid extractions conducted to evaluate changes in uranium surface phases (Figure 4.62c) in general showed slightly higher fraction of $U$ associated with harder to extract carbonate (yellow bar), less adsorbed/aqueous $\mathrm{U}$ (red), but equal or less hard to extract $\mathrm{U}\left(8 \mathrm{M} \mathrm{HNO}_{3}\right.$, green bar). The total uranium extracted from these sediments (ERDF pit) was very small, averaging $0.18 \mu \mathrm{g} / \mathrm{g}$.

\subsection{1 $\mathrm{NH}_{3}$ Gas and Co-Contaminants: Influence on Pertechnetate Mobility}

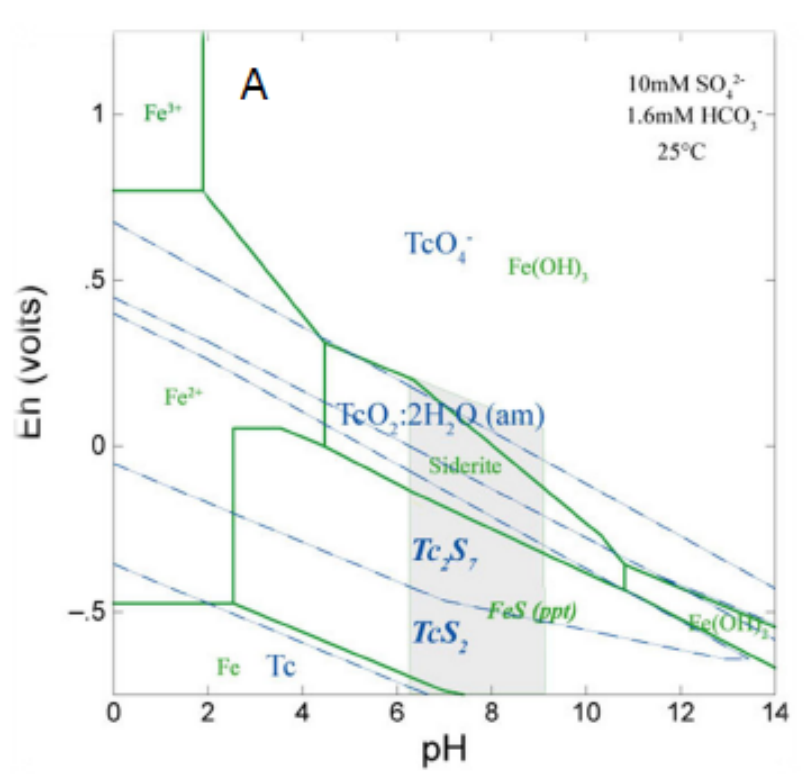

Figure 4.63. Calculated pertechnetate stability (blue) and iron oxide stability over an Eh-pH range.
A limited number of experiments were conducted with ammonia treatment of sediments containing pertechnetate to evaluate $\mathrm{NH}_{3}$ treatment effectiveness on this anion. In oxic sediment systems, as the pore water $\mathrm{pH}$ increases from 8 to 12, pertechnetate $\left(\mathrm{TcO}_{4}{ }^{-}\right)$will remain an anion (Figure 4.63). In order to decrease the mobility of pertechnetate, some sort of precipitate would have to substitute the pertechnetate anion in for the structure (phosphate, for example), or the pore water pertechnetate anion would have to be coated by a precipitate. Therefore, it is unlikely that just this $\mathrm{pH}$ increase can be used to immobilize anions. In addition, grout treatment of high level waste tanks (Lukins et al. 2005), in which the concrete used increases the $\mathrm{pH}$ to 12 , typically do not immobilize pertechnetate for the same reason.

If reducing conditions were present (i.e., a small concentration of $\mathrm{H}_{2} \mathrm{~S}$ gas used with the $\mathrm{NH}_{3}$ gas injection), then $\mathrm{Tc}_{2} \mathrm{~S}_{7}$ (with excess sulfide present) or $\mathrm{TcO}_{2}$ (with little sulfide present) should form (Figure 4.63). $\mathrm{TcO}_{2}$ is readily oxidized, whereas $\mathrm{Tc}_{2} \mathrm{~S}_{7}$ oxidation occurs more slowly (Lukins et al. 2005). Under these conditions (i.e., formation of even a temporary Tc precipitate), ${ }^{99} \mathrm{Tc}$ can be immobilized by precipitate coatings on the Tc precipitate, as previously observed (Szecsody et al. 2010, Figure 2.4). In that study, treatment of water-saturated sediment with 4M NaOH resulted in significant dissolution of multiple minerals, some of which (biotite, magnetite) created sufficient aqueous ferrous iron to reduce pertechnetate to $\mathrm{TcO}_{2}$. The subsequent precipitation of aluminosilicates on this Tc precipitate kept the Tc in a IV valence state, as measured by EXAFS/XANES.

Two different sediment samples were used in these pertechnetate experiments. For two experiments, field-contaminated sediments from the $\mathrm{BC}$ crib borehole $\mathrm{C} 7534,53-\mathrm{ft}$ depth were used (containing $144 \mathrm{pCi} / \mathrm{g}{ }^{99} \mathrm{Tc}$ ). In two additional experiments, clean ERDF pit sediment was used with ${ }^{99} \mathrm{Tc}$ addition (as pertechnetate), at a concentration of $918 \mathrm{pCi} / \mathrm{g}$. It was hypothesized that some ${ }^{99} \mathrm{Tc}$ in the field contaminated sediment may not be present as a pore water anion or would have diffused into sediment microfractures after decades of contact time (i.e., would be harder to extract) compared with ${ }^{99} \mathrm{Tc}$ just added to sediment. Extractions of BC crib sediments (Figure 4.64) show that most of the ${ }^{99} \mathrm{Tc}$ is present as an anion (pertechnete) which sorbs little at this $\mathrm{pH}$, so is extractable with water. Pertechnetate is 
present at a 50- to $65-\mathrm{ft}$ depth in both boreholes C7534 and C7540. Pore water pertechnetate concentrations were as high as $480 \mathrm{pCi} / \mathrm{mL}$ (C7534, 53-ft depth, used in experiments), with acetate (carbonate) extractable ${ }^{99} \mathrm{Tc}$ about 7 times lower concentration, and $8 \mathrm{M} \mathrm{HNO}_{3}$ extractable ${ }^{99} \mathrm{Tc}$ even lower. This indicates that some ${ }^{99} \mathrm{Tc}$ may be incorporated (or coated) in phases removed with the carbonate extraction, such as carbonates dissolved from a coating within a microfracture that contained immobile pore water with $\mathrm{TcO}_{4}{ }^{-}$.

There were a significant number of batch and 1-D column ammonia gas treatment experiments conducted with this sediment (Results Section 4.8), which showed significant mineral phase dissolution and precipitation, and a reduction in uranium mobile phases for the low concentration of uranium present.

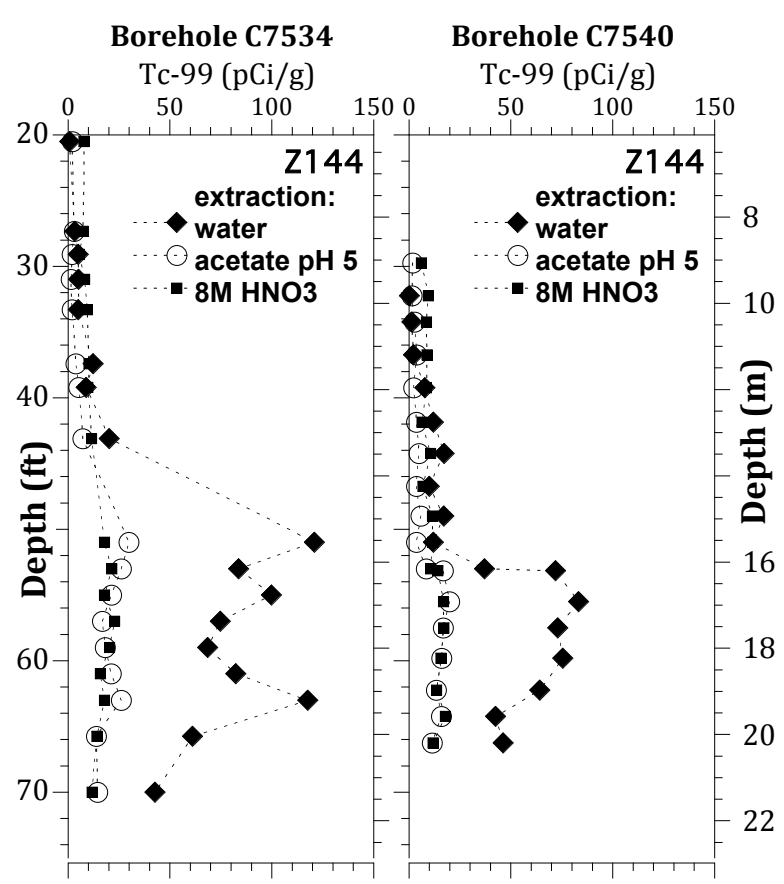

Figure 4.64. Liquid extractions of $\mathrm{BC}$ crib sediments and ${ }^{99} \mathrm{Tc}$ analysis.

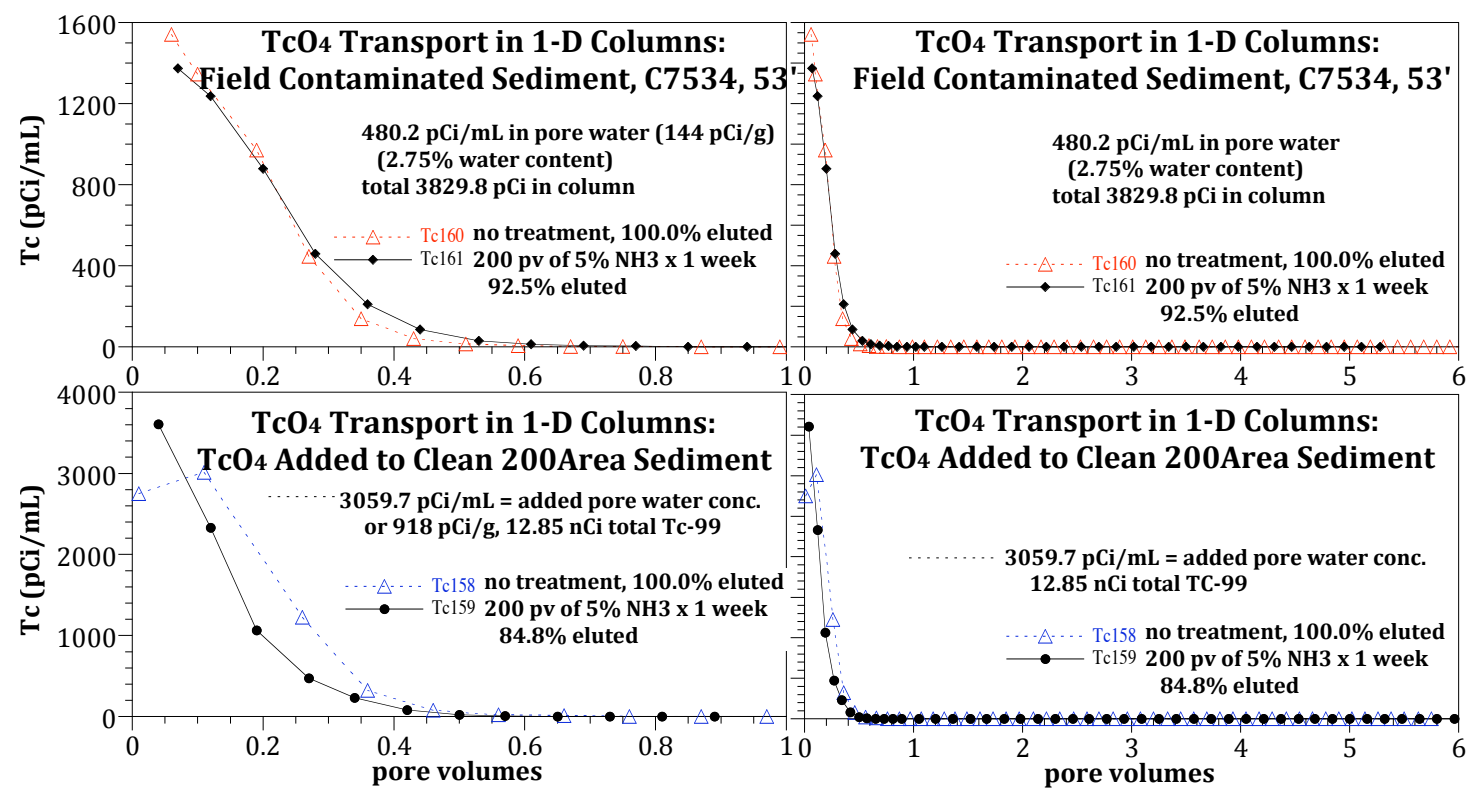

Figure 4.65. 1-D column experiments of Tc-99 leaching with groundwater without and with $\mathrm{NH}_{3}$ treatment in field-contaminated sediment $(\mathrm{a}, \mathrm{b})$, or Tc-99 addition to sediment $(\mathrm{c}, \mathrm{d})$.

Two column experiments conducted with the field contaminated sediment (Figure $4.65 \mathrm{a}, \mathrm{b}$ ) show the influence of some ammonia treatment for 1 week on ${ }^{99} \mathrm{Tc}$ leaching from the column using Hanford groundwater (red triangles) compared with untreated sediment (black diamonds). The breakthrough 
curves look nearly identical, plotted for the full 6 pore volumes of the experiment (Figure 4.65b), or just the first pore volume (Figure 4.65a). The ammonia gas treatment did, in fact, result in $7.5 \%$ less ${ }^{99} \mathrm{Tc}$ mass eluted from the column.

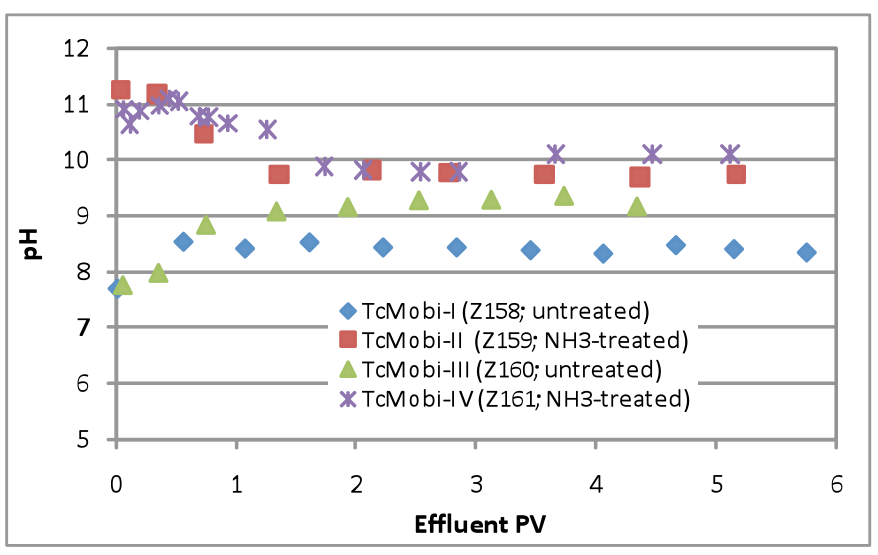

Figure 4.66. Effluent $\mathrm{pH}$ in Tc-99 1-D column experiments.
Two additional 1-D column experiments were conducted with ${ }^{99} \mathrm{Tc}$ addition to sediment. The ammonia gas treatment was identical $\left(5 \% \mathrm{NH}_{3}\right.$ for 200 pore volumes $\times$ 1 week). Results were very similar, with nearly no change in the pertechnetate leaching from the untreated sediment (black circles in Figure 4.65c, d) as $\mathrm{NH}_{3}$-treated sediment (blue triangles). In this case, $15.2 \%$ less ${ }^{99} \mathrm{Tc}$ mass leached from the sediment. Effluent $\mathrm{pH}$ in these four 1-D columns (Figure 4.66) show $\mathrm{pH} 11$ initially for the two columns that received $\mathrm{NH}_{3}$ gas treatment.

Sediment experiments with higher ammonia gas treatments with longer wait time before ${ }^{99} \mathrm{Tc}$ extraction were conducted in small 1-D columns. In this case, the different ammonia gas treatments were: a) $5 \% \mathrm{NH}_{3} \times 100$ pore volumes $\times$ 1 month, b) $5 \% \mathrm{NH}_{3} \times 1000$ pore volumes $\times 1$ month, and c) $100 \% \mathrm{NH}_{3} \times 1000$ pore volumes $\times 1$ month. Again, based on the fact that ${ }^{99} \mathrm{Tc}$ is present as an anion that exhibits nearly no sorption under the range of geochemical conditions used, it is not expected that the $\mathrm{NH}_{3}$ treatment will decrease ${ }^{99} \mathrm{Tc}$ mobility.

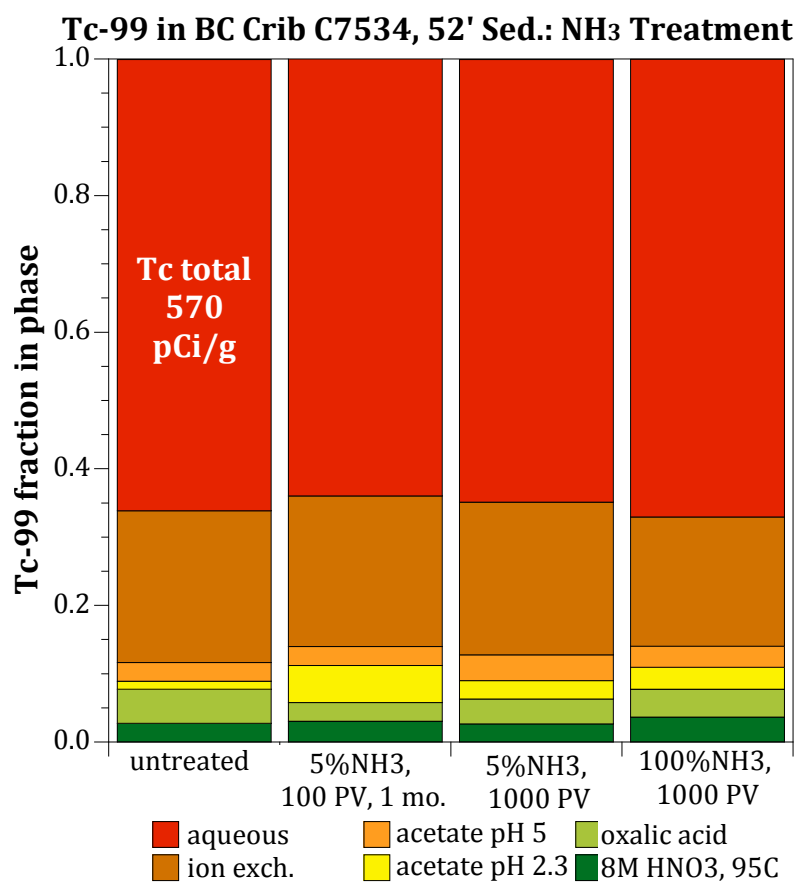

Figure 4.67. Tc-99 extraction of $\mathrm{NH}_{3}$-treated sediment.
A series of six liquid extractions were used to characterize the ${ }^{99} \mathrm{Tc}$ present on the surface. The untreated sediment (left bar, Figure 4.67) showed $65 \%{ }^{99} \mathrm{Tc}$ present in pore water, with $25 \%$ apparently adsorbed (at the low $4 \%$ water content), and the balance of $10 \%$ extracted with the four additional extractions. Ammonia gas treatments showed no significant change in ${ }^{99} \mathrm{Tc}$ extractions. There did appear to be an increase in carbonate-extractable ${ }^{99} \mathrm{Tc}$ (i.e., yellow bar, acetic acid $\mathrm{pH} 2.3$ ).

In summary, ammonia treatment of sediments increases the $\mathrm{pH}$ in Hanford sediments from 8.0 to 11-12, which has little influence on the geochemical stability of the anion pertechnetate, which exhibits very little adsorption under these conditions. Temporary adsorption and/or precipitation of ${ }^{99} \mathrm{Tc}$ with subsequent coating by aluminosilicates (under highly alkaline $\mathrm{pH} 14$ conditions in water-saturated systems) has been 
shown in previous studies to immobilize Tc-99. Therefore, a potential treatment that could be investigated in future experiments is the use of a mixed $\mathrm{NH}_{3} / \mathrm{H}_{2} \mathrm{~S}$ gas to initially precipitate Tc-99 $\left(\right.$ as $\mathrm{TcO}_{2}$ or $\mathrm{Tc}_{2} \mathrm{~S}_{7}$ ), then precipitate aluminosilicate coatings on this precipitate.

\subsection{Alternate Technology: $\mathrm{Foam} / \mathrm{PO}_{4}$ Advection into Sediment at Low Water Content}

Immobilization of uranium by formation of autunite $\left[\mathrm{Ca}\left(\mathrm{UO}_{2}\right)_{2}\left(\mathrm{PO}_{4}\right)_{2} \cdot \mathrm{XH}_{2} \mathrm{O}\right]$ by injection of sodium phosphate or polyphosphate mixture into sediment is well established in water-saturated sediment as well as in unsaturated sediment (Wellman et al. 2006a, 2006b; 2007, 2008a). To date, a polyphosphate mixture (i.e., mixture of ortho-, pyro-, and tripolyphosphate) has been injected at field scale in the Hanford Site 300 Area aquifer to sequester U(VI) species. For vadose zone uranium in situ immobilization via formation of autunite, remedial amendments are conventionally injected or infiltrated using water as the carrier. An even spatial distribution of the remedial amendment solution into the vadose zone, especially to the deep vadose zone is a challenge because the injected/infiltrated liquid preferentially percolates through some high permeable pathways or to be sucked into zones with higher capillary pressure in the vadose zone. Furthermore, highly mobile contaminants such as hexavalent chromium $[\mathrm{Cr}(\mathrm{VI})]$ and technetium $\left({ }^{99} \mathrm{Tc}\right)$ sorbed to the vadose zone soil are easily mobilized by the flushing water. It was shown that at least $95 \%$ of $\mathrm{Cr}(\mathrm{VI})$ was leached out in the first 2 pore volumes of water-based solution leaching (Zhong et al. 2009). This mobilization will form a $\mathrm{Cr}(\mathrm{VI}) /{ }^{99} \mathrm{Tc}$ moving front during the amendment solution injection. The movement of this front is out of control and may cause a spread of contamination, or even a significant contamination to the underlining ground water. The primary problem with water-based delivery systems for remedial amendments in the vadose zone is that gravitational forces have a dominating influence over the flow direction of these fluids and the flow is very hard to manipulate, resulting in risk of contamination spreading. In summary, water-based remedial amendments delivery to the vadose zone faces technical challenges.

Aqueous foam can be used to improve the delivery of remedial amendments in the vadose zone. In contrast to water-based delivery, foam-delivery has several significant advantages. First, foam flow in the vadose zone is not dominated by gravity but can be directed by pressure gradient. The flow of foam is much easier to manipulate in the vadose zone than the flow of liquid. Second, when amendments are delivered by foam, the contaminant mobilization can be remarkably minimized due to the low water content of the foam (1\%-3\% volume), thus considerably increase in-situ sequestration.

When foam is used to deliver phosphate, the presence of the surfactant in the foam may cause increased U(VI) mobility. Column tests were conducted to investigate the uranium mobility during foam injection, and to study the uranium immobilization by foam delivered phosphate. The surfactant distribution, electrical conductivity (EC) profile in foam-flushed sediment, and liquid uptake by sediment and the liquid distribution were also studied in this study.

\subsubsection{Foam Advection in Sediments at Low Water Saturation}

A few 1-D column tests were used to evaluate processes that limit foam transport in sediment. In these columns, foam was injected until the foam was part way through the column. Two columns (Figure 4.56, Z111a, b) had 2.5-cm inner diameter, while the length of Z111a was $150 \mathrm{~cm}$ and that of $\mathrm{Z} 111 \mathrm{~b}$ was $100 \mathrm{~cm}$. Sediment with $4.0 \%$ (w/w) water content was used in both columns. Surfactant 
sodium lauryl ether sulfate (STEOL CS-330) at $0.5 \%(\mathrm{w} / \mathrm{w})\left(3.75 \mathrm{mmol} \mathrm{L}^{-1}\right)$ concentration was added to the foaming solutions in both tests. For Column Z111a, sodium phosphate was added to the solution as an amendment at a concentration of $250 \mathrm{mmol} \mathrm{L}^{-1}$, while for Column $\mathrm{Z111}$ b, $1.76 \mathrm{~kg} \mathrm{~m}^{-3} \mathrm{Br}^{-}$was added to the foaming solution as a conservative tracer. The foam quality (the percentage of gas volume in total foam volume) was $98 \%$ in both tests. Sediment samples were taken across the columns after testing. The water content, surfactant concentration, and electrical conductivity (EC) of the pore water in the samples were measured for Column Z111a. The water content and $\mathrm{Br}^{-}$concentration in the pore water were determined for Column Z111b.

The water content distribution in sediment, the surfactant concentration, and the electrical conductivity (EC) in pore water in Column Z111a after foam flow into a portion of the column are shown in Figure 4.56a. In this test, foam injection was stopped when the liquid wetting front nearly reached the column effluent end. The foam flow front and liquid wetting front was at $110 \mathrm{~cm}$ and $148 \mathrm{~cm}$, respectively, when the sediment/pore water samples were taken. Figure $4.56 \mathrm{~b}$ shows the bromide concentration and water content profile obtained in Column Z111b. The foam front and liquid wetting front was at $60 \mathrm{~cm}$ and $97 \mathrm{~cm}$, respectively.
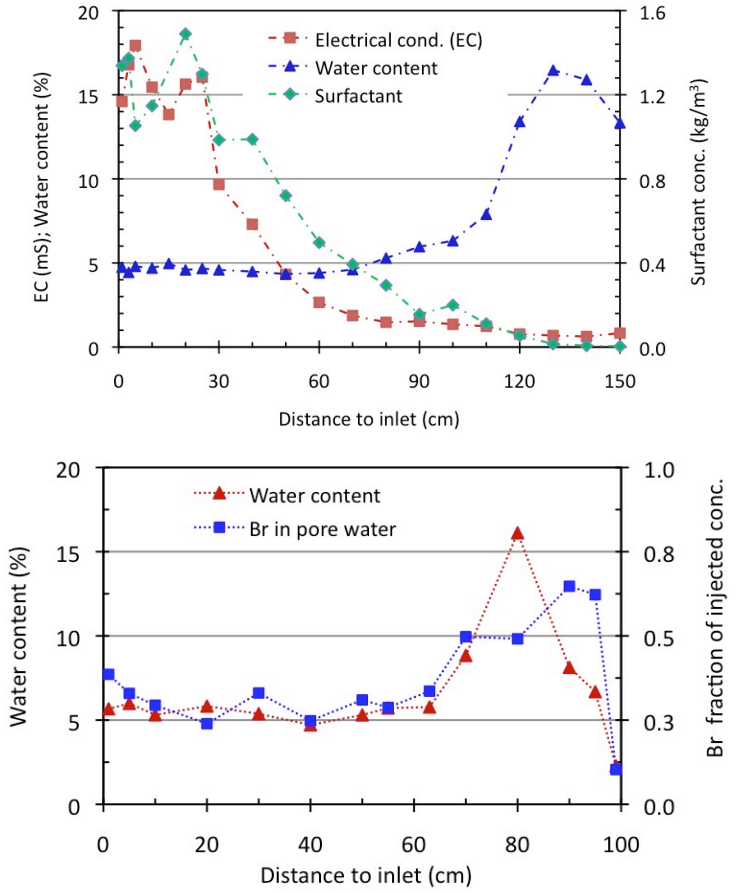

Figure 4.68. Foam injection showing: a) surfactant, EC, and water content, b) water content and $\mathrm{Br}-$.
The initial water content in the sediments was $4.0 \mathrm{wt} \%$ established by adding synthetic groundwater to the sediment. In the foam occupied region, the final water content increased to around $5.0 \mathrm{wt} \%$. Ahead of the foam front, the water content was as high as $16 \mathrm{wt} \%$ (Figure $4.68 \mathrm{a}, \mathrm{b}$ ), indicating the formation of a water accumulation zone. The bromide concentration in the foamflushed sediment was around $35 \%$ of the injected concentration $\left(C_{o}\right)$. Br concentration was higher in the accumulated liquid, reaching nearly $70 \%$ of $C_{o}$ (Figure 4.68b). The Br concentration profile indicated that the initial pore water in the sediment was generally not displaced by foam flow. Instead, the pristine water stayed in the sediment and injected water associated with the foam was advected through the larger pores with little mixing. The higher Br concentration ahead of the foam front was resulted from the accumulation of foaming liquid due to foam bubbles breakdown and thus less dilution by the pristine pore water. This observation has an important implication for field remediation. During foam delivery, the mobile (aqueous or sorbed) contaminants will not be significantly displaced by foam flow, as was observed in a previous study of chromate-contaminated sediments (Zhong et al. 2009). Contaminants stay in foam occupied regions and react with foam delivered reactants, upon foam breakdown.

The surfactant concentration and the EC in this accumulated water were close to zero (Figure 4.56a), indicating the chemicals in the water (anionic surfactant, ions in water) were not advecting beyond the 
foam front. The majority of specific conductance was contributed by the ions associated with the phosphate amendment, since its molar concentration was 67 times higher than that of the surfactant in the foaming solution. The surfactant concentration (Figure 4.67a), EC profile, and bromide distribution (Figure 4.68b) demonstrated that significant sorption of surfactant $\left(\mathrm{R}_{\mathrm{f}}=3.7, \mathrm{~K}_{\mathrm{d}} \sim 0.074 \mathrm{~cm}^{3} / \mathrm{g}\right.$ ) and phosphate amendment occurred during the foam delivery. The sorption of surfactant and remedial amendment to the delivery pass has to be considered in a field remediation design, therefore, the foaming solution keeps its foamability and sufficient amendment will be delivered to the target zone.

It was shown that the initial water content in the sediment and foam injection rate had minor impact on the final moisture content distribution in the sediment after foam injection (Zhong et al. 2010). The influence of foam quality on the final water content and distribution was not reported in literature. Two column tests, Column Z122a and $\mathrm{Z} 122 \mathrm{~b}$, were performed here to study the influence of foam quality. The foam quality was $95 \%$ and $99 \%$ for Column Z122a and Z122b, respectively. The test set up and experimental procedures were the same as described above. The foam fronts were at $\sim 65 \mathrm{~cm}$ when the tests were stopped.

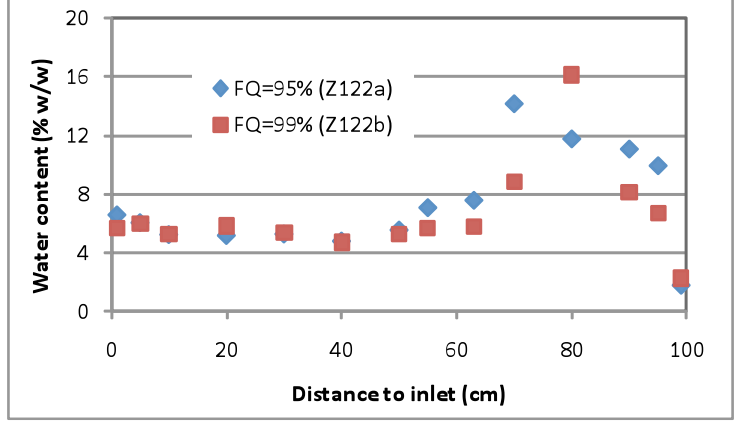

Figure 4.69. Influence of foam quality on moisture distribution in sediment.

The final water distribution across the column was shown in Figure 4.69. A distribution pattern similar to that in Figures 4.68 was observed in tests Column Z122a and Z122b. In the foam-flushed section, the water content was around $5 \% \mathrm{w} / \mathrm{w}$. A water accumulation front with similar saturation was formed in both tests. The difference in foam quality, $95 \%$ vs. $99 \%$, did not cause a significant difference in the final water content distribution in the sediment.

\subsubsection{Influence of the Presence of Foam and $\mathrm{PO}_{4}$ on $\mathrm{U}$ Advection}

A series of five 1-D column experiments were conducted to compare uranium mobilization between water and foam advection into sediment without and with phosphate.

The sediment used in all five experiments was Hanford formation 300 Area sediment from 23- to 32-ft depth (i.e., smear zone with moderate U contamination). Two water injection experiments conducted included: a) groundwater injection with no phosphate treatment (i.e., baseline experiment, Figure 4.70a), and b) groundwater injection with $47 \mathrm{mmol} / \mathrm{L}$ Na-phosphate buffered to $\mathrm{pH} 7.5$ (Figure 4.70b). Three foam injection experiments
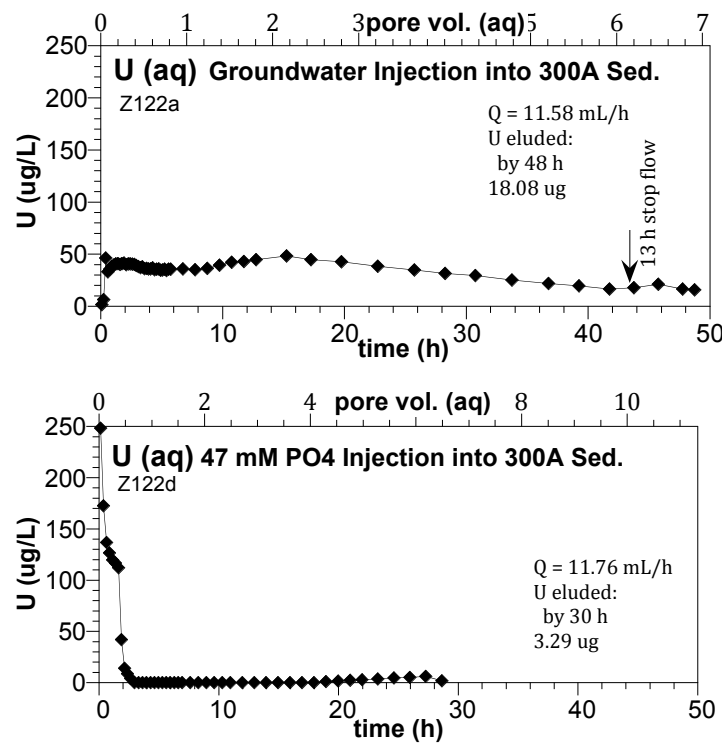

Figure 4.70. Groundwater injection into U-contaminated sediment with: a) no phosphate, and b) $47 \mathrm{mmol} / \mathrm{L} \mathrm{Na}-\mathrm{PO}_{4}$. 


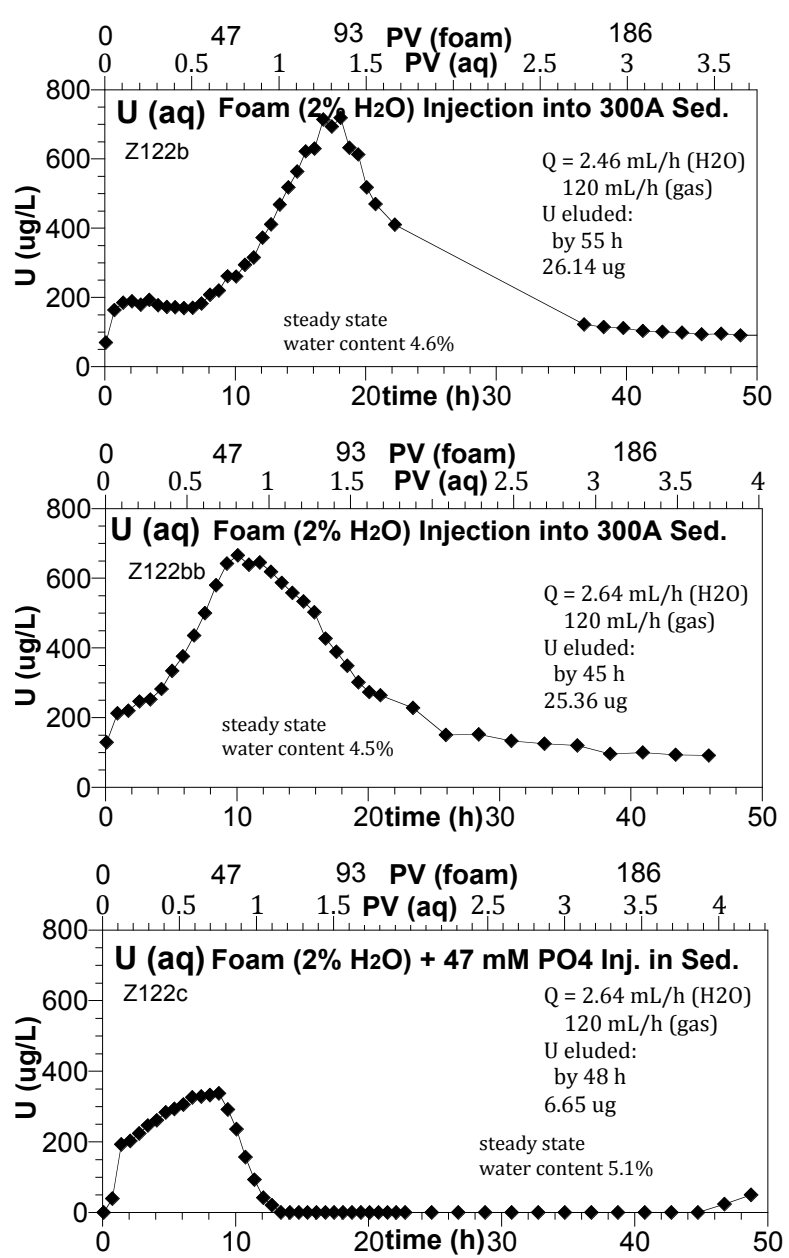

Figure 4.71. Foam injection into U-contaminated sediment with: a) no phosphate, b) no phosphate (repeat) and c) $47 \mathrm{mmol} / \mathrm{L} \mathrm{Na}-\mathrm{PO}_{4}$. Foam injection at $2 \% \mathrm{H}_{2} \mathrm{O}$; final $\mathrm{H}_{2} \mathrm{O}$ content in columns $\sim 5 \%$. included: a) foam with $2 \%$ water content (i.e., foam quality $98 \%$ ) containing $0.5 \%$ surfactant (STEOL CS-330; two experiments Figure 4.71a, b) foam with $2 \%$ water content, $0.5 \%$ surfactant and $47 \mathrm{mmol} / \mathrm{L} \mathrm{Na-phosphate} \mathrm{solution} \mathrm{(Fig-}$ ure $4.71 \mathrm{c})$. Water injection experiments were initially at low water saturation (4\%), but were at water saturation through most of the experiment. Foam injection experiments were also initially at $4 \%$ water content, and by the end of the experiments were at $4.2 \%$ to $5.1 \%$ average water content. The columns had dimensions of $2.54 \mathrm{~cm}$ inner diameter and $14.5 \mathrm{~cm}$ length. Around $140 \mathrm{~g}$ of sediment was dry-packed in each column with pore volumes of $26 \mathrm{~cm}^{3}$. Foam experiments had a liquid flow rate of $0.02 \mathrm{~mL} / \mathrm{min}$ and gas flow rate of $2.0 \mathrm{~mL} / \mathrm{min}$. Solid phase uranium extractions were conducted on the untreated sediment and sediment samples after each column treatment to address uranium mass balance.

Effective phosphate treatment takes time (weeks, months) for precipitated phosphates to slowly recrystallize from amorphous to di-Ca$\mathrm{PO}_{4}$ to apatite. Then U-carbonates highly adsorb to the phosphate precipitates and slowly recrystallize into autunite. Therefore, the comparisons in this section between untreated and $\mathrm{PO}_{4}$-treated sediments represent only the initial mobilization caused by $\mathrm{PO}_{4}$, and do not clearly show the long-term interactions of $U$ aqueous species with the precipitated phosphates.

Groundwater injection (with no phosphate, Figure 4.70a) showed the expected slow uranium breakthrough with significant tailing. Peak aqueous $\mathrm{U}$ concentration was $48 \mu \mathrm{g} / \mathrm{L}$ and the mass eluted after $50 \mathrm{~h}(7$ pore volumes) was $18 \mu \mathrm{g}$. In contrast, water injection with a high ionic strength solution containing $\mathrm{Na}_{-} \mathrm{PO}_{4}$ (Figure 4.70b) showed the expected high initial peak (250 $\mu \mathrm{g} / \mathrm{L}$ aqueous $\left.\mathrm{U}\right)$, but then little tailing. The total $\mathrm{U}$ mass eluted after $30 \mathrm{~h}$ was $3.3 \mu \mathrm{g}$, or $18 \%$ that of the untreated case. A visual comparison of the mass of $U$ eluted from these two columns over time (Figure 4.72a) show the large $\mathrm{U}$ mobilization of the untreated injection experiment and much more limited $U$ mobilization with phosphate addition. Uranium extractions (Figure 4.72b) of the untreated sediment shows $12 \%$ aqueous plus adsorbed U. Groundwater treatment removed $15 \%$ of the uranium mass (second bar), and interestingly enough appeared to reduce the uranium extracted with the weak acetic acid ( $\mathrm{pH} 5)$ extraction, which dissolves a small portion (or rind) of the carbonate. While this phase is considered a precipitate, these results clearly show this phase is partially mobilized, even in groundwater. Approximately $60 \%$ of this 
extracted phase (orange bar) was stripped out of the sediment by 7 pore volumes of groundwater injection. In comparison, phosphate addition (bar graph on the extreme right), shows that advection of the phosphate solution removed $3.1 \%$ of the uranium mass (pink), but nearly all the aqueous and adsorbed $U$ was removed, or converted into less mobile precipitates. With the initial $12 \%$ adsorbed plus aqueous $\mathrm{U}$, and $3 \%$ advected, the remaining $9 \%$ was either coprecipitated with phosphate or adsorbed phases were coated by phosphate precipitates. Over a long period of time (1 year) phosphate treatments appear to become more effective for uranium immobilization (Figure 4.1), as phosphates recrystallize and some $\mathrm{U}$ adsorbed to phosphates is converted into autunite (U-phosphate precipitate).

In comparison, foam advection (with no phosphate, Figures $4.71 \mathrm{a}, \mathrm{b}$ ) results in a high uranium initial aqueous peak (700 to $800 \mu \mathrm{g} / \mathrm{L}$ ) compared to $50 \mu \mathrm{g} / \mathrm{L}$ for groundwater injection. The mass of uranium mobilized by the foam, at $26.1 \mu \mathrm{g}$ and $25.4 \mu \mathrm{g}$, was $40 \%$ greater than groundwater $(18.1 \mu \mathrm{g})$. Addition of phosphate in the foam reduces the peak uranium concentration to some extent $(360 \mu \mathrm{g} / \mathrm{L}$, Figure $4.71 \mathrm{c})$, and significantly reduces the eluted mass $(6.6 \mu \mathrm{g})$. Clearly, the initial mobilization of uranium by foam $(<2$ pore volumes) is a concern. It should be noted that it is difficult to compare water advection experiments to foam advection experiments, as the definition of a "pore volume" for foam has multiple meanings. In Figure 4.71, U concentrations reported are in liquid (i.e., after the foam has dissipated into a small liquid volume). There are two pore volume scales, one for the equivalent water-saturated liquid, and a second pore volume scale for the actual total gas plus liquid injection ( $2 \%$ liquid, so predominantly gas flow). As these foam injection experiments were initially at $4 \%$ water content and ended at $4.4 \%$ to $5.1 \%$ water content, the general process for advecting uranium was within the liquid film of the foam bubbles in larger pores, and most of the initial pore water was not advecting in the system.
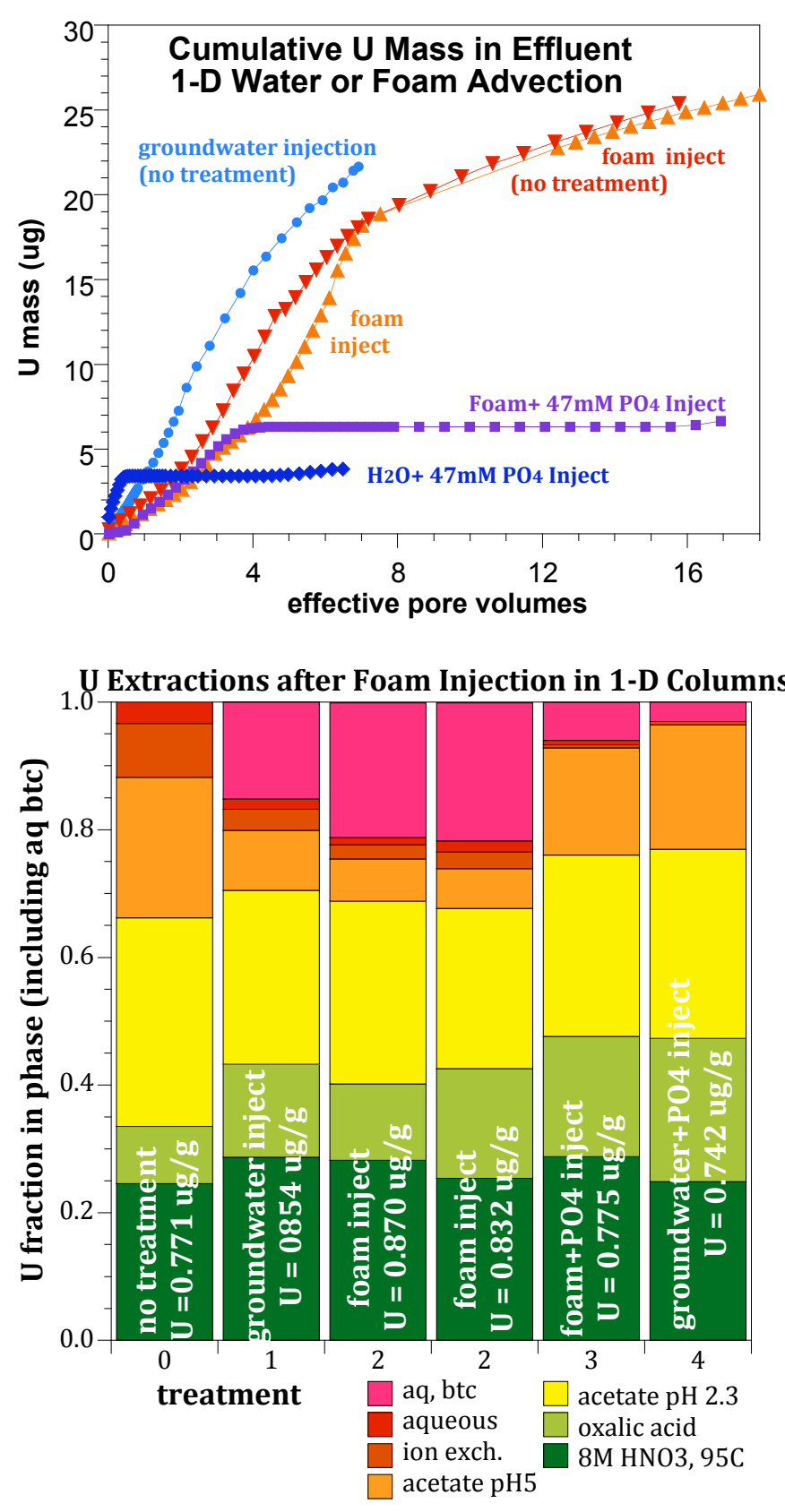

Figure 4.72. Uranium cumulative effluent mass in columns (a), and mass balance from effluent and liquid extractions (b). 
A comparison of the cumulative uranium mass advected out of foam columns to water-saturated columns (Figure 4.72a) shows somewhat slower mass advection for foam advection (although greater total mass). Foam advection resulted in the removal of $21 \%-22 \%$ of the uranium mass from the column, compared with $15.2 \%$ for water advection. For treatments with phosphate, foam advection also advects uranium out of the column more slowly than water, although the total mass advected for the foam was twice $(6.6 \mu \mathrm{g}$ or $6 \%)$ that of the water/phosphate injection $(3.3 \mu \mathrm{g}$ or $3.1 \%)$.

Uranium mass balance before and after foam injection experiments (Figure 4.72b, third and fourth stack bars) also show that foam (with no $\mathrm{PO}_{4}$ ) advected a significant fraction of the aqueous, adsorbed, and acetate ( $\mathrm{pH}$ 5) U mass initially in the column. Foam advection with phosphate (fifth stack bar, Figure 4.72b) shows a similar distribution of $U$ surface phases to water-injected phosphate, with a larger oxalate (light green) phase and decreased aqueous and adsorbed U.

\subsubsection{Influence of Heterogeneities on Foam Transport}

Vadose zone heterogeneity challenges uniform delivery of amendments. Foam injection has the potential to enhance the delivery in heterogeneous vadose zone systems attributed to its transport properties. A 2-D flow cell foam injection test was conducted to demonstrate the delivery improvement.

The flow cell had dimensions of $60 \mathrm{~cm}$ by $120 \mathrm{~cm}$ (vertical) by $1.2 \mathrm{~cm}$. Pasco gravel pit sediment $(<2 \mathrm{~mm}$ ) was used as the packing matrix. The sediment system contains random, low-permeability (low$\mathrm{K}$ ) and high-K zones and lenses distributed in the matrix with medium permeability (medium-K), which tends to occur from fluvial deposited sediment found in the 100-N Area at the Hanford Site. In both of the flow cell tests, Hanford formation sediment with sizes between $0.053 \mathrm{~mm}$ and $2.0 \mathrm{~mm}$ was used as the matrix. Fine sand (\#20326) and grade \#16 Accusand was used to pack the low-K and high-K zones and lenses, respectively. Solution with phosphate at a concentration of $47 \mathrm{mM}$ and STEOL CS-330 surfactant at $0.5 \% \mathrm{w} / \mathrm{w}$ was used as the foaming liquid. During foam injection, the $120-\mathrm{cm}$ sides of the flow cell were placed vertically. Foam with a quality of $96.2 \%$ (i.e., $3.8 \%$ of the total foam volume is liquid) was injected through a vertical well installed at the left side of the cell at a rate of $26 \mathrm{~mL} / \mathrm{min}$. Vacuum was applied to the right site of the cell. When foam injection was completed, the test cell was disassembled immediately, and sediment samples were taken to determine the water content and phosphate concentration. The liquid and chemical distribution in the heterogeneous sediment system was compared with the relevant data obtained in a 2-D flow cell phosphate infiltration test (Szecsody et al. 2009) to evaluate the two approaches of remedial chemical delivery.

The fluid distribution indicated by sediment wetting in the whole flow cell in the liquid-infiltration and foam-injection tests are illustrated in Figure 4.73. In the infiltration test, the solution migrated vertically with little lateral spreading in the matrix (medium-K) sediment. After a 4-hour infiltration period, liquid content accumulated at the bottom of the cell with sediment saturated while the liquid was distributed only about halfway across the sediment in majority of the cell (Figure 4.73). Better lateral distribution of liquid was achieved with foam injection. After 4-hours of injection, liquid distribution covered more than half of the sediments in the flow cell while no liquid had reached the bottom of the cell (Figure 4.75). With infiltration at a relatively high rate, liquid transport is dominated by gravity; therefore, migration is downward mainly. In foam injection, liquid transport is controlled mostly by the pressure gradient, which was in the horizontal direction in this foam injection test. 


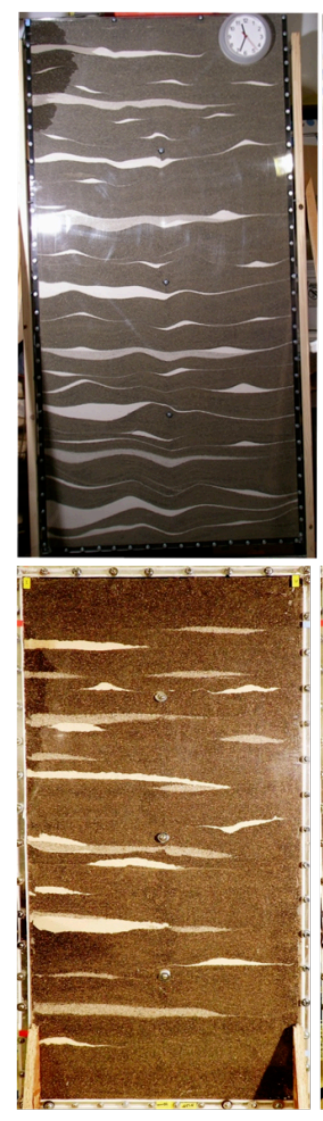

$10 \mathrm{~min}$
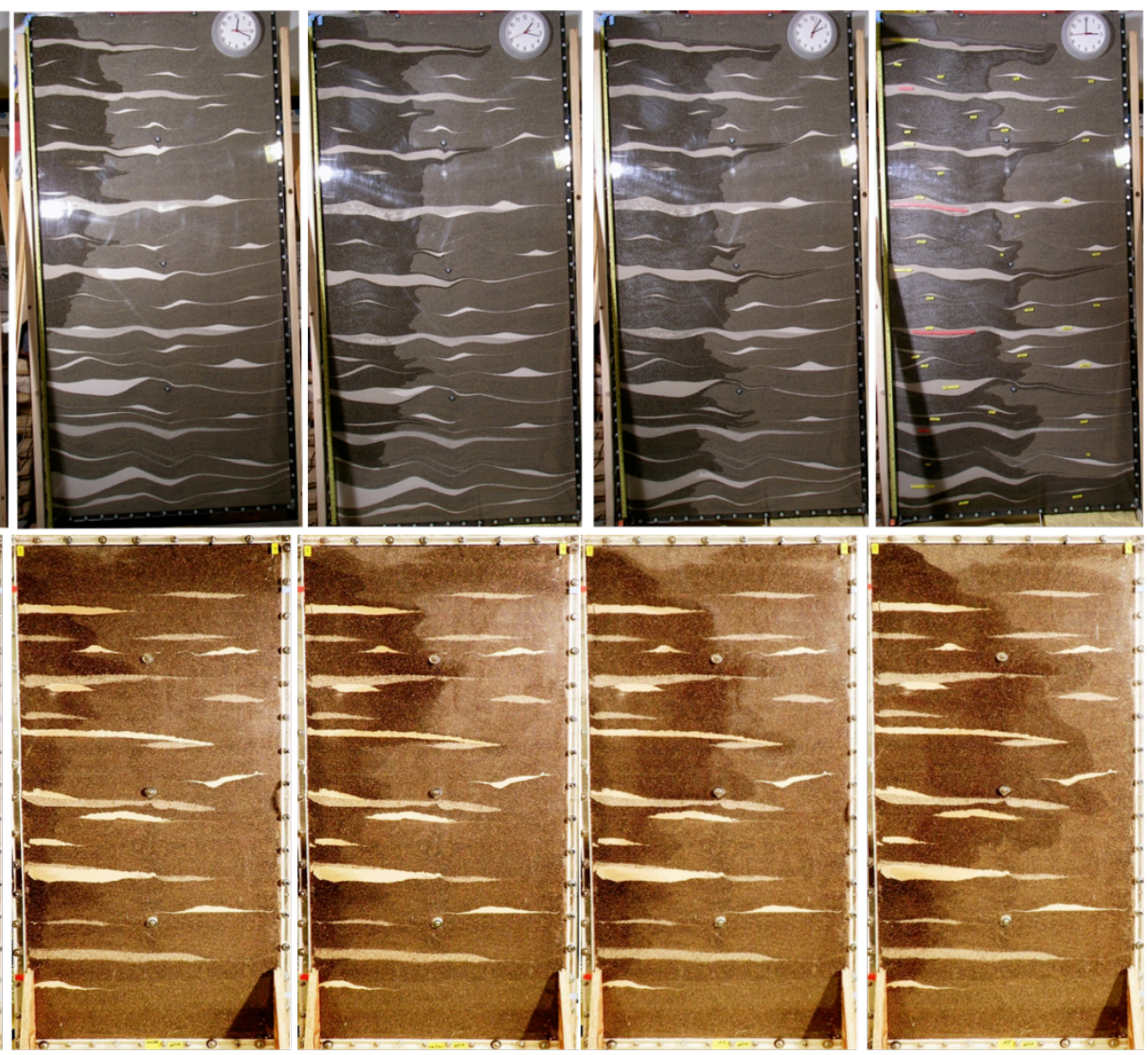

$60 \mathrm{~min}$

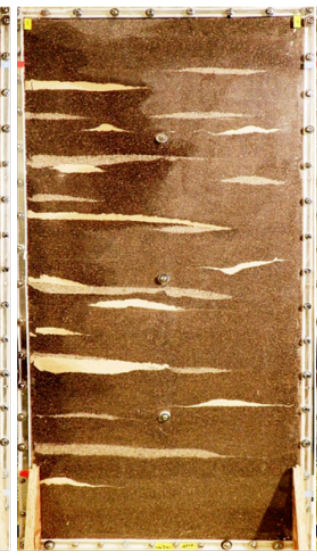

$120 \mathrm{~min}$

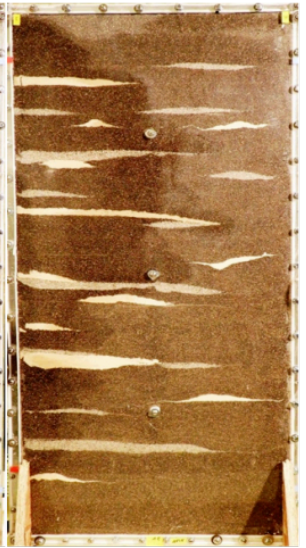

$180 \mathrm{~min}$

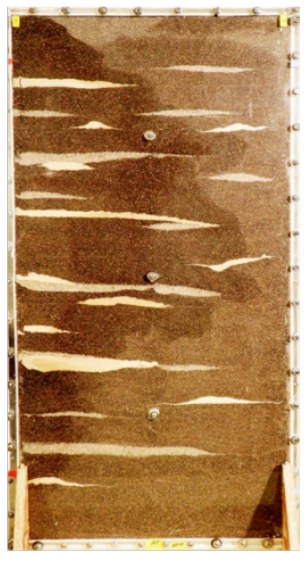

$240 \mathrm{~min}$

Figure 4.73. Liquid distribution in heterogeneous vadose zone sediment systems: infiltration (top) vs. foam injection (bottom). Infiltration system was $8 \mathrm{ft}$ (vertical) by $4 \mathrm{ft}$; foam injection system was $4 \mathrm{ft}$ (vertical) by $2 \mathrm{ft}$.

In a heterogeneous system, capillary force plays an important role in pulling more liquid into the low-K zones/leases in solution infiltration. As shown in Figure 4.73, solution migrated laterally twice the distance in low-K zones compare to that in the med-K matrix. It was also observed that lateral movement of water in low-K zone resulted in additional water saturation in the med-K sediment near to low-K zone. In the high-K zones/lenses, liquid distribution is limited and liquid transport fingering was clearly observed as shown in the close-up picture in Figure 4.74. The solution was infiltrating through the high-K zones in discontinuous pathways, leaving low residual water content. This would result in lower amendment concentration in the high-K zones (Szecsody et al. 2009).

In foam injection, the liquid flow and distribution in the high-K zones were enhanced as demonstrated in Figure 4.75, 4.76. Foam flows into/out of zones as a result of a pressure gradient. In the high-K zone, the resistance to foam transport is less than in the matrix, resulted in enhanced foam flow. More flowing foam bubbles were observed in the high-K sediment than in the matrix sediment, while no flowing bubbles could be seen in the low-K layers/zones. The preferential flow of foam in high-K media is highly useful since it brings remedial amendment into the high-K layers/zones that will be "by-passed" in liquid infiltration. In the foam injection flow cell test, capillary suction also played a role in collecting liquid into the low-K zones, as was observed in the infiltration test (Szecsody et al. 2009). 


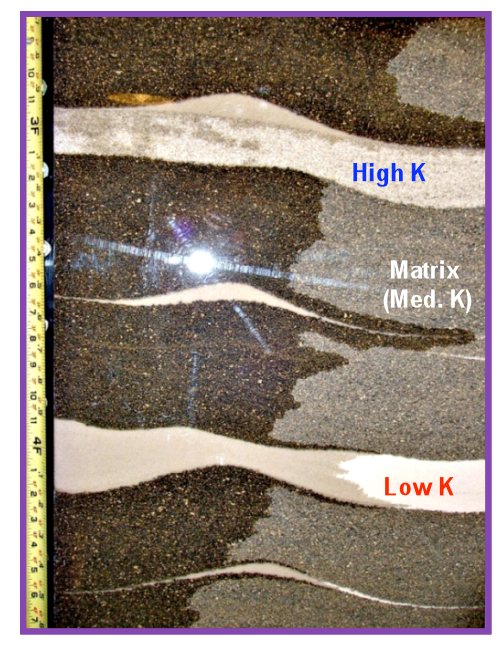

Infiltration

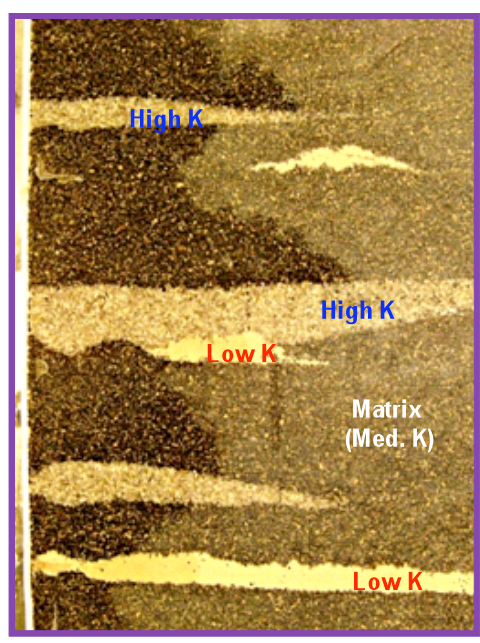

Foam injection

Figure 4.74. Liquid distribution comparison between fluid infiltration and foam injection.

The wetting front in the low-K zones was ahead of that in the matrix (Figure 4.74). Under unsaturated conditions, the bubbles at the foam front break and the foaming liquid accumulated in the sediment at the front (Zhong et al. 2010). The stronger capillary suction in the low-K zones moves the accumulated liquid into these zones, resulted a higher moisture content than that in the matrix sediment (Figure 4.75, 4.76). Low-K zones at 28, 48, and $81 \mathrm{~cm}$ (y-axis) show elevated $\mathrm{PO}_{4}$ (Figure 4.75b), whereas elevated moisture is in medium to coarse layers adjacent to low-K zones (Figure 4.75a). Foam delivery of amendments into heterogeneous vadose zone systems results in enhanced distribution of amendments into both high-K zones and low-K zones, which is beneficial for vadose zone remediation. 

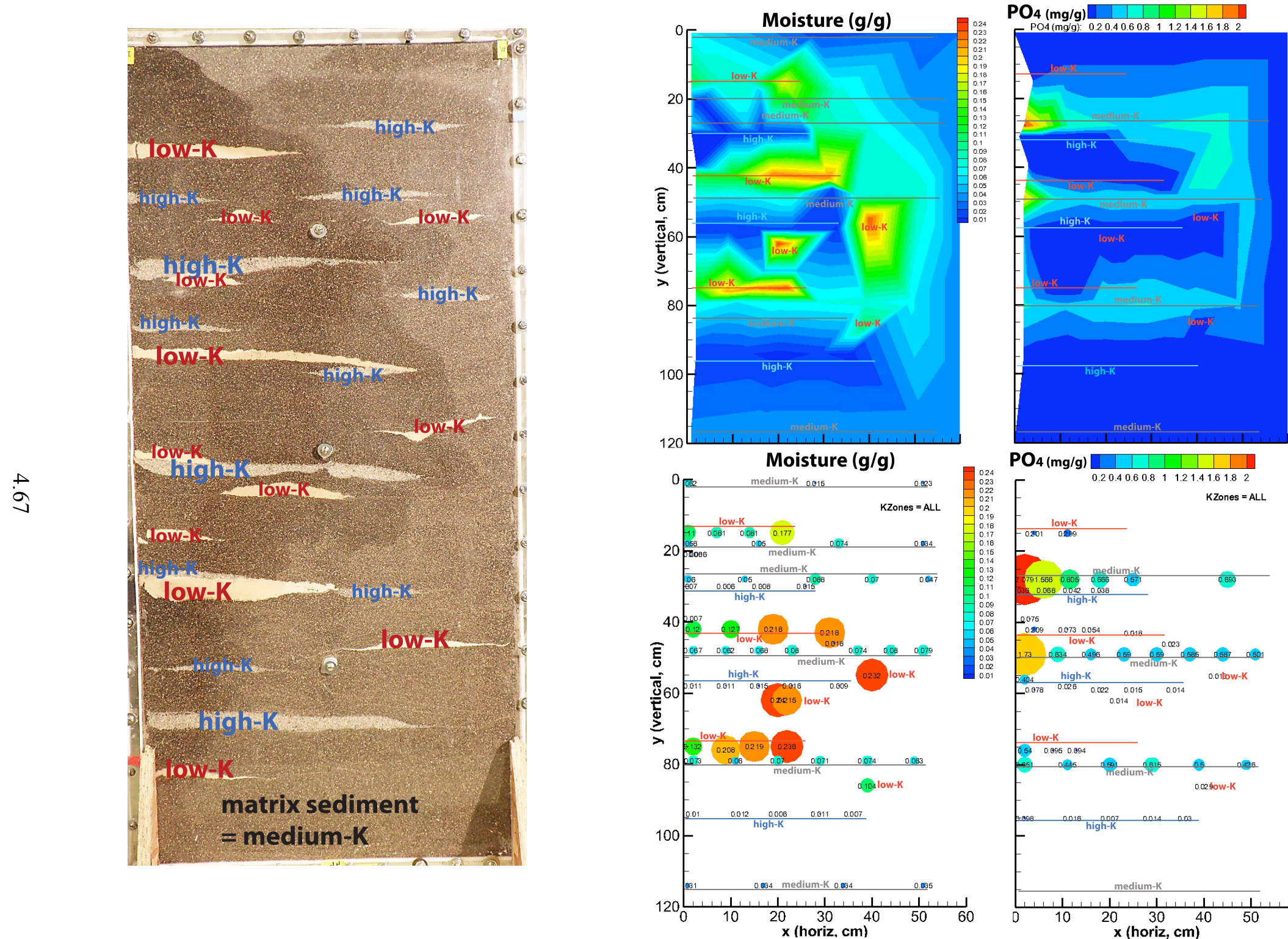

$\mathbf{P O}_{4}$ (mg/g)

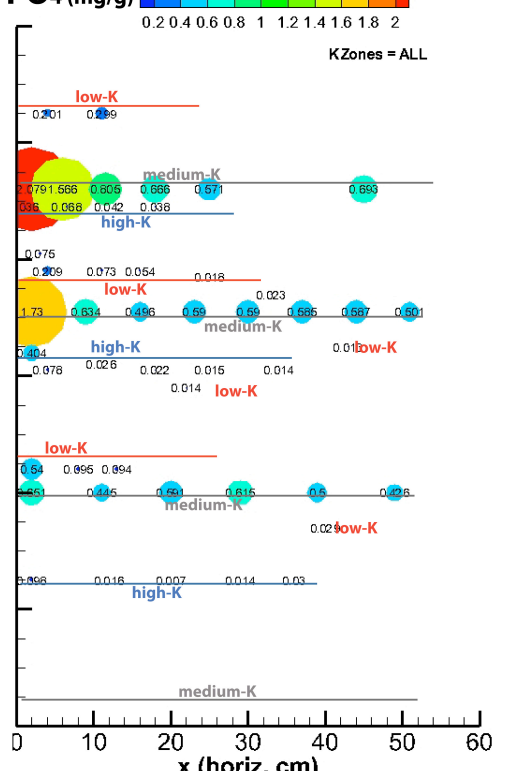

Figure 4.75. 2-D foam injection experiment moisture distribution (a) and $\mathrm{PO}_{4}$ distribution (b). 

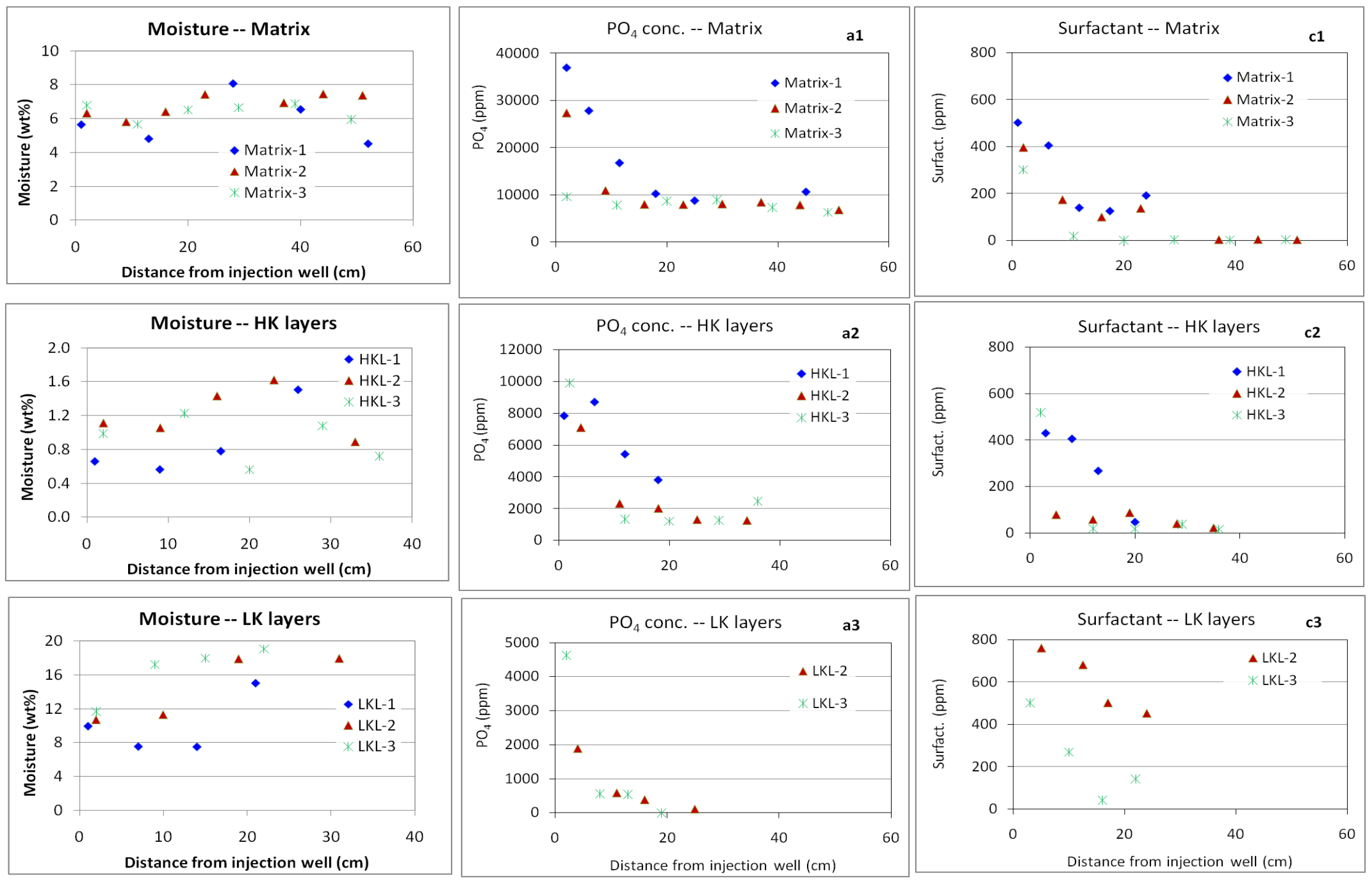

Figure 4.76. Moisture, phosphate, and surfactant concentration distribution in matrix, high-perm (HK) layer, low-perm (LK) layer from the foam injection flow cell test. 


\subsection{Discussion: U Remediation Mechanisms and Scale Up to Field}

For ammonia gas injection into vadose zone sediments to be successful as a uranium remediation technology, it needs to show decreased uranium mobility in a variety of field conditions that include 1) different sediments (mineralogy), 2) different uranium surface phases, 3) different uranium concentrations, 4) the presence of different co-contaminants, and 5) distribution of the uranium contaminants in layers of differing permeabilities. Batch, 1-D column, and 2-D flow system experiments were conducted during FY 2010 to understand the mechanisms controlling $\mathrm{NH}_{3}$ gas reactions with sediments and its limitations as a remediation approach. The following sections describe the current understanding of 1) $\mathrm{NH}_{3}$ gas reactions with low-water-content sediments and the associated impacts of the reactions on uranium form and mobility, 2) sediment mineralogy changes induced by $\mathrm{NH}_{3}$ treatment, and 3) processes that impact $\mathrm{NH}_{3}$ transport.

\section{1 $\mathrm{NH}_{3}$ Reactions with Sediment: Uranium Mineral and Mobility Change}

Different Hanford sediments (and separate minerals found in sediments) were used in experiments to quantify $\mathrm{NH}_{3}$ reactions with U-contaminated sediments. The total uranium in sediments investigated (as defined by the sum of liquid extractions used) varied from $0.18 \mu \mathrm{g} / \mathrm{g}$ to $690 \mu \mathrm{g} / \mathrm{g}$. The three main fractions of uranium in Hanford sediment include Na-boltwoodite $\left(\mathrm{Na}\left(\mathrm{UO}_{2}\right)\left(\mathrm{SiO}_{4}\right) * 1.5 \mathrm{H}_{2} \mathrm{O}\right)$ /uranophane [both hydrous U-silicates], uranium coprecipitated with carbonates, and aqueous/adsorbed U-carbonate complexes. Most of the sediments were from the Hanford formation, so the mineralogical characteristics were similar. One sediment investigated was from the Cold Creek Unit, which had significantly greater clay (29\%) and $\mathrm{CaCO}_{3}(25 \%)$. Finally, two U-bearing minerals (Na-boltwoodite, U-containing $\mathrm{CaCO}_{3}$ ) were used in an extraction study. Changes in uranium surface phases were investigated by: a) sequential liquid extractions (i.e., leaching), b) electron microprobe with elemental detectors, c) scanning electron microscope with EDS detector, d) X-ray fluorescence, and e) x-ray near edge structure (XANES) for $\mathrm{U}(\mathrm{IV}) / \mathrm{U}(\mathrm{VI})$ in combination with extended $\mathrm{x}$-ray absorbed fine structure (EXAFS) for U mineralogy. The sequence of liquid extractions used in FY 2010 included: a) aqueous U by Hanford groundwater (or synthetic groundwater) for $1 \mathrm{~h}, \mathrm{~b}$ ) ion exchangeable $\mathrm{U}$ by $0.5 \mathrm{M} \mathrm{Mg}\left(\mathrm{NO}_{3}\right)_{2}$ for $1 \mathrm{~h}$ [which will be changed to a $0.01 \mathrm{M} \mathrm{Na}-\mathrm{CO}_{3}$ solution at $\mathrm{pH} 9.3$ ), c) dissolution of a small portion of carbonates (and $13 \%$ of Na-boltwoodite) using Na-acetate at pH 5.0 for $1 \mathrm{~h}$, d) dissolution of most carbonates (and $84 \%$ of Na-boltwoodite) using acetic acid at pH 2.3 for $120 \mathrm{~h}$, e) dissolution of various (Fe-, Mg-, Al-) oxides by oxylic acid for $1 \mathrm{~h}$, and $\mathrm{f}$ ) dissolution of some remaining hard-to-extract $\mathrm{U}$ phases using $8 \mathrm{M} \mathrm{HNO}_{3}$ at $95^{\circ} \mathrm{C}$ for $2 \mathrm{~h}$. The average standard deviation of all extractions was $11.2 \%$. The standard deviation of the total $\mathrm{U}$ mass balance was $3.1 \%$. These extractions do not identify the cause of the decreased mobility, which may be an actual change in the uranium surface phase (i.e., adsorbed $U$ is now incorporated into U-carbonate), and/or precipitation of non-U-bearing minerals that coat $\mathrm{U}$ surface phases.

Sequential reactions were tested on two U-bearing minerals: Na-boltwoodite $\left(\mathrm{Na}\left(\mathrm{UO}_{2}\right)\left(\mathrm{SiO}_{4}\right) * 1.5 \mathrm{H}_{2} \mathrm{O}\right)$ and U-substituted carbonate. Na-boltwoodite $(409 \mathrm{~g} / \mathrm{mol})$ is $57.4 \%$ uranium by weight. Na-boltwoodite dissolves predominantly ( $84 \%$ of the $\mathrm{U}$ ) by the fourth (acetic acid $\mathrm{pH} 2.3$ ) extraction, with additional dissolution by the $\mathrm{pH} 5$ acetate extraction (13\% of $\mathrm{U}$ mass). The U-substituted carbonate mainly dissolved in the $\mathrm{pH} 5$ acetate extraction (extraction \#3, 84\% of $U$ mass), and was completely dissolved by 
the pH 2.3 acetic acid extraction (15\% of the $U$ mass). Therefore, in sediments that are known to contain high Na-boltwoodite concentration (BX-102, U-105 sediments reported below), the uranium extracted by acetic acid contains uranium from the dissolution of Na-boltwoodite. It should be noted that Na-boltwoodite and U-substituted carbonate found in sediments may behave somewhat differently than these pure phases because the crystal morphology may differ. A pure crystal structure present as multiple micron-sized crystals will dissolve more quickly than a single, large crystal. The Na-boltwoodite sample used for this dissolution study contained $41 \% \mathrm{U}$ by weight, so may be semicrystalline, as the calculated $\mathrm{U}$ weight fraction is $57.4 \%$.

Liquid extractions conducted on 19 different sediments (or differing $\mathrm{NH}_{3}$ treatments, Table 5.1) show that $\mathrm{NH}_{3}$ gas treatment resulted in a decrease in the most mobile uranium surface phases: 1) aqueous uranium fraction ( $86 \%$ of sediments), 2) adsorbed uranium fraction (89\% of sediments), and 3) pH 5 acetate fraction (63\% of sediments). There also was a corresponding increase in the least mobile uranium surface phase, the $8-\mathrm{M} \mathrm{HNO}_{3}$-extracted uranium (extraction 6 , in $79 \%$ of sediments). The amount of the increase in extraction 6 (i.e., the hard-to-extract uranium surface phases) varies from $0.4 \%$ to $47 \%$. There was insufficient data to support a conclusion for the oxalate-extracted uranium (extraction 5). The total carbonate extraction ( $\mathrm{pH} 2.3$ acetate, extraction 4) showed mixed results, with $\mathrm{NH}_{3}$ treatment resulting in a decrease for the uranium fraction in $53 \%$ of sediments. Liquid extractions provide an accurate value for the two most mobile phases (aqueous, adsorbed), but provide only an operationally defined measure of how mobile the remaining uranium surface phases are (extractions 3 through 6).

Quantifying a decrease in uranium mobility with these extractions is challenging because no single metric, such as a decrease in extractions 1 to 3 and an increase in extractions 4 to 6 , can describe the results. For example, the TX-104, 110-ft depth sediment (sediment 3b, Table 5.1) shows a small decrease in the sum of extractions 1,2 , and $3(3.2 \%)$ and small increase in extractions 4, 5, and $6(2.9 \%)$. However, uranium is substantially less mobile, as the adsorbed uranium fraction decreased by $26.4 \%$ and the two carbonate extractions increased by $30.4 \%$ ( $23.5 \%$ for $\mathrm{pH} 5$ acetate and $6.9 \%$ for $\mathrm{pH} 2.3$ acetate). Therefore, our judgment of uranium mobility change is based on three general categories of uranium surface phases: 1) the most mobile uranium (aqueous uranium, adsorbed uranium), 2) uranium associated with carbonates or other easily dissolved uranium phases such as sodium-boltwoodite (extractions 3 and 4), and 3) the least mobile uranium (extracted with 8- $\mathrm{M} \mathrm{HNO}_{3}$ ). $\mathrm{NH}_{3}$ gas treatment of sediments clearly decreases the amount of aqueous/adsorbed uranium (87\% of sediments tested). As described below, $\mathrm{NH}_{3}$ gas treatment also results in a major decrease in uranium associated with carbonates, but results in mixed success for sediments containing sodium-boltwoodite (i.e., a minor-to-major decrease in uranium mobility resulting from the treatment).

Measurement of the changes in uranium surface phases was done for three sediments using LIFS and EXAFS analysis. The BX-102 sediment (152-ft depth) contains uranium primarily as sodiumboltwoodite. $\mathrm{NH}_{3}$ gas treatment of this sediment also appears to reduce mobile uranium phases, as three times more uranium was extracted with extraction $6\left(8-\mathrm{M} \mathrm{HNO}_{3}\right)$. We hypothesize that $\mathrm{NH}_{3}$ gas treatment dissolves some of the sodium-boltwoodite, as alkaline conditions lead to dissolution of this mineral phase (Figure 2.6). $\mathrm{NH}_{3}$ gas treatment is not as effective for decreasing the total uranium mobility for sodium-boltwoodite compared with uranium associated with carbonates. A LIFS scan of the $\mathrm{NH}_{3}$ treated sediment shows mainly sodium-boltwoodite with a trace of adsorbed uranium, so there appears to be little change in the U surface phases. Decreased mobility (as defined by the sequential liquid extractions) is significant. It is hypothesized that: a) Na-boltwoodite is dissolving and reprecipitating, 
Table 5.1. Uranium surface phase change from ammonia gas treatment.

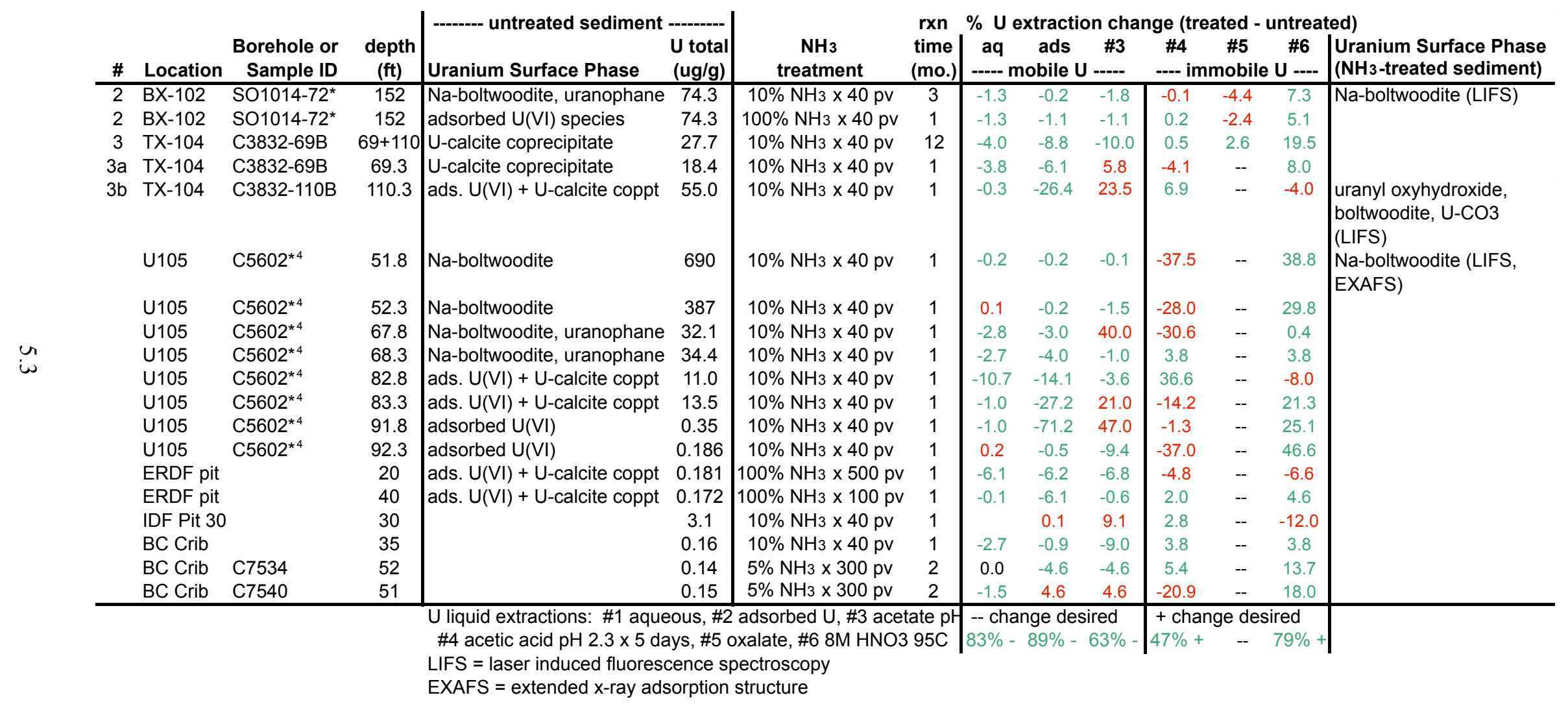


and b) mineral precipitates (non-U-bearing) are coating the Na-boltwoodite, which is resulting in the decreased overall $\mathrm{U}$ mobility. Changes in non-U-bearing precipitates are described in the following section.

The TX-104 sediment (110-ft depth, Table 5.1) has predominantly adsorbed U and U-calcite co-precipitates (Table 3.1). Sequential liquid extractions show that after ammonia gas treatment, there is a significant decrease in adsorbed $U$ and an increase in extraction \#3 (either carbonate- $U$ or Na-boltwoodite). Fluorescescence scans (LIFS) have identified the present of multiple U surface phases, including uranyl oxyhydroxide, Na-boltwoodite, and uranyl tricarbonate.

Ammonia gas treatment was also conducted on a series of sediment samples from U-105 tank borehole C5602 at eight different depths. Untreated sediments are well characterized (Um et al. 2009), and vary from a high $(690 \mu \mathrm{g} \mathrm{U} / \mathrm{g})$ uranium concentration at a 52-ft depth that is primarily

Na-boltwoodite (LIFS, EXAFS), then decrease to $32 \mu \mathrm{g} / \mathrm{g}$ by a $67-\mathrm{ft}$ depth with a mixture of U-silicates and $U$ carbonates, then decrease to near background levels $(0.35 \mu \mathrm{g} / \mathrm{g})$ by a $92-\mathrm{ft}$ depth (U likely mainly adsorbed $U$ and carbonate associated $U$ ). Ammonia treatment of sediments from eight depths all show a significant decrease in U mobility, except the 67.8-ft depth, which actually shows an increase in the $\mathrm{U}$ associated with a thin layer of carbonates. This series of extractions also shows a higher fraction of $U$ surface phase change for the carbonate/adsorbed $U$ and a smaller fraction for the Na-boltwoodite.

Laser fluorescence (LIFS) of the C5602, 52.3-ft depth $\mathrm{NH}_{3}$-treated sediment shows primarily Na-boltwoodite. Additional XANES and EFAFS analysis was conducted in the untreated and $\mathrm{NH}_{3}$-treated sediment. X-ray near edge structure (XANES) is used to identify the U valence state [i.e., fraction $\mathrm{U}(\mathrm{VI})$ and $\mathrm{U}(\mathrm{IV})$ ], whereas the extended $\mathrm{x}$-ray adsorption structure (EXAFS) is used to identify the elements that $U$ is associated with (i.e., carbonates, silicates, oxides). Preliminary analysis of the scans show little to no change in the EXAFS by the NH3 treatment, so there is little change in the local molecular structure around $U$ molecules. Changes in the $U$ release rates from sediment (as shown by sequential liquid extractions) may be due to changes in porosity, or coating by other precipitates on top of the U mineral phases.

In summary, $\mathrm{NH}_{3}$ treatment of sediments increases the $\mathrm{pH}$ in Hanford sediments from 8.0 to levels in the 11 to 12 range, which has resulted in an apparent decrease in uranium mobility, as defined by sequential liquid extractions. Surface-phase analysis has showed essentially no change in sediments initially containing sodium-boltwoodite, but some surface-phase uranium changes in uranium-calcite co-precipitates to uranyl oxyhydroxide, sodium-boltwoodite, and uranyl tricarbonate. The small fraction of aqueous and adsorbed uranium present in nearly all sediments decreased in nearly all sediments (87\%) with $\mathrm{NH}_{3}$ treatment. Therefore, the $\mathrm{NH}_{3}$ gas treatment appears most effective for uranium present as aqueous uranium, adsorbed uranium, and carbonate-associated uranium, and there were clearly changes in these uranium surface phases. For sediments containing mainly sodium-boltwoodite, the treatment was less effective (in terms of fraction change in uranium surface phases), and we hypothesize that any apparent change in uranium mobility is caused by precipitation of other mineral phases on uranium surface phases. This mechanism is described in the following section. However, there may be less need to treat uranium present as sodium-boltwoodite because it is already relatively immobile. If treatment is necessary, sodium-boltwoodite should dissolve under alkaline conditions with increased carbonate; thus, treatment could be via mixtures of $\mathrm{NH}_{3}$ and $\mathrm{CO}_{2}$, although this process would need to be tested in the laboratory. 
Representative plots of untreated and $\mathrm{NH}_{3}$-treated sediments for differing combinations of uranium total mass, uranium surface phase, and sediment mineralogy (Figure 5.1) show differences in effectiveness of the $\mathrm{NH}_{3}$ gas treatment. $\mathrm{NH}_{3}$ gas treatment for all these sediments was $10 \% \mathrm{NH}_{3}$ for 40 pore volumes (i.e., low treatment) for 1 month (relatively short duration). Previous data showed that higherlevel treatment (i.e., $\sim 300$ pore volumes of $\mathrm{NH}_{3}$ gas to achieve higher pore water $\mathrm{pH}$ ) and greater time generally result in better conversion to less mobile uranium surface phases. The three Hanford sediments shown in Figure 5.1 range from high uranium concentration (uranium as sodium-boltwoodite) in shallow sediment [Figure 5.1a]), uranium primarily associated with carbonates in deeper sediment (Figure 5.1b), and some sediments with low uranium concentration primarily as aqueous and adsorbed uranium (Figure 5.1c). The Cold Creek Unit has greater clay content and carbonate concentration when compared with sediment from the Hanford formation. Uranium in the Cold Creek Unit sediment (Figure 5.1d) primarily contains aqueous and adsorbed uranium. In all cases, aqueous and adsorbed uranium decreased substantially (red, dark orange fractions, Figure 5.2) with $\mathrm{NH}_{3}$ gas treatment. In most cases, the hard-toextract uranium phases (dark green fractions, Figure 5.2) increased, most likely because of aluminosilicate coatings on the uranium surface phases.
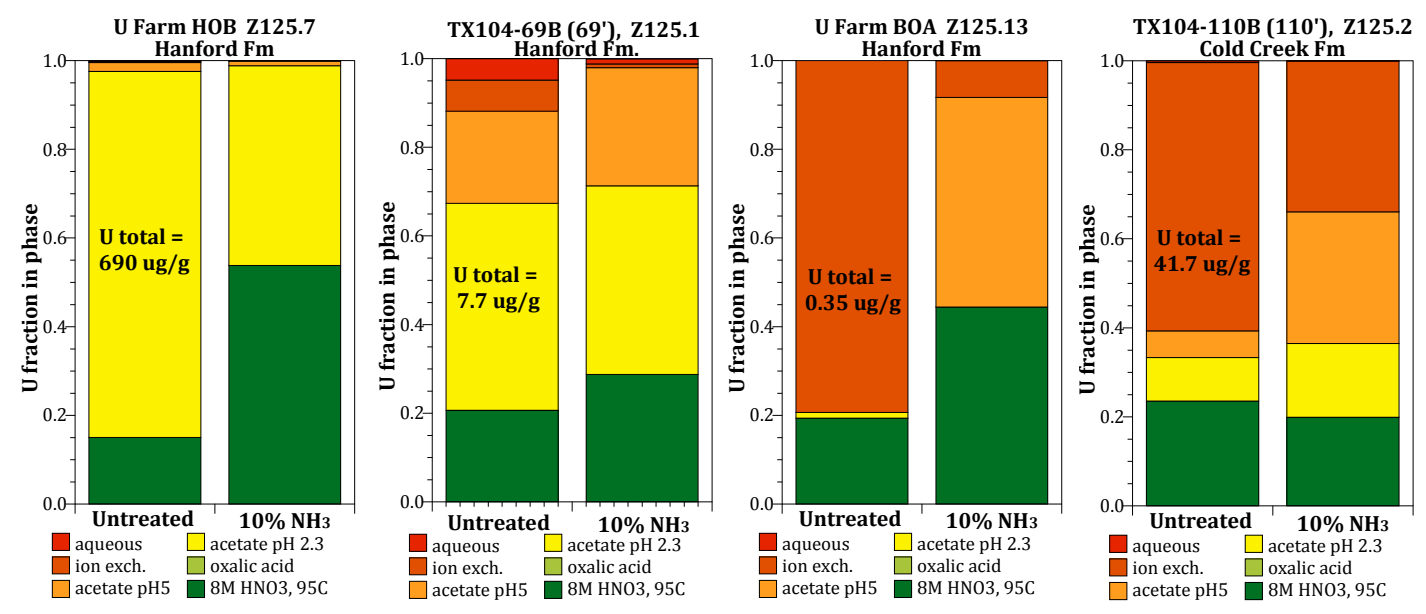

Figure 5.1. Representative U surface phase changes as defined by liquid extractions: a) high U concentration $(690 \mu \mathrm{g} / \mathrm{g})$ as Na-boltwoodite in shallow Hanford formation, b) moderate U concentration $(7.7 \mu \mathrm{g} / \mathrm{g})$ as U-carbonate deeper in the Hanford formation, c) low U concentration $(0.35 \mu \mathrm{g} / \mathrm{g})$ as primarily aqueous/adsorbed $U$ deep in the Hanford formation, and d) $U$ in the Cold Creek Formation (higher clay and carbonate content) primarily as aqueous/adsorbed U. Treatment was $10 \% \mathrm{NH}_{3} \times 40$ pore volumes for 1 month.

The influence of co-contaminants was addressed to a limited extent for two cases: a) $\mathrm{NH}_{3}$ gas treatment of ${ }^{99} \mathrm{Tc}$, and b) influence of high ionic strength in contaminated-sediments on $\mathrm{NH}_{3}$ gas treatment for $\mathrm{U}^{99} \mathrm{Tc}$ (as pertechnetate, $\mathrm{TcO}_{4}{ }^{-}$) is present in subsurface sediments at some Hanford tank/crib sites. Ammonia gas treatment resulting in an increase in pore water $\mathrm{pH}$ from 8.0 to $11-12$, has little influence on the geochemical stability of the anion pertechnetate, which should exhibit little adsorption over this $\mathrm{pH}$ range in oxic sediment. For a decrease in pertechnetate mobility to occur, it would either need to be incorporated in a surface precipitate or be on the sediment surface (i.e., adsorbed) and coated by other precipitates. Batch experiments under varied ammonia gas treatments showed no surface phase changes in Tc. Surprisingly, sequential liquid extractions showed $65 \%$ of Tc-99 mass was aqueous and $25 \%$ 


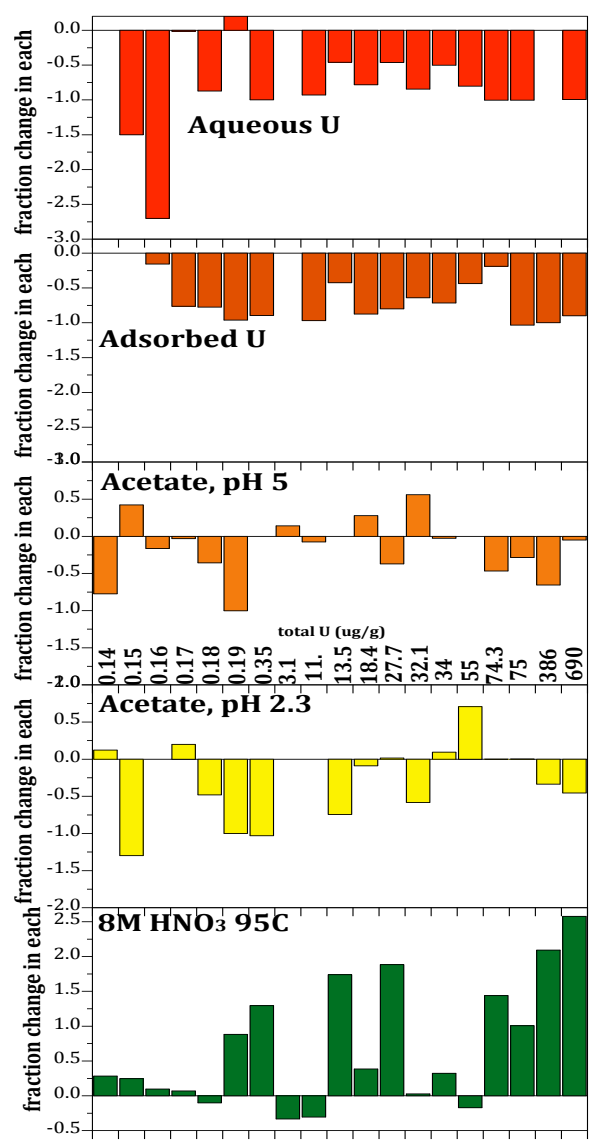

Figure 5.2. Fraction change in $U$ liquid extractions over $\mathrm{U}$ concentration as a fraction change in each extraction. adsorbed (possibly in clay interlayers). Column experiments showed a minor ( $8 \%$ to $15 \%)$ decrease in pertechnetate mobility due to the ammonia treatment, which could possibly be accounted for by clay dissolution (which occurs) and precipitate coating of a portion of the adsorbed ${ }^{99} \mathrm{Tc}$ fraction. Temporary adsorption and/or precipitation of ${ }^{99} \mathrm{Tc}$ with subsequent coating by aluminosilicates (under highly alkaline $\mathrm{pH} 14$ conditions in water-saturated systems) has been shown in previous studies to immobilize ${ }^{99} \mathrm{Tc}$. That aqueous hyperalkaline treatment was effective because biotite dissolution produced sufficient ferrous iron that pertechnetate was temporarily reduced/precipitated all aqueous ${ }^{99} \mathrm{Tc}$ (i.e., pertechnetate) mass to $\mathrm{Tc}(\mathrm{IV}) \mathrm{O}_{2}$, and then coated by aluminosilicate precipitates, which prevented its remobilization once the system was oxidized. Although $\mathrm{NH}_{3}$ gas itself was not effective, a potential treatment that could be investigated in future experiments is the use of a mixed $\mathrm{NH}_{3} / \mathrm{H}_{2} \mathrm{~S}$ gas to initially precipitate Tc-99 (as $\mathrm{TcO}_{2}$ or $\mathrm{Tc}_{2} \mathrm{~S}_{7}$ ) and then coat this precipitate with aluminosilicate induced by the ammonia treatment.

A subsurface sediment from the $\mathrm{BC}$ crib area (borehole C7534, 52-ft depth), which contained a high $(2.5 \mathrm{~mol} / \mathrm{L})$ concentration of predominantly $\mathrm{Na}-\mathrm{NO}_{3}$, was evaluated for the effect of the ionic co-contaminants on the $\mathrm{NH}_{3}$ treatment of sediment and $\mathrm{U}$ mobility change. Ammonia gas treatments (low to high mass) resulted in similar $\mathrm{pH}$ increases (i.e., $\mathrm{pH} 10.5$ to 12) to uncontaminated sediments, although pore water cation and anion concentrations changes were difficult to measure. This sediment contained low $\mathrm{U}$

$(0.165 \mu \mathrm{g} / \mathrm{g})$, which contained very little adsorbed/aqueous $\mathrm{U}$, but likely $\mathrm{U}$ carbonates and other, unidentified U surface precipitates. Ammonia gas treatments resulted in a more limited decrease in mobile $U$ phases compared with uncontaminated sediments of similar $U$ concentration (Table 5.1, C5602 borehole, 92-ft depth). It is likely that the high ionic strength pore water prevented some precipitates from forming that were coating $U$ surface phases. Therefore, the presence of co-contaminants can influence the $\mathrm{NH}_{3}$ treatment of $\mathrm{U}$ surface phases in sediments, but the geochemistry of the system (i.e., type and concentration of co-contaminants) would need to be evaluated.

\section{2 $\mathrm{NH}_{3}$ Reactions with Sediment: Major Mineralogical Changes}

Hanford formation sediment treated with $\mathrm{NH}_{3}$ gas increases the $\mathrm{pH}$ significantly (pH 10.5 to 12.5), which also results in significant mineral dissolution and precipitation. Experiments were conducted quantifying changes in aqueous/adsorbed cations and anions over time and to characterize solid phase changes. Individual minerals found in Hanford sediments also were treated with $\mathrm{NH}_{3}$ gas to evaluate dissolution. These results were compared with simulations of Hanford groundwater and sediment minerals subjected to $\mathrm{NH}_{3}$ gas treatment. Surface spectroscopic techniques used indicated that dissolution 
reactions occurring in these sediments did not result in significant dissolution of one or more mineral phases. In addition, precipitates that formed also were not present as large masses, so were difficult to identify. Therefore, dissolution/precipitation that does take place is probably similar to a thin rind of weathering on mineral surfaces, which may be responsible for coatings on some uranium surface phases, thus decreasing its mobility. Sediment minerals that did show substantial dissolution (as defined by pore water cation concentrations that are $50 \%$ to 6 times greater for $\mathrm{NH}_{3}$ treated sediment relative to untreated sediment) were clays/sheet aluminosilicates (montmorillonite, muscovite, kaolinite). This increasing cation concentration was mainly from dissolution (i.e., elevated silicon, potassium, calcium), but also to a lesser extend, desorption of cations.

The dominant aqueous cations present as a result of ammonia treatment of sediment are silica and sodium, which, as the $\mathrm{pH}$ decreases over 100 s to 1000 s of hours, decrease in concentration by only a limited (50\%) extent. Under equilibrium conditions, aqueous silica should decrease with increasing $\mathrm{pH}$ ( 8 to 11). In contrast, pore water concentrations of $\mathrm{Ca}^{2+}$ and $\mathrm{Mg}^{2+}$ decreased an order of magnitude and the $\mathrm{Fe}^{3+}$ concentration decreased two or more orders of magnitude. Therefore, the change in $\mathrm{U}$ mobility in these multiple surface phases may be dependent on specific pore water ions such as $\mathrm{Al}^{3+}$, which precipitates quickly or be largely dependent on silica, which appears to not precipitate quickly.

Ammonia gas treatment of sediment also results in an increase in pore water anion concentrations. These results also show increasing amounts of Cl- and F- with increasing ammonia treatment (and decreasing carbonate). In addition, nitrate increases with ammonia treatment in the sample with highest ammonia gas treatment. These results do show that while ammonia gas injection can result in nitrification for a zone of sediment that receives 1000 s of pore volumes of $100 \%$ ammonia treatment, this area is likely to be small at field scale with 5\% ammonia gas injection. In addition, the calculated ammonia concentration in the sediment (Table 2.1) is 1 to $4 \mathrm{~mol} / \mathrm{L}$, so $50 \mathrm{mmol} / \mathrm{L}$ nitrate (highest observed value) represents $1.2 \%$ to $5 \%$ of the $\mathrm{N}$ mass (as ammonia) being oxidized to nitrate. Actual measured values of ammonia in pore water (see Results Section 4.9) are as high as $2 \mathrm{~mol} / \mathrm{L}$.

Mineral samples of the nine most common minerals in Hanford sediment and two rocks (granite, basalt) were treated with ammonia gas to evaluate cation dissolution. Minerals that showed similar total cation concentrations between untreated and $\mathrm{NH}_{3}$-treated samples included biotite, chlorite, illite, microcline, hornblende, and quartz. Minerals that showed elevated aqueous cation concentrations included montmorillonite (producing predominantly silica), muscovite (producing predominantly potassium), and kaolinite (producing predominantly silica and potassium). However, all minerals (and rocks) showed a change in the major mineralogy from a $\mathrm{Ca}, \mathrm{Mg}$-dominated pore water to $\mathrm{Si}-\mathrm{K}-\mathrm{Ca}$ dominated pore water, so cations were both desorbing from some surfaces (clays) and the mineral phase was dissolving. Past research has shown that the most likely dissolving soil mineral in these sediments are quartz $\left[\mathrm{SiO}_{2}\right]$, feldspars $\left[\mathrm{KAlSi}_{3} \mathrm{O}_{8}-\mathrm{NaAlSi}_{3} \mathrm{O}_{8}-\mathrm{CaAl}_{2} \mathrm{Si}_{2} \mathrm{O}_{8}\right]$, micas (such as biotite) $[\mathrm{K}(\mathrm{Mg}$, $\left.\mathrm{Fe})_{3} \mathrm{AlSi}_{3} \mathrm{O}_{10}(\mathrm{~F}, \mathrm{OH})_{2}\right]$, and chlorite (most likely clinochlore: $\left(\mathrm{Mg}_{5} \mathrm{Al}\right)\left(\mathrm{AlSi}_{3}\right) \mathrm{O}_{10}(\mathrm{OH})_{8}$ or ferroan clinochlore $\left[(\mathrm{MgFeAl})_{6}(\mathrm{SiAl})_{4} \mathrm{O}_{10}(\mathrm{OH})_{8}\right]$.

To identify mineral phases dissolving and precipitating, solid phase analysis of pre- and postammonia treated sediments were analyzed by scanning electron microscopy and an electron microprobe. These studies are in progress, so mineral phases that precipitate under the low water saturation with $\mathrm{NH}_{3}$ gas treatment have not been positively identified. Under much more alkaline conditions $(4 \mathrm{M} \mathrm{NaOH}$, pH 14, Qafoku et al. 2003b, 2003c), water-saturated Hanford sediments resulted in significant mineral phase dissolution that produced sufficient ferrous iron (from biotite dissolution) that a reducing 
environment was created. Under these conditions, minerals in the groups of cancrinite, sodalite and zeolite formed. These mineral precipitates were not observed in the $\mathrm{pH}$ 11-12, oxic, low water content conditions of the $\mathrm{NH}_{3}$-gas-treated sediments. Aqueous concentrations of $\mathrm{Si}$ and $\mathrm{Al}$ formed in $\mathrm{NH}_{3}$-treated sediments were also smaller.

Carbonate was present in the pore water, but at a lower concentration than the untreated sediment. At equilibrium, the aqueous concentration of carbonate decreases with increasing $\mathrm{pH}$ (8 to 11) due to precipitation (Ca-, Mg-, Na-carbonates). At field scale, it is expected that a large sediment zone flushed with $100 \mathrm{~s}$ of pore volumes of $\mathrm{NH}_{3} / \mathrm{N}_{2}$ will not interact with soil gas $\mathrm{CO}_{2}$ over most of the flushed zone (likely some near edges that received low $\mathrm{NH}_{3}$ treatment), so carbonate is not likely to increase. However, forced advection of a secondary gas $\left(\mathrm{N}_{2}\right.$ or air) may be used after months of $\mathrm{NH}_{3}$ treatment in order to accelerate the $\mathrm{pH}$ return to natural $(\mathrm{pH} 8)$ conditions. If there is exposure to a mixed gas containing $\mathrm{CO}_{2}$, greater pore water aqueous carbonate concentrations will result (i.e., higher $\mathrm{CO}_{2}$ gas/liquid partitioning at elevated $\mathrm{pH}$, which will then precipitate as metal-carbonates. Therefore, under these conditions, carbonates will coat and/or include U surface phases. Some sequential gas treatment experiments were conducted, as described later in this section.

Sequential $\left(\mathrm{NH}_{3}\right.$, then air or $\left.\mathrm{CO}_{2}\right)$ was evaluated for $\mathrm{pH}$ neutralization after $\mathrm{NH}_{3}$ gas treatment, and parallel mixed gas $\left(\mathrm{NH}_{3} / \mathrm{CO}_{2}\right.$, then air or $\left.\mathrm{CO}_{2}\right)$ treatments were evaluated to increase sodium-boltwoodite dissolution during $\mathrm{NH}_{3}$ gas treatment. $\mathrm{NH}_{3}$ gas treatment elevates the sediment pore-water $\mathrm{pH}$, leading to mineral phase dissolution and precipitation. If a high concentration of $\mathrm{NH}_{3}$ gas is used and the gas is not flushed out of the system, the $\mathrm{pH}$ remains elevated for months, and then gradually decreases. Alternatively, if the $\mathrm{NH}_{3}$ gas is flushed with air $\left(3 \% \mathrm{CO}_{2}\right)$, the $\mathrm{pH}$ decreases more rapidly. Long-term studies did show the secondary treatment with air did result in a substantial $\mathrm{pH}$ decrease to 9.0 after 3 months; whereas, for systems that were not flushed, the $\mathrm{pH}$ remained $>10$ for systems 6 or more months ( $\mathrm{pH}$ was decreasing, but more slowly). A few experiments were conducted in which air $\left(3 \% \mathrm{CO}_{2}\right)$ or $100 \% \mathrm{CO}_{2}$ was used as secondary gas treatment after 1 month of reaction time of the $\mathrm{NH}_{3}$ with the sediment pore water. The hypothesis for evaluating mixed $\mathrm{NH}_{3} / \mathrm{CO}_{2}$ treatments is that sodium-boltwoodite dissolves to a greater extent under alkaline conditions with higher carbonate concentration, as shown in aqueous systems in a previous study (Ilton et al. 2006, Figure 2.5). To date, preliminary mixed $\mathrm{NH}_{3} / \mathrm{CO}_{2}$ treatments have not shown significant differences, but the sediments contained low sodium-boltwoodite concentrations.

\subsection{Reactive Transport of $\mathrm{NH}_{3}$ : Laboratory Results and Field-Scale Planning}

Ammonia gas partitions into sediment pore water because of low volatility (dimensionless Henry's Law partition coefficient $=6.58 \times 10^{-4}$ ), resulting in an increase in $\mathrm{pH}$. Gases have small masses per volume relative to liquids, so hundreds of pore volumes of $5 \% \mathrm{NH}_{3}$ gas are needed to reach the $\mathrm{pH}$ equilibrium conditions in pore water. During this $\mathrm{NH}_{3}$ gas/water partitioning, there are other physicochemical changes that occur including 1) pore water EC increase, 2) temperature increase, 3) liquid volume increase, 4) water viscosity decrease, and 5) pore water desiccation for very high anhydrous $\mathrm{NH}_{3}$ gas treatments. The amount of change is dependent on the $\mathrm{NH}_{3}$ gas concentration, but for $100 \% \mathrm{NH}_{3}$ (water at $15.7 \mathrm{~mol} / \mathrm{L}$ ), the water EC increases by a factor of 90 , the temperature increases $30^{\circ} \mathrm{C}$, the water volume increases by $30 \%$, and the water viscosity decreases by a factor of 4 . For $5 \% \mathrm{NH}_{3}$ gas (likely to 
be used at field scale), experiments show that the water EC increases by a factor of 15 times and the temperature increases by $4^{\circ} \mathrm{C}$. These changes might be useful as secondary indicators of reaction front movement.

Six 20-to 30-ft long 1-D column experiments and one 2-D layered system injection experiments were conducted primarily to evaluate ammonia gas reactivity during advection, to compare to previous batch studies. The focus of the 1-D column experiments included quantifying 1) the fraction of $\mathrm{NH}_{3}$ gas injected and reaction front advance, 2) the rate of $\mathrm{NH}_{3}$ gas injection and reaction front advance, and 3) the desiccation front advance. For most of the 1-D column experiments, the $\mathrm{NH}_{3}$ gas was injected only part way through the column so that the reactivity $\left(\mathrm{NH}_{3}\right.$ gas concentration, $\left.\mathrm{pH}, \mathrm{EC}\right)$ ahead, at, and behind the observed reaction front could be quantified. The $\mathrm{pH}$ and $\mathrm{EC}$ of the pore water showed a sharp reaction front, with a 1 to $2 \mathrm{pH}$ unit increase in $\mathrm{pH}$ over a short distance $(<5 \mathrm{~cm})$, due to the rapid partitioning of $\mathrm{NH}_{3}$ gas into the pore water. The concentration of $\mathrm{NH}_{3}$ injected $(1 \%, 2 \%, 5 \%$, and $100 \%)$ increased the pore-water $\mathrm{pH}, \mathrm{EC}$, and sharpness of the reaction front. Results from the 1-D column experiments in which the $\mathrm{NH}_{3}$ was injected at different velocities did not show a difference in the sharpness of the resulting $\mathrm{pH}$ or EC fronts (Figure 4.47), even though the data shown is for experiments in which there is two orders of magnitude difference in the injection velocity, indicating kinetics of the $\mathrm{NH}_{3}$ gas to liquid partitioning is rapid. An average of 234 pore volumes of $5 \% \mathrm{NH}_{3}$ gas were needed to achieve the $\mathrm{pH}$ (10.2 to 11.4) of the reaction front observed. To reach $\mathrm{pH}$ equilibrium (somewhat higher $\mathrm{pH}$ ) of the $\mathrm{NH}_{3}$ gas/liquid $(\mathrm{pH}=11.88), 465$ pore volumes of $5 \% \mathrm{NH}_{3}$ are theoretically needed. The desiccation front moved 37 times more slowly than the $\mathrm{NH}_{3}$ reaction front, so an average of 8600 pore volumes of gas would be needed to desiccate the sediment initially at $4 \%$ water content (Table 4.6). A separate desiccation study showed 25,000 pore volumes of a dry gas are needed to dry sediment that initially had a water content of $5 \%$ water content (i.e., results are similar). Therefore, in proposed $\mathrm{NH}_{3}$ gas field injections, only a small area near the injection well would be desiccated.

An $\mathrm{NH}_{3}$ gas injection experiment was conducted in a 1.2-m-long, wedge-shaped flow system to evaluate the reactive front advection during radial injection in layered sediment, which would occur at field scale. The $\mathrm{NH}_{3}$ gas front did travel faster in coarser layers at lower water content compared with the same layers at higher water content and finer grained layers. In addition, discontinuous, fine-grained layers (at higher water content) also showed lagging reactivity, as was expected. The $\mathrm{NH}_{3}$ gas reactivity in a radial system produced significantly greater effect near the injection location (thousands of pore volumes of $\mathrm{NH}_{3}$ gas), and demonstrated that desiccation and $\mathrm{NH}_{3}$ reduction to $\mathrm{NO}_{3}$ would occur in a small area near an injection well. Elevated $\mathrm{pH}$ (11 to 13.2) that initially resulted from $\mathrm{NH}_{3}$ reactivity had been buffered by 7 months of exposure to air ( $\mathrm{pH} 9$ to 10.2), and lower cation/anion concentrations indicated that significant precipitation had occurred.

Hanford Site subsurface hydraulic properties in different layers vary, which influences the field scale $\mathrm{NH}_{3}$ injection design and effectiveness. For a typical Hanford formation sediment at $20 \%$ porosity, as the water content varies from $1 \%$ (with a coarser grain size fraction) to $8 \%$, the air-filled pore space decreases, so the effective number of pore volumes of gas needed to achieve $\mathrm{pH}$ equilibrium increases from 174 pore volumes (for $1 \%$ water content, Table 5.2) to 6900 pore volumes (for $8 \%$ water content). This increases the injection time given a fixed injection rate, although a decrease in air permeability (i.e., corresponding pressure increase) also is likely to occur. The average water content in the Hanford formation vadose zone is $4 \%$, which corresponds to $\sim 1056$ pore volumes of $5 \% \mathrm{NH}_{3}$ needed to be flushed through a sediment zone to achieve $\mathrm{pH}$ equilibrium in the pore water. The Cold Creek Unit has an estimated averaged porosity of $29 \%$ (and lower bulk density of $1.7 \mathrm{~g} / \mathrm{cm}^{3}$ ), and higher water content 
$12 \%$ ). An estimated 3600 pore volumes of $5 \% \mathrm{NH}_{3}$ is needed to achieve $\mathrm{pH}$ equilibrium. The Cold Creek Unit sediment also is likely to have significantly lower gas permeability, so the injection rate will be slower. A change in the fraction of $\mathrm{NH}_{3}$ gas injected changes the resulting pore water equilibrium $\mathrm{pH}$, but not the number of pore volumes needed.

Table 5.2. Ammonia gas treatment needed under varied field conditions.

\begin{tabular}{|c|c|c|c|c|c|c|c|c|}
\hline bulk density & $\begin{array}{c}\text { total } \\
\text { porosity }\end{array}$ & water content & $\begin{array}{c}\text { water } \\
\text { vol }(\mathrm{cm} 3) \\
\end{array}$ & $\begin{array}{c}\text { air } \\
\text { vol }(\mathrm{cm} 3) \\
\end{array}$ & $\begin{array}{c}\text { temperature } \\
\text { (C) } \\
\end{array}$ & $\%$ NH3 gas & $\begin{array}{c}\text { gas pore } \\
\text { vol. needed } \\
\end{array}$ & $\begin{array}{c}\text { injection time at } \\
50 \mathrm{cfm} \text { (days) }\end{array}$ \\
\hline \multicolumn{9}{|c|}{ change water content } \\
\hline 2.05 & 0.20 & 0.01 & 0.021 & 0.180 & 17 & 5.0 & 174 & 5.4 \\
\hline 2.05 & 0.20 & 0.02 & 0.041 & 0.159 & 17 & 5.0 & 392 & 10.9 \\
\hline 2.05 & 0.20 & 0.04 & 0.082 & 0.118 & 17 & 5.0 & 1056 & 21.7 \\
\hline 2.05 & 0.20 & 0.08 & 0.164 & 0.036 & 17 & 5.0 & 6921 & 43.5 \\
\hline \multicolumn{9}{|c|}{ Hanford Formation Average Hydraulic Properties } \\
\hline 2.05 & 0.20 & 0.04 & 0.082 & 0.118 & 17 & 5.0 & 1056 & 21.7 \\
\hline \multicolumn{9}{|c|}{ Cold Creek Formation Average Hydraulic Properties } \\
\hline 1.7 & 0.29 & 0.12 & 0.204 & 0.086 & 17 & 5.0 & 3605 & $270 *$ \\
\hline
\end{tabular}




\subsection{Summary}

The objectives of this study were to 1) refine the technique of $\mathrm{NH}_{3}$ gas treatment of low-water-content sediments to minimize uranium mobility by changing uranium surface phases (or coat surface phases), 2) identify the geochemical changes in uranium surface phases during $\mathrm{NH}_{3}$ gas treatment, 3) identify broader geochemical changes that occur in sediment during $\mathrm{NH}_{3}$ gas treatment, and 4) predict and test injection of $\mathrm{NH}_{3}$ gas for intermediate-scale systems to identify process interactions that occur at a larger scale and that could impact field-scale implementation. For $\mathrm{NH}_{3}$ gas injection into vadose zone sediments to be successful as a uranium remediation technology, it needs to show decreased uranium mobility in a variety of field conditions that include different uranium surface phases (i.e., aqueous, adsorbed, minerals), uranium concentrations, presence of co-contaminants, and in different sediments. The three main fractions of uranium in Hanford sediment include sodium-boltwoodite $\left(\mathrm{Na}\left(\mathrm{UO}_{2}\right)\left(\mathrm{SiO}_{4}\right) * 1.5 \mathrm{H}_{2} \mathrm{O}\right) /$ uranophane [both hydrous uranium-silicates], uranium co-precipitated with carbonates, and aqueous/ adsorbed uranium $\left[\mathrm{Ca}_{2} \mathrm{UO}_{2}\left(\mathrm{CO}_{3}\right)_{3}(\mathrm{aq}), \mathrm{CaUO}_{2}\left(\mathrm{CO}_{3}\right)_{3}{ }^{2-}\right.$ (aq) complexes].

Ammonia treatment of sediments raises the $\mathrm{pH}$ in Hanford sediments from 8.0 to 11-13, which has resulted in a decrease in uranium mobility, as evidenced by decrease in aqueous and adsorbed uranium in $85 \%$ of the different sediments tested (different $U$ surface phase distributions or $\mathrm{NH}_{3}$ treatments) tested and an increase in $8 \mathrm{M} \mathrm{HNO}_{3}$ extracted $\mathrm{U}$ (hard to extract $\mathrm{U}$ phases, silicates/phosphates/oxides) for $79 \%$ of sediments tested. There were also inconsistent changes in two acetate extractions of $U$ surface phases as a result of the $\mathrm{NH}_{3}$ treatment. This is likely the result of dissolution of multiple surface $\mathrm{U}$ phases, as both U-carbonates and Na-boltwoodite are dissolved in these acetate extractions, and sediments contained different distributions of these phases. Liquid extractions on Na-boltwoodite showed $13 \%$ dissolution in the $\mathrm{pH} 5$ acetate solution and $84 \%$ dissolution in the $\mathrm{pH} 2.3$ acetate solution, whereas the U-carbonate tested showed $84 \%$ dissolution in the $\mathrm{pH} 5$ acetic acid solution and $100 \%$ dissolution by the $\mathrm{pH} 2.3$ acetic acid solution.

Changes in uranium surface phases were measured for three sediments using laser induced fluorescence spectroscopy (LIFS) and extended x-ray adsorption structure (EXAFS). Surface phase analysis has showed essentially no U surface mineral change in sediments initially containing Na-boltwoodite, but some U surface phase changes in U-calcite coprecipitates to uranyl oxyhydroxide, Na-boltwoodite, and uranyl tricarbonate. Therefore, the ammonia gas treatment appears most effective for $\mathrm{U}$ present as aqueous $\mathrm{U}$, adsorbed $\mathrm{U}$, and carbonate associated $\mathrm{U}$, and there were clearly changes in these U surface phases. For sediments containing mainly Na-boltwoodite, the treatment was less effective and inconsistent between Na-boltwoodite-bearing sediments (in terms of fraction change in $U$ surface phases), and any apparent change in U mobility is hypothesized caused by precipitation of other mineral phases on U surface phases. There may be less need to treat Na-boltwoodite because it is already relatively immobile (i.e., found in shallow sediments). If treatment is necessary, Na-boltwoodite should dissolve under alkaline conditions with increased carbonate; thus, treatment could be via mixtures of $\mathrm{NH}_{3}$ and $\mathrm{CO}_{2}$, although this process would need to be further tested.

Hanford formation sediment treated with ammonia gas increases the $\mathrm{pH}$ significantly $(\mathrm{pH} 10.5$ to 12.5), which also results in some mineral dissolution and precipitation. Experiments were conducted quantifying changes in aqueous/adsorbed cations and anions over time and to characterize solid phase changes. Individual minerals found in Hanford sediments were also treated with $\mathrm{NH}_{3}$ gas to evaluate dissolution. These results were compared with simulations of Hanford groundwater and sediment 
minerals subjected to $\mathrm{NH}_{3}$ gas treatment. Surface spectroscopic techniques used indicated that dissolution reactions that did occur in these sediments did not result in significant dissolution of one or more mineral phases. In addition, precipitates that formed were also not present as large masses, so were not easily identified. Therefore, the dissolution/precipitation that did take place is likely similar to a thin rind of weathering on mineral surfaces, which may be responsible for coatings on some uranium surface phases, thus decreasing its mobility. Sediment minerals that did show significant dissolution (as defined by pore water cation concentrations being $50 \%$ to 6 times greater for ammonia treated sediment relative to untreated sediment) were clays/sheet aluminosilicates (montmorillonite, muscovite, kaolinite). This increased cation concentration was mainly from dissolution (i.e., elevated $\mathrm{Si}, \mathrm{K}, \mathrm{Ca}$ ), but also to a lesser extent, desorption of cations. Most minerals (and rocks) treated with $\mathrm{NH}_{3}$ showed a change in the major ions from a $\mathrm{Ca}, \mathrm{Mg}-\mathrm{CO}_{3}$-dominated pore water to $\mathrm{Si}$-Na-Ca-Cl-dominated pore water.

Two co-contaminant issues were addressed; $\mathrm{NH}_{3}$ gas treatment effect on Tc-99 mobility and influence of high ionic strength in contaminated-sediments on $\mathrm{NH}_{3}$ gas treatment for U. Because Tc-99 (as pertechnetate, $\mathrm{TcO}_{4}{ }^{-}$) is stable and exhibits minimal sorption over geochemical conditions created by $\mathrm{NH}_{3}$ gas (i.e., oxic, $\mathrm{pH}$ 11-13), for a decrease in pertechnetate mobility to occur, it would either need to be incorporated in a surface precipitate or be coated by other precipitates that do not oxidize and remobilize Tc-99 once the system returns to natural conditions. Batch experiments with moderate (100 pore volumes of $10 \% \mathrm{NH}_{3}$ ) to high (1000 pore volumes of $100 \% \mathrm{NH}_{3}$ ) treatments showed no surface phase changes in Tc. Extractions showed that $65 \%$ of Tc- 99 mass was aqueous and $25 \%$ adsorbed. Column experiments showed a minor (8\% to $15 \%)$ decrease in pertechnetate mobility due to the ammonia treatment. Temporary adsorption and/or precipitation of Tc-99 with subsequent coating by aluminosilicates (cancrinite) under highly alkaline $\mathrm{pH} 14$, reducing conditions in water-saturated systems in a previous study did immobilize Tc-99. In that study, biotite dissolution produced sufficient ferrous iron to reduce/precipitate all aqueous $\mathrm{Tc}(\mathrm{VII}) \mathrm{O}_{4}{ }^{-}$to $\mathrm{Tc}(\mathrm{IV}) \mathrm{O}_{2}$, and was then coated by aluminosilicate precipitates, which prevented its remobilization once the system was oxidized. Although $\mathrm{NH}_{3}$ gas itself was not effective, a potential vadose zone treatment that could be investigated is $\mathrm{NH}_{3} / \mathrm{H}_{2} \mathrm{~S}$ gas to initially precipitate $\mathrm{Tc}-99\left(\right.$ as $\mathrm{TcO}_{2}$ or $\left.\mathrm{Tc}_{2} \mathrm{~S}_{7}\right)$ and then coat this precipitate with aluminosilicates.

The effect of the ionic co-contaminants on the $\mathrm{NH}_{3}$ treatment of sediment and $\mathrm{U}$ mobility change was evaluated with a subsurface sediment from the BC crib area (borehole C7534, 52-ft depth), which contained a high $(2.5 \mathrm{~mol} / \mathrm{L})$ concentration of predominantly $\mathrm{Na}-\mathrm{NO}_{3}$. Ammonia gas treatments (low to high mass) resulted in similar $\mathrm{pH}$ increases (i.e., $\mathrm{pH} 10.5$ to 12) to uncontaminated sediments, although pore water cation and anion concentrations changes were difficult to measure. Ammonia gas treatments resulted in a more limited decrease in mobile $U$ phases compared with uncontaminated sediments of similar $U$ concentration. It is likely that the high ionic strength pore water prevented some precipitates from forming that were coating $\mathrm{U}$ surface phases. Therefore, the presence of co-contaminants can influence the $\mathrm{NH}_{3}$ treatment of $\mathrm{U}$ surface phases in sediments, but the geochemistry of the system (i.e., type and concentration of co-contaminants) would need to be evaluated.

Ammonia gas injection experiments conducted in 20- to 30-ft-long, 1-D systems and a layered 2-D radial flow system were used to quantify 1) the fraction of $\mathrm{NH}_{3}$ gas injected and the resulting reaction front advance rate, 2) the rate of $\mathrm{NH}_{3}$ gas injection and the reaction front advance, 3) the desiccation front advance, and 4) influence of water content and permeability on the reaction front advance. $\mathrm{NH}_{3}$ gas injection resulted in a sharp reaction front, with a 1 to $2 \mathrm{pH}$ unit increase in $\mathrm{pH}$ over a short distance $(<5 \mathrm{~cm})$ and tenfold pore water EC increase, due to the rapid partitioning of $\mathrm{NH}_{3}$ gas into the pore water. The concentration of $\mathrm{NH}_{3}$ injected $(1 \%, 2 \%, 5 \%$, and $100 \%)$ increased the pore water $\mathrm{pH}, \mathrm{EC}$, and the 
sharpness of the reaction front. The 1-D columns experiments of $\mathrm{NH}_{3}$ injection at different velocities did not show a difference in the front sharpness for two-orders-of-magnitude difference in the injection velocity, indicating that the kinetics of the $\mathrm{NH}_{3}$ gas to liquid partitioning is very rapid. An average of 234 pore volumes of $5 \% \mathrm{NH}_{3}$ gas were needed to achieve the $\mathrm{pH}$ (10.2 to 11.4) of the reaction front observed. To reach $\mathrm{pH}$ equilibrium between $\mathrm{NH}_{3}$ gas and pore water $(\mathrm{pH}=11.88), 465$ pore volumes of $5 \% \mathrm{NH}_{3}$ theoretically would be needed (for the system porosity and water content). The desiccation front moved 37 times more slowly than the $\mathrm{NH}_{3}$ reaction front, so an average of 8600 pore volumes of gas would be needed to desiccate sediment initially at $4 \%$ water content. $\mathrm{An}^{\mathrm{NH}_{3}}$ gas injection experiment conducted in a 1.2-m-long, wedge-shaped (radial) flow system showed that the $\mathrm{NH}_{3}$ gas front did travel faster in coarser layers at lower water content compared with the same layers at higher water content and in finer-grained layers. In addition, discontinuous, fine-grained layers (at higher water contents) also showed lagging reactivity, as would be expected. $\mathrm{NH}_{3}$ gas reactivity in the 2-D radial system produced significantly greater effect near the injection location (thousands of pore volumes of $\mathrm{NH}_{3}$ gas), and demonstrated that desiccation and $\mathrm{NH}_{3}$ reduction to $\mathrm{NO}_{3}$ would occur in a small area near an injection well. Elevated $\mathrm{pH}$ (11 to 13.2) initially the result of $\mathrm{NH}_{3}$ reactivity had been buffered by 7 months of air exposure ( $\mathrm{pH} 9$ to 10.2), and lower cation/anion concentrations indicated that significant precipitation had occurred.

Overall, $\mathrm{NH}_{3}$ gas treatment of low-water content sediments appears quite effective at decreasing aqueous, adsorbed uranium concentrations. The $\mathrm{NH}_{3}$ gas treatment also is fairly effective for decreasing the mobility of uranium-carbonate co-precipitates, but shows mixed success for uranium present in sodium-boltwoodite. There are some changes in uranium-carbonate surface phases that were identified by surface-phase analysis, but no changes observed for sodium-boltwoodite. It is likely that dissolution of sediment minerals (predominantly montmorillonite, muscovite, kaolinite) under the alkaline conditions created and subsequent precipitation as the $\mathrm{pH}$ returns to natural conditions coat some of the uranium surface phases, although a greater understanding of these processes is needed to predict the long-term impact on uranium mobility. Injection of $\mathrm{NH}_{3}$ gas into sediments at low water content (1\% to $\left.16 \%\right)$ can effectively treat a large area without water addition, so there is little uranium mobilization (i.e., transport over smaller [centimeter] or larger scales). 


\subsection{References}

Anthony JW, RA Bideaux, KW Bladh, and MC Nichols. 1995. Handbook of Mineralogy, volume II, Silicates Mineral Data Publishing.

Ballirano P, E Bonaccorsi, A Maras, and S. Merlino. 2000. "The Crystal Structure of Franzinite, the Ten-Layer Mineral of the Cancrinite Group.” The Canadian Mineralogist 38:657-668.

Bao Y, MW Grutzeck, and CM Jantzen. 2005. "Preparation and properties of hydroceramic waste forms made with simulated Hanford low-activity waste." Journal of the American Ceramic Society $88: 3287-3302$.

Barnes MC, J Addai-Mensah, and AR Gerson. 1999a. "The solubility of sodalite and cancrinite in synthetic spent Bayer liquor.” Colloids Surf. A 157:101-116.

Barnes MC, J Addai-Mensah, and AR Gerson. 1999b. "The mechanism of the sodalite-to-cancrinite phase transformation in the synthetic spent Bayer liquor." Microporous Mesoporous Mater. 31:287-302.

Bickmore BR, KL Nagy, JS Young, and JW Drexier. 2001. "Nitrate-Cancrinite Precipitation on Quartz Sand in Simulated Hanford Tank Solutions." Environmental Science and Technology 35(22):4481-4486.

Blackford MG, JV Hanna, KJ Pike, ER Vance, and DS Perera. 2007. “Transmission electron microscopy and nuclear magnetic resonance studies of geopolymers for radioactive waste immobilization." Journal of the American Ceramic Society 90:1193-1199.

Bloch M and W Luecke. 1970. "The origin of fixed nitrogen in the atmosphere." Israel Journal of Earth Sciences 19:41-49.

Brimblecombe P and G Dawson. 1984. "Wet removal of highly soluble gasses." J. Atmospheric Chemistry 2:95-107.

Brina R and A Miller. 1992. "Direct detection of trace levels of uranium by laser-induced kinetic phosphorimetry." Analytical Chemistry Spectroscopy 8:1-14.

Buck EC and BK McNamara. 2004. "Precipitation of nitrate-cancrinite in Hanford tank sludge." Environ. Sci. Technol. 38:4432-4438.

Buhl J-C and J Lons. 1996. "Synthesis and crystal structure of nitrate enclathrated sodalite Na8[A1SiO4]6 (NO3)2." J. Alloys Compd. 235:41-47.

Buhl J-C, F Stief, M Fechtelkord, TM Gesing, U Taphorn, and C Taake. 2000. "Synthesis, X-ray diffraction and MAS NMR characteristics of nitrate cancrinite Na7.6[A1SiO4]6NO1.6 (H2O)2." J. Alloys Compd. 305:93-102.

Chorover J, S Choi, P Rotenberg, RJ Serne, N Rivera, C Strepka, A Thompson, KT Mueller, and PA O'Day. 2008. "Silicon control of strontium and cesium partitioning in hydroxide-weathered sediments." Geochimica et Cosmochimica Acta 72:2024-2047. 
Deng Y, JB Harsh, M Flury, JS Young, and JS Boyle. 2006a. "Mineral formation during simulated leaks of Hanford waste tanks." Appl. Geochem. 21:1392-1409.

Deng YJ, M Flury, JB Harsh, AR Felmy, and O Qafoku. 2006b. "Cancrinite and sodalite formation in the presence of cesium, potassium, magnesium, calcium and strontium in Hanford tank waste simulants." Applied Geochemistry 21:2049-2063.

DOE/RL. 2008. Deep Vadose Zone Treatability Test Plan for Hanford Central Plateau. DOE/RL-2007-56, Rev. 0, U.S. Department of Energy, Richland Operations Office, Richland, Washington.

DOE/RL. 2010. Field Test Plan for the Soil Desiccation Pilot Test. DOE/RL-2010-04, Revision 0, U.S. Department of Energy, Richland Operations Office, Richland, Washington.

Gamerdinger A, D Kaplan, and C Resch. 1998. Uranium (VI) Sorption and Transport in Unsaturated, Subsurface Hanford Site Sediments - Effect of Moisture Content and Sediment Texture: Final Report for Subtask 2b. PNNL-11975, Pacific Northwest National Laboratory, Richland, Washington.

Gerson AR and K Zheng. 1997. "Bayer process plant scale: transformation of sodalite to cancrinite." J. Cryst. Growth 171:209-218.

Green-Pedersen H and GV Korshin. 1999. "Separation of Cesium from high ionic strength solution using a cobalt hexacyanoferrate-modified graphite electrode." Environ. Sci. Technol. 33:2633-22637.

Hassan I. 1997. "Feldspathoids and their relationship to zeolites." Kuwait Journal of Science and Engineering 24:163-183.

Ilton E, C Liu, W Yantasee, Z Wang, D Moore, A Felmy, and JM Zachara. 2006. "The dissolution of synthetic Na-boltwoodite in sodium carbonate solutions." Geochimica et Cosmochimica Acta 70:4836-4849.

Leyva-Ramos R, A Jacobo-Azuara, PE Diaz-Flores, RM Guerrero-Coronado, J Mendoza-Barron, and MS Berber-Mendoza. 2008. "Adsorption of chromium(VI) from an aqueous solution on a surfactantmodified zeolite." Colloids and Surfaces A: Physicochemical and Engineering Aspects 330:35-41.

Liu C, J Zachara, O Qafoku, J McKinley, S Heald, and Z Wang. 2004. "Dissolution of Uranyl Microprecipitates in Subsurface Sediments at Hanford Site, USA." Geochimica et Cosmochimica Acta 68(22):4519-4537.

Martin P, A Gomez-Parra, and E Gonzalez-Mazo. 2006. "Simultaneous Extraction and Determination of Anionic Surfactants in Waters and Sediments." J. Chromatography A. 1114(2):205-210.

Mashal K, JB Harsh, and M Flury. 2005a. "Clay mineralogical transformations over time in Hanford sediments reacted with simulated tank waste." Soil Sci. Soc. Am. J. 69:531-538.

Mashal K, JB Harsh, M Flury, and AR Felmy. 2005b. "Analysis of precipitates from reactions of hyperalkaline solutions with soluble silica." Appl. Geochem. 20:1357-1367. 
Mashal K, JB Harsh, M Flury, AR Felmy, and H Zhao. 2004. "Colloid formation in Hanford sediments reacted with simulated tank waste." Environ. Sci. Technol. 38:5750-5756.

Mon J, YJ Deng, M Flury, and JB Harsh. 2005. "Cesium incorporation and diffusion in cancrinite, sodalite, zeolite, and allophane.” Microporous and Mesoporous Materials 86:277-286.

Park H and P Englezos. 1999. "Thermodynamic modeling of sodium aluminosilicate formation in aqueous alkaline solutions.” Ind. Eng. Chem. Res. 38:4959-4965.

Qafoku NP, CC Ainsworth, and SM Heald. 2007a. "Cr(VI) fate in mineralogically altered sediments by hyperalkaline waste fluids." Soil Sci. 172:598-613.

Qafoku NP, O Qafoku, CC Ainsworth, A Dohnalkova, and SG McKinley. 2007b. "Fe-solid phase transformations under highly basic conditions." Appl. Geochem. 22:2054-2064.

Qafoku NP, CC Ainsworth, JE Szecsody, and OS Qafoku. 2004. “Transport-controlled kinetics of dissolution and precipitation in the Hanford sediments under hyperalkaline conditions." Geochim. Cosmochim. Acta 68:2981-2995.

Qafoku NP, CC Ainsworth, JE Szecsody, and OS Qafoku. 2003a. "Aluminum effect on dissolution and precipitation under hyperalkaline conditions: I. Liquid phase transformations." J. Environ. Qual. 32:2354-2363.

Qafoku NP, CC Ainsworth, JE Szecsody, and OS Qafoku. 2003b. "Effect of coupled dissolution and redox reactions on $\mathrm{Cr}(\mathrm{VI})$ aq attenuation during transport in the Hanford sediments under hyperalkaline conditions." Environ. Sci. Technol. 37:3640-3646.

Qafoku NP, CC Ainsworth, JE Szecsody, DL Bish, JS Young, DE McCready, and OS Qafoku. 2003c. "Aluminum effect on dissolution and precipitation under hyperalkaline conditions: II. Solid phase transformations.” J. Environ. Qual. 32:2364-2372.

Serne RJ, GV Last, GW Gee, HT Schaef, DC Lanigan, CW Lindenmeier, MJ Lindberg, RE Clayton, VL LeGore, RD Orr, IV Kutnyakov, SR Baum, CF Brown, MM Valenta, and TS Vickerman. 2002. Characterization of Vadose Zone Sediment: Borehole 299-E33-45 Near BX-102 in the B-BX-BY Waste Management Area. PNNL-14083, Pacific Northwest National Laboratory, Richland, Washington.

Serne RJ, MJ Lindberg, SR Baum, GV Last, RE Clayton, KN Geiszler, GW Gee, VL LeGore, CF Brown, HT Schaef, RD Orr, MM Valenta, DC Lanigan, IV Kuthyakov, TS Vickerman, CW Lindenmeier. $2008 \mathrm{a}$. Characterization of Vadose Zone Sediment: Borehole 299-E33-45 Near BX 102 in the B-BX-BY Waste Management Area. PNNL-14083, Rev. 1, Pacific Northwest National Laboratory, Richland, Washington.

Serne RJ, MJ Lindberg, MM Valenta, BN Bjornstad, RE Clayton, IV Kutnyakov, DG Horton, VL LeGore, TS Vickerman, DC Lanigan, KN Geiszler, RD Orr, HT Schaef, SR Baum, CF Brown, and CW Lindenmeier. 2008b. Characterization of Vadose Zone Sediments Below the T Tank Farm: Boreholes C4104, C4105, 299-W10-196, and RCRA Borehole 299-W11-39. PNNL-14849, Rev. 1, Pacific Northwest National Laboratory, Richland, Washington. 
Simpson BC, RA Corbin, MJ Anderson, CT Kincaid, and JM Zachara. 2006. Identification and Classification of the Major Uranium Discharges and Unplanned Releases at the Hanford Site Using the Soil Inventory Model (SIM) Rev. 1 Results. NUV-06-21106-ES-001-DOC Rev. 1, Novotec, USA Inc., Cincinnati, Ohio.

Smith S and J Szecsody. 2010. "Influence of Contact Time on the Extraction of 233 Uranyl Spike and Contaminant Uranium from Hanford Sediment.” Radiochimica Cosmochemica Acta (In Press).

Szecsody J, N Hess, and JP McKinley. 2001. "Pertechnetate Reduction During Transport at High Ph in Natural Sediments." Presented at U.S. DOE Environmental Management Science Program Vadose Zone Principal Investigator Workshop, Environmental Molecular Sciences Laboratory, November 5-6, 2001, Pacific Northwest National Laboratory, Richland, Washington.

Szecsody J, M Rockhold, M Oostrom, R Moore, C Burns, M Williams, L Zhong, J Fruchter, J McKinley, V Vermeul, M Covert, T Wietsma, A Breshears, and B Garcia. 2009. Sequestration of Sr-90 Subsurface Contamination in the Hanford 100-N Area by Surface Infiltration of a Ca-Citrate-Phosphate Solution. PNNL-18303, Pacific Northwest National Laboratory, Richland, Washington.

Szecsody, JE, MJ Truex, L Zhong, MD Williams, and CT Resch. 2010. Remediation of Uranium in the Hanford Vadose Zone Using Gas-Transported Reactants: Laboratory-Scale Experiments. PNNL-18879, Pacific Northwest National Laboratory, Richland, Washington.

Um W, Z Wang, J Serne, B Williams, C Brown, C Dodge, and A Francis. 2009. "Uranium Phase in Contaminated Sediments Below Hanford's U Tank Farm.” Environmental Science and Technology 43(12):4280-4286.

Um W, J Zachara, C Liu, D Moore, and K Rod. 2010. "Resupply mechanism to a contaminated aquifer: A laboratory study of U(VI) desorption from capillary fridge sediments." Geochimica et Cosmochimica Acta (In Press).

Wan JM, JT Larsen, TK Tokunaga, and ZP Zheng. 2004a. "pH neutralization and zonation in alkalinesaline tank waste plumes.” Environ. Sci. Technol. 38:1321-1329.

Wan JM, TK Tokunaga, JT Larsen, and RJ Serne. 2004b. "Geochemical evolution of highly alkaline and saline tank waste plumes during seepage through vadose zone sediments." Geochim. Cosmochim. Acta 68:491-502.

Weast R. 1984. CRC Handbook of Chemistry and Physics, 64th Edition. CRC Press, Boca Raton, Florida.

Wellman DM, JP Icenhower, AP Gamerdinger, and SW Forrester. 2006a. "Effects of Ph, Temperature, and Aqueous Organic Material on the Dissolution Kinetics of Meta-Autunite Minerals ( $\mathrm{Na}, \mathrm{Ca}) 2$ 1[(UO2)(PO4)]2 3H2O.” American Mineralogist 91:143-158.

Wellman DM, JP Icenhower, and AT Owen. 2006b. "Comparative Analysis of Soluble Phosphate Amendments for the Remediation of Heavy Metal Contaminants: Effect on Sediment Hydraulic Conductivity." Environmental Chemistry 3:219-224. 
Wellman DM, EM Pierce, EL Richards, BC Butler, KE Parker, JN Glovack, SD Burton, SR Baum, ET Clayton, and EA Rodriguez. 2007. Interim Report: Uranium Stabilization Through Polyphosphate Injection - 300 Area Uranium Plume Treatability Demonstration Project. PNNL-16683, Pacific Northwest National Laboratory, Richland, Washington.

Wellman DM, EM Pierce, DH Bacon, M Oostrom, KM Gunderson, SM Webb, CC Bovaird, EA Cordova, ET Clayton, KE Parker, RM Ermi, SR Baum, VR Vermeul, and JS Fruchter. 2008a. 300 Area Treatability Test: Laboratory Development of Polyphosphate Remediation Technology for In Situ Treatment of Uranium Contamination in the Vadose Zone and Capillary Fringe. PNNL-17818, Pacific Northwest National Laboratory, Richland, Washington.

Wellman DM, JM Zachara, C Liu, NP Qafoku, SC Smith, and SW Forrester. 2008b. “Advective Desorption of Uranium(VI) from Contaminated Hanford Vadose Zone Sediments Under Saturated and Unsaturated Conditions." Vadose Zone Journal 7(4):1144-1159.

Yoo K, S Lee, and W Lee. 1986. "Ionization and Henry's Law constants for volatile, weak electrolyte water pollutants." Korean J. of Chemical Engineering 3(1):67-72.

Zachara J, C Liu, C Brown, S Kelly, J Christensen, J McKinley, J Davis, J Serne, E Dresel, and W Um. 2007. A Site-Wide Perspective on Uranium Geochemistry at the Hanford Site. PNNL-17031, Pacific Northwest National Laboratory, Richland, Washington.

Zhao HT, YJ Deng, JB Harsh, M Flury, and JS Boyle. 2004. "Alteration of kaolinite to cancrinite and sodalite by simulated Hanford tank waste and its impact on cesium retention." Clays Clay Min. 52:1-13.

Zheng K, AR Gerson, J Addai-Mensah, and RSC Smart. 1997. "The influence of sodium carbonate on sodium aluminosilicate crystallisation and solubility in sodium aluminate solutions." J. Cryst. Growth 171:197-208.

Zheng Z, G Zhang, and J Wan. 2008. "Reactive transport modeling of column experiments on the evolution of saline-alkaline waste solutions." Journal of Contaminant Hydrology 97:42-54.

Zhong L, N Qafoku, JE Szecsody, PE Dresel, and ZF Zhang. 2009. "Foam Delivery of Calcium Polysulfide to Vadose Zone for Chromium-VI Immobilization: A Laboratory Evaluation." Vadose Zone Journal 8(4):976-985.

Zhong L, JE Szecsody, ZF Zhang, and SV Mattigod. 2010. "Foam Delivery of Amendments for Vadose Zone Remediation -- Propagation Performance in Unsaturated Sediments." Vadose Zone Journal 9(3):757-767. 


\section{Appendix A}

\section{Electron Microprobe Analysis of}

$\mathrm{NH}_{3}$-Treated Sediments 


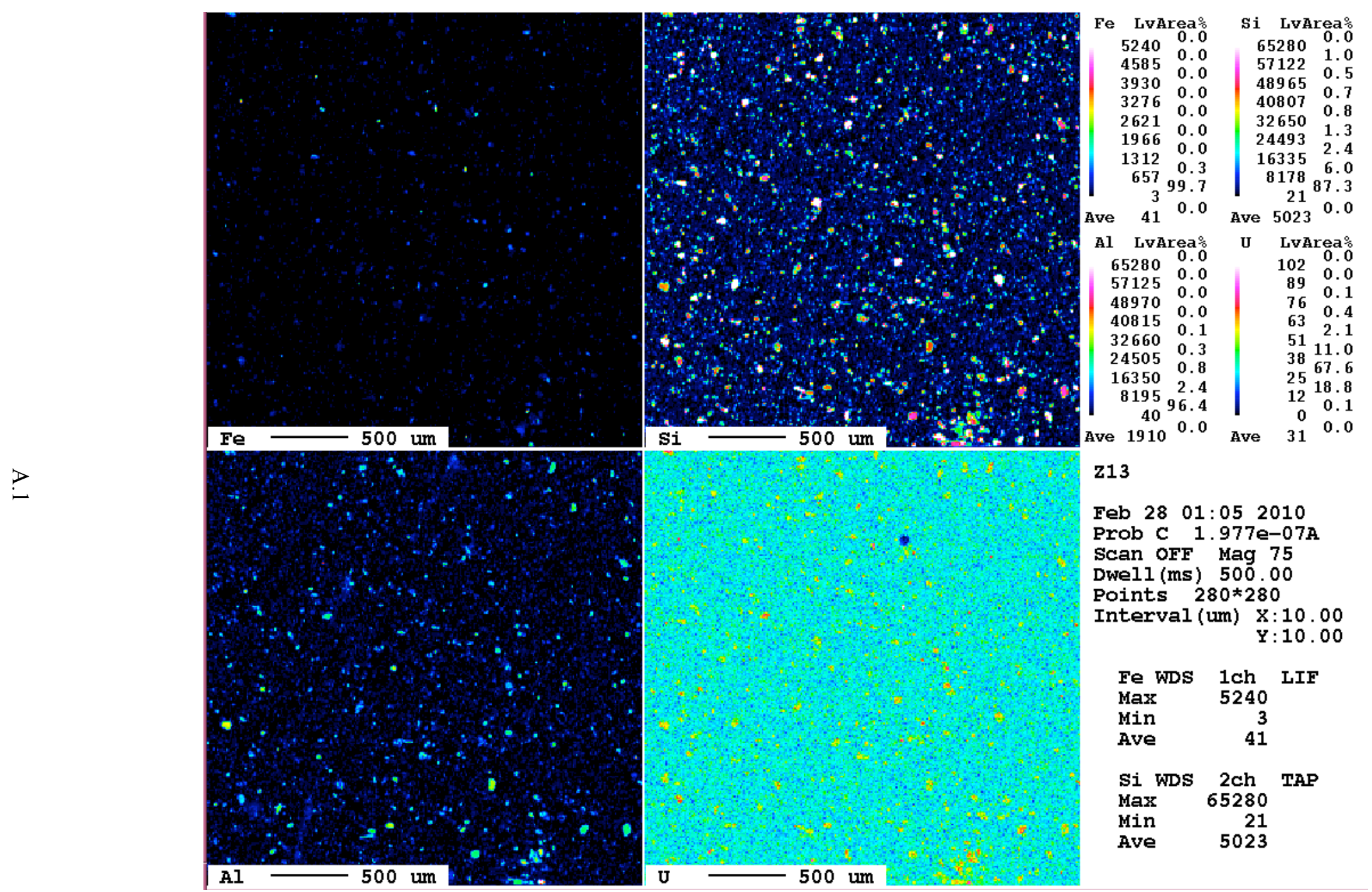

Figure A.1. Untreated TX104, 69-+110-ft sediment, Fe, Si, Al, U elements on a $2.8 \times 2.8 \mathrm{~mm}$ grid (78400 points). 


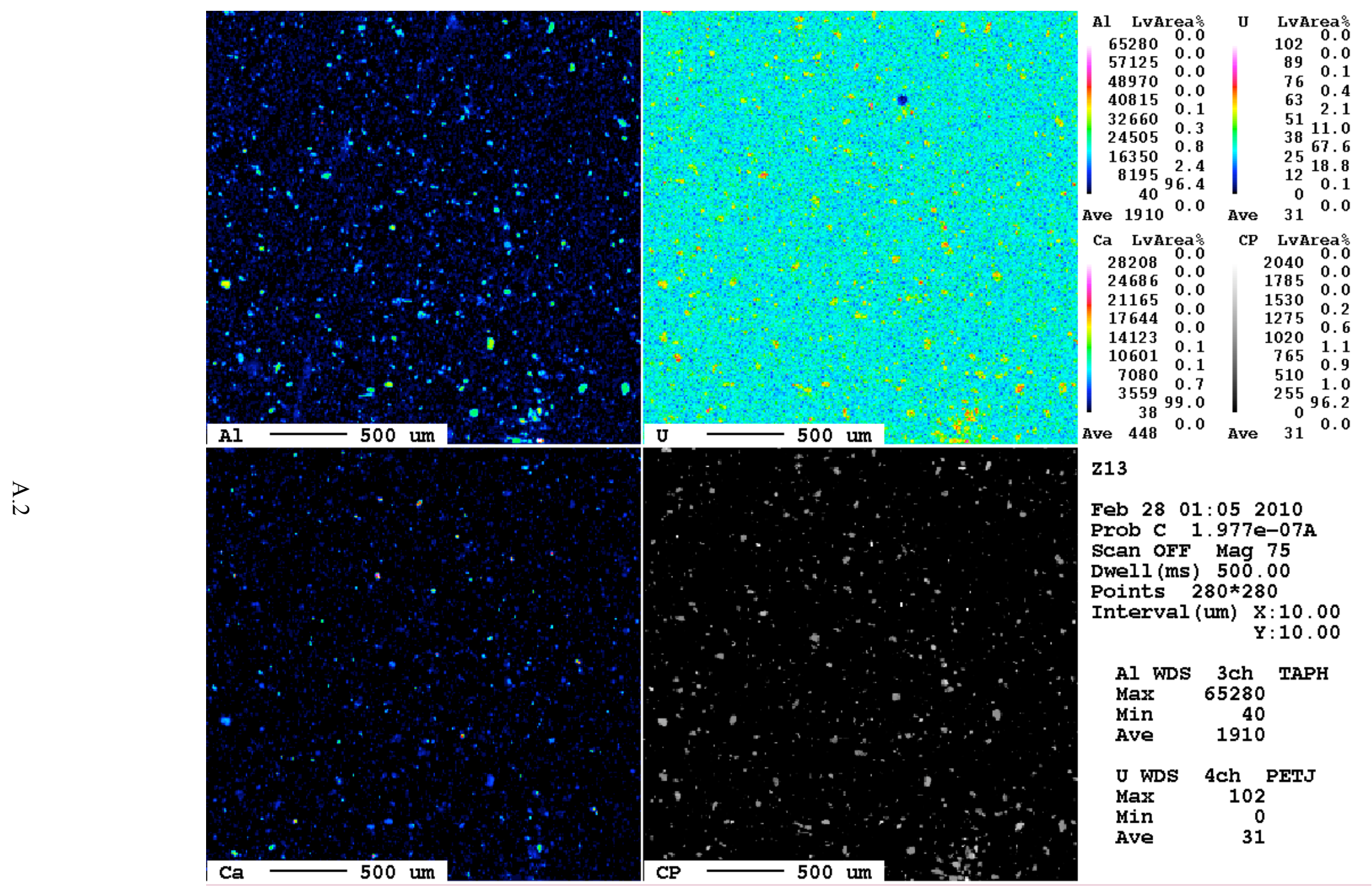

Figure A2. Untreated TX104, 69-+110-ft sediment, Al, U, Ca, and electron backscatter (CP) on a $2.8 \times 2.8 \mathrm{~mm}$ (78400 points). 


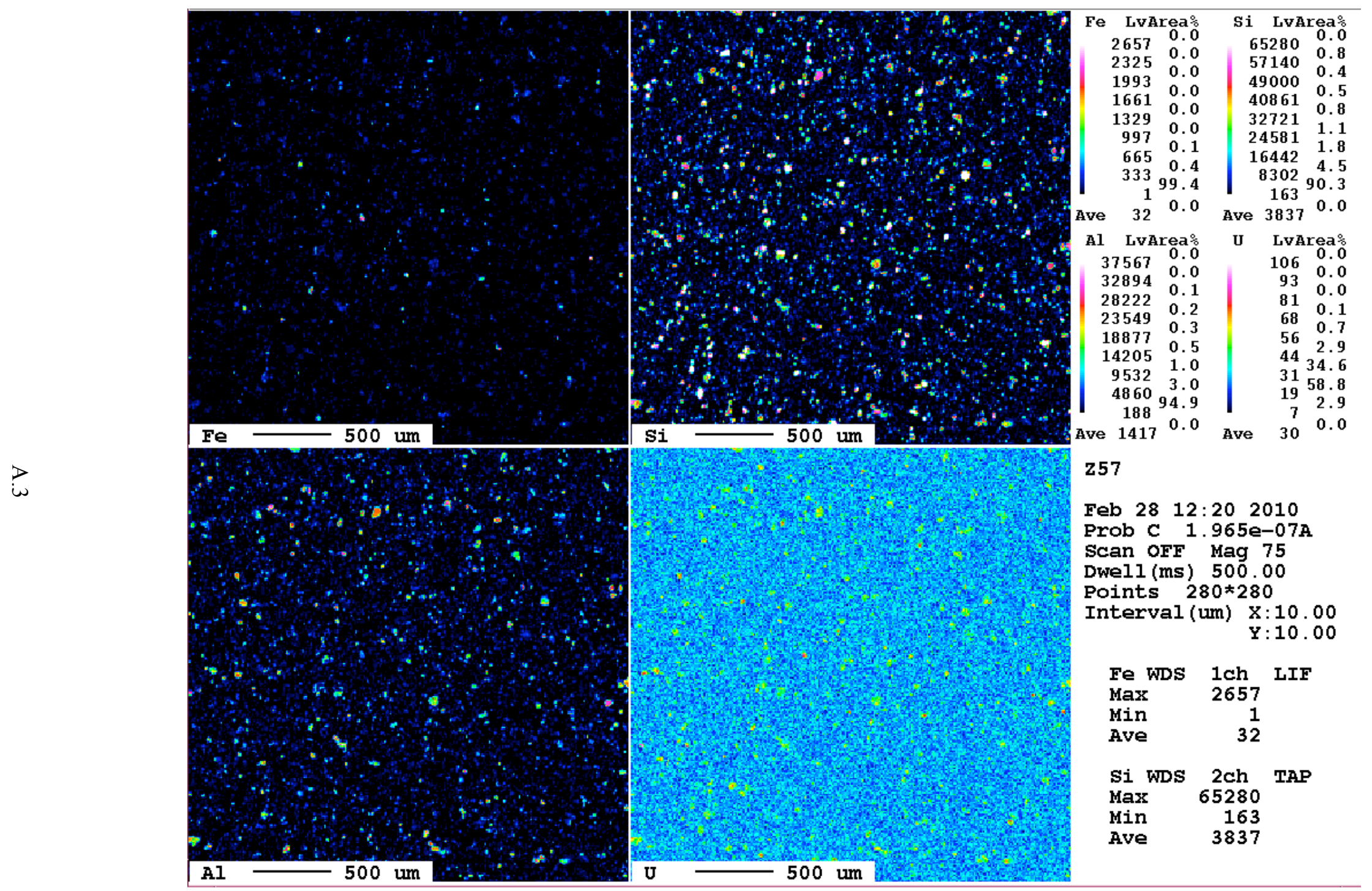

Figure A3. $\mathrm{NH}_{3}$-treated TX104, 69-+110-ft sediment, Fe, Si, Al, U elements on a $2.8 \times 2.8 \mathrm{~mm}$ grid (78400 points). 


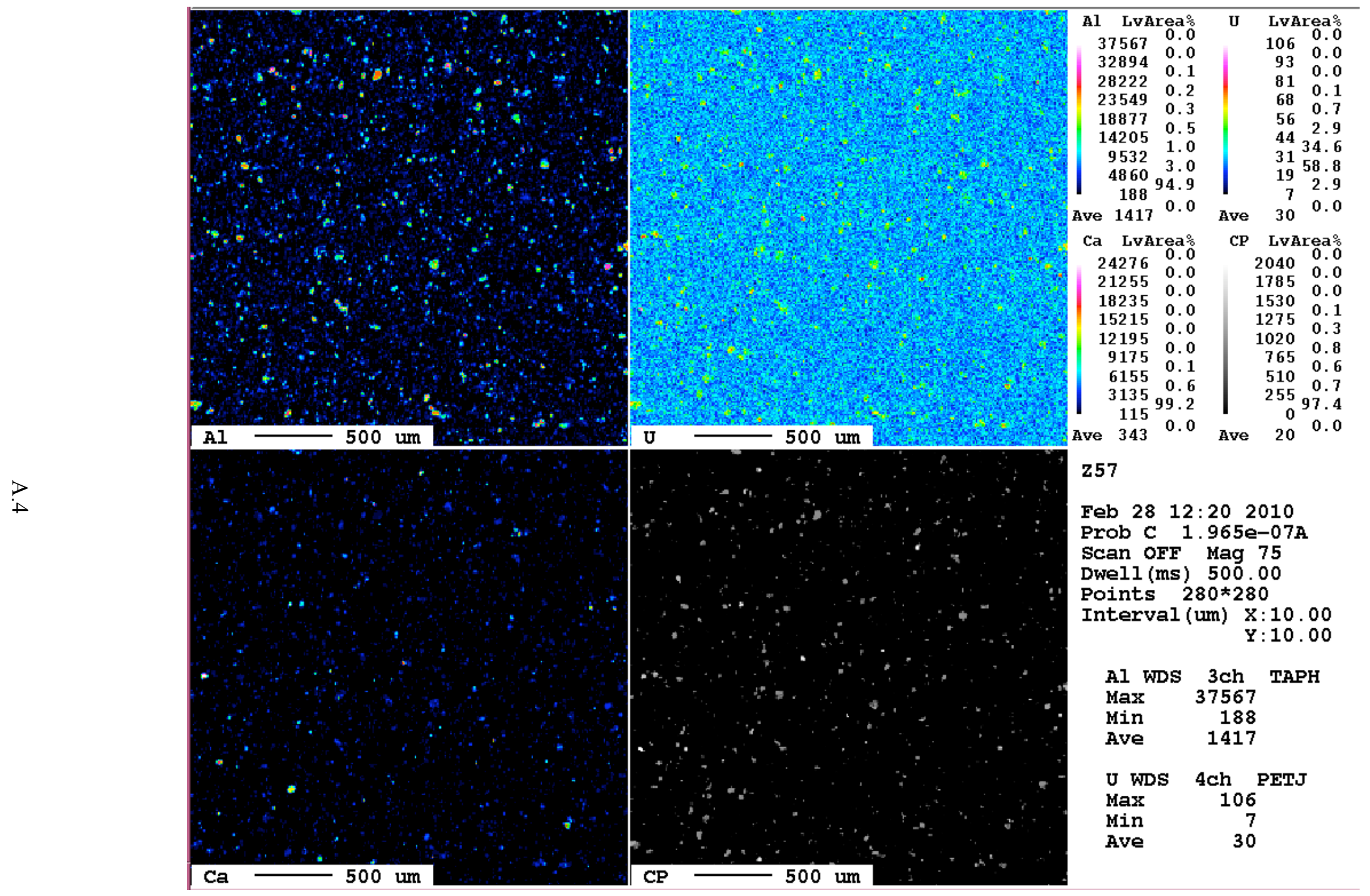

Figure A4. $\mathrm{NH}_{3}$-treated TX104, 69-+110-ft sediment, Al, U, Ca, and electron backscatter (CP) on a $2.8 \times 2.8 \mathrm{~mm}$ (78400 points). 


\section{Appendix B}

Scanning Electron Microscopy Pictures and EDS Elemental Identification of $\mathrm{NH}_{3}$-Treated Sediments 

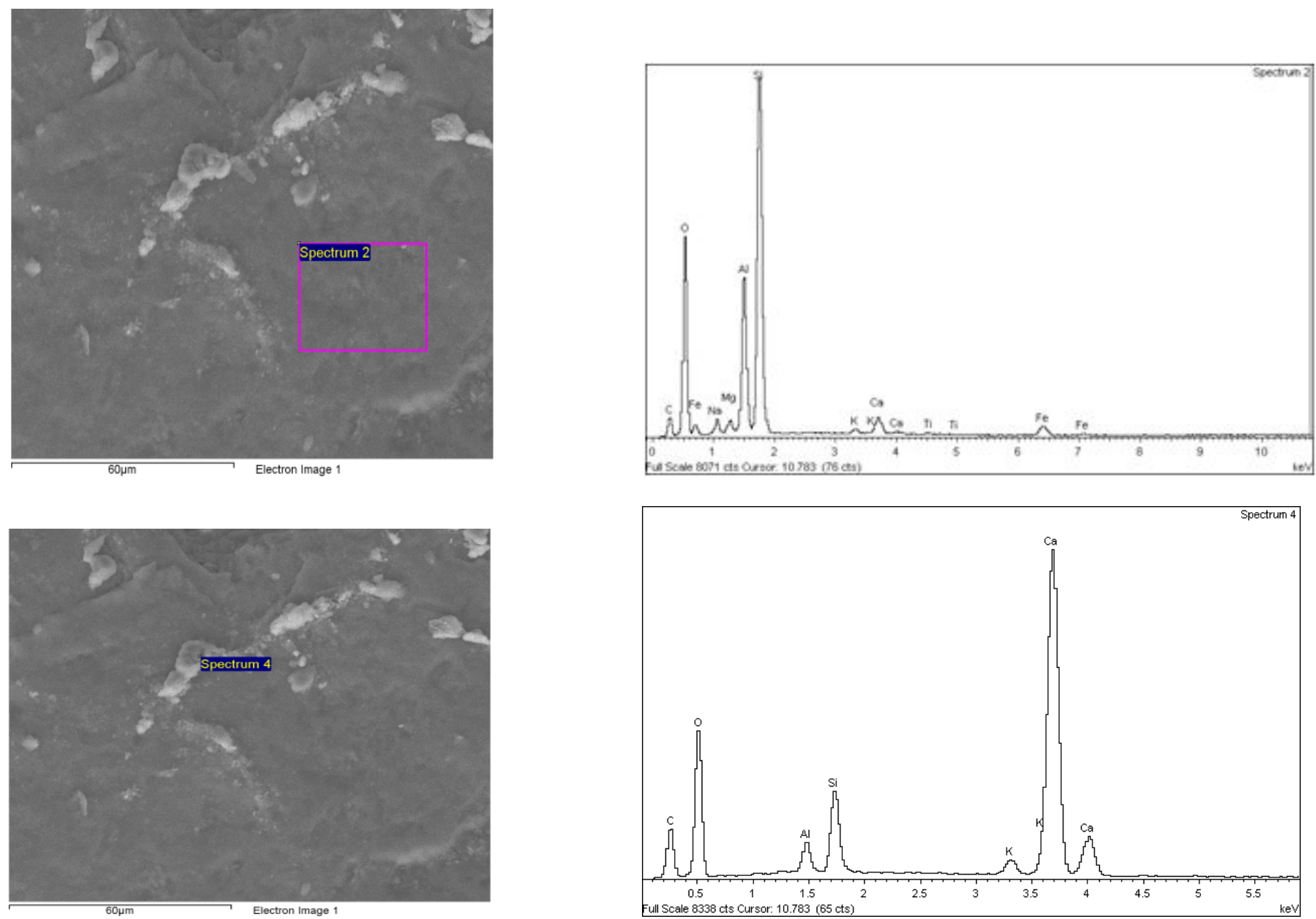

Figure B.1. The dissolution of the base mineral (in this case the base mineral is feldspar - EDS spectrum above) and formation of Ca-rich oxides or other surface precipitates (EDS spectrum below). 

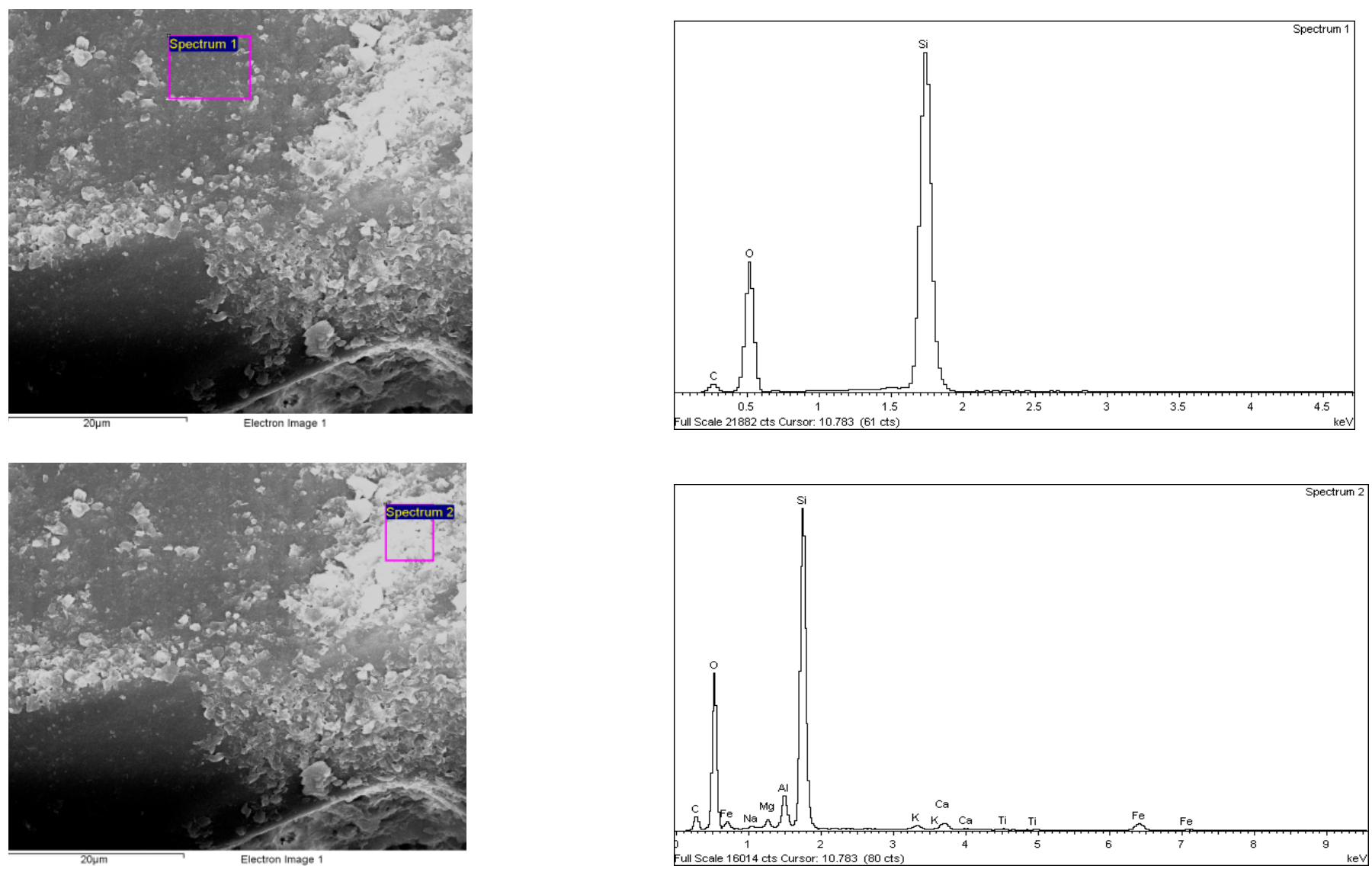

Figure B.2. The dissolution of the base mineral (in this case the base mineral is quartz - EDS spectrum above) and formation of Si oxides and other minor phases (EDS spectrum below). 

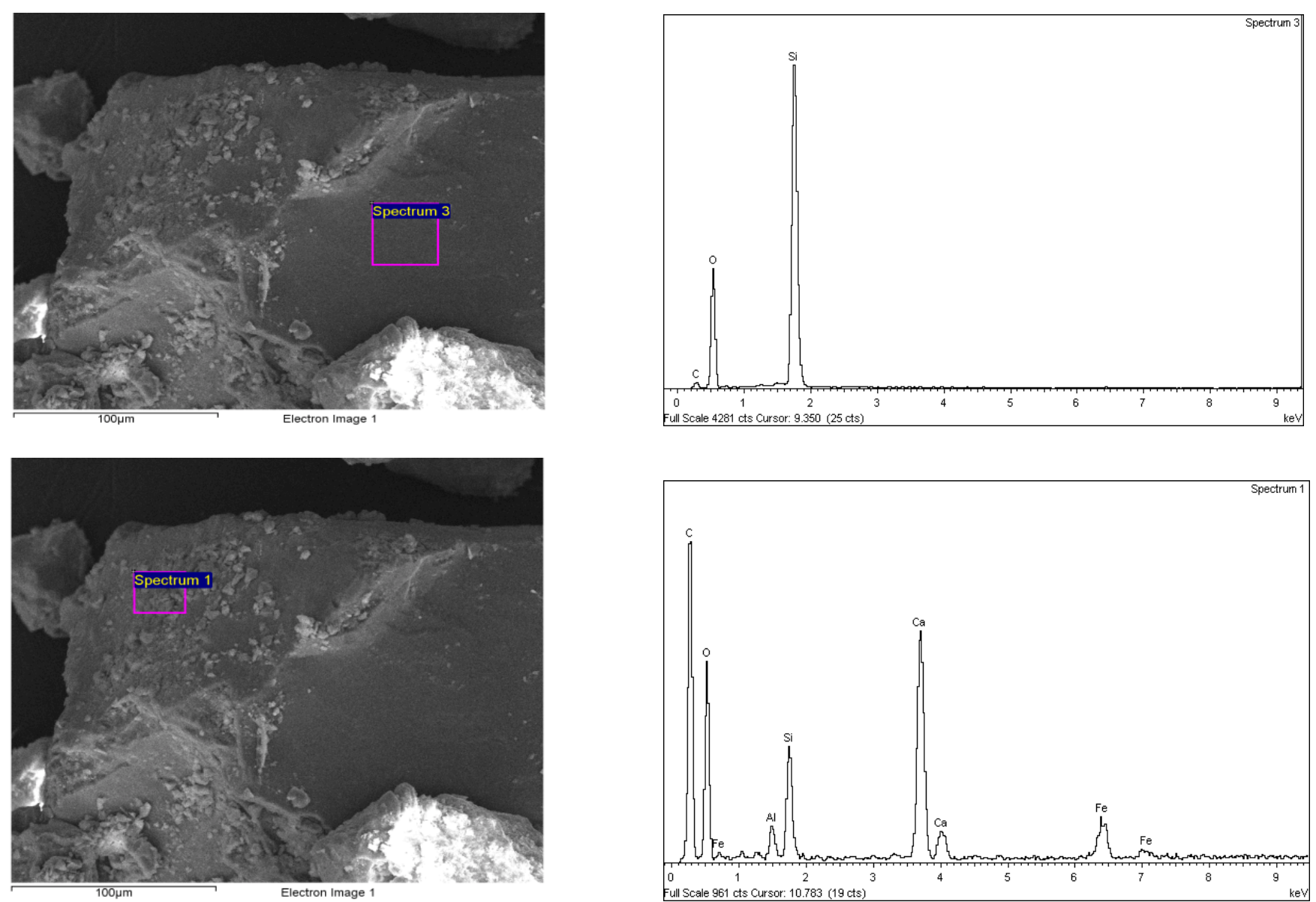

Figure B.3. The dissolution of the base mineral (in this case the base mineral is quartz - EDS spectrum above) and formation of Ca-carbonate and other $\mathrm{Al}, \mathrm{Si}, \mathrm{Fe}$-rich phases (EDS spectrum below). 

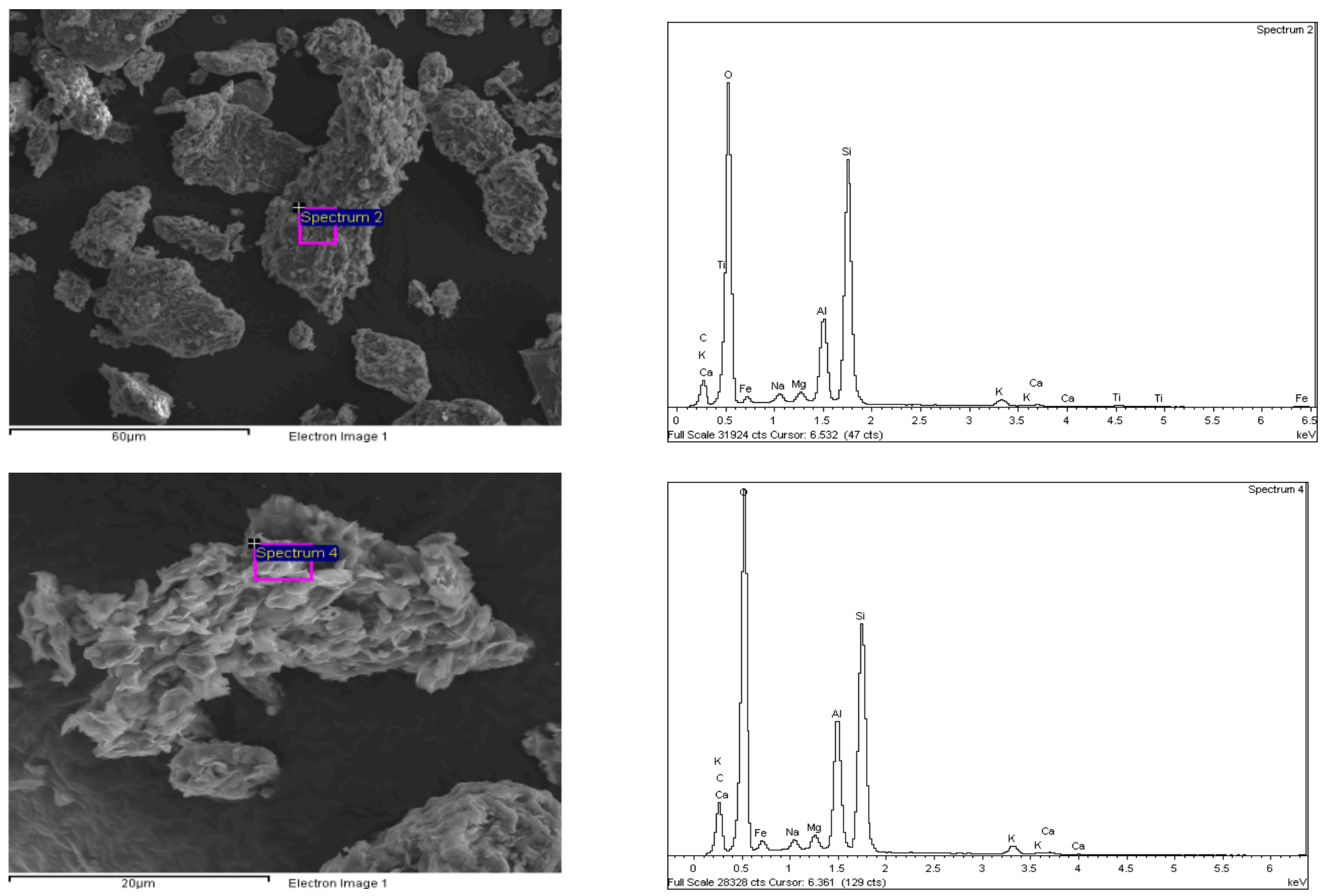

Figure B.4. The dissolution of the base mineral (in this case the base mineral is montmorillonite - an EDS spectrum taken in the untreated sample is presented above) and formation of surface precipitates with a similar composition as the base mineral, i.e., montmorillonite; EDS spectrum below). 

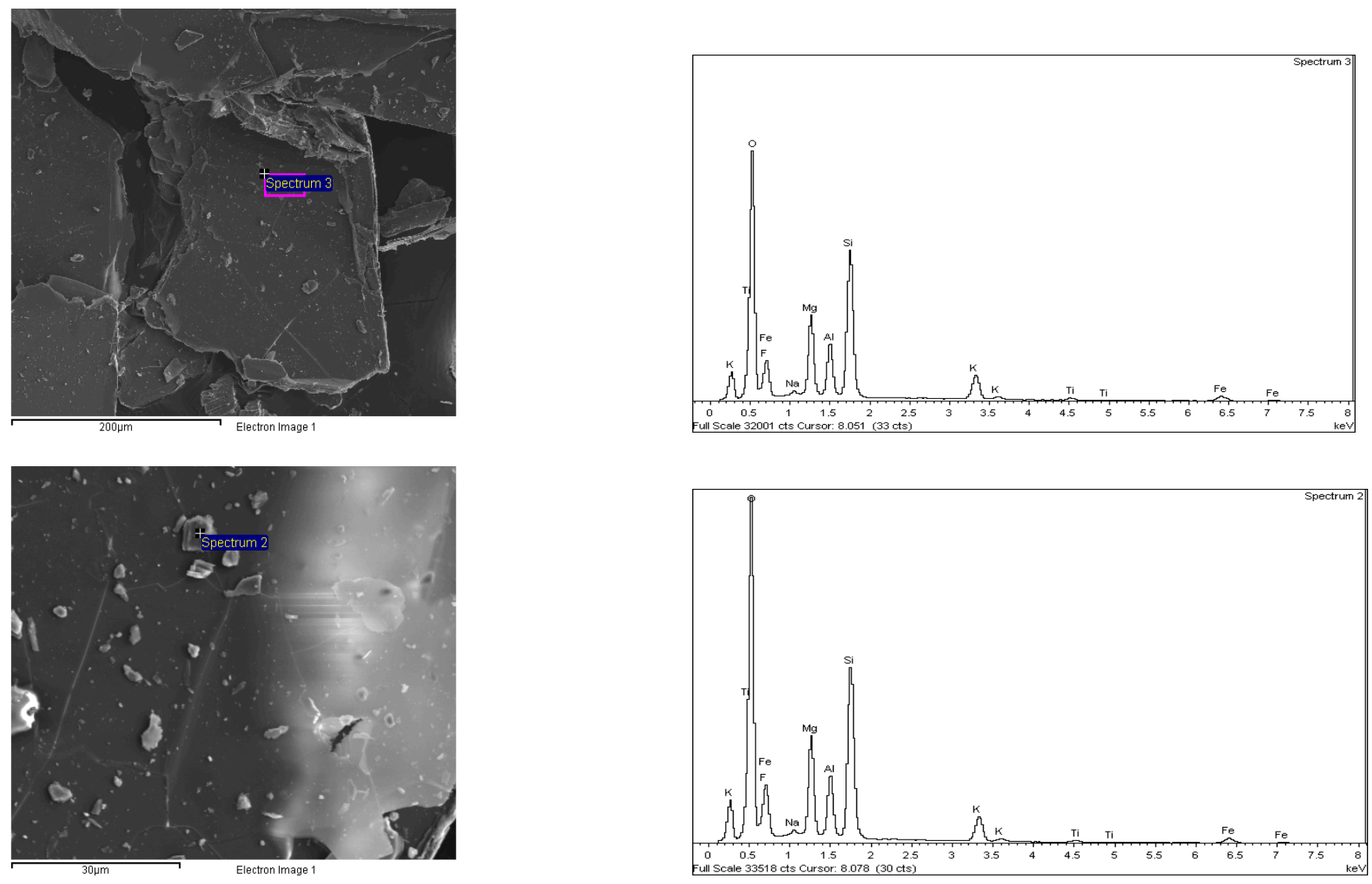

Figure B.5. SEM micrographs of a sample of untreated biotite and the corresponding chemical composition determined with EDS (above panels). Small particles on the surfaces of bigger particles had similar chemical composition to the bigger biotite particles (the panels below). 

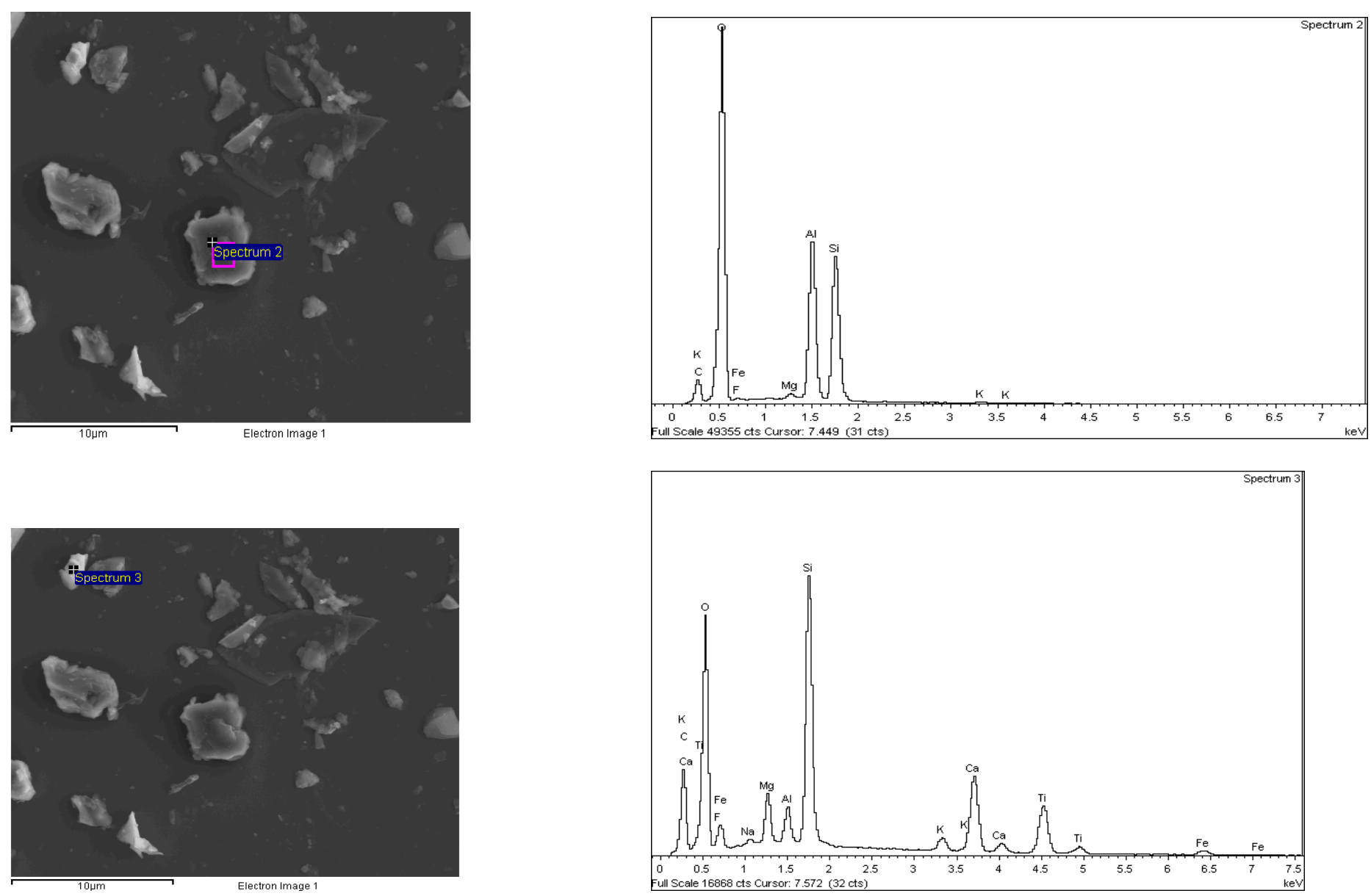

Figure B.6. SEM micrographs of a sample of treated biotite and the corresponding chemical composition determined with EDS. In addition to small particles, which had a similar chemical composition to the bigger particles of biotite, small particles with a 1:1 $\mathrm{Si}$ and Al ratio were also present (above panels). In addition, small particles rich in $\mathrm{Si}, \mathrm{O}$, and $\mathrm{Ca}$ were also present in the treated samples (the panels below). 


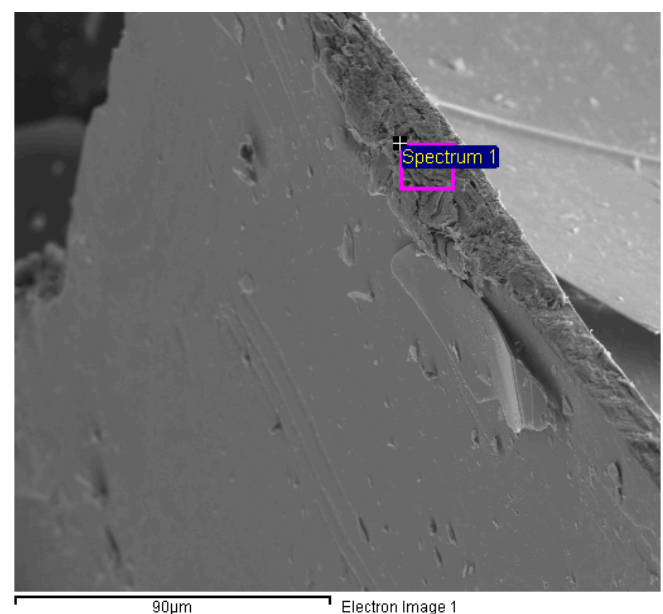

90um Electron Image 1
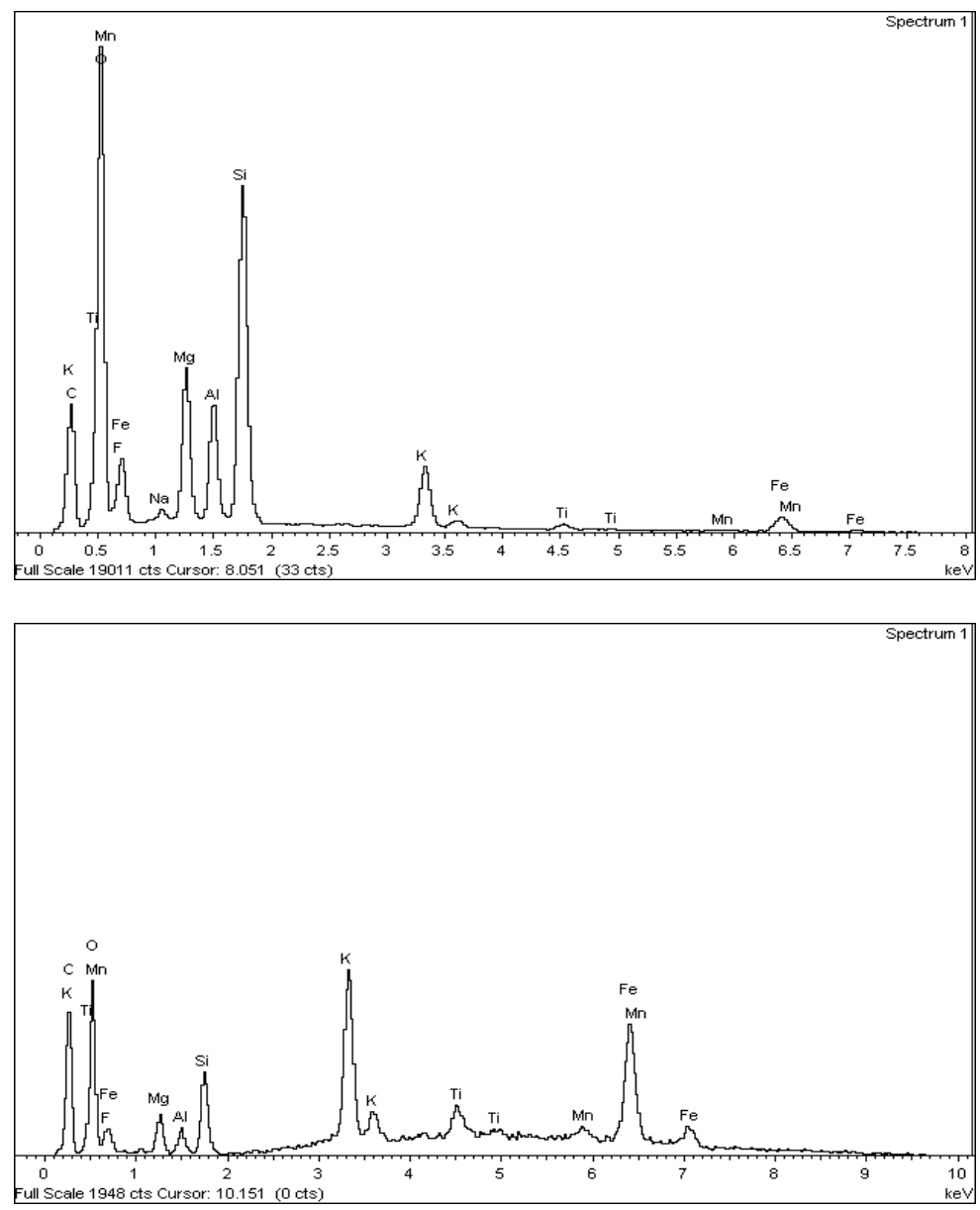

Figure B.7. SEM micrographs of a sample of treated biotite and the corresponding chemical composition determined with EDS. The edge of the biotite particle depicted in the above panel shows signs of distortion, which may be caused by the base attack on the edge, which is the most vulnerable segment of the biotite particle. The SEM micrograph below shows some smaller size particles that were present on the edge of a treated biotite particle. The small particles happened to be rich in $\mathrm{K}$. This could be considered as an indirect indication that this particle may have undergone dissolution and interlayer $\mathrm{K}$ was initially released and subsequently precipitated to form the small particles. 

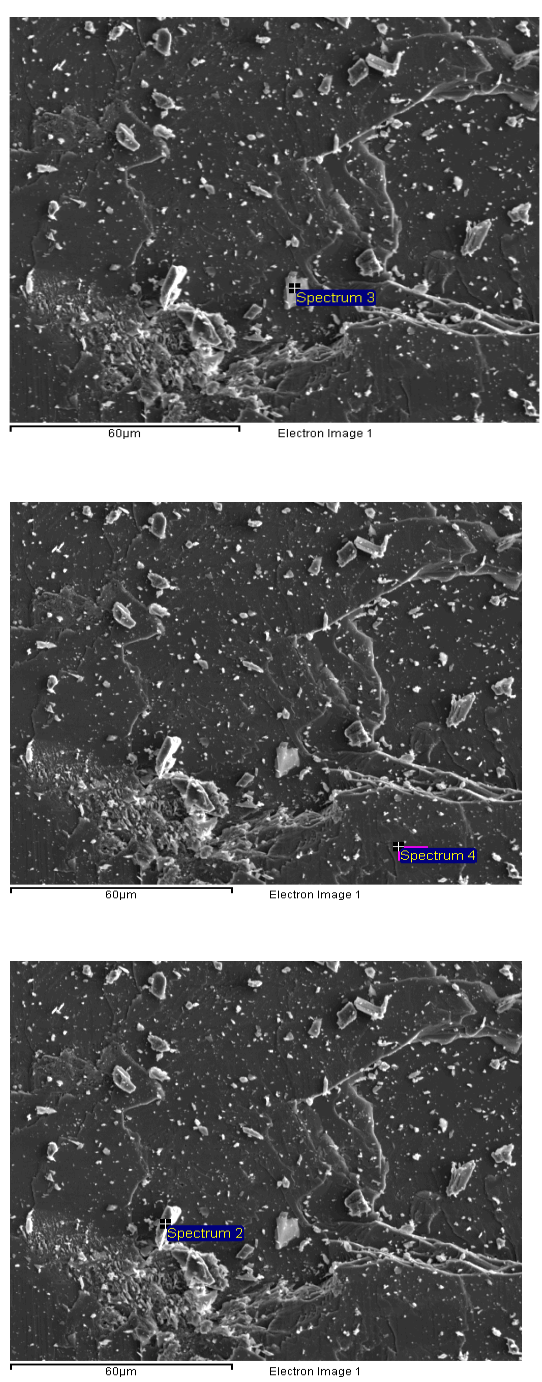

Figure B.8. SEM micrographs of a sample of untreated microcline and the corresponding chemical composition determined with EDS (above

panels). Small particles on the surfaces of bigger particles had similar chemical composition to the bigger microcline particles (the panels below).
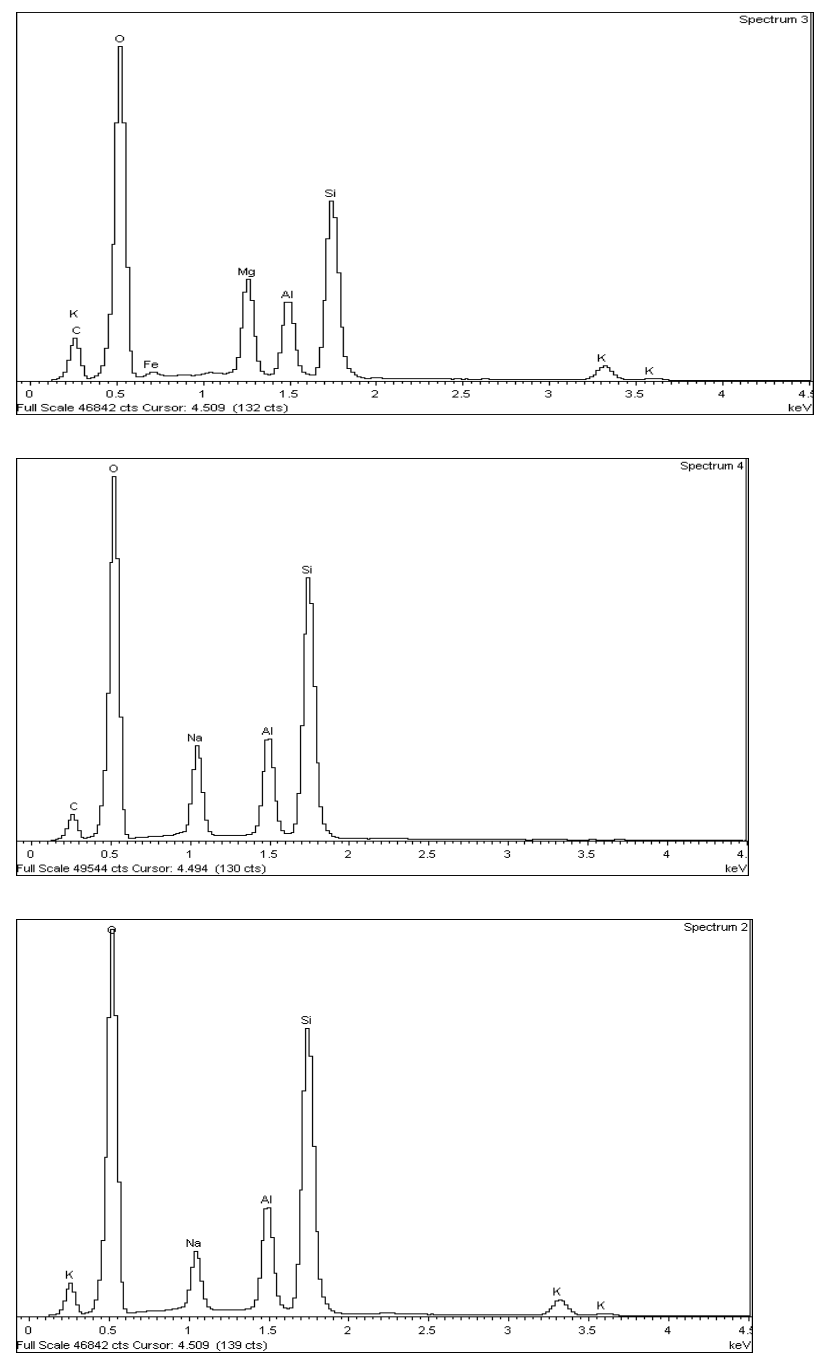

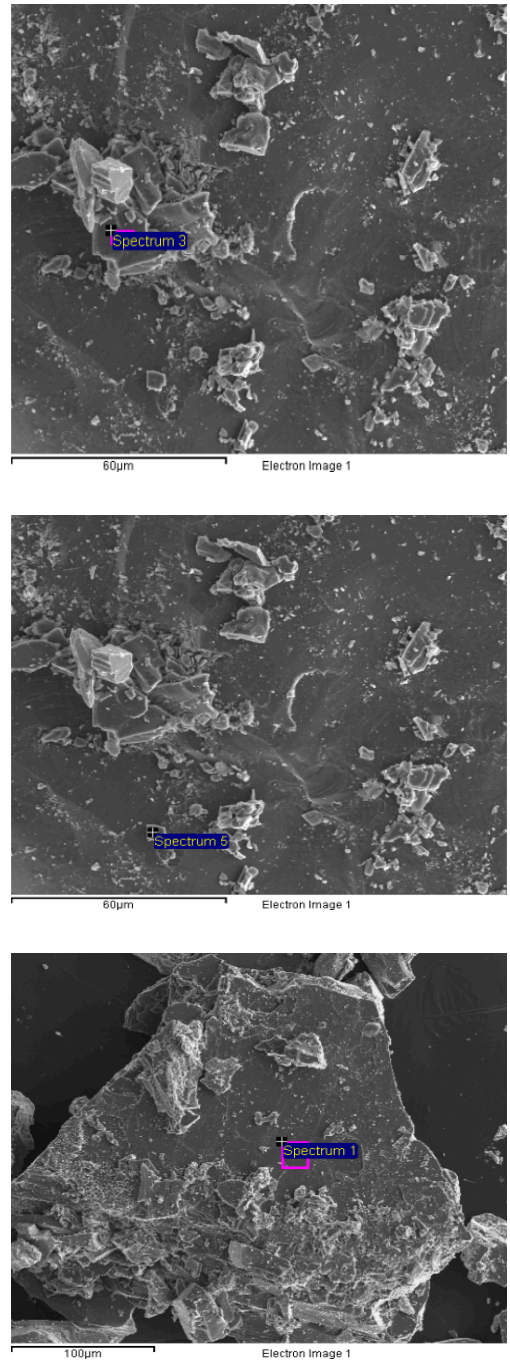
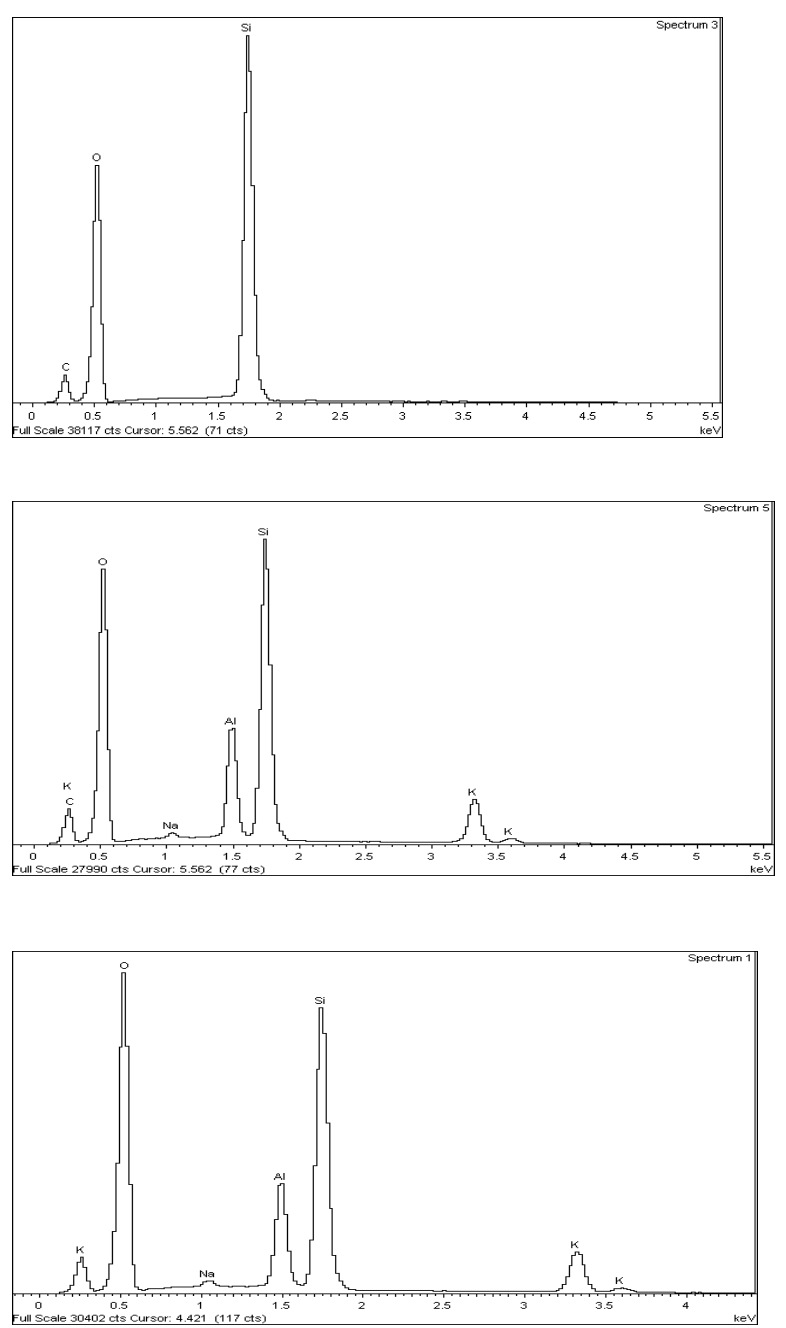

Figure B.9. SEM micrographs of a sample of treated microcline and the corresponding chemical composition determined with EDS (above panels). Majority of small particles on the surfaces of bigger particles had similar chemical composition to the bigger microcline particles. However, there were also small particles with a slightly different chemical composition as the three ones depicted in the above SEM micrographs and EDS panels. 


\section{Distribution}

No. of

Copies

ONSITE

3 DOE Richland Operations Office

RD Hildebrand (2P, CD)

JG Morse (P, CD)

4 CH2M HILL Plateau Remediation Company

MW Benecke (3)

GB Chronister
No. of

\section{$\underline{\text { Copies }}$}

8 Pacific Northwest National Laboratory

NP Qafoku

P7-54

JE Szecsody (4)

MJ Truex

K3-61

K6-96

MD Williams

K6-96

L Zhong

$\mathrm{CD}=\mathrm{CD}-\mathrm{ROM}$

$\mathrm{P} \quad=$ Paper copy

R3-60

R3-60

Distr.1 


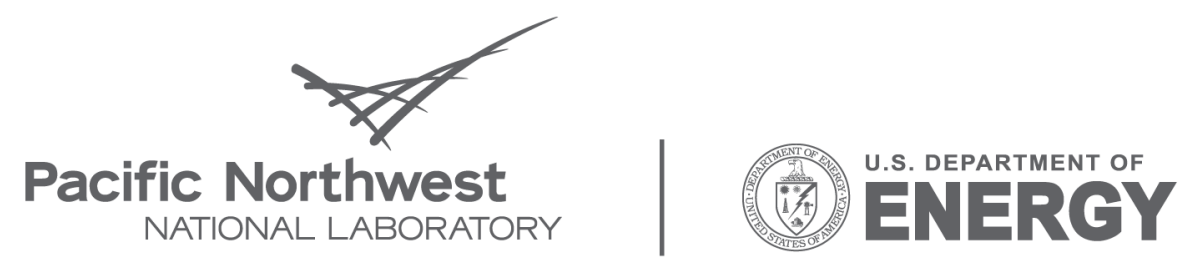

Proudly Operated by Battelle Since 1965

902 Battelle Boulevard

P.O. Box 999

Richland, WA 99352

1-888-375-PNNL (7665)

www.pnl.gov 